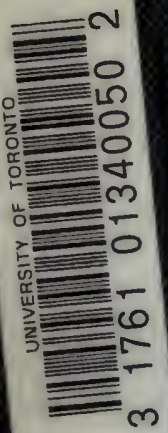



ets -15.

Yuturns 2idusty in Englan Hastank ketory fenghot aque labounes

$$
\begin{aligned}
& \{1,\} \\
& 43^{14}
\end{aligned}
$$






\section{LIBRARY OF ECONOMICS AND POLITICS.}

\section{Independent Treasury System of the United States.}

By Uavid Kinley, A.B. rmo........................\$ $\$$ r.50

Repudiation of State Debts in the United States.

By William A. Scot, Ph.D. 12 mo .................... 1.50

Sociailism and Social Reform.

By Richard T. Ely, Ph.D., LL.D. 12mo............. 1.50

American Charitles.

By Amos G. Warker, Ph.D., Professor of Economics in the

Leland Stanford, Jr., University 12 mo.................. 8.75

Hall-House Maps and Papers.

A Presentation of Nationalities and Wages in a Congested

District of Chicago. With maps. 8vo ....................

Special Edirion, with maps mounted on Linell. 8vo...........

Punishment and Reformation.

By F. H. Wines, LL.D. 12 mo....................... 1.75

Social Theory.

A Grouping of Social Facts and Principles. Вy ЈонN ВАsсом,

Professor of Political Economy in Williams College. $12 \mathrm{mo}$.

Proportional Representation.

By John R. Commons, Professor of Sociology in Syracuse

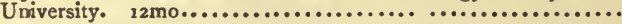

State Rallroad Control.

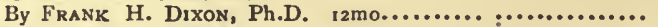

Sonthern Side Lights.

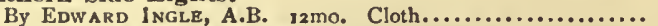

Taxation and Taxes in the United States under the Internal Revenue System.

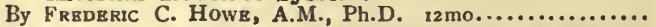

An Esfay on the Present Distribution of Weaith in the United States.

By Charles B. Spahr, Ph.D. 12mo.................. x.50

Southern Stategmen of the Old Régine.

By WILliam P. Trent, A.M. 12mo. Gilt top, with portraits.. 2.00

Workingmen's Insurance.

By W. F. WilloughвY, Department of Labor, Washington,

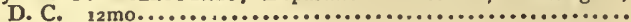

Congressional Committees.

By Lauros G. McConachie, A.M. 12mo................ x.75

Municipal Monopolies.

Edited by Professor E. W. Bemrs. 1zmo............... 2.00

The Jew in London.

By C. Russell and H. S. Lewrs. With an introduction by Canon BARNeTt, and a preface by the Right Hon. James

BRYCE, M P. $12 \mathrm{mo}$, with colored map....................

Monopolies Past and Present.

By James Edward Le Rossignol, Ph.D., Professor of

Economics in the University of Denver. 12mo, Cloth.......

The French Revolution and Modern French Socialisin.

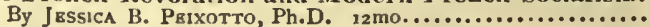

The Economics of Forestry.

By Prof. B. E. FrRnow, Department of Forestry, Cornell University ...................................net Irrigation.

By F. H. Newrlz, U. S. Geological Survey.............. net 2.00 


\title{
ECONOMICS OF FORESTRY
}

A REFERENCE BOOK

FOR STUDENTS OF POLITICAL ECONOMY AND

PROFESSIONAL AND LAY STUDENTS

OF FORESTRY,

\begin{abstract}
BY
BERNHARD E. FERNOW, LL.D.

Director of the New York State College of Forestry, in Cornell University; Late Chief, Division of Forestry, United

States Department of Agriculture
\end{abstract}

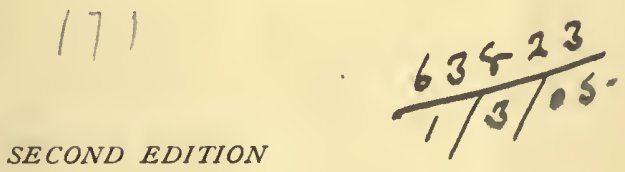

NEW YORK

THOMAS Y. CROWELL \& CO.

PUBLISHERS 
COPYRIGHT, 1902,

By THOMAS Y. CROWELL \& CO.

Published December, rgo2. 


\section{Ta fty Jrient}

\section{EDWARD A. BOWERS}

TO WHOSE PERSISTENT, UNSELFISH AND UNOSTENTATIOUS EFFORTS, IN AND OUT OF OFFICE, IS SO LARGELY DUE THE ESTABLISHMENT OF THE FEDERAL FOREST RESERVATION POLICY 
Digitized by the Internet Archive in 2007 with funding from Microsoft Corporation 


\section{EDITORIAL PREFACE.}

Some years ago I made a contract with Messrs. T. Y. Crowell \& Co. for the editorship of certain volumes in their Library of Economics and Politics, and among them the present work by Dr. Fernow was included. Although I have resigned my position as general editor of this Library, I am glad to accede to the request of the publishers to continue the original arrangement for this volume.

RICHARD T. ELY. 



\section{PREFACE.}

IN this volume it is proposed to treat of forests and forestry from the standpoint of political economy.

The statesman, the student of economics, as well as the layman who desires knowledge on these matters, is to find here such information as will enable him to form an intelligent view and a true estimate of the position which forests and forestry should occupy in our political household, or rather the position which the community and governments should take with reference to their forest resources; it is to furnish a trustworthy basis for formulating public policy. At the same time it is hoped that this presentation of the subject will be acceptable to the growing number of professional foresters, assisting them in an intelligent survey of their art from a point of view outside of that of the technicist.

Hitherto the questions arising in connection with the proper utilization of our forest resources and with forest preservation have, in the United States, been largely discussed in a popular way, mostly by amateurs and laymen, who were without a 
knowledge of the technical side of the subject; the professional economists who, only incidentally and sporadically, refer to the question have also, at best, possessed only a reading knowledge of the natural history of the forest and of the forester's art. As a result of this insufficient knowledge, these writings are only too frequently characterized by one-sided arguments and a partisan attitude without sufficient basis in fact.

Nor is there, as far as the writer knows, any book in the English language which attempts a full and systematic discussion of the subject in the manner in which it is to be treated here. This book, then, is not intended as a popular discussion, but proposes to supply a lack in the professional literature of economics in the English language; in fact, even the Germans have with perhaps one exception not yet produced a publication exactly analogous, as may be learned from the annotated index to the literature given in the Appendix.

The main difference between the present volume and other existing books may be found in the fact that not only the things which directly interest the economist have been discussed, but also a more or less comprehensive exposition of the technical details of the forester's art is given, which permits the forming of a judgment as to the conditions and limitations under which this art, or how much of it, can or must be practised. 
In discussing doubtful questions, the writer has endeavored to maintain a judicial spirit of inquiry, and to point out not only ideals, principles, and truths, but also practical limitations which prevent the attainment of the ideals.

In order not to encumber the text too much, an appendix of notes, tables, and references has been added, which will assist in verifying conclusions drawn and give direction to those who desire to study further.

To the unnamed friend who has kindly undertaken to revise the proof-sheets I desire to express my thanks.

B. E. FERNOW.

ITHACA, November, 1902. 



\section{CONTENTS.}

\section{CHAPTER I.}

Introductory: The Relation of the State to pagr Natural Resources . . . . . . I I

CHAPTER II.

The Forest as a Resource • • . • • 21

CHAPTER III.

The Forest as a Condition . . • • 54

CHAPTER IV.

Forest AND Forestry Defined . . . . $8 \mathrm{I}$

CHAPTER V.

Factors of Forest Production and Business

ASPECTS • • • • • • • • 106

CHAPTER VI.

Natural History of the Forest • • • . I40

CHAPTER VII.

Methods of Forest Crop Production: SilviCULTURE . . . . . . . . 165 
CHAPTER VIII.

Methods of Business CONDUCt: Forest ECONOMy 197

CHAPTER IX.

Principles and Methods of Forest Policy • . 228

CHAPTER $X$.

Forest Policies of Foreign Nations . . . 274

CHAPTER XI.

Forest Conditions of the United States

CHAPTER XII.

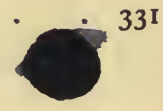

The Forestry Movement in the United States 369

APPENDIX • . . . . . . . . $4 \mathrm{I} 3$

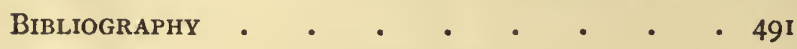

INDEX • • • • • • . . 509 


\section{ECONOMICS OF FORESTRY.}

\section{CHAPTER I. \\ INTRODUCTORY: THE RELATION OF THE STATE TO NATURAL RESOURCES.}

THE natural resources of the earth have in all ages and in all countries, for a time at least, been squandered by man with a wanton disregard of the future, and are still being squandered wherever absolute necessity has not yet forced a more careful utilization.

This is natural, as long as the exploitation of these resources is left unrestricted in private hands; for private enterprise, private interest, knows only the immediate future - has only one aim in the use of these resources, namely, to obtain from them the greatest possible personal and present gain.

Occasionally there may enter into its consideration a desire to prolong the source of profit, so that it may not only hold out during the lifetime of the individual, but continue flowing for his heirs; or else other than business considerations 
may, for a while at least, preserve possible sources of profit from mismanagement, usually by mere non-use, much more rarely by conscious management for continuity. In most cases it will be found that the busy competition of the present has a destructive tendency and leads to wasteful methods, especially if the resources are large in comparison with the population and its needs. Density of population is the index of the intensity with which resources will be husbanded. Plenty breeds extravagance; dearth breeds care.

Thus in the United States, with its enormous resources in fields and forests and mines, which are open to the unrestricted, licentious use of a comparatively small population, the destruction of valuable material in the exploitation of these natural riches, the careless and extravagant use of them, the neglect to which they are abandoned as soon as the cream is taken, are simply characteristic of all pioneering populations. With us, moreover, the pioneering stage fell into a period when the invention and development of railroad transportation intensified the disproportion of population and resources, opening up new territory and making virgin supplies available more rapidly than the needs of a resident population required, thus creating destructive competition in the attempts to profit from a non-intensive, rapacious exploitation and exportation. For, in thè absence of a resident population to use the less valuable portions of the 
products, these had to go to waste, since only the best portions could bear the cost of transportation to distant centres of consumption.

The amount of waste in materials, natural resources, and in energy, which this uneven settlement and development of the country has produced, has ${ }^{\circ}$ been enormous in all directions, and more especially in fields and forests. The desire for a tangible share in the wealth that can be derived by the exploitation of these resources, the greed of the individual, together with the unfavorable distribution of population, have led to their careless and wasteful use.

From the standpoint of the individual, that use of his opportunities which gives him greatest satisfaction in the present appears justifiable; while society may incidentally benefit from his efforts in producing and distributing wealth, the individual, as a rule, cares little about that result of his activity, nor does he care if the results of his endeavors are the opposite from beneficial to society, unless society itself step in and protect its interests.

From the fact that within any aggregation of people inimical interests arise, that the interests of one set of individuals may clash with those of another set, or that the welfare of the whole may be jeopardized by the unrestricted exercise of the rights of the few, the necessity for the limitation of the rights of the members arises, which, as far as the exercise of property rights 
goes, finds expression in the old Roman law, "Utere tuo ne alterum noceas," namely, such use of the property as shall not entail damage to another party.

This ancient restrictive principle, which is recognized in all civilized states, was at first probably applied only to interferences between private interests; but finally the protection of the interests of the aggregation against those of the individual must have necessitated its application, whenever a communal interest would suffer by the unre. stricted exercise of individual rights.

This restrictive function of the state, in addition to that of defending the aggregation against outsiders, will probably be admitted by all parties and schools as elementary and essential to the existence of the state. Divergence of opinion arises, however, not only when additional, more positive, and directive functions are claimed for the state, - as, for instance, when the laissez-faire policy is to be supplanted by a faire-marcher promotive policy, but also in the interpretation of the meaning of the terms of the mere restrictive function, when the question arises, what is to be considered damage and who the other is that is to be protected.

The very nature of the modern civilized government necessitates the very widest interpretation of these terms. Civilized states of to-day are intended and built for permanency; they are not held together by mere compacts of the single members of 
society, which may be broken at any time. While forms of government may change, the organization, moder $x$ the state idea, promises to be permanent. This con- $90 v^{\prime} t .-$ ception of the permanency of the state, the realization that it is not a thing of to-day and for a limited time, but forever, widens its functions and extends its sphere of action; for it is no longer to be regarded as merely the arbiter between its present members, but it becomes the guardian of its future members; government becomes the representative, not only of present communal interests, as against individual interests, but also of future interests as against those of the present. Its object is not only for the day, but includes the perpetuity of the well-being of society, and the perpetuity of such favorable conditions as will conduce to the continued welfare and improvement of the same; in short, its activity must be with regard to continuity, it must provide for the future, it must be providential. We do not create this special providence for the individual, but for society; the individual will have to work out his own salvation to a large extent, with the opportunities for advancement offered by society, but society itself can only act through the state; and, as the representative of the future as well as the present, the state cannot, like the individual, "let the future take care of itself." In our present state activity and legislation there is as yet but little realization of its providential functions. Even 
the question of education, which in part provides for future improvement, is only imperfectly considered from this point of view. The question of the franchise, as well as that of immigration, both of which are of the greatest influence upon the future composition and condition of our society, are much more often discussed with reference to the rights of present members than with reference to the future of society.

The one condition of social life in which the action of the present influences the future almost more than in any other direction, namely, the condition of the means of material existence and their economical use (the economy of resources), has received perhaps the least recognition in practice as well as in theoretical discussion; and especially is this absence of attention to this most important branch of economics noticeable in English literature.

The reason probably is that the need of careful analysis of this factor of social life has as yet not been pressing. But as the world has been explored in all corners and the extent of its resources has become more nearly known, and as it is being rapidly peopled everywhere and the causes of depopulation are becoming less, the warnings of Malthus and Mill come home to us with new force; and the study of the nature of resources, their relation to social life and development, and their economy, becomes a most important branch of social science, 
which will overshadow some of the other branches, now appearing all-important. When the questions of the extension of suffrage to women, of tariff, of taxation, of coinage and currency, which are all merely incidents, will have sunk into the background, the question of the economy of the resources which constitute and sustain the political, commercial, and social power of the nation - long neglected - will still claim attention; for only those nations who develop their natural resources economically, and avoid the waste of that which they produce, can maintain their power or even secure the continuance of their separate existence. A nation may cease to exist as well by the decay of its resources as by the extinction of its patriotic spirit. While we are debating over the best methods of disposing of our wealth, we gradually lose our very capital without even realizing the fact. As Marsh ${ }^{1}$ points out in his classical work, man is constantly modifying the earth and making it more and more uninhabitable; he goes over its rich portions and leaves behind a desert.

Whether we have a high tariff or no tariff, an income tax or a head tax, direct or indirect taxation, bimetallism or a single standard, national banks or state banks, are matters which concern, to be sure, the temporary convenience of the members of society, but their prejudicial adjustment is easily

${ }^{1}$ George P. Marsh, "The Earth as modified by Human Action," 1874. 
remediable; when ill effects become apparent, the inconveniences may be removed with but little harm to the community, and none to mankind at large or to the future. But whether fertile lands are turned into deserts, forests into waste places, brooks into torrents, rivers changed from means of power and intercourse into means of destruction and desolation - these are questions which concern the material existence itself of society; and since such changes become of ten irreversible, the damage irremediable, and at the same time the extent of available resources becomes smaller in proportion to population, their consideration is finally much more important than those other questions of the day. Increase of population and increased requirements of civilization call for a continual increase of our total economic forces, and increased "intensity" in the management of our resources; and this requires such continued care and administration, that it is not safe to leave it entirely to the incentive of private competition, which always means wasteful use.

It is true that as individuals the knowledge of the near exhaustion of the anthracite coal-fields does not induce any of us to deny ourselves a single scuttle of coal, so as to make the coal-field last for one more generation, unless this knowledge is reflected in increased price. But we can conceive that, as members of society, we may for that very purpose refuse to allow each other or the miner to 
waste unnecessarily. That this conception is not absurd, and may be practically realized without any strain in our conceptions of government functions, is proved by the fact that it has been carried out in practice in several cases, in our country as well as in others, without opposition.

Absurdly enough we have begun such action with reference to our resources where it is perhaps of least consequence, as, for instance, when, by the establishment of hunting and fishing seasons and by other restrictions, we seek to prevent the exhaustion of the fish and game resources. This is a good illustration of the fact that emotion rather than reason, sentiment rather than argument, are the prime movers of society. It was only partially fear for the exhaustion of this readily restorable resource or economic reasons which led to this protection of our fisheries and game, but love of sport gave the incentive. And again, it needed the love of sport to set on foot the movement for the improvement of the roads in the United States, which the realization of true economy had not the power to bring about.

While we do not prevent single individuals from ruining themselves financially and hazarding the future of their families, we do prevent associated portions of the community, - corporations, towns, and cities, - from jeopardizing their future by preventing them from extravagant expenditures and contracting of debts. This, too, is perhaps less 
designed for the future, than to protect present members against undesirable burdens.

There are, then, enough precedents established to show that, whatever the greed and selfishness of - the individual may dictate, society recognizes its right to interfere with the individual in the use of resources, not only for its present objects, but even for considerations of the future.

wesein a nd To recognize how far - to what degree and in what manner - any of the resources must become objects of national concern, it is necessary to understand their relative significance for the present and for the future development of society or of the particular aggregate of society called a nation. From this point of view resources may be classified under four heads, namely :-

I. Resources inexhaustible.

2. Resources exhaustible and non-restorable.

3. Resources restorable, but liable to deterioration under private activity.

4. Resources restorable, yielding increased returns under increased activity.

Of the first class, hardly any can be mentioned that are usually denominated as resources; land, water, air, and the forces of nature would fall under this class, but since it is not so much these things themselves as the conditions in which they are found that make them resources, and since these conditions are alterable by human agency, their inexhaustibility with reference to human re- 
quirements is not entirely established. With the land it is rather the fertility of the soil that makes it a resource, except so far as it serves for building purposes. With the water, except for the absolute necessity of life, it is its desirable distribution terrestrial and atmospheric - which constitutes it a resource in the sense of satisfying human wants.

Of such resources as are in time exhaustible without the possibility of reproduction, we may mention the mines. The supply of coal, "thè bread of industries," in Europe is calculated to last not more than three or four centuries, although scarcity is expected long before that time; and in our own country we are told that anthracite coal mines do not promise more than seventy-five to one hundred years of supply under present methods of working. ${ }^{1}$ The silver and gold mines, upon the basis of which Nevada became a state, are said to show signs of exhaustion. Oil-fields and natural gas wells of very recent discovery belong to this class of exhaustible resources. With their consumption in satisfying our wants, they are destroyed forever.

The timber of the virgin forest and its game, the water-power of the streams, largely dependent on the conditions of the forest, the fisheries, and to some extent the local climatic conditions, are

1 The present output of the anthracite mines is $50,000,000$ tons, and the visible supply of the field is estimated at a little over $5,000,000,000$ tons. 
resources of the third order, capable in most instances of reproduction or restoration under human care, after having been deteriorated by uneconomic exploitation or by change of contingent conditions, as when brooks and rivers are lessened in volume or else filled with flood-waters and débris, in consequence of forest destruction.

The extensive and absolute destruction of forestcover in Western Asia and portions of Eastern and Southern Europe has desolated vast regions and transformed them into lifeless deserts. Such rapine has sterilized almost beyond recovery the once highly productive regions of Sicily and Algeria; and in our own country we can point to similar results already apparent, as in Wisconsin, where over $4,000,000$ acres have practically been turned into deserts, ${ }^{1}$ in Mississippi, ${ }^{2}$ and other portions of our domain, where erosion carries the fertile soil into rivers, occasioning, in addition to its loss, disturbance of favorable water stages and expenditures in river and harbor bills.

Even climatic conditions, - a resource which we have hardly yet appreciated as such, - it seems, can be changed by mismanagement beyond recovery, as exemplified by the experience of France, where, it is asserted, the cultivation of the olive has be-

1 See "Forestry Conditions and Interests of Wisconsin," Bulletin No. 16, U. S. Dept. of Agriculture, Division of Forestry, 1898.

${ }^{2}$ See J W McGee, quoted in "Forest Influences," Bulletin No. 7, U. S. Dept. of Agriculture, Division of Forestry, I894. 
come impossible in the northern departments, due to the removal of forest cover, which furnishes protection against northern winds.

Lastly, as resources restorable and yielding increased returns to increased activity, we would find most of those resources which are the product of human labor, industry, and ingenuity: the accumulated wealth, the accumulated educational fund, and other conditions of civilization, the people themselves, capable of performing labor.

It might appear that, of the natural resources, the soil with its fertility, capable under intensive cultivation of increasing its yield, should be placed here; but when this increased activity is unaccompanied by rational method, this resource, too, will deteriorate almost to a degree where its restoration is practically precluded.

Altogether, while possibility of restoration has served in our classification, the practicability of such restoration, i.e. the relation of expenditure of energy and money to the result, will have to be taken into consideration when state activity with regard to them is to be discussed.

From yet another point of view we can distinguish between those resources, which yield directly a tangible material, necessaries or conveniences of life, serving the purposes of gain, and which are, therefore, objects of industrial enterprise ; while others, though desirable and necessary, serving indirectly for the comforts of society, industry, and progress 
of civilization, do not call for the exertion of private enterprise and offer no incentive, or only an imperfect one, for private action, or are beyond the limits of control by private individuals.

Thus, if there is the possibility of influencing climatic conditions by human action, which is doubted by some climatologists in defiance of many patent facts, it would be a matter of public concern rather than of private interest to preserve favorable or improve unfavorable conditions. As far as the forest yields useful material for the arts, it is an object of private industry; but when, by its position on a watershed, the forest becomes an influential factor in the water conditions of the plain, it may still serve the purposes of gain and wealth, which are the objects of private industry, but its indirect significance for society at large exceeds the private interest.

Of the proper condition of waterways, of navigation and transportation, it may be said, that while private interest may be concerned with it for private gain, public interest is involved in it to a much greater extent. For private interest lies only in the direction of individual gain, while state interest lies in the direction of social gain, of gain for a larger number. Whenever, therefore, other purposes, which do not contemplate the.highest profitableness, are to be subserved, especially purposes which are of interest to the community at 
large, this class of resources must become an object of public economy by the state or community.

Often it will be a difficult task in practice to assign a particular resource to a proper position with regard to its bearing upon social interests, but conservatism, which is the logical policy of society, will lead us in cases of doubt to lean toward the presumption that the interests of society are more likely to suffer than those of the individual; and att. t k e a mistake in curtailing private interests will be more easily corrected than a mistake in not having in time guarded social interests. Thus it has been urged against the selection of forest areas as state reserves for the purpose of protecting watersheds, that it would be difficult to decide which areas are necessarily comprised in such selection, without withdrawing those of simply commercial value. That the widest construction of the idea of protective forests will be safer than the opposite, and should be the one adopted by the government, seems quite reasonable.

To properly appreciate the position in any given case, we will have to weigh the present and future significance of the resource, the likelihood of its permanence, and the likelihood of its fate under private treatment, whence the necessity of bringing it under sovereign control of the state and the quality of the control will appear.

That each individual case will require its own consideration and adjudication holds there as well

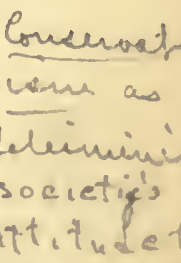


as with legislation in reference to industrial action, and the general classification here attempted offers simply a suggestion as to the general points of view from which each case must be considered.

With the conception of the government before us, as outlined, namely, as the instrument to secure the possibility of not only social life but of social progress, the representative of communal interests as against private interests, of the future as against the present, we can get an idea as to how far the providential functions of the state are to be called into action.

The policy of governmental control over waterways, roads, and lands falling under the operation of eminent domain is well established in most governments. The ownership and management of railways has proved itself to be in the interest of society in several countries. It should be extended with even more reason to all exhaustible, nonrestorable resources. That in the interest of society and of production as well the mines should belong to the state in order to prevent waste, we may learn from the actual experience of France, where they are state property, and only the right to work them under supervision is leased to private individuals.

Of the restorable resources it is apparent that, with regard to those which yield increased returns to increased labor, the interests of society and of the individual run on parallel lines. Where inter- 
ference of the state in their behalf exists it is not from providential reasons. The ameliorative functions only are called into requisition. Whatever tends to stimulate private activity is to be promoted, whatever retards development of intensive methods is to be removed, by government. Industrial education, cultural surveys, bureaus of information, experiment stations, and other aids to private enterprise eonstitute the chief methods of expressing/state interest with regard to these resources.

The three great resources upon which mankind is most dependent, and which, therefore, demand foremost attention of the state, are the soil as food producer, the water, and the climatic conditions. The utilization of these three prime resources by agriculture forms the foundation of all other industries, or, as Sully puts it, "Tillage and pasturage are the two breasts of the state." It is true the manufacturer increases the utility of things, but the farmer multiplies commodities; he is creative, and he therefore above all others can claim a right to first consideration on the part of the state.

The soil is a valuable resource as far as it is fertile and capable of agricultural production; the fertility, while liable to deterioration, can, with few exceptions, be said to be restorable, and it certainly yields increased returns to intelligent increased labor. It ranks, therefore, with those resources which can be left to private enterprise, 
calling only for the ameliorative functions of the government. But while this condition prevails when the soil is put to agricultural use, it does not exist as long as the soil is not so utilized. By the withdrawal of large sections of land from. such use, society is harmed, and deprived of the benefit which it would derive from the use of its property. The proper disposal and the appropriation of the soil to proper use form, therefore, fit functions of government control.

The rational appropriation of soil for either farm use, pasturage, or timber production, one would think, could be left to the regulation of private intelligence; yet the fact is, that the thin, rocky soils of mountain districts are worked for a scanty agricultural crop, when they should be left to timber; while thousands of acres in fertile valleys are still under the shade of virgin forests.

Water and climate are the accessories to agricultural production, and supplement the resources of the soil. Not objects of private enterprise directly, except in a limited manner, it is evident that, as far as they or the conditions which influence them can be at all controlled, they should be under the direct control of the state. A rational management of the water capital of the world in connection with agricultural use of the soil will become the economic problem of the highest importance as the necessity for increased food production calls for intensive methods. And in 
connection with this problem, it must become a matter of state interest, by a rational management of existing forests and by reforestation at the head waters of rivers and on the plains, to secure the conditions which make a rational utilization of the waters possible. For without forest management, no satisfactory water management is possible for any length of time, no stable basis for continued productive agriculture, industries, and commerce!

It is the object of this volume to elucidate in greater detail the significance and character of the forest resource, to show its relationship to the conditions of social life, to point out the various aspects from which it can be viewed, with the final object of determining the position which the state should take with reference to it, based upon the conception of state functions as outlined in this chapter.

We shall recognize that to the individual it is the timber, the accumulated growth of centuries, which is of interest, and which he exploits for the purpose of making a profit on his labor and outlay without any interest in the future of the exploited area. The relation of the forest to other conditions, direct or indirect, immediate or future, hardly ever enters into his calculations.

On the other hand, the function of the forest, which it exercises as a soil cover by preventing erosion of the soil, by regulating water flow, changing surface drainage into subsoil drainage, and thereby 
influencing the water stages of rivers, and its possible relation to the local climatic conditions, preëminently renders it an object of government consideration.

Here the general principle of the Roman law, Utere tuo ne alterum noceas, prevention of the obnoxious use of private property, readily establishes the propriety of state interference, and by alterum we are to understand, not only the other citizen of the present, but of the future as well.

We will see, that the forest resource is one which, under the active competition of private enterprise, is apt to deteriorate, and in its deterioration to affect other conditions of material existence unfavorably; that the maintenance of continued supplies as well as of favorable conditions is possible only under the supervision of permanent institutions with whom present profit is not the only motive. It calls preëminently for the exercise of the providential functions of the state to counteract the destructive tendencies of private exploitation. 


\section{CHAPTER II.}

\section{THE FOREST AS A RESOURCE.}

IT may be stated without fear of contradiction that outside of food products no material is so universally used and so indispensable in human economy as wood. Indeed, civilization is inconceivable without an abundance of timber.

The nomad of to-day, who herds over the treeless plains and prairies, is still like the Scythian of ancient times; his life, his culture, his attainments, are no more advanced. The successful settlement and civilization of our own treeless regions of the West became possible only through the development of means for the transportation of this most needful material. So general and far-reaching has its use become that a wood famine, however improbable its occurrence, would be almost as serious as a bread famine. We may become less wasteful, both as regards food and wood, but the necessity of wood, as far as we can foresee at present, will always be second only to the necessity of food, and far greater than that of any other material used in the arts.

The necessity to us of any material depends on the extent and nature of its use, and on the possi- 
bility of replacing it by other materials. If we regard the chair we sit on, the table we eat from, the paper we write on, as necessities, it is fair to say that over 99 per cent of all wood is used in supplying real wants, while less than I per cent is used to furnish luxuries, such as fancy articles, carvings, and other decorations. But even if only the use of wood as fuel, for the construction of shelter for man and goods, for the building of bridges and harbors, for purposes of transportation, agriculture, mining, and manufacture, is considered as necessary in distinction to unnecessary or luxurious uses, it may still be asserted that there is more than 95 per cent in bulk or weight thus consumed.

Our civilization is built on wood. From the cradle to the coffin, in some shape or other, it surrounds us as a convenience or a necessity. It enters into nearly all our structures as an essential part. Over half our people live in wooden houses, and the houses of the other half require wood as an indispensable part in their construction. It serves to ornament them, to furnish them with conveniences, to warm them, to cook the food. More than two-thirds of our people use wood as fuel, and until recent times it was the only or principal means of melting the ores and shaping the metals with which to fashion the wood itself (see Appendix). For every hundred tons of coal mined, two tons of mining timber are needed, and wood 
in large quantities is needed to mine our metals. Every pound of iron, every ounce of gold, requires wood in its mining, wood in its manufacture, wood in its transportation. There is hardly a utensil, a tool, or even a machine, in the construction of which wood has not played a part, were it only to furnish the handle or the mould or pattern.

The articles, useful or ornamental, made wholly or in part of wood, are innumerable. Our houses are filled with them, our daily occupations necessitate them wherever we are. For our means of transportation we rely mainly on wood. Our 260,000 miles of railroad track (190,000 miles railroad), the carriers of civilization, lie on not less than. $700,000,000$ of wooden ties and need I40,000,000 annually for renewals; ${ }^{1}$ they run over more than 2000 miles of wooden trestles and bridges, they carry their passengers and freight in over $1,000,000$ wooden cars, and much of the millions of tons of freight is shipped in wooden boxes and barrels, and

1 This drain on our forest resources for railroad ties or sleepers, which requires a wasteful use of our most durable timbers, is gradually being reduced by preservative processes which lengthen the "life" of ties, and it bids fair to be soon avoided by the use of metal ties, which, except in initial cost, have proved themselves superior in all other respects. Their use is long past the experimental stage in other countries, there being, in 1894, not less than 35,000 miles, or 9 per cent, of total track lying on metal, while the cheap initial cost of woorlen ties in the United States has retarded their use here. Very exhaustive reports on the metal tie question were published by the U. S. Dept. of Agriculture, Division of Forestry, in Bulletin No. 4, 1889, and Bulletin No. 9, 1894. 
stored in wooden sheds. Ten million telegraph poles are needed to keep up communication between distant markets.

The forest furnishes the cooperage to market our vintage, to store our flour and fruit. The forest furnishes the plough handle and harrow frame to cultivate, the threshing machine and windmill to prepare the crops, the cart to bring them to market, the bottoms in which they cross the ocean to foreign marts, and even the tar and pitch needed to keep the cargo safe. While iron ships have largely replaced the wooden bottoms in ocean travel, our coastwise and inland shipping, which requires a tonnage twice as large as the transatlantic trade, is carried mostly in wooden ships. ${ }^{1}$ We are rocked in wooden cradles, play with wooden toys, sit on wooden chairs and benches, eat from wooden tables, use wooden desks, chests, trunks, are entertained by music from wooden instruments, enlightened by information printed on wooden paper with black ink made from wood, and even eat our salads seasoned with vinegar made from wood.

1 According to the report of the Commissioner of Navigation, there were in the merchant marine of the United States in the year $1900,2,507,042$ tons of sailing vessels, practically all of wood, and $2,657,797$ tons of steam vessels, of which, undoubtedly, a large part was in wooden hulls, besides over $4,000,000$ tons unrigged vessels, wooden barges, etc., permitting the above estimate. During the year 1900, 1447 vessels, with a tonnage of 393,790 , were built, of which only half the tonnage was of iron and steel. 
The uses of wood, multifarious now, are constantly increasing. With the manufacture of wood pulp and cellulose, an entirely new direction of use has been opened; originally designed to furnish a cheap substitute for linen paper, its application in many ways is growing daily, and promises for the future the largest drain on our forest resources, the manufacture of wood pulp having increased more than threefold in the last ten years (see Appendix).

To give briefly an idea of the extent of our own wood consumption, we may say that, if 5 persons are counted to a family, each family in the United States uses on an average about 2000 cubic feet or about 80,000 pounds of dry wood per year, the annual product of at least 50 acres of forest.

The reasons for this universal and varied application of wood may be found in several directions. In the first place, the general occurrence of forest growth and the ease with which wood could be obtained and shaped directly to the purpose in hand made it naturally the material of earlier civilizations, but there are certain qualities in addition which will make its use always desirable, if not necessary. In the combination of strength, stiffness, elasticity, and relatively light weight, it excels all other known materials. Not only is a stick of long leaf pine superior in strength to one of wrought iron of the same weight, but employed as a beam it will bear without bending a load six to 
eight times as great as an iron bar of the same length and weight. Moreover, the wooden beam will endure greater distortion than the metals without receiving a "set" or permanent injury.

The ease with which it can be shaped and keeps its shape, the softness and yet unchangeableness, its non-conductivity of heat, of electricity, which makes its use more comfortable than that of metals, in addition, its light specific weight and many other qualities, recommend it for many purposes in preference to other materials.

But above all things its cheapness recommends it, - we are paying now, leaving out fancy woods, at the most 60 cents per cubic foot for the best wood, shaped, as against $\$ 5$ to $\$ 10$ per cubic foot for iron in sheets or bars. Moreover, it is the only material of construction which we can produce and reproduce at will, while we know that most other materials now in use must be sooner or later exhausted.

Other materials have displaced wood in some uses, but other uses have arisen for wood, and often the substitutes have again been displaced by wood, when its superiority or peculiar qualities have been more fully recognized. Even in such nicely balanced structures as the bicycle, for which metal seemed the only proper material, wood has proved itself superior, at least in certain parts.

A remarkable instance of this return to the use of wood instead of metal is that for factory and warehouse construction in order to reduce danger 
from fire, it having been found that in case of fire iron beams and posts are twisted out of shape by the heat, causing the collapse of the whole building, while with wooden posts and beams the chances of keeping the walls intact are much greater.

Coal has largely displaced wood as fuel, yet according to the census of 1880 more than half of our population relied still on wood for fuel, and there is no. reason to believe that the proportion has changed measurably. In fact, if we may be allowed to consider the figures of the census of I 880 still proportionately true, as far as bulk is concerned, our fuel consumption represents about three-fourths of our total wood consumption, and even in value this part represents nearly one-half of our entire enormous consumption of forest products, and exceeds in bulk more than ten times the iron and steel handled in this country.

Very interesting statistics regarding the displacement of wood by coal in Germany show that from the beginning of the last century, when coal began to be generally used as fuel, the consumption of wood increased in the same proportionate rate as the consumption of coal.

The development of the cellulose and wood pulp industry, with the consequent extension in the use of paper made from this material for all kinds of purposes where elasticity and durability combined with strength and lightness is demanded, from collars and cuffs and combs to car wheels, has 
given new and constantly growing employment to wood.

Considering, moreover, the very extensive and the very varied employment of wood, it will be apparent that substitution by other materials cannot be readily accomplished and means inconvenience, and, in many cases, decrease of comfort. Hence large wood supplies are, and unquestionably will continue to be, an indispensable requirement of our civilization, almost like water, air, and food.

Besides wood supplies, the forest furnishes other materials of no small value. Of these, two classes at least give rise to industries of considerable extent, namely the tanning industry and the naval store industry.

The bark of certain trees, notably the hemlock and the oaks among our native species, contain the chemical compounds known as tannic acids, which serve for the manufacture of leather. The fact that this property of the bark has made the value of the same to exceed by far the value of the wood itself, especially as it is easier to transport the former, has led to an enormous waste of useful wood material, the trees, in mountainous regions especially, having been peeled and left to rot in the woods; and in certain mountain regions difficult of access this waste still continues.

Thus I,500,000 cords of tan bark worth about $\$ 10,000,000$, which we use annually, entailed formerly a sacrifice of nearly rooo feet of lumber per 
cord of bark; of this now probably the larger part is saved.

Lately, too, it has been found that the wood itself of some species yields paying quantities of tannin, which can be and are being extracted by special processes, thus again widening the field of usefulness of the wood article itself; while the metallic substitutes for tannins have so far not been able to displace the same to any great extent.

The naval store industry, concerned in extracting from the living trees of certain kinds of pine, especially the Southern long leaf pine, and from other species, the resinous contents, and-by distillation obtaining turpentine, rosin of various kinds, and tar, is indebted to the forest to the extent of about $\$ 8,000,000$ per year in our country. ${ }^{1}$ This industry could be carried on without any direct injury to the wood product, provided the utilization of the trees followed at once the operations of the turpentine gatherer; but under the neglectful methods pursued, with fires sweeping through the woods, the scarred trees are to a large extent either burnt beyond usefulness, or injured by fungus and insects and laid low by wind storms, so that here again is an enormous and largely unnecessary loss to the forest resources, entailed in this industry. Here too, of late, improvement is observed, the sawmiller following more closely the turpentine gatherer.

I In 1899 the value reported by the census was over $\$ 20,000,000$, as against the above figure for 1889 . 
A similar industry is the tapping of the maple for sugar, which is peculiar to the Unit States, producing, with over $50,000,000$ pounds of sugar and 3,000,000 gallons of syrup, values to the extent of $\$ 6,000,000$ annually.

Finally, by distillation of the wood itself and condensing of the gaseous products, considerable amounts of wood alcohol, wood vinegar, and acetates, creosote and other tar oils useful in the arts, are derived, adding another $\$ 3,000,000$ or more to the annual revenue furnished by our forest resource.

In addition to these materials, which come from the tree growth itself, there are many useful things growing in the forest, which in our country have hardly yet attained the dignity of industrial development; although the distillation of wintergreen oil from birch brush and the gathering of ginseng occupy quite a number of people industrially, while the huckleberry and cranberry crops furnish considerable additions to the fruit supply of gardens and orchards.

How much may be obtained from the careful use of these by-products of the forest may be seen from the statement that in the Prussian state forests the revenues for I 894-I 895 were:-

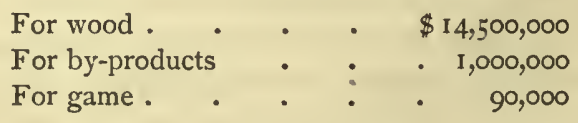

It is seen that the by-products furnished about 7 per cent of the total income. 
In one small village of Pomerania (Prussia), the amount paid for huckleberries which the poor population gathers in the forest amounts to $\$ 20,000$ or $\$ 30,000$ a year. In another small forest district it is calculated that the berry and mushroom harvests represent to the gatherers an annual income of $\$ 22,500$, showing that even the revenues derived from the minor products of the forest may attain a considerable economic significance.

What relative position from the standpoint of wealth production the forest resources and their exploitation take in the household of the nation may best be learned from a comparison with other sources of wealth and their production, considering the revenues from the different forms of wealth, the capital invested, the value of product, the number of people employed, and the wages paid. Unfortunately for such comparisons the data are, at least in our own country, but unsatisfactory, since the statistics of an industry like the forest industries, which are largely removed from centres of production, and in which a large number of people are occupied only occasionally and for parts of the year, are necessarily deficient and must remain below the truth to an uncertain extent.

It is, for instance, impracticable to ascertain the amounts of wood cut and used on farms for home consumption, or to apportion the employment of 
labor in this home exploitation. In addition, the values of a material which on account of its bulkiness is only to a limited degree object of the world trade, are but little influenced by the world's demand, and dependent much more than food supplies on home demand only; and hence the values of such material as wood are at a disadvantage, or at least on a different footing, when compared with other export materials.

While the value of the raw forest products consumed every year in the United States at places of consumption, roughly shaped for further use, may be placed at $\$ 600,000,000$, this is enhanced by their further manufacture to over $\$ 1,200,000,000$, thus making the result of the forest industries second only to those of agriculture, the value of whose products reached in the census year ( 1890 ) nearly $\$ 2,500,000,000$, while the total production of metals which could in any way replace wood - gold and silver and iron included-reached only $\$ 270,000,000$, and the entire mining industry (quarries and every kind of mineral or earthy product included) but little over $\$ 600,000,000$. (See Appendix for details.)

Although the forest industries are carried on with proportionately small capital, over $\$ 560,000$,oo were invested in the mere exploiting and first preparation of the material in the lumber business, while another $\$ 900,000,000$ are employed in manufactures which rely either entirely, or to an extent of over one-third of their product, on wood. 
Of the total value of manufactured products, aggregating nearly $\$ 10,000,000,000$ worth in the census year 1890 , I 7 per cent is to be credited to the forest resource, and nearly 20 per cent of the capital invested, of labor employed, and of wages paid in all manufactures.

In addition to the capital and labor involved in the exploitation of the forest, we have to consider the large but indeterminable amount of labor involved in the transportation of the material from points of manufacture, which adds to the economic importance of these industries in the same, in perhaps greater proportion, than other industries.

So large is the money value resulting from the mere conversion of the products of our woodlands that it equals at present annually a 2 per cent dividend on the entire wealth of the nation ( $\$ 65,000,000,000$, according to census in 1890$)$. This dividend, to be sure, is unfortunately largely paid, not from surplusage, but from capital stock, and a future generation will have to make good the deficiency.

One very important factor often overlooked by laymen in appreciating the economic value of the forest resources of a country is the fact, that it is not wood simply that is wanted, but wood of certain quality useful for given purposes. A country may be well covered with woodlands and yet lack those valuable kinds of woods which lend 
themselves readily to the everyday uses of civil-ized life.

Again, it may be well supplied with valuable kinds, but these are found so scattered among the less valuable growth, the tree weeds, that their exploitation becomes cumbersome and expensive.

Thus we see Brazil and other South American countries, and Australia, in spite of their extensive forest areas, come to the United States for their lumber supplies, lacking as they do the soft, easily worked, yet strong and elastic coniferous kinds, which are par excellence the materials of construction.

Again, the valuable hardwoods of those countries, possessing excellent qualities, besides their beauty, for which alone we use them at present, will never be able to compete or supplant our own materials, for they occur in single individuals scattered among hundreds of other species, so that to supply any considerable quantity of any one kind requires culling over many acres, which renders them too expensive for general use.

There is therefore nothing but ignorance in the comfortable ideas of those who look forward to a supply of wood from those countries when our own supplies give out.

A proposition to secure statistics of the productive forest area and timber supplies of the world ready for the axe, and of the consumption by the 
population, was brought before the International Forestry Congress at Paris, in 1900. The attempt to secure such statistics in any way reliable is almost hopeless, when we cannot even in our own country get more than the roughest approximations; moreover, even if it were possible to secure some approximate figures, as long as there are no attempts at management of the resource, the knowledge would not be worth the expense it would entail to gather it, since the conditions would change without record being kept, hence the value of the figures would be most ephemeral.

A rough approximation would bring out the fol'lowing condition of the earth's surface, from which at least the potential forest area, that which, under natural conditions, did or does or is able to produce timber forest, can be estimated :-

\section{Percentic Distribution of Land Area}

\begin{tabular}{|c|c|c|c|c|c|}
\hline 1 & a & & $\begin{array}{l}\text { Potential and } \\
\text { actual forest } \\
\text { soils. }\end{array}$ & Prairie. & $\begin{array}{c}\text { Plains and } \\
\text { Barrens. }\end{array}$ \\
\hline North America & . . & • & 45 & 5 & 50 \\
\hline South America & . & • & 78 & 12 & Io \\
\hline Europe . & - & - & 84 & 10 & 6 \\
\hline Asia . . & - & - & 45 & 3 & $5^{2}$ \\
\hline Africa . & - & - & 60 & 12 & 28 \\
\hline Australia . & - & - & $\frac{37}{60 \%}$ & $\frac{3^{8}}{7 \%}$ & $\frac{25}{33 \%}$ \\
\hline In billion acres & - . & - & 18 & & IO \\
\hline
\end{tabular}


One-third of the land area, then, is incapable of forest growth (not tree growth), 7 per cent is unfitted for it, and 60 per cent must be divided between farm and forest. How much is actually wooded it is impossible even to estimate, and how much contains available wood supplies, still less so.

The world's requirement of wood materials may be estimated as follows, actual figures and statistics in some cases allowing reasonable approximations, but lacking, of course, for all oriental countries, Africa, Australia, South America, any tangible basis: for these, therefore, merely allowances by guess are made:-

\begin{tabular}{l|r|r|r|r|r}
\hline & & \multicolumn{2}{|c|}{ Woon Requirement. } & \\
& $\begin{array}{c}\text { Inhabitants, } \\
\text { millions. }\end{array}$ & $\begin{array}{c}\text { Per } \\
\text { capita, } \\
\text { cu. ft. }\end{array}$ & $\begin{array}{c}\text { Total } \\
\text { million } \\
\text { cu. ft. }\end{array}$ & $\begin{array}{c}\text { Of which } \\
\text { ft. B.M. } \\
\text { million. }\end{array}$ & $\begin{array}{c}\text { Per capita, } \\
\text { ft. B.M. }\end{array}$ \\
\hline North America . & 80 & 300 & 2,400 & 40,000 & 500 \\
Europe . . . & 360 & 40 & 1,440 & 22,000 & 60 \\
All other countries, & 1,160 & 19 & 2,200 & 4,500 & 4 \\
\hline
\end{tabular}

This, for the $1,600,000,000$ inhabitants, would average about 38 cubic feet per capita, of wood of all descriptions, of which 6 to 7 cubic feet are saw material equivalent to 40 feet board measure.

The following countries furnish about the following quota of the saw material :- 


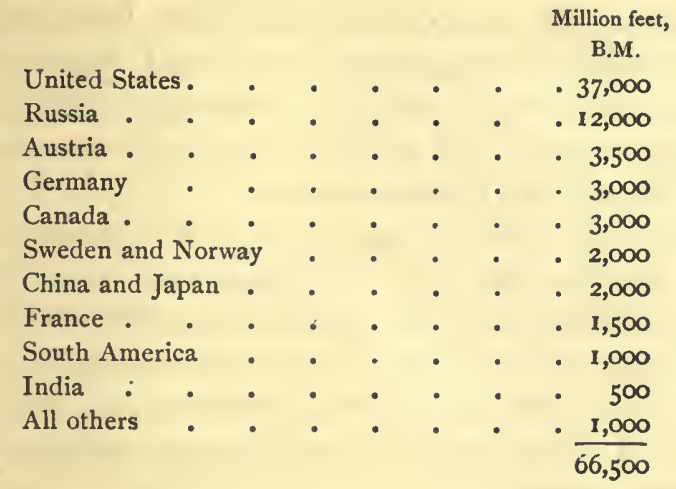

The use of wood per capita in the United States, with about 350 cubic feet, exceeds that of all other civilized nations; nearly one-quarter of this wood, or 85 cubic feet, is log material ( 100 cubic feet log material may be roughly figured as producing 600 feet B.M. sawed material), while England, importing nearly all her requirements, can get along with about I 3 cubic feet of log material, and Germany with a consumption of 43 cubic feet of wood per capita, of which 15 cubic feet is log material. Both these countries, Great Britain importing practically all and Germany over 25 per cent of her needs, would indicate that a civilized nation in a northern country requires between 12 and I 5 cubic feet of log material. Outside of the United States and Canada, which export $280,000,000$ cubic feet, the countries which cut more than they consume are Russia with $420,000,000$, Austria with 240,000,000, Norway and 
Sweden with $400,000,000$ cubic feet; these exporting countries, with additional small exportations from India and South America, supply the I,400,000,000 cubic feet which Europe imports, and for which she pays $\$ 200,000,000$.

For the United States the available timber ready for the axe has been estimated variously at from I, 380,000,000,000 to $2,300,000,000,000$ feet B.M., corresponding to 35 to 50 years' requirements, which, if only a distant approach to the truth, impresses the need of careful husbanding and attention to reproduction. ${ }^{1}$

If one would wish to know what the needs of a people for wood supplies is (when there is no extravagance permissible, and when every stick is used down to the brush, and when coal is not so plentiful as to supplant all firewood), the figures for Germany, which possesses unusually good statistics to make such calculation possible, furnish a good basis.

Its $50,000,000$ people live on $133,000,000$ acres of land, $-I$ on $2 \frac{2}{3}$ acres as against $I$ on 26 acres in the United States, - hence forest growth is mostly confined to the poorer soils, which are not fit for agriculture. From their 35,000,000 acres of such forest growth $-\frac{3}{4}$ acres per person - the Germans

1 Many foolish assertions regarding existing wood supplies in the United States and Canada, which are rehearsed by pseudo-statisticians to show inexhaustible supplies, are not worthy of consideration. 
take mostly only the annual accumulations, striving to keep their stock, or wood capital, intact and in good reproductive condition. The annual cut amounts to $1,870,000,000$ cubic feet of all sorts and sizes, or 53 cubic feet per acre, of which, however, only 27 per cent, or round $500,000,000$ cubic feet, is of size fit for manufactures. These amounts are, however, not sufficient for the needs of the population; and hence, although some $48,000,000$ cubic feet of wood and woodenware, worth $\$ 26,700,000$, are exported, over $305,000,000$ cubic feet of wood and wood articles, worth $\$ 53,500,000$, are imported; so that nearly ro per cent of the total consumption comes from outside, not counting bruch wood that forms part of manufactures imported, like pianos, wagons, etc.

We have then here a consumption of 43 cubic feet per capita, of which I 5 cubic feet is sizable material, and the value would figure to little less than $\$ 3$ per capita, or say $\$ 150,000,000$ is the wood bill of these economical people annually, as against 7 times that amount, which we spend. If you ask as to relative cost or price of these wood materials, one interesting fact stands out, namely, that while the value of their imports is $\$$ I 4 I per ton, the value of their exports is $\$ 255$ per ton; in other words, Germany is careful to export more manufactured and high-priced material than she imports; thus, the exported lumber and wood brings her 32 cents per cubic foot, while she pays only 23 cents for the 
imported wood. Again, the exported wood manufactures bring her at the rate of $\$ 4.20$ per cubic foot, while she pays only $\$ 2.40$ for the imported ware. We, on the other hand, export twice as much as we import, and that mostly raw materials, namely, twice as much in value of raw materials as of manufactures, and by so much decimating our resources, which we exploit beyond their power of reproduction.

The temperate zones are the favored ones in that they abound not only in a variety of woods which are most readily turned to use in all the various directions in which wood is required in our civilization, but the most useful ones occur more or less gregariously, so that their exploitation can be most readily and cheaply accomplished. This is especially the case with the conifers, spruces, firs, redwoods, and above all, the pines, which cover large areas exclusively or nearly so, and excel in the combination of desirable qualities all other materials, so that without them our civilization would be badly crippled. Of the enormous yearly lumber consumption in the United States, amounting nearly to $40,000,000,000$ feet of board measure (enough to make a plank walk 300 feet wide around the world, or floor over entirely the states of Delaware and Rhode Island), the conifers furnish more than $\frac{3}{4}$ and the pines alone $\frac{1}{2}$; and again the white pine of the lake states furnishes $\frac{3}{5}$ of this half, giving to these supplies of one species an economic 
significance beyond all others. The amount of virgin coniferous material standing ready for the axe amounts, probably, to less than $1,500,000,000,000$ feet.

This lumber consumption, to be sure, represents only one-quarter of our wood consumption; but it is the important part, to supply which trees of large size, of good form, of special quality, must be on hand, and which it has taken a century or more to produce, - most of our lumber is furnished at present by trees over 200 years old. The other threequarters of our consumption, for firewood and small dimensions, can be easily supplied from inferior material, the offal of the lumber trees and young growth, although at present much body wood-is still cut into billets for firewood.

The layman, who has no experience with the requirements and practice of lumber production, can hardly realize what a small percentage of the actual wood in a tree or an acre of forest growth reappears in useful shape from the sawmill. Not only is a large part of the tree in the virgin woods often altogether unfit for sawing, being crooked or knotty or rotten or windshaken, but the unavoidable waste at the mill in shaping the material reduces the output by at least one-third to two-thirds of the contents of the logs that are placed before the saw. That this mill waste increases rapidly with the reduction in size of the log will become a significant fact, when the heavy sizes of the virgin 
forest are exhausted and smaller sizes must satisfy our demands.

It is, then, not woodlands, not the area of wooded country, which has a meaning as far as material forest resources are concerned, but the composition and condition of the timber on that area determines its value.

Thus nearly 50 per cent of Massachusetts is covered with a wood growth, but the lumber product of that state would not suffice to supply the needs of one-tenth of its population. Not only is there hardly any lumber to be found ready for the axe, but the percentage of growth capable of producing desirable material is exceedingly small.

Thousands of square miles in the United States are in similar condition; they are woodlands, but the composition and condition of the forest growth is such as to have no significance as regards lumber supply for the present and for a long future.

The capacity of the forest to produce new supplies depends both as to quantity and quality on the climate, character of the soil, and still more on the care which the forest receives.

In the uncared-for, natural, or virgin forest the production is always much smaller than in the forest properly managed, and, on the average, of a much inferior kind. Not that the magnificent clear lumber which we find in virgin woods could be much improved in quality, but considering the time and space, the product has been obtained with the maximum waste of both. 
The virgin forest is always stocked largely with very old, and necessarily often decaying trees, which are doing little or nothing in the way of growth or else are deteriorating faster in quality than they increase in quantity; then there are myriads of saplings and small brush either of kinds which are undesirable or of individual trees which under the shade of the older will never have opportunity to develop into valuable wood. Moreover, the virgin forest rarely covers fully the ground it occupies, but usually leaves larger or smaller openings growing to grass or shrubs, and among the trees forming the forest there are a large number which are not useful in the arts, - tree weeds.

In addition dead trees and fallen timber always occupy considerable space which is thus withdrawn from wood production. Hence it is almost impossible to give even an approximate estimate of what the virgin forest actually produces, how much per acre and year grows in it.

This is certain, that while the few trees which overtower the general level of the rest of the growth and. are fully developed, may have made as much wood as the species in the soil and climate could make, yet the useful wood production on the whole acre has been far below its capacity.

The timber in our pineries which is considered fit for sawing is mostly over one hundred and fifty years old, and it has, therefore, taken at least a century and a half to produce the five to ten thou. 
sand feet B.M. per acre, which are ordinarily har. vested from these virgin woods. But this product was probably ready for the axe these thousand years, without increasing, the decay balancing the new growth; generations of similar large trees have come to maturity, have fallen and decayed before and during the one hundred and fifty years in which the present crop developed. At the same time, to judge from the number and character of the decaying trunks which are found covering the ground, these generations have not been very many during the time that the present crop has been growing: the land has largely been wasted in producing useless material, - brush and tree weeds.

In other words, the natural forest resource as we find it consists of an accumulated wood capital lying idle and awaiting the hand of a rational manager to do its duty as a producer of a continuous highest revenue.

Such management, however, it does not receive in the crude exploitations to which it is subjected in all newly developed and developing countries; on the contrary, the wasteful use of the soil is only intensified; for these exploitations, the operations of the lumberman, consist in a mere removal of the valuable portions of the growth, a cashing of the accumulated wood capital, without the slightest reference to future revenues which might be derived from it in the shape of wood growth. In 
fact he does not recognize or consider that the forest is not merely a mine, but a reproducible resource, - a living, growing crop, the product of the soil and climate, which can be reproduced ad libi. tum in even superior quantity and quality to what nature alone and unaided has done.

His methods of removing the standing timber are not only wasteful, - for under the present economic conditions prevailing in most parts of the United States hardly more than 20 to 30 per cent, rarely 40 to 50 per cent, of the material in the felled trees is utilized, - but they decrease the capacity of the land for producing valuable timber.

By culling out the most valuable kinds, leaving undesirable kinds and poor trees to shade the young growth that may have developed, he prevents the reproduction of a valuable crop, and hence such culled areas, while they still appear as forested, have often lost their entire value as producers of useful material; the growth on the land being an encumbrance rather, to be got rid of first, before profitable use of the soil either for agricultural crops or for useful wood crops can take place.

It thus may happen that the charcoal burner, who cuts the entire growth of wood, produces less injury to the future condition of the forest resource, for he gives at least equal chance to the valuable and less valuable kinds to reoccupy the ground, while the lumberman gives the advantage to the 
weeds in tree growth whenever he culls the better kinds. Under these conditions, when the timber is harvested and the land burned over, the conditions are so changed and so variable as to preclude every estimate of future supplies that might be reproduced.

The rational way in treating the resource of virgin woods, from national economic if not from private pocket interest, would be as far as possible to prepare first for a desirable reproduction by cutting out the poor kinds and the useless brush, then logging out first only the largest trees of the better kinds with proper precaution against injury to younger growth, and against fires, then gradually, as younger trees grow on, the older ones may be harvested and as much as possible in such a manner that the young aftergrowth is given room and light.

Thus, by mere care in utilizing the resource, not only can all the product be harvested but a new crop, increased in quantity, can be secured. From such simple care we come to the finest methods of forestry, for these are only different in the degree of care, hardly in the kind.

By these methods man makes the forest resource produce easily the treble and quadruple of what it does when left alone; so that merely by we judicious use the capacity of useful production grows.

How much intensive management can increase the yield of the resource may be judged from the 
experiences of German forest administration. Here the forest resources are nearly if not entirely brought under rational management and are treated as a crop, constantly furnishing harvests, and being reproduced without diminishing the wood capital.

The results in quantity of raw product depend of course largely on soil, climate, and species, and in amount of money returns, also on market conditions and means of transportation.

These last conditions, if favorable, may render a more intensive management and especially a closer utilization of all kinds and classes of wood possible, and hence the results differ widely.

Thus the more extensively managed Prussian government forests, which with an area of $6,750,000$ acres are perhaps also stocked on poorer soils and are less favorably situated, produced as an average for a series of years 42 cubic feet of timber wood (over 3 inches diameter) per acre, those of Bavaria 55 , those of Baden 59, of Würtemberg 67 , while the most intensively managed state forests of Saxony of only 430,000 acres extent produced 90 cubic feet of wood per acre per year, of which 68 cubic feet was timber wood, the highest production for such a large area.

In Austria from nearly 25,000,000 acres the cut in I 890 was 43 cubic feet per acre; and for France the cut in the state forests, supposed to equal the annual growth, was stated for 1876 at 50 cubic 
feet, while the more poorly managed communal forests were capable of furnishing only 40.6 cubic feet per acre.

The money returns depend, of course, in some degree on the quantity of product, quality, and local demand. In the densely populated, highly industrial state of Saxony they were $\$ 4.00$ per acre net, as against \$I.I9 and \$0.96 in the same period for Bavaria and Prussia respectively. ${ }^{1}$

A further illustration of the increase in yield which comes with proper management of this resource is furnished by the Prussian state forest administration; while during the years from 1829 to 1867 the cut was increased from 28 to 37 cubic feet per acre and to 46.7 cubic feet in 1880 , nearly double what it was in 1829 , yet the proportion of old timber over 80 years, or stock of merchantable timber on hand increased during the last 20 years of the period from 23 per cent to 27 per cent,

1 How much the money results per acre vary according to the species and the fact whether the production is directed more to the production of firewood or of saw timber may be seen from a calculation by Schwappach (Forstpolitik), according to which the net yield on an acre, stocked on best soil for a rotation of 120 years, i.e. the crop being allowed to grow that length of time, would be, when mainly firewood is produced, for pine, $\$ 375$; for spruce, $\$ 672$; for beech, $\$ 456$; when the management is directed to a greater production of saw timber, these results can be increased for pine to $\$ 1,470$; for spruce, $\$ 3,195$; for beech, $\$ 836$, making the acre produce respectively 3 times, 4 times, and double the result. This consideration may serve as a pointer to our New England woodland owners, who are satisfied with the production of firewood. 
showing that the cut remained below the produc. tion. In Saxony, the cut in the most intensively managed state forests has been doubled in the last fifty years, and yet the stock of wood capital standing has increased over I6 per cent; while, in I 845 , of the cut per acre of 56 cubic feet, I I per cent was saw timber, in 1893 , of the 90 cubic feet cut, 54 per cent was timber fit for the mill. The gross revenue increased in that time 234 per cent, and the net revenue over 80 per cent. A financial calculation shows that the state's property has not only paid 3 per cent continuously in revenue, but has appreciated in value 24 per cent by mere accumulation of material.

Since, then, these yields have been kept up for a considerable period without decreasing the amount of wood capital on hand, it is fair to assume that these figures approach nearly to the true producing capacity of these forest lands under the methods employed.

Altogether, the $10,000,000$ acres of German state forests, managed in a conservative manner for continuous production, average about 46 cubic feet of wood (exclusive of brush and rootwood) per year per acre, in which about 50 per cent, or 22 cubic feet, are millable product, log or bolt size.

It is significant to note that the private forests of the empire fall much below these amounts, producing not more than 30 and 12 cubic feet per acre respectively. 
According to a conservative calculation based upon these experiences, the forest resource of Germany represents, in round numbers, a capital value of $\$$ I 80 per acre (\$25 for the soil and $\$ 155$ for the stock of wood), paying a constant revenue of 3 per cent on such capitalization; or since there are somewhat over $35,000,000$ acres of forest, their capital value is equal to $\$ 6,340,000,000$, producing a continuous annual income of $\$ 190,000,000$. The state properties are, moreover, constantly improving, and the revenue constantly increasing.

While, to the casual reader, this showing may hardly appear as a very profitable business, we must not forget that the result is obtained for the most part from soils which would otherwise be unproductive, for the forest areas in these countries are in the main confined to the non-agricultural lands, and to such as may not with impunity be deprived of their forest cover.

Furthermore, from the standpoint of national economy the productive employment of labor directly or indirectly concerned is of moment, representing in laborers' wages annually round $\$$ I 50,000,000, namely, $\$ 35,000,000$ for exploitation, planting, road building, and hauling of forest products, not including rail and water transportation, and \$I I 5,000,000 for labor in industries concerned in shaping the wood, so that not less than $1,000,000$ laborers' families may be estimated to find support from the forest. 
Although we are without the statistics which would permit a similar statement regarding the value of our own forest resource, especially as it has not yet come to a stable condition as a managed property, yet we may venture to make a reasonable guess at some of its conditions, based upon such statistical data as are at hand, and judgment of probabilities.

Our consumption we can' reasonably approximate with a round $25,000,000,000$ cubic feet of large-size material, for we do not use the brushwood to any extent. This, with an estimated area of round $500,000,000$ acres, means a cut per acre of 50 cubic feet, while even the most sanguine estimate of new growth for this vast and variously stocked area could not be made to exceed ro cubic feet of such wood as we utilize per acre and year, and is probably far below this.

Of this large consumption, however, only onequarter, or $6,000,000,000$ cubic feet goes into bolt or log-size material for mill use, the rest being firewood, for which, to be sure, also mostly log-size material is used. The value of the mill material, two-thirds of which is coniferous wood, represents about $\$ 500,000,000$.

An extravagant estimate of the available timber supplies ready for the axe-a guess which the writer has ventured upon the basis of various statistical data, experiences, and considerations of 
possibilities and probabilities - would make the stock on hand about as follows:-

Billion feet,

B.M.

Northern States . . . . . 500

Southern States . . . . . . 700

Western States . . . . . . 800

It is apparent that we are bound to exhaust these stores in less time than they can be replaced, that we are not living on interest, but are rapidly attacking our wood capital, - a process fully in keeping with the development of any new country, but also one against which reaction must set in in time, if serious consequences are to be avoided.

Such reaction may be secured first through a more economical use of the timber resources, for our per capita consumption falls hardly short of 350 cubic feet, nearly nine times that of Germany and twenty-five times that of England, and hence a large margin is left for such economies.

Finally, however, forest management, as practised in other countries, will become an unavoidable necessity to secure the continued production of needed wood supplies.

There is one factor of national importance resulting from the industries concerned in the conversion of our virgin forests, which does not at all, or not to the same extent, attach to them in other countries, and which, in the end, is of more moment than estimates of stumpage or land values or values of products can express. 
Not only does the lumberman with the systematic development of his business, which has enabled him to supply a superior article as cheaply as the inferior one is sold in Europe, give rise to many manufactories and industries and render possible the development of distant agricultural regions, which in turn renders profitable the building of railroads and the employment of labor, but he has been the pioneer in bringing 'the wilderness itself within reach of civilized influences; and while this has often been done at an unnecessarily extravagant sacrifice of much of our natural forest resources, the opening up of these backwoods must nevertheless be considered as a potent influence for good, resulting from his business.

Per aspera ad astra, through rough work to civilization, is the history of the settling of the backwoods, which the logger has accomplished.

Such settlement is necessary before forest management can be profitably applied to the remnants of woodlands; and while we may regret the wastefulness with which this settlement has been made, we must consider it as a necessary step toward an extension of civilized conditions. 


\section{CHAPTER III.}

\section{THE FOREST AS A CONDITION.}

THE earth may be said to be a potential forest. A cover of tree growth more or less dense is or has been the natural condition at least of the larger portion of the habitable earth; and of the entire land surface not less than 60 per cent may be classed as actual or potential woodland.

In the struggle for existence and for occupancy of the soil between the different forms of vegetation, tree growth has an advantage in its perennial nature and in its elevation above its competitors for light, the most essential element of life for most plants. These characteristics, together with its remarkable recuperative powers, assure to the arborescent flora final victory over its competitors, except where climatic and soil conditions are not adapted to it.

The entire absence of tree growth from some localities, such as the northern tundras and the high peaks above timber line, is due both to temperature and soil conditions. Here the two characteristics of perennial life and persistent height growth, become unfavorable, since extreme winter 
temperatures above the snow cover, droughty winter storms, and frosts every month in the year can be endured only by those plants which have a rapid cycle of development, or are sheltered near the ground by the snow cover; the wet soil on the tundras, frozen for most portions of the year, or the thin soil on the Alpine peaks, adds to the difficulties for deep-rooting species in their contest with the lower vegetation. Again, in the interior of continents and other localities unfavorably situated with reference to the great sources of moisture and moisture-bearing currents, deficiency of water, namely scant rainfall or low relative humidity, or both, and excess of evaporation, are inimical to tree growth. Occasionally soil conditions, especially with reference to drainage, and climatic conditions combined, may be more favorable to the graminaceous vegetation, at least for a time, giving rise to pampas, prairies, and savannas; or else the unfavorable conditions combine to such a degree as to give rise to deserts.

In addition, there are other inimical agencies in the animal world, which prevent the progress of forest growth and tend to preserve the prairie: locusts, rodents, ruminants, buffalo, antelope, horses, etc., impede the growth and spread of trees; and especially where compact soil and deficient moisture conditions are leagued with these animals, the change from prairie to forest is prevented, at least for a time. 
Woodlands are the most unfavorable form of vegetation for the life of ruminants, and therefore for the support of the largest number of men. For food production, for agricultural pursuits, man must subdue and remove the tree growth. Hence forest devastation, forest destruction, is the beginning of civilization, its necessary prerequisite.

But while the removal and repression of the wood, as an impediment to culture and food production, is a necessary step toward a higher cixili-, zation, the fact that at the same time it furnishes material equally indispensable in building up a civilization requires consideration also, and the necessity for its preservation in part, its continuance in possession of some portions of the soil, is indicated.

Happily, the very soils and situations which are not fit for agriculture are still capable of supporting tree growth; and although the best timber, no doubt, may be grown on land most favorable to agricultural crops, the poorer soils and mountain slopes unfit for plough land will still yield wood crops of useful description.

In reducing, therefore, the woodland condition to one adapted to the highest civilization, the relegation of the different soils and sites to the different uses to which they are best adapted, as fields, pastures, or forest, is a problem of true national economy.

Besides the consideration of a proper proportion of woodlands to furnish the needful supply of wood 
material, - supply forests, - there are other considerations which enter into this problem of the economic use of the soil and of distributing the various conditions of its occupancy. These are based upon knowledge of what we may call forest influences: the influence which the existence of a forest cover as a surface condition of the soil exerts upon soil conditions, temperature conditions, and water conditions, and by virtue of which we may characterize them as protective forests. While the most economic use of the soil for material production necessitates relegation of forests to the poorer soils, protective considerations necessitate its relegation to certain localities.

While our modern philosophy of nature readily perceives that all things are interdependent, and hence no change can take place in one condition without corresponding changes in other conditions, even the oldest civilized men intuitively recognized or at least suspected and appreciated the fact that the forest cover had some influence upon its surroundings, upon climate, health, and water conditions of a country, as is evidenced by many sayings of Mosaic, Roman, and Greek writers, by which farsighted priests prevented their destruction. The consecration of groves to religious use and various mythological conceptions connected with them, point in this direction.

Thus Homer calls the mountain woodlands the

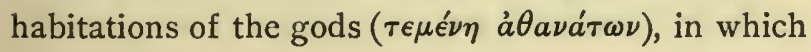


the mortals never fell the trees, but where they fali from age when their time has come. His tree and woodland nymphs, originating in springs, seem to suggest the suspected relation of forests and springs. The legend of Erichthonios most beautifully hints at the dependence of agriculture and forest cover : when, by the felling of a holy oak, he has offended the dryads, Ceres, the patroness of agriculture, is asked to send one of their number to the mountains of the Camasus to fetch Famine, who takes hold of Erichthonios and kills him.

These relations, thus darkly hinted at in earliest times, became more clearly recognized by philosophical writers. While Aristotle, in his " $\mathrm{Na}$ tional Economy," points out that an assured supply of accessible wood material is one of the necessary conditions of existence for a city, Plato, in his "Civitas," writes of the " sickening of the country" in consequence of deforestation. The Roman "Twelve Table Laws," the organic law of the republic, recognizes the necessity of forest protection, and Cicero, in his second Philippica, designates as enemies to the public interest those engaged in forest devastation. Laws prohibiting forest destruction in the mountain forests of the Apennines were generally enforced in the early middle ages; as, for instance, in Florence, where deforestation within one mile of the summit of the Apennines was forbidden, and it was only about the first part of the eighteenth century that these wise provisions 
which had preserved the cover of the higher mountain ranges were abolished and the present sad condition of things was inaugurated in Italy.

Mesopotamia, once praised as the paradise of fertility, where, according to Herodotus, the culture of the grape could not succeed on account of its moisture, has become a sand waste, in which the Euphrates, once an ample source of water supply, is drowned. Most of the springs and brooks of Palestine, and with them the fertility still celebrated in the early middle ages, have gone. Greece shows the progress of a similar decadence; Sicily, once the never-failing granary of the Roman Empire, once well wooded, now entirely deforested, suffers from repeated failures of crops. The socalled fumari, deep gullies in gravel, filled with washed débris, encroach after every rain upon the fertile fields, emptying them of water in a few hours.

The first definite expression of such relations of forest cover to climate appears in a biography of Admiral Almirante, written before I 540, by the Spaniard, Fernando Colon, in the following words :

"The Admiral ascribed the many invigorating, cooling rains, to which he was exposed while sailing along the coast of Jamaica, to the extent and density of the woods which covered the slopes of the mountains, and adds that formerly Madeira, the Canaries, and Azores enjoyed the same abundance of water, but that since the woods which 
had shaded the ground have been decimated, the rains have become less frequent." Similar language is laid into the mouth of Christopher Columbus in the "Historia de S. D. Fernando Columbo," $157 \mathrm{I}$, which is supposed, however, to be a spurious work.

But it was not until the beginning of the eighteenth century that both in France and Germany voices became loud regarding the evil effects of forest devastation, and then, too, the growing deficiency of material supplies formed a still more prominent argument for action. Thus, in France, where-in spite of Sully's celebrated epigrammatic warning, "La France périra faute des bois," and Colbert's forest ordinance of 1669only indifferent attention to a conservative forest policy was paid, the members of the académie royale, Buffon (1739), and later the Marquis de Mirabeau (1750), exerted themselves to bring about a better conception of the value of forests.

Buffon expressed himself, as a result of extended observations, that "the longer a country is inhabited, the poorer it becomes in forest growth and water." But the most forcible demonstration of this relation between woods and waters was had as a consequence of the extensive forest devastation which took place during the years of the French Revolution, when an unrestricted people in their greed denuded' large tracts of mountain woodlands in the southern mountain districts of 
that country. So soon did the evil effects become apparent, that even in 1792 the governor of the Department of Basses-Alpes reported: "The clearings progress rapidly; from Dique to Entrevaut the mountain slopes have been denuded of the finest forest growth; the smallest brooks have grown into torrents, and several communities have lost by floods their harvests, herds, and houses."

In 1803 the agricultural society of Marseilles complains as follows: "The winters have become severer, the summers drier and hotter, the beneficial rains of spring and autumn fail; the Méjeanne river, flowing east and west, tears away its banks with the smallest thunder-storm, and inundates the richest meadows; but nine months of the year its bed is dry, since the springs have given out ; irregular destructive thunder-showers are of yearly occurrence, and rain is deficient at all seasons."

Yet, in spite of these early warnings, which were supported by theoretical discussions of such sound reasoners as Boussingault, Becquerel, and others, action to stem the destruction and to recuperate the lost ground was obtained only within the last forty years, after at least $1,000,000$ acres of mountain forest had been denuded, and all aftergrowth had been destroyed by fire and excessive grazing, in consequence of which the mountain streams, turned into torrents, had laid waste about $8,000,000$ acres of tillable land, and the population of eighteen departments had been impoverished or driven 
out. Now, although with the expenditure of more than $\$ 40,000,000$ only a small part has been recuperated, the efficiency of a forest growth in holding the soils of the slopes and retarding the run-off water seems experimentally demonstrated beyond peradventure.

In Germany the greatest exponent of natural philosophy, Alex. von Humboldt, from observations in many parts of the globe, came to the conclusion that forest conditions and climatic conditions are intimately related. Among the causes which tend to lower the mean annual temperature, he cited in his "Cosmos," "extensive woods, which hinder the insolation of the soil by the vital activity of their foliage, producing intense evaporation owing to the extension of these organs, and increasing the surface that is cooled by radiation, and acting consequently in a threefold manner, by shade, evaporation, and radiation;" and in another place he gives expression to his conviction of the relation of forest cover and water conditions in the often-cited words, "How foolish does man appear to me in destroying the mountain forests, for thereby he deprives himself of wood and water at the same time."

In the beginning of this century, when the tendency of dismembering and selling the forest property accumulated by the state governments began to spread, in part as a consequence of Adam Smith's doctrine, those opposed to such a 
policy, especially in Germany, made vigorous propaganda for the theory of the protective value of forest cover, and, as is natural for propagandists, made many sweeping and extravagant claims, and an extensive literature, characterized by vigorous declamation of unsubstantiated facts, and by absence of exact data, was the result.

The condition of Palestine and other Eastern countries, of Greece, Sicily, and Spain, once fertile, now more or less desolate, was cited, and morals were drawn from these experiences; discrimination as to historic evidences of cause and effect was mostly wanting, so that this historic method of discussing the problem has been largely discredited.

Systematic attempts to establish by experiments and exact methods the truth in the matter, at least as far as climatic influence is concerned, were made only within the last thirty-five or forty years. In France, Becquerel began in 1858 a series of observations on temperatures within and without a forest cover; in I866, the forestry school at Nancy was engaged in determining moisture conditions at stations in the forest, and later in the open; and several other investigators, both in France and Germany, carried on such observations about the same time. In 1868 , the Bavarian government instituted an exhaustive series of observations under Dr. Ebermayer, to determine the climatic conditions within a forest area. Switzererland followed 
with three pairs of parallel stations, and in 1875 Prussia established an investigation, which still continues, with seventeen stations, observations being taken at each on instruments set up within the forest and another set in a neighboring field. In I884, Austria instituted a series of radial stations at which not only the difference of meteorological data within and without a forest, but the influence of the forest on its surroundings, were to be measured directly.

Although, by these many and long continued observations, some valuable facts have been established, and our ideas as to the elements which enter into the problem have been cleared up, the real object of inquiry, namely, whether and how far forests exercise an influence upon climate, cannot be said to have progressed far to a solution, and it is questionable whether the present methods will ever lead to a solution.

The reasons for this failure are at least threefold. Both instruments and methods of meteorological inquiry are as yet unsatisfactory. When, for instance, rain gauges will, according to their construction, the manner of their position, and the character of the wind and rain, during the same storm, register amounts varying from 7 to 40 per cent, we are without any means of applying a constant factor of correction, and it would appear that no reliance can be placed on such measurements for the purpose of determining the difference of rain- 
fall within and without the forest. The difficulty of finding stations within and without the forest which differ in no other respects than the forest cover, excluding all topographic and other influences upon meteorological phenomena, is well-nigh insurmountable.

Finally, whatever we may be able to do in ascertaining the single meteorological data that give us an insight into the differences regarding these single elements under varying conditions, the difference in their combined effect, which we know as climate, still requires the application of a philosophical mind to the interpretation of the data. Hence we find that not only are the collected data often discordant, but the same data have been used by students of the question both to assert and to deny proof of the existence of forest influences. In other words, the problem is too complicated for our present means and methods to be settled by the mathematical method.

We are, therefore, for the present, thrown back upon the method of general observations in the field and the application of reasoning from well-known physical laws, for this is one of those problems which withdraw themselves from exact mathematical treatment now, and we must rely upon empiricism until we have further advanced in developing the means and methods of meteorological inquiry.

The immaterial influence of the forest is claimed to extend in at least four or five more or less sepa- 
rate, yet, nevertheless, more or less closely related, directions, namely:-

I. Upon the climatic conditions within its own limits and beyond.

2. Upon the distribution and character of the waterflow.

3. Upon the mechanical condition and erosion of the soil under its cover.

4. Upon the health conditions.

5. Upon the ethics of a people.

This last influence is one which we cannot measure or even argue with any determinable force, but which we ourselves may feel more or less strongly, according to the degree to which our emotions in general are susceptible. In either of the other directions in which an influence of forest cover is asserted, the mechanical obstruction which it represents is the principal effective element; the physiological functions of the living plant playing, to be sure, a part, but of much less importance, probably, than has been often supposed.

It requires no instrument to find out that the effective temperature is higher when the sun has full sway upon our skulls than if we interpose the shade of a densely foliaged tree to obstruct the sun's rays; on the other hand, the cooling breeze, which may pass over the open field, is also obstructed by the forest growth, and its absence may make the air temperature appear higher, even in spite of the shade. Again, it stands to reason 
that a dense old growth, such as one may find here and there on the Pacific coast, with trees towering 250 to 300 feet above ground and so close together that no ray of light reaches the soil, must have a different effect from the low and scanty growth of cedar and piñon which we find on the slopes of the Rocky Mountains and elsewhere, or the young coppice growth of New England, interposing but little shade. Whether the forest lies to the leeward or in the direction of the prevailing wind, whether it be coniferous and evergreen through the year, or only summer-green, will also have to be considered in estimating its protective value.

While the single tree undoubtedly acts in the same manner as a collection of trees, its influence cannot reach very far beyond its surroundings, nor can it be very appreciable. It is also quite evident that neither a few scattered trees and bushes, nor a belt of trees, like a wind-break, nor a small clump of trees in a large open field, nor even an extensive orchard, can act singly as practically appreciable climatic factors, although all these aggregations of trees must have their influence upon their surroundings.

It is the effectiveness with which sun and wind are excluded from the soil, and thereby air temperatures and air humidity are modified, that determines also the degree and distance beyond the limits of the cause to which the modification is felt. 
In other words, while the quality of the influence remains the same, its degree, and especially its effective and appreciable value, must vary as much as there are varying local conditions possible. The size and character of the forest, its density, height, situation, and composition, are of more importance in determining its influence than is usually realized by those who discuss the question.

Another matter which it is also necessary to accentuate, because it is usually overlooked, is that the influence, if any, can only be of local character, it must therefore be discussed only with reference to given local conditions. It cannot be put in comparison with that of the large oceans, the great air currents, the extensive mountain ranges, which determine the general or cosmic climate. The forest can modify only locally the effects of this general climate, in about the same manner as we modify it by building houses around us and heating them, whereby we change the temperature and moisture conditions at least in our habitation; -or by building cities, which we know differ, as far as our feeling is concerned, from the climate of the adjoining country.

It may also be proper here to state that, in view of the fact that whatever influence exists, it is dependent on local conditions, the attempt to fix a certain general percentage of forest cover as necessary for a country is childish, and also that there are conditions where the existence of forest 
growth is at least practically prevented by climatic conditions, - although the limits are by no means known, - and hence no expectation can be had of utilizing this influence in these conditions.

Again, since undoubtedly the forest influence on surroundings, as far as climatic factors are concerned, can extend only to a limited distance, the most effective result must be secured by alternations of forest cover and open land, hence the distribution of these two conditions is of as much importance as the relative size of the parcels.

Without going into the detail of the difference of meteorological conditions that may exist in the forest and the adjoining open country, it may be. briefly stated that the tendency of a forest cover is to reduce extremes of high and low temperature in about the same manner as does a sheet of water, and this effect is most noticeable in the hot months. But whether and how far this temperature difference is felt outside is not as yet determined. Nor do we know much regarding the important influence on the moisture conditions of the air and on the rainfall. The tendency of a forest growth would be, on account of its cooling effect, to keep the air within and to some extent above it nearer saturation, and as a consequence it might occur that moisture-bearing currents passing over would precipitate their moisture more readily above or near the forest growth. Whether they do is still doubtful, and indeed, to make an appreciable difference 
in the amount of rainfall, it would appear that the forest area must be of considerable extent.

Although some writers have, from existing measurements, argued an influence on precipitation, others have denied it. As stated above, we hold that no reliable rainfall measurements are, as yet, obtainable, and we must leave the question open.

The more readily conceivable effect of a forest growth on moisture conditions of the air is that which it has in common, probably in increased degree, with the so-called wind-break. By breaking the velocity of dry winds and possibly enriching them somewhat with moisture, the rate of evaporation over a neighboring field is considerably reduced, so that, in regions where winds are common, the protection shows itself in increased crops on protected fields.

The same protection against cold winds may make life more bearable, and enable the growing of crops which could otherwise not succeed. Thus it is believed that during the abnormal frosts which a few years ago killed most of the orange groves in Florida, many which had good forest shelter survived. It is also reported that in France the cultivation of the olive has become impossible in the more northern departments, owing to deforestation. On the other hand, it may happen that the opening toward warmer southern winds may modify a severer climate favorably. This consideration again points to the entirely local 
character of forest influences, which may change their value.

As far, then, as forest influence on climate is concerned, we must admit that no satisfactory conclusions have been reached, excepting as to the favorable wind-break effect. That wholesale forest destruction and removal must change the climatic conditions of the denuded area seems an entirely reasonable assumption.

The climatic influence of the forest upon its neighborhood would finally consist in the communication of its own climatic characteristics; i.e. shorter range of thermometrical extremes and more even humidity, in general modifying extremes of winter and summer.

The influence on waterflow, although much fewer attempts at exact determination have been made, seems much more generally admitted. Here, too, extravagant claims have been made as to the efficacy of forest cover, while other factors which influence waterflow have been often given less consideration than they deserve. Thus the topography and the geologic structure exert necessarily a potent influence, which a forest cover may either not be sufficient or else is not needed to modify.

The philosophy of the influence on waterflow rests mainly upon the recognition that the rain and snow waters penetrate more readily a forest-covered soil than one that is bared of this protective cover. The action here is of a threefold nature: 
first, the mechanical obstruction which the foliage offers reduces the amount of the water which reaches the soil and lengthens the time during which it can do so; the foliage, together with the loose litter of the forest floor, also reduces the compacting effect of the raindrops and the drying effect of sun and wind, and keeps the soil granular, so that the water can easily percolate; then the mechanical obstruction which the litter, underbrush, and trunks, and possibly here and there moss, offer to the rapid surface drainage of waters, lengthens the time during which this percolation may take place; and thirdly, the network of deeply penetrating roots, live and decayed, offers additional channels for a change of surface drainage into subdrainage. In addition, it is claimed that, owing to the influence on temperature and moisture conditions of the air, together with reduced evaporation, more water becomes available to the soil, and certainly the fact that the water, by ready percolation, is withdrawn from the dissipative effects of sun and wind must tend in this direction.

The sponge theory so often proclaimed by lay writers is rather a misconception of physical laws and of the behavior of a sponge, although a mosscover - which is by no means the usual cover of a forest soil - may be of great value in preventing rapid surface drainage. This is attested by Robert Gerwig, the builder of the St. Gotthard railway:"One German square mile of moss-cover," he 
says, "can retain $1,000,000$ to $1,500,000$ cubic meters of water (I English square mile will hold $14,000,000$ to $20,000,000$ cubic feet). It will, in many cases, depend on a difference of 20 to 30 cubic meters (700 to I000 cubic feet) per second of waterflow from the surface of a square mile, whether a flood will be dangerous or not. The bare slope would give up these 20 to 30 cubic meters per second, and déliver the $1,000,000$ to $1,500,000$ cubic meters in 15 hours. If it is remembered that damaging flood-waters are of short duration, it becomes evident how even moderate assumptions regarding the amount of water retained in the moss-cover (or in the forest litter and soil of a forest) produce favorable results."

It stands to reason that in this direction the condition of the forest cover must have much to do with the degree of its effectiveness, and that in this connection the condition of the forest floor is of more moment than that of the leaf canopy. Hence we may find that while the tree growth may be left intact, yet, if the loose litter and underbrush has been burned off and the soil been compacted by the tramping of sheep and cattle, the effectiveness in regulating waterflow is much impaired.

It is also apparent that with heavy rainfalls and on steep declivities on compact and sparsely fissured limestone rock, even the best-kept forest growth may not be capable of retarding the surface 
drainage long enough to prevent a resultant flood in the river.

Particular interest in this connection attaches to the influence of forest cover on the melting of snow masses, which gives rise to spring floods. In the dense forest, the snow is usually less deep, a part being intercepted by the crowns of trees and evaporated, and lies more uniformly, owing to the absence of drifting winds. It is a well-noted experience that it will lie in the shade of the woods from one to two weeks longer, i.e. melt so much more slowly. These elements of distribution in space and time must have an influence upon the rapidity of surface flow, and if the soil is not frozen, time is given for percolation and gradual removal.

Here, again, weather conditions may be unfavorable, the soil remaining frozen and the melting proceeding rapidly, when the forest effect may be lost. Nevertheless, while the forest effect may become powerless in exceptional cases and under special conditions, the tendency of changing surface drainage into subterranean drainage must be beneficial in the majority of cases. It may also happen that the soil conditions, by their loose structure, as in cinder cones, lava, or loose sand hills, are such as to permit percolation readily, when the office of the forest cover can be dispensed with.

The value of the change of surface drainage into subterraneous drainage becomes apparent in 
the more even riverflow. While the waters that run off over the surface collect rapidly and are carried away in floods, giving rise to high water stages, the percolated water finds its way into the river slowly by underground channels, feeding, on its way, springs and brooks, or is collected as ground water by seepage at lower levels.

This distribution of the water, which lengthens the time during which the atmospheric precipitation can be usefully employed, and which, under circumstances, may lengthen the supply for years, the water reaching the river years after it fell on the mountain top, renders the riverflow independent of wet and dry seasons, and equalizes its flow, - a condition of most importance for all industries dependent on water-power, navigation, irrigation, etc.

This forest effect on the run-off of terrestrial waters is naturally greatest and most important in mountainous regions, where the water has the tendency to collect quickly and to be carried off rapidly, but it also exists in the level plain, where it has the tendency to elevate the general groundwater level and thereby make a reserve available during times of drouth.

In close connection with these effects of forest cover upon the flow of water stands its influence on the stability of the soil. The tendency of the rain waters falling on hills and mountains is to carry in their descent to the valley loose particles of soil 
with them, and as the little rivulets run together and acquire force, gravel, stones, and even large rocks and boulders are broken loose and moved to lower levels by the torrent. This action, known as erosion, takes place everywhere more or less rapidly, according to the presence or absence and character of the soil cover, and no better and more efficient protection against it is to be found than a dense forest cover.

A grass cover may also protect the soil underneath against the erosive action of the waters, whenever the declivity is not too steep, but since the rains do not penetrate through the dense greensward of the mountain meadows, and hence are carried off superficially, they acquire a momentum which finally leads to the same gullying and erosive action which a naked soil experiences.

The forest alone is capable of obstructing the mechanical effect of the rainfall upon the soil, and retarding the rapid surface drainage which becomes the carrier of the débris. Here, again, the condition of the forest floor, rather than the tree growth, is the effective element.

If it is considered that, in the United States, the amount of erosion at present may be estimated at 200 square miles per year, rendering thereby large areas of fertile soil unfertile and at least temporarily useless for human occupancy, the economic importance of a conservative policy for the mountain forests may be readily apparent. 
The experiences of France in this particular are incontrovertible arguments, and furnish, in later years, experimental evidence of the effectiveness of a forest cover in arresting the progress of erosion. France, too, furnishes perhaps the most striking and most extensive example of how the loose, shifting sands, the dunes and sand hills in the plain, may be changed by a forest cover from a useless, nay dangerous, condition into one of profitable occupation.

Regarding the sanitary influence of forests, there have also been many claims made which cannot be substantiated. The original principal claim was that the physiological action of the foliage, in absorbing carbonic acid from the air and exhaling oxygen, made forest air healthier, but it has been calculated that the amount of oxygen so exhaled is insignificant in proportion to the needs of human respiration, and is probably offset by the increase of carbonic acid resulting from the decomposition of organic matter in the forest.

Then it was claimed that by the transpiration of the foliage wet ground may be drained, and thus made healthier, and in this connection the Eucalyptus plantations at the monastery of Tre Fontane in the Campagna Romana are frequently cited as having removed the malarial conditions of that region. As a matter of fact, the fevers still occur, even under the Eucalyptus plantation, although more rarely. This comparative improvement seems 
attributable mainly to the rebuilding of the old Roman drainage canals, which had been allowed to collapse, and the malaria-breeding mosquitoes have been reduced thereby. In any case, where drainage is to be secured, artificial canalization could probably be made more effective than forest planting. Nevertheless, a sanitary influence exists, as every one can experience, but it is mainly of a negative character: absence of smoke, dust, obnoxious gases, and of strong winds which characterize - the air of cities, and which to some extent (at least dust and winds) occur in the open, renders a forest region more healthful.

Furthermore, it has been found that forest air is more free from pathogenic microbes. Especially those bacilli which develop in the soil, like the cholera, typhus, and yellow fever bacilli, find in the forest soil less favorable conditions for development, and, owing to the absence of strong winds, are less apt to be carried into the air, where they would be breathed by man. In fact, in the dense forest, where the variation of soil moisture is small and decomposing humus keeps the soil acid, no pathogenic microbes have as yet been found. Here, too, to be sure, the degree of effectiveness must depend on the condition of the forest and especially of the forest floor.

It is also not impossible that the opening of large swampy forest districts may improve health conditions by changing moisture conditions; this 
especially with regard to malarial diseases. These are not produced by bacilli, but by parasitic protozoa (Plasmodium malaria), which seem to thrive in the swamp conditions. As long as the water covers the soil, there is no danger, but as soon as the water recedes, the plasmodia develop, and with the assistance of mosquitoes or by other means are communicated to man.

A further indirect sanitary influence must not be overlooked in our modern economy of city life. The recuperation of bodily energy and of spirit which an occasional sojourn in the cool, bracing, and inspiriting forest air brings to the weary dweller in the city must not be underestimated as an element in the general health conditions of a people. In addition, the question of a good water supply is being recognized as more and more dependent upon the condition of the sources of supply.

Knowing that a large number of diseases are bred in soils, it becomes essential that the drinking water carry as little soil particles' as possible, and although, by artificial means of filtration and sedimentation, the river water may be freed of sand and bacilli, we would have more assurance of freedom from disease, if the water came from a well-forested region, where, as we have seen, no pathogenic bacteria are produced, and if the washing of the soil into the river on the way to the reservoirs were prevented by proper attention to preventing the erosion along its banks. 
Summarizing the present knowledge of forest influences and viewing it from the standpoint of the practical economist, it will appear that there is sufficient evidence of the value of properly located forest areas, as affecting at least water and soil conditions in a marked degree, and in a minor degree health and climatic conditions, to make the subject of forest conservancy one of great importance. Especially is this the case with the forest cover on mountain sides and in the hill country, where the destructive tendencies of the water are apt to gather force, if not modified by the obstruction of the forest floor.

It is always to be kept in mind that not the extent, so much as the location and condition of the forest cover is of greatest importance, and that the effect can be determined only with reference to local conditions in every particular case.

The protection of the soil cover at the head waters of streams thus becomes a concern of state activity, and the establishment of forest belts in drouth-ridden countries, or the fixation of sand dunes and drifting sands, becomes a public work of internal improvement.

In the Appendix will be found further details regarding the measured forest influences, in the form of a resumé, taken from Bulletin VII, Forestry Division, U. S. Dept. of Agriculture, entitled "Forest Influences," I 893, in which this question is exhaustively discussed. 


\section{CHAPTER IV}

\section{FOREST AND FORESTRY DEFINED}

From age to age the relations of man to man, and of man to nature, change according to the development of science and art and the progress of civilization in general. What was important once has lost its significance to-day, and what appears to us highly significant at the present time had no existence in the minds of our ancestors. With these changes in our conditions and conceptions the language used in expressing them also changes; not only does our vocabulary increase, but words long used change their meaning, sometimes so radically, that little is left of the first meaning.

The conception and the word "forest" has in this way through historical development experienced a change to such an extent, that the original conception and meaning are almost, if not entirely, obliterated. In this change, both of conception and meaning, Teutonic development has made its impress. The word of Old High German origin, "voorst," used to designate the segregated property of the king, or leader of the tribe. Toward 
the end of the eighth century, latinized into "foresta," or "forestis," it assumed a more restricted meaning, namely, as referring to all the royal woods, in which the right to hunt was reserved by the king, either for himself or for those of his vassals to whom he ceded the right to the chase. (See Appendix.) Gradually, however, the kings employed their royal prerogative of forbidding any kind of action, under threat of the "ban," in extending their exclusive right to the chase, not only to neighboring woods, but to fields as well.

By and by the temporal and spiritual princes and feudal lords succeeded in having their own holdings protected in the same manner, and declared as "ban forests," as far as the hunting was concerned, and by the thirteenth century this prerogative was freely exercised by noble landholders. Under the plea of protecting the chase, the rights to cut wood (which had been free to all), to clear for agricultural use, and to pasture, were gradually restricted, and these restrictions, which had referred at first only to the property of the lords, were soon extended to apply also to the property of others which lay within the "ban," so that at the end of the ninth century a "forest" meant a large tract of land, including woods as well as pastures, fields, and whole villages, on which not only the rights to the chase were reserved to the king or his vassals, but the persons living on it in all their relations fell under the special jurisdiction of the "forest 
laws." It was then a legal term, and had no reference to natural but only to legal conditions, with the royal prerogative, the right to hunt, as a basis. Afforesting and disafforesting were correspondingly the legal terms which denoted the placing of districts under the forest ban and forest laws, or their release from these restrictions.

The forests of Dean, of Windsor, of Epping, of Sherwood, and the New Forest, in England, made famous by legend and history, were such districts, set aside by the Norman kings for their pastime. ${ }^{1}$

The care which, under the forest laws, was bestowed upon the woodlands by special officers called foresters, first for the sake of preserving the game, then for the sake of continuity of wood supplies, and the later release of the fields from the application of these laws, no doubt had a tendency to restrict the term forest again to the woodlands alone, until finally, with the decadence of the regal prerogative, the old meaning wore away entirely, and it referred no longer to a legal but to a natural condition, land covered with wood growth

${ }^{1}$ It is interesting to note that this mediæval conception and use of the terms lingered until nearly the present day, as evidenced by a suit at court, decided in 1862 , instituted by one of the dukes of Athole in Scotland, who hold extensive mountain districts either in their own right or as "foresters" for the crown, in virtue of which one of them claimed the power of preventing his neighbor, the Laird of Lude, from killing deer on his own lands, and the right to enter the Laird's lands himself for the purpose. The courts decided adversely. 
in contradistinction to prairies and plains, meadow and field.

In the German language, with the more intensive development in the rational treatment of the woodlands, the limitation is carried farther, the word Forst being specific, and meaning the woods which are placed under management, the woods as an object of man's cultivatory activity, while the term Wald is generic, and refers to the natural condition of the soil cover. In the English language this distinction has not yet become settled; especially in the United States the lexicographers seem to consider large extent and virgin or natural growth, an absence of cultivation, as distinctive attributes to the word forest, while the word woodlands is vaguely and inconsistently defined as the generic term for land covered or interspersed with trees and of less extent than forest, or else land on which "trees are suffered to grow either for fuel or timber" (Webster), accentuating thereby relation to the uses of man. (See Appendix.)

Etymology, linguistic sense, and as we believe actual usage, especially in the literature of later times, since the subject of forests and forestry has become prominent, would warrant us to define, more precisely, woodland as the general or generic term for land naturally covered with woody growth in contradistinction to land not so covered; forest as the restricted or specific term, namely, woodland whether of natural growth or planted by man, con- 
sidered in relation to the economic interests of man and from the standpoint of national economy, as an object of man's care, a woodland placed under management for "forest purposes," and, we may also add, exhibiting "forest conditions." These last linitations are important ones and lead to the necessity of further definition.

By the first restriction we exclude at once those lands covered with trees or woody growth, which serve other than forest purposes, such as coffee plantations, orchards, which are grown for fruit, roadside plantings and parks, which are planted or kept for shade and ornament, wind-breaks consisting of single rows of trees, which, although like the other conditions of tree growth mentioned may answer some functions of a forest growth, are not primarily intended to fulfil forest purposes and lack what we have called "forest conditions."

The first and foremost purpose of a forest growth is to supply us with wood material; it is the substance of the trees itself, not their fruit, their beauty, their shade, their shelter, that constitute the primary object of this class of woodland.

With the settlement of the country and the growing needs of civilization this use must and will attach as an essential predicate, a fundamental requisite, to any woodland left as such, whatever other purposes it may or may not be designed to subserve, temporarily or continuously.

Thus if the state of New York withdraws from 
such use a large woodland area in the Adirondacks to subserve solely other purposes, this can be only a temporary withdrawal from its main purpose which time and intelligent conception of rational economy will reverse.

Just so, if a private individual sets apart for the purpose of a game preserve a piece of woodland, and keeps out the axe which would utilize in part the useful timber, he frustrates the primary object of the forest growth temporarily and commits an economic mistake.

Occasionally it is not the wood but some other part of the tree itself that is the main object of the harvest, as for instance the bark for tanning purposes or the resinous contents which are transformed into naval stores. Yet, as a rule, the wood too is utilized and at least forest conditions are maintained in the production of the crop. But when it comes to a maple sugar orchard, expressly grown for the purpose, or the cork oak plantation, managed for the cork, the primary object not only begins to vanish, but also the second criterion of a forest, namely, forest conditions, is absent, and this kind of woodland ceases to fall properly under the term "forest," the designation of orchard or plantation being more appropriate.

Besides the great primary object of forest growth, that of furnishing useful materials either of wood or parts of the wood substance, there has been recognized indistinctly through all ages, more clearly 
during the last century and with greater precision during the last thirty to forty years, that forest growth serves an object in the economy of nature and of man which under certain conditions may become equally if not more important than this direct primary one.

We have learned that in general all conditions in nature are interrelated, and in particular that the condition of the surface cover of the ground not only influences more or less potently the condition of the soil and meteorological factors under the cover, but that this influence reaches even beyond the limits of the cover to its neighborhood; and, with the recognition of this influence upon soil, temperature, and water conditions a new important forest use, namely, as a protective cover and climatic factor, has become established, so that we may distinguish, according to whether the one or the other purpose becomes more prominent, supply forests and protection forests, although the latter invariably also furnish supplies, and finally, when pleasure and game cover are the main objects, we may speak of luxury forests.

To fulfil either or both of the first two, more important functions satisfactorily or continuously, to furnish most useful material and to act as a protective cover, it is needful that the woodland designated as forest exhibit what we have called "forest conditions."

A forest in the sense in which we use the term, 
as an economic factor, is by no means a mere collection of trees, but an organic whole in which all parts, although apparently heterogeneous, jumbled together by accident as it were and apparently unrelated, bear a close relation to each other and are as interdependent as any other beings and conditions in nature.

Not only is there interrelation between plant and climate and between plant and soil conditions, but also an interrelation between the individuals composing the forest growth based on definable laws, and finally an interrelation between the arborescent growth and the lower vegetation; the whole being a result of reactions of plant life to all surrounding influences and reciprocally of influences on all elements of its environment. Even the seemingly lawless mixture of species which we find in the virgin forest is not altogether fortuitous, but a result of such reactions.

Out of these reactions and interrelations result conditions which we call forest conditions, and which not only distinguish the forest from other collections of trees or woodlands, but also impart a particular individuality and character to the forest growth of each locality. Even the virgin woodlands may lack what we conceive as ideal forest conditions, when in the struggle for existence other forms of vegetation have still the advantage over the arborescent growth and hence forest purposes are imperfectly performed, or when 
the latter has not yet been able to fully establish itself under unfavorable soil and climatic conditions. In such cases, which are frequent in the arid and sub-arid and the arctic regions, the single stragglers of trees, the park-like open stand, their stunted and scrubby appearance may leave it doubtful whether the term "forest," with its economic significance, is applicable to these woodlands, or may exempt them from consideration under the term.

$X$ Forest conditions, then, imply a more or less exclusive occupancy of the soil by arborescent growth, a close stand of trees, as a consequence of which a form of individual tree development results unlike that produced in the open stand, and a more or less dense shading of the ground which excludes largely the lower vegetation.

By so much as these conditions are deficient, by so much does the forest fail to fulfil its economic functions, as a source of useful material and as a factor in influencing climatic and soil conditions.

With regard to the first function, it must be understood that it is not wood simply that is required for the industries of man, but wood of certain qualities and sizes, such as are fit to be cut into lumber, as boards, planks, joists, scantlings, or into timber as beams, sills, and posts, into bolts free from blemish, which can be advantageously manufactured into the thousands of articles that are indispensable to human civilization. Such 
sizes and qualities combined are not as a rule produced by trees in open stand. Their production requires the close stand, by which the trees are forced to reach up for light in order to escape the shade of their neighbors and all growth energy is utilized in the bole or trunk, the most useful part to man, instead of being dissipated in the growth of branches.. The useful forest tree is the one that has grown up with close neighbors, which have deprived it of side light and thereby forced it to form a long cylindrical shaft, to shed its side branches early, which if persisting would have produced knotty lumber, to confine its branch growth to the crown alone.

Such conditions are also the most favorable in fulfilling the second function of the forest as regulator of waterflow and climate, for it is the shaded condition of the soil and the effective barrier to sun and winds, results of a dense stand, by which the forest exercises these regulatory functions.

The history of the woodlands has been the same in all parts of the world, progressing according to the cultural development of the people. First the forest was valued as a harbor of game; then it appeared as an impediment to agricultural development, and relentless war was waged against it, while at the same time the value of its material stores made it an object of greedy exploitation, and only in a highly civilized nation and in a well-settled country does the conception of the relation of for- 
ests to the future welfare of the community lead to a rational treatment of forests as such for continuity and to the application of the principles embodied in the science of forestry.

There existed some knowledge as to the nature of forest growth and the advantages of its systematic use among the Romans and Greeks. Ancus Marcius, the fourth king of Rome (about 640 B.c.), claimed the forests as a public domain and placed them under special officers. Later, under the republic, they were in special charge of the consuls. Subsequently the continuous wars seem to have wiped out not only the administrative features but the forests themselves, and the Italians of modern times until lately had no more conception of the inportance of the forest cover than the people of the United States, so that Italy to-day furnishes about as good an object lesson as any country of the evil effects of forest devastation.

The real art of forestry is unquestionably of Teutonic origin, or was at least conceived rather early among the Germanic tribes; the first attempts at it seem to antedate even Charlemagne's time.

Long before the royal prerogative of the chase lent an incentive to conservative treatment, there existed among the communistic villagers, who were aggregated in the so-called "Mark," owning all their land in common, crude but systematic attempts at rational utilization and even reproduction. The amount of wood that might be harvested with- 
out detriment to future crops was determined, the better kind of timber being more economically cut, and the timber to be cut was designated by officials, whose duty it was to superintend the felling, the removal, and even the use of the same. By and by even the firewood was designated, the dead and inferior material being assigned for it. Charring and boxing for resin were carried on under precautions. The number of swine to be allowed in the oak and beech forests was determined according to the quantity of seed mast. Grazing in the woods was allowed only under certain regulations as to districts and number of cattle for every "Märker." The great damage by sheep and goats was recognized and their pasturing in the woods prohibited as early as I I58. Even an Arbor-day was anticipated in some parts, each man having to plant, under the supervision of the forester, a number of trees proportionate to his consumption.

In 1368 , the city of Nuremberg began on a larger scale systematic reforestation of waste lands with pines, which was imitated by other communities, and we have documentary evidence that in r49 I a regular system of annual sowings of oak was in existence in the communal forests of Seligenstadt. By the end of the fifteenth century, indeed, fully organized forest administrations existed, and various "Forstordnungen" (forest ordinances) prescribed in detail the manner of exploiting and reëstablish- 
ing of wood crops, and trespasses of all kinds were punished with heavy penalties.

The first beginnings, then, of a rational forest management were of democratic origin, - a management by the people for the people, who held the welfare of the community higher than the satisfaction of the greed of the few. To be sure, this state of things did not last. The Thirty-years War, which extirpated many of the cities and villages, and brought other economic changes, reduced their holdings of forest property, which fell into the hands of princes and the nobility, and gradually the communal forest was supplanted by the royal or lordly forest, or through partition by the private forest of the single farmer. Then came a period of decline in forest management. Private greed disregarded the many regulations and ordinances against devastation. Fires ruined large areas in the seventeenth and eighteenth centuries, and in addition excessive exploitation reduced the forest area in extent and brought it into poor condition. That era, reaching partly into the beginning of the nineteenth century, presents conditions somewhat similar to those with which we are now confronted in this country. The Revolution of 1792 opened wide the doors to the destructive element, and the teachings of Adam Smith still further reduced the wholesome restrictive functions of governments, and induced a movement to sell all government property. The damage which France 
- up to that time living under a tolerably well developed forest policy - is now working to repair resulted from these times of forest dismemberment and forest destruction. Naturally voices against this reckless procedure became louder and louder, as the effects of continued forest devastation and improper clearing became more and more visible, and, as the governments became stronger after the Napoleonic wars, reconstruction and return to conservative policies were bound to follow. At the same time the technical part of forestry, the methods of forestry practice, had been gradually developed in an empiric way, and with the development of natural sciences were placed on a more stable basis and taught in special forestry schools and at universities by the end of the eighteenth and beginning of the nineteenth century. We can fairly well compare our present movement in the United States on behalf of rational forest management with what was going on in Germany a hundred years ago. A fuller study into the history of this movement in the old countries, at which we have here glanced only briefly, would aid better than any academic discussions and arguments to a full understanding of both the economic and technical problems involved.

In the pioneer days of a newly settled country, which is forest-covered like the eastern United States, man by necessity must remove a part of the forest growth for the purpose of gaining ground for 
food production. That part which is not cleared for such purpose he exploits, usually regardless of the conditions in which he leaves it, cutting out the best trees of the most useful species or else cutting off the entire growth and leaving nature to take care of the future.

When this crude forest exploitation and destructive process has gone on so long that virgin supplies are nearly exhausted, that the effects of inconsiderate clearing or forest devastation becomes visible in soil washes, in high and low water stages of rivers, more frequent and more destructive floods, etc., then he begins to consider more carefully the relation which the forest and its continuance bears toward the further development of society, toward the conditions of his surroundings; he realizes that he may not continue to disturb the balance of nature unpunished, nay, that he must be active in improving the methods of nature, and weight that side of the balance which is favorable to him and his pursuits; he begins to bring more rational method into his use of the forest, he attempts to apply knowledge and care in its treatment, he makes it an object of economic thought, in other words he arrives at a first conception of and applies forestry, which may be most comprehensively defined as the rational treatment of forests for forest purposes. First he determines upon a rational policy for his further conduct toward the forest, and then, having studied the 
manner in which forests grow, having become familiar with the science of forestry, he develops superior positive methods in treatment and perpetuation of the forest and applies the art of forestry; and, adding the financial aspect in the application of the art, he practises the business of forestry.

In its broadest sense thus, the term "forestry," according to the point of view, represents a policy, a science, an art, a business. A policy is a general plan of behavior, a general line of conduct with reference to our affairs, embodying the philosophy, the motives and object of our programme. By determining upon a policy with reference to a resource like the forest, we assign it a place in our political or domestic economy, we make up our mind as to what to do with it. It is from this point of view that this volume proposes to discuss the subject.

Such a policy we naturally base on knowledge or science which furnishes us the reason for our policy, the why to do. This science of forestry comprises all the knowledge regarding forest growth, - its component parts, the life history of the species, and their behavior under varying conditions, its development and dependence upon natural conditions, its retroactive influence upon those natural conditions, in short its place in the economy of nature and of man.

When we come to formulate our knowledge into rules of procedure and apply the same to the 
treatment of forest areas specifically, we begin to practise the art of forestry - we learn how to do ; and finally, applying this art systematically for the purpose for which all technical arts are carried on, namely, for money results, we come to practise the business of forestry.

Like agriculture, forestry is concerned in the use of the soil for crop production; as the agriculturist is engaged in the production of food-crops, - so the forester is engaged in the production of wood-crops, and finally both are carrying on their art for the practical purpose of a revenue.

Forest crop production is the business of the professional forester.

A forester then is not, as the American public has been prone to apply the word, one who knows the names of trees and flowers, a botanist; nor even one who knows their life history, a dendrologist; nor one who, for the love of trees, proclaims the need of preserving them, a propagandist; nor one who makes a business of planting parks or orchards, an arboriculturist, fruit grower, landscape gardener, or nurseryman; nor one who cuts down trees and converts them into lumber, a woodchopper or a lumberman; nor one set to prevent forest fires or depredations in woodlands, a forest guard; nor even one who knows how to produce and reproduce wood-crops, a silviculturist; but in the fullest sense of the term, a forester is a technically educated man who, with the knowledge 
of the forest trees and their life history and of all that pertains to their growth and production, combines further knowledge which enables him to manage a forest property so as to produce certain conditions resulting in the highest attainable revenue from the soil by wood-crops.

The virgin forest grows where it pleases, and as it pleases, without reference to the needs of man. It covers the rich agricultural soils as well as the dry and thin soils of the mountain slope and top; it may encumber the ground which can more profitably be employed in the production of food-materials, and it may be absent where its protection is needed for human comfort or for successful agriculture.

Nature produces weeds - tree weeds - and useful species side by side; she does not care for the composition of the crop; tree growth, whatever the kind, satisfies her laws of development; nor has she concern with the form of the component trees, - they may be branched and crooked, short and tapering. In time, in a long time, she too may produce long clear shafts, but by her methods such results will only be accomplished in centuries; nature takes no account of time or space, both of which are lavishly at her command. The area of virgin forest which we harvest to-day has produced a tithe of the useful material which it is capable of producing, and has taken two to threefold the time which it would take under skilful 
direction to secure better results, quantitatively and qualitatively.

It is in the application of the economic point of view, in relegating forest growth to non-agricultural soils, in influencing its composition and its development toward usefulness, in securing its reproduction in a manner more satisfactory to human wants and human calculations, than nature's fitful performances promise, that the forester's forest differs.

Forestry in more or less developed form is begun when this economic point of view is applied, when care, however slight, is bestowed upon the virgin wood to secure its improvement and continuance.

Before the finer methods of forest management become practicable under such economic conditions as surround us, a common-sense management may be possible, which consists in more careful utilization of the natural forest, protecting it against fire, fostering young volunteer growth of the better kinds, by keeping out cattle, and in general avoiding whatever prevents a satisfactory reproduction of the natural woods. For large sections of this country, this will for some time to come be the only forestry that is practicable, namely, wherever distance from market for inferior material makes finer methods unprofitable or impracticable.

Finally, however, the art in its fullest and finest 
development will become applicable through the length and breadth of our country, just as in the old countries.

As in every productive industry, so in the forestry industry we can distinguish two separate yet necessarily always closely interdependent branches, namely, the technical art which concerns itself with the production of the material, and the business art which concerns itself with the orderly, organized conduct of the industry of production.

Since the materials and forces of nature are the source of the mighty processes of organic life which find expression in forest growth, the art of forest crop production naturally relies mainly upon a knowledge of natural sciences, by which the forester may be enabled to direct and influence nature's forces into more useful production, than its unguided activity would secure.

The nature of the plant material, its biology, its relation to climate and soil, must be known to secure the largest, most useful, and most valuable crop; that portion of botany which may be segregated as dendrology - the botany of trees in all its ramifications - must form the main basis of the forester's art. To study such a segregated portion of the large field of botanical science presupposes, to be sure, a sufficient amount of general botanical knowledge. In order to know, recognize, and classify his materials the methods of classification, the general anatomy and histology, must be familiar to him, 
as well as general physiology and biology; finally, he must specialize and become an expert on biological dendrology, i.e. a knowledge of the life history, the development, and dependence upon surroundings, the ecology, of trees, in individuals as well as in communities, - a very special study, to which few botanists have as yet given much attention. Forest crop production, or silviculture, in its widest sense, may be called applied dendrology. And the forester is not satisfied only to know the general features of the biology of the species, their development from seed to maturity, their requirements regarding soil and light conditions, but as he is a producer of material for revenue, he is most emphatically interested in the amount of production and the rate at which this production takes place. Far different from the agriculturist's crop, his is not an annual one, but requires many years of accumulations, and as each year's waiting increases the cost of production by tying up the capital invested, it is of importance not only to know the likely progress of the crop, the mathematics of accretion, but also how its progress may be influenced.

In this connection the study of geology and meteorology, of soil and climate, the factors of site, is required, as far as necessary to understand the relationship of plant life to surroundings, and teach the chemico-physical basis for wood production. The protection of his crop not only against 
climatic ills, but against enemies of the animal and plant world, requires studies in that direction, and finally to harvest his crop and bring it to market and dispose of it to best advantage calls for engineering knowledge and acquaintance with wood technology.

The business side of the forestry industry, which we call forest economy, relies mainly upon mathematical calculations and the application of principles of political economy. The fact that the time from the start of the crop to the harvest may be fifty, one hundred, or more years - the time it takes to grow a useful size of timber - necessitates a more thoroughly premeditated and organized conduct, more complicated profit calculations, more careful plans, than in any other business which deals with shorter time periods.

In this connection one of the first and most important mathematical problems for the forester to settle, is when his crop is ripe. This is not as with agricultural crops and fruits determined by a natural period, but by the judgment of the harvester, based upon mathematical and financial calculations.

There are various principles which may be followed in determining the maturity of a stand, or what is technically called the rotation, i.e. the time within which a forest, managed as a unit, shall be cut over and reproduced; but all rely finally upon measurements of the quantity of production as basis of the business calculation, and hence forest 
mensuration has been developed into a special branch of mathematics and many methods have been developed, by which not only the volume and rate of growth of single trees, but of whole stands, can be more or less accurately determined. Similarly, finance calculations have been more fully developed in the forestry business than are usually practised in any other business excepting perhaps Life Insurance.

Without going into further details of the contents of the science of forestry, reserving for two chapters a fuller discussion of the two main branches, a comprehensive view may be gained by the following systematic statement of the various branches into which forestry may be divided.

SYSTEM OF FORESTRY KNOWLEDGE.

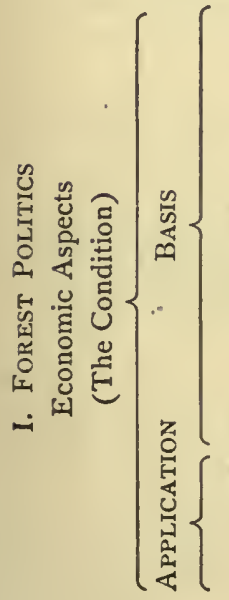

I. Forestry Statistics.

Areas : forest conditions - distribution composition.

Products : trade - supply and demand prices - substitutes.

2. Forestry Economics.

Study of relation of forests to climate, soil, water, health, ethics, etc.

Study of commercial peculiarities, and position of forests and forestry in political economy.

3. History of Forestry.

4. Forestry Policy.

Formulating rights and duties of the state, forestry legislation, state forest administration, education. 
5. Forest Botany.

Dendrology, systematic and biologic forest geography - forest weeds.

6. Factors of Site.

Soil physics, soil chemistry, meteorology and climatology with reference to forest growth.

7. Timber Physics.

Structure, physical and chemical properties of wood, influences determining same, diseases and faults.

8. Wood Technology.

Application of wood in the arts - requirements - working properties - use of minor and by-products.

9. Silviculture.

Methods of producing the crop and influencing it: progress.

ro. Forest Protection.

Forest entomology - climatic injuries fire, etc.

II. Forest Utilization.

Methods of harvesting, transporting, preparing for market.

12. Forest Engineering.

Road building - water regulation - treatment of special cases, sand dunes, barren swamps, moors, denuded slopes. 
FOREST AND FORESTRY DEFINED. 105

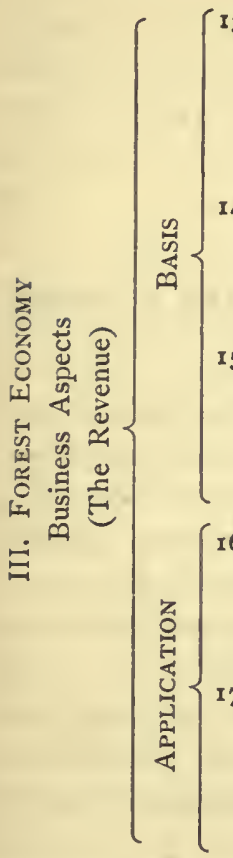

13. Forest Survey.

Area and boundary - topography - ascertaining forest condition - establishing units of management and administration.

14. Forest Mensuration.

Methods of ascertaining volumes and rates of growth of trees and stands, and determining yields.

15. Forest Valuation, Statics, and Finance.

Ascertaining money value of forest properties and financial results of different methods of management, and comparing same.

16. Forest Regulation.

Preparing working plans, determining felling budgets, and organizing for continuows wood and revenue production.

17. Forest Administration.

Organization of a forestry service : business practice and routine, including forest law and business law applicable to forestry practice.

Besides these essential and directly applicable branches of knowledge, it is desirable that the manager of a large forest property have also some knowledge of fish and game preservation, and of agriculture, if game, fish, meadows, agricultural lands, form integral parts of the property. 


\section{CHAPTER V.}

FACTORS OF FOREST PRODUCTION AND BUSINESS ASPECTS.

Forestry, as we have seen, is, like agriculture, concerned in producing continuously crops or equivalent money values from the use of the soil; yet forestry differs from agriculture, not only in the kind of crop, but it differs totally in the manner of producing the crop and in the use and combination of all the factors of production.

This difference is mainly brought about by that element in production by which forest production differs from all other productive industries, namely, the time element.

Agricultural crops are usually ready for harvest the same year they are planted, or at least in a year or two; orchard-crops require a few years to establish the basis for an annual or biennial return of crops; but a wood-crop does not become useful until many years' growth has been accumulated.

Every year a new layer of wood is laid on, over the layers that have been formed before, cornucopia-like, increasing the wood plant in height and circumference and consequently in 
volume. The crop is ready for harvest when a sufficient number of annual growths is accumu. lated to make wood of useful size. This differs according to the use to which the material is to be put.

A five to ten years' growth of some kinds might suffice for hop and bean poles, for barrel hoops, canes, and the like; at fifteen to twenty years the crop might furnish in addition some fence posts and poles as well as firewood, especially if grown from coppice. At fifty years some of the trees may have in part accumulated sufficient size to furnish bolts for the manufacture of carriage stock, hubs, and spokes, or small cooperage and other articles of small dimension, or even railroad ties and telegraph poles. But with most species which are used to supply the large demands of the lumber market, sizes fit for the sawmill are in the temperate zones attained hardly in less than 75 to 100 years; while most of the trees that are now cut for that purpose nature has taken 150 to 200 years and up to 500 years or more to produce.

In addition to size, quality, too, is a function of age, improving as a rule with increase in size. To produce a sawlog which will furnish a sufficiently large amount of clear boards free from knots, many years must have elapsed to cover with annual layers the stumps of branchlets of the younger tree, which by the shading of neighbors were killed and broken off by winds or otherwise. 
Moreover, the wood of many species undergoes a chemical change as yet unexplained, but supposed to improve its quality, or, as in the black walnut, its usefulness, - the change into heart-wood, which begins earlier or later with different species and progresses more or less slowly, so that, while the useful size and form may have been attained, the useful quality may still have to be waited for.

As the tree develops, it exhibits in all its parts the various sizes and qualities of all its stages of development, but in varying relative proportion, and as the log timber of the bole begins to preponderate over the branch and brushwood of the crown, naturally the value production increases, and influences the financial result of the production.

Now, the accumulation of annual layers of wood does not proceed by any means in a regular, even rate of equal proportions for each year. Not only is this rate of accretion varying with every species, and with every difference in soil and climate and other surrounding conditions, and with the seasons, but it differs in the different life periods of the tree.

The soft, light-wooded trees, like the cottonwood, aspen, silver maple, willow, and others, start out with a rapid growth, making good-sized trees in thirty to forty years, then rapidly decline in the rate of growth, and soon cease almost entirely, being comparatively short-lived. Others, like many of our important hardwoods and useful conifers, grow 
slowly in their youth, then increase in their rate, continuing for a long time in an even, rapid development, then persisting at a slower but uniform rate to an old age.

If we were to utilize these latter as soon as they reach useful size and then renew the crop, we would again and again repeat the period of slow growth, and hence lose in relative quantity of production. If, on the other hand, we allowed the soft woods mentioned to grow beyond the stage of rapid growth, we would lose equally at the other end. The study of rates of growth of species and of quantitative production of stands of different species, the mathematics of forest growth, the results of forest mensuration, is so important a matter that we devote to it a special chapter.

Here we only wish to point out that, among the factors of production, time plays a much greater rôle than in any other business, and in fact influences the use of all other factors of production and methods of procedure to such an extent, that, if forestry be carried on as a business by itself, its conduct becomes in many respects sui generis.

The time when the crop is ready for the harvest, it will be apparent from the above considerations, is not a matter of natural period as in the ripening of fruits, but depends not only upon many complex considerations, varying with species and soil and climate, but upon market conditions, economical considerations, and industrial requirements, and 
is determined by the judgment of the harvester; it is a matter of choice influenced by technical, financial, and national economic points of view.

The time which elapses between the first establishment of the crop and the harvest is technically called rotation or revolution or turnus, involving the idea of return to the same area for harvest, again and again; its determination is one of the most important problems for the business manager, and will find consideration in a later chapter.

Besides the time element, there are, as in every producing business, three factors of production to be considered, which in varying combinations produce the result, the creation of values - namely, nature, labor, and capital.

The relative significance of each of these productive forces, as is well known, varies in every industry, and also to a degree with the intensity of their management. Forestry being the twin sister of agriculture, both attempting to produce values from the soil, it is natural to compare these two industries with reference to the part which each of the factors of production takes in it. It is difficult, if not impossible, to compare these industries without assuming as a basis a more or less equal development and degree of intensity. In our country, forestry as a business does not exist as yet, except in small beginnings here and there and without intensity, while agriculture, also, is as yet relatively poorly developed as an industry upon a 
scientific basis. Forest exploitation, the mere robbing of the natural forest resources, and extensive farming, agricultural rapine, the robbing of soils of their native fertility, are as yet mainly practised.

In trying to find economic differences in principle between the two industries, we must, therefore, for illustrations, largely rely upon countries where both the forestry and the farming industry are fully developed side by side, and have reached a high degree of intensity, as in Europe. In comparing the two industries under such conditions, we will find that they differ widely in the relative significance and importance which the three factors of production assume. For while in agriculture the factor of labor is most important, nature second, and capital last, in the forestry business, in general, the reliance on nature is greatest, on capital next, while labor plays a less important part.

The fact that nature unassisted has produced the virgin woods, which furnish us satisfactory materials, while agricultural production is almost entirely dependent on human effort, will at once settle the relative importance of these two factors. Even when the mere exploitation of natural woods is supplanted by the systematic application of skill and labor in reproducing wood crops, the element of labor remains less important, for during the long period from seed to harvest time the forester can do but little to influence the progress of his 
crop, and must allow nature and time to mature it; while the farmer is constantly busy during the progress of his annual crop, cultivating it to secure best results; annually, ploughing and sowing recur; or, if he apply himself to pasturing, his attendance upon the cattle is incessant, his business is "labor-intensive." The forester's crop grows mostly unattended; only when harvest time comes is he busy; and since, as we will see farther on, he may reproduce his crop without direct labor by the mere manner of harvesting the old crop, even seeding time may not call for much effort; his business is "labor-extensive." And since most of his work comes during the late fall and winter, and ceases during the growing season, he cannot offer continuous employment for many workmen, and must rely largely upon an unstable crew, as does the lumberman. On the other hand, much of his work, although dependent on the season, is not limited so closely as regards the time of its performance as is the farmer's, and it is possible to concentrate or lengthen out the work more or less, as desirable. The fact that most of the forest work falls into the winter time, when farm labor is idle, is of the utmost economic value where a dense, poor population must find continuous employment through the year.

If we compare these conditions in a country where both agriculture and forestry are most highly developed, as in Germany, we will find that agricul- 
ture occupies for the same acreage from Io to 20 to even 30 times as much labor according to intensity of management, as forestry, ${ }^{1}$ namely, I 5 to 50 laborers continuously employed on 250 acres of farm as against $\mathrm{I}$ to 3 , or in the average 2 laborers on the same acreage of forest. The 35,000,000 acres of German forest afford only \$I per acre in labor earnings, while, to be sure, they also give rise to a labor earning of over $\$ 3$ per acre in woodworking industries.

In other directions, too, does the labor question differ in the forest. While in agriculture intensive application of labor produces equivalent improvement in results, such improvement can in forestry rarely and only to a limited degree be secured by increased labor. Not only is most labor in the forest technically simple, very little skill being needed and very little variety offered, but it permits piecework to a much larger extent than is practicable on the farm, while opportunity for the use of machinery is very limited, or at least as yet little developed. Nor does it permit much division, organization, specialization, such as is practised in manufacturing establishments.

The greater intensity with which agriculture can

1 The Prussian state forest administration of nearly $7,000,000$ acres employs one official for every 1465 acres, namely, I guard (Förster u. Waldwärter) for every I 800 acres, I manager (Oberförster) for every 9800 , and I inspector (Oberforstmeister u. Forstrath) for every 61000 acres; and the common labor represents the annual employment of one man for every 175 acres. 
be profitably practised also makes a difference in the amount of superintendence which it necessitates. While an intensively managed farm of 250 acres would occupy a superintendent fully, a hundred times such acreage in forest may be placed under one manager to execute the working plans if, according to location and conditions, he is assisted by a number of guards.

The protection of the property, indeed, requires under circumstances the comparatively largest attention. In German forest administrations, one guard is employed for every 500 to 2000 acres, exercising mainly police functions, which the dense indigent population, prone to stealing and trespass of various kinds, necessitates.

In India, ${ }^{1}$ with a forest area under more or less intensive management of 75,000,000 acres, of which about two-thirds are reserved, the rest only protected - after various reorganizations since 1864 when the first administration was organized, - the controlling staff consists of I inspector general, I9 conservators, II 7 deputy conservators, 63 assistant conservators, and II 2 provincial conservators, or all together 312 officers, double the number employed in 1885 ; the executive and protective service is satisfied with 1663 rangers and foresters and 8533 guards; all together 10,508

1 These figures refer to conditions in the year 1900, and are taken from the excellent book, "Forestry in India," by B. Ribbentrop, Inspector General. 
permanent employees, or one to a little less than 7500 acres, are at present required.

The gross income of this largest forestry establishment in the world, constantly growing, was in I 892 to 1897 only about $\$ 8,000,000$, while the expenditures represented 55 per cent of the gross revenue, of which over $\$ 2,000,000$ was paid for the permanent service.

With us, where for the present less intensive management must form the rule, and where in some respects properties are less endangered, the size of a superintendent's and a guard's district may be four times as large and more.

While the conduct of the business requires a small amount of labor, it is a peculiarity of the business that the formulation of working plans to be followed by the manager requires not only much more careful consideration, and also involves a considerable amount of skilled labor in securing the data, while their circumspect use requires a good deal more judgment than would be needed in a business which can change its modus operandi readily every year.

It will have appeared from this discussion of the relation of labor to the industry, that the size of the area upon which forestry is to be practised not only may, but must, be of considerable acreage if it is to be carried on profitably as a business by itself, if for no other reason than to occupy the manager fully and to leave enough margin for the 
owner. While the small farm, owing to the possibility of increasing returns to increased labor, and hence a relatively large return per acre, can exist, the small farm earning per acre as much as the large one, or more, - the small wood-lot cannot exist as a separate business proposition; only as attached to a farm or other business can it have economic justification, but, as we will see later, it is even then at a disadvantage from mere silvicultural points of view.

The indirect employment of labor to which forest products give rise in transportation and final shaping and use of the wood material is probably greater than with farm crops.

We referred just now to the amount of labor earnings of $\$ 3$ which each acre of forest produces in woodworking establishments in Prussia. In our own country the forest products annually consumed involve the moving over shorter or longer distances of not less than 500,000,000 tons, or, if we only refer to the lumber product, at least I 00,000,000 tons must be handled to and from the mill and yard, which, if the average haul were not over Ioo miles, may readily involve a cost of $\$$ I $50,000,000$ to $\$ 200,000,000$, while $\$ 300,000,000$ is about the amount of wages paid to the 500,000 employees occupied in transforming the raw forest product into articles of trade, and $\$ 100,000,000$ to the loggers and mill men. With these and other figures (see Appendix) we come to an esti- 
mate which brings the labor earnings for our 500,000,000 acres of forest, that are being exploited but not managed, to not less than $\$ 600,000,000$, or perhaps one laborer for each 250 acres, as a lowest figure. The 360,000,000 acres of improved farm land reported in the census of I 890 occupied only one man for every 43 acres and the total crop translated into weight remains considerably below 200,000,000 tons, including meat, milk, butter, cheese, etc. It is well-nigh impossible to get even approximations to the number of laborers employed in conversion of these foodstuffs, but the likelihood is that all together not more labor earnings can be credited to one acre of farm land than to the acre of forest land. This disparity is probably explained by the lack of intensity in farming, and the probability that much of the farm land does not really participate in the crop, lying idle.

If there exists, then, great difference regarding the amount and character of the labor element in agricultural and forest production, the use of the element of nature shows no less difference in the two industries.

Not only is the element of nature relatively much more prominent in forest production, but the single factors, soil and climate, have different significance. For a crop which must withstand the rigors of winter and the variable conditions of all seasons, not for one, but for many years, and which by its character forbids the expedients of cultiva- 
tion on which the farmer relies, special considerations regarding the relation of crop to climate occur. While most of our farm crops come originally from climates very different from those in which they are now grown, the possibility of extending forest crops beyond their native limits is very much more circumscribed, and even with native species the climatic influences of frost, drought, winds, require the adaptation of the crop to the site, and aftertreatment different from farm crops. On the other hand, where, as in the high altitudes and northern latitudes, agriculture finds its climatic limits, forest cropping is still possible; again, good farm crops may be raised in the semi-arid regions, where forest crops, while possible to establish, must by necessity be of only inferior value. Agriculture deals almost entirely with vegetable products, which, to be sure, originated with nature, but have been improved by man for human use; its products are, if we may be permitted to exaggerate, unnatural, artificial ones, and the possibility of varying their character and adapting them to climatic conditions seems almost unlimited.

Wood-crops, on the other hand, are still, even under the forester's hand, as nature unaided can and does produce them ; the possibility of influencing their character is exceedingly limited: under the skilful guidance of the forester, to be sure, the manner in which the wood is deposited on boles and branches, the development of clear long shafts 
in preference to low-crowned and branched trees, and to a slight extent the structure of the annual ring, can be directed; but so far the wood of nature's production and that of man's are very nearly if not quite the same, and forms which are better adapted to climatic or soil conditions have not been bred by man. The short cycle of development in agricultural crops and the long cycle in forest crops explain this difference. The forester can improve upon nature mainly by making it produce a larger quantity of material of useful form and of useful species per acre.

But the greatest and radical difference between the two industries, one of the highest national economic importance, is the difference in the use of the soil.

Agriculture is engaged in producing starch and sugar, proteids and albuminoids, in short, the compounds which are directly food materials; and this production relies largely on the fertility, the minerals of the soil, especially the rarer phosphorus, sulphur, potash, nitrogen. With the. harvest all these are removed from the soil, and must be replaced by manures or through rotation of crops, or else the soil is sooner or later exhausted and becomes infertile.

Forestry is engaged mainly in the production of cellulose and its derivatives, carbohydrates, ${ }^{1}$ which contain a minimum of these rarer elements.

1 The composition of wood is approximately 50 per cent C, 6 per cent $\mathrm{H}, 42$ per cent $\mathrm{O}$, I per cent $\mathrm{N}$, I per cent mineral ash. 
The air furnishes one-half the constituents, namely, the carbon, which the chlorophyll cells of the leaves assimilate under the influence of the sunlight, and almost the entire other half is furnished by the water of the soil. Not that tree life and wood production can entirely dispense with the presence of these minerals, but it requires them in smallest amounts, and the final product, which the forester harvests, is practically devoid of them. Moreover, those parts of the tree which in its life processes accumulate the largest amounts of these elements, namely, the foliage and small branchlets, do not usually form part of this harvest, but are returned to the soil, so that, in fact, not only does the soil not lose any of its fertility, but, on the contrary, it is enriched at its surface by the decay of the litter, not only through the vegetable humus and the nitrogen-condensing bacteria formed in the same'(see Appendix), but through mineral constituents in soluble form, which the tree has brought up from greater depths. Hence the well-known fertility of virgin woodland soil; while agriculture exhausts soils, forestry enriches them. ${ }^{1}$ From the soil the forest crop derives mainly the

1 A field of potatoes, for instance, uses of phosphoric acid three times as much as a beech forest, five times as much as a spruce forest, and nine times as much as a pine forest, and of potash nine, thirteen, and seventeen times as much as the three tree species respectively, while of nitrogen wood requires 1o to 13 pounds per acre as against 60 to 90 pounds in potatoes, the conifers generally requiring less than the deciduous-leaver trees. 
water which is required for the biological processes, including the transpiration of the leaves, and for the composition of the wood, adding the hygroscopic water which is finally-lost when the wood seasons. Chemically water forms 48 per cent of the wood substance, while 40 to 60 per cent more is hygroscopically bound to it in the living tree, and 8 to 12 per cent remains so in the wood after seasoning; the whole forest area, therefore, produces only 40 per cent of dry substance to 60 per cent of water, so that the 8000 pounds annual product on a fully stocked acre divides itself up into 3000 pounds dry substance, I250 pounds chemically bound, and 3750 hygroscopic, water. These are small quantities of water, but the transpiration current requires many times more. Figures on this point are difficult to establish, as the variations, by species not only, but from day to day, in different seasons, are extremely great. An acre of beech may some days transpire not more than 5000 pounds, other days four times that amount, while agricultural crops seem to need from 50 to IOo per cent more. The interesting and important point is that coniferous trees, especially pines, require from one-sixth to one-tenth of what deciduous-leaved trees transpire, which makes them especially valuable for dry soils and climates. The silviculturist draws from these facts, regarding the frugality of forest crops, the conclusion that he need not like the farmer manure nor change his 
crop, provided the litter is left, and, moreover, that he can grow his crop on soils which are not fit for agriculture.

This fact, which also refers to soils and situations that are topographically unfit for ploughing, is one of greatest importance to the political economist. For with the increased need of food supplies, the necessity of using the soils to their utmost arises, and the possibility of relegating the nonagricultural soils to forestry use is a welcome aid in the solution of this problem. This relegation of soils to their best use is now-actively and consciously going on in the densely populated German states, the economic policy being to exchange worn-out, poor agricultural soil for forest use, and to turn agricultural soil under forest to farm use. ${ }^{1}$

Hence, also, the mountain slopes, the very places where, for the sake of favorable water conditions, a forest cover is needed, are par excellence forest lands; for a slope of $15^{\circ}$ makes them unfit for plough land, and one of $20^{\circ}$ to $30^{\circ}$ excludes them from use as pastures, while forest growth will still maintain itself satisfactorily on slopes of $40^{\circ}$ or more.

We come here to the recognition of a natural subdivision of our soils into absolute forest soils, those which are only fit for forest crops, and relative forest soils, which may come into competition

1 Prussia has for some years appropriated large sums $(\$ 250,000$ annually) for the purchase and reforestation of poor, worn-out lands. 
with pasture and farm use, and which require careful consideration as to which use is financially, or for other reasons, preferable.

If we compare the amount of production per acre in the two industries, it must not be forgotten that in such countries as Europe the forest occupies already mostly these poorer sites and situations, the absolute forest soils, and hence the comparison must be unfavorable, apparently, as far as money returns are concerned.

In amount of vegetable material produced, forest crops, to be sure, are in no way inferior; nay, if we do not confine ourselves to the wood, but add the leaf litter produced per year, offsetting the straw of agricultural crops, the forest produces larger quantities in weight than the farm. Taking average crops of the common farm produce, there are produced dry weights of 3400 to 4600 pounds vegetable substance per acre, of which, mostly, not more than one-third is represented in the grain; while the forest acre produces ( 8000 to 10,000 pounds, of which one-half or more is wood, namely, 4500 to 6500 pounds, with 450 pounds for roots, and 3000 pounds for leaves, the dry substance of wood grown per acre per year varying between $I 500$ and 3600 pounds, according to the site. ${ }^{1}$ The interesting fact is that all species produce on the same site the same weights,

1 A one-hundred-year-old stand then contains at best 180 tons of dry wood, equivalent to about 90 tons of carbon. 
but, to be sure, the cubic contents vary greatly on account of the difference in specific weight, due to the manner in which the wood is deposited. This production in cubic feet is dependent on the condition of the forest crop, varying from less than 30 to Ioo cubic feet, including the brushwood. Taking only the more useful wood down to 3 -inch diameter, which we call timber-wood, the results of large forest administrations average between 35 and 75 cubic feet, or about 55 cubic feet in the average, deciduous-leaved forest producing the smaller, coniferous forest the higher, figures. Differentiating qualities still further, we may state that to these figures corresponds a lumber product of 200 to 500 feet B.M.

In this connection it is significant to note that in Switzerland the product in the government forests (was 7 r cubic feet (maximum 96, minimum 29), in the cantonal and communal forests 50 , and in private forests 47 cubic feet, i.e., 40 per cent. less than in the government forests, an indication of superior management in the latter. In France the same difference appears, the government forests in r 876 producing at the rate of 49 , the communal of 40, cubic feet. How the forest product responds to superior management appears in all German forest administrations. In Prussia, for instance, the cut, supposedly gauged to the annual growth, rose from 28 cubic feet in 1830 to $4 \mathrm{I}$ cubic feet in 1868, and to 51.5 cubic feet in 1900 ; in Saxony 
the yield doubled in 50 years to 70 cubic feet for the average acre.

The third factor of production, capital, must, as usually, be divided in to the current or working fund which expresses the capital required to carry on the current business, and the fixed investment, which expresses the capital tied up permanently as a basis for continuous production.

Since the labor expense is relatively small, since none or only simple machinery is necessary, and simple tools and no buildings are required to house the crop, and even the procurement of seed and plants may be often dispensed with, the current working fund in the forestry business may be rather small. While, according to statistics gathered by the United States Department of Agriculture in I893, the current expenditure for wheat and corn crops was $\$ 8.88$ and $\$ 8.68$ respectively, not counting rent for land and superintendence; in German forest administrations the cost of management to be paid from a working fund averages about $\$ 2$ per acre, being, for the single items, from 22 to 65 cents per acre for protection and administration, 30 cents to $\$$ I for harvest, I 5 to 22 cents for planting and cultural measures generally, 6 to 33 cents for road building, most of which might correctly be charged to investment.

In the logging business, which deals only or mainly with exploitable timber, lacking or not taking into consideration the younger age classes, the 
case is entirely different, and the expenditures for harvest alone may range from $\$ 25$ to $\$ 75$ per acre and more.

But the difference, that renders the established regulated forestry business unique, is the amount and the character of the permanent or fixed capital.

Both the farming and the forestry industry have in common, besides buildings and tools, the soil as the basis of production. Since forestry is gradually relegated to the poor soils, this part of the investment is comparatively much smaller than in agriculture, unless agricultural soils are used in forest growing. Thus in Prussia, where, as we have seen, lately purchases of absolute forest soils have been made by the government, the average price paid in 3 years for about 7500 acres was less than $\$ 22$, including occasionally inferior timber and buildings, the range being from $\$ 3$ to $\$ 33.30$, while the better agricultural soils bring in the province of Brandenburg $\$ 100$ to $\$ 160$ per acre. In other districts, where forest products are higher in price, the value of forest soils ranges somewhat higher, namely, from $\$ 15$ to $\$ 60$ and occasionally $\$ 80$. But in forestry the fixed capital is not confined to the soil; the much larger value is represented in the growing stock of wood, which must be allowed to accumulate before it is ready for the axe. This is the most characteristic feature in the wood-cropping business carried on for continuity: that only the accumulated accretions of many years can be 
harvested, and that, until harvest time has arrived, they are tied up and are in the nature of fixed capital, accumulating with compound interest charges.

To understand the nature of this capital and get an idea of the amount involved, we will have to look at it from various points of view.

If we were to start on a blank area and were to plant our crop, we would have only the soil $(S)$ as fixed capital; but since we could not harvest from year to year, and thus withdraw the interest, the expenditure for planting $(E)$ would also have to be considered fixed; moreover, the interest on both soil and other expenditures, being by necessity accumulating, becomes fixed, until at harvest time both capital and accumulated interest, except the soil capital, become liquidated and then again the process of fixation is gone through. The fixed capital would then be $(S+E)$ I.० $p^{r}-(S+E)$, or $(S+E)$ $\left(\mathrm{I} .0 p^{r}-\mathrm{I}\right) ; r$ being the time during which the capital is tied up, and $p$ the interest-rate at which the capital is supposed to produce.

If we started, as the forest exploiter does, with a ready-made crop of virgin timber, we might take the position which he usually does, namely, remove at once the valuable part of the crop, and turn it into cash, when as a rule both the current capital involved in harvesting and transporting the crop, and the investment in land or stock, are liquidated at once, or in short time, the stumpage value paid under such crude conditions being usually kept 
disproportionate to its actual value; and the basis of future production may be said to be a zero capital, neither the soil nor the prospective undergrowth being considered of any value, and in fact no conscious forest management for new crop being intended, the reproduction being left to accident and nature alone and allowing perhaps a return for further harvest at some later time. The aspect changes when real forest management, not for intermittent returns, but for annual business, is contemplated, when the forest is to be so regulated that every year forever a harvest is to be secured in proportion to the capacity of soil and species of producing it continuously, i.e. when the increment only is to be harvested, which every year brings. We can readily conceive what the ideal condition of such a forest must be. If we had determined that our crop is best harvested when one hundred years of age, then, in order to harvest always one-hundred-year-old timber, we must have a series of one hundred stands, each one differing by one year in age down to yearling growth, so that each year one stand becomes ripe. It appears then clear that the contents of the ninety-nine stands from one to ninety-nine years old, expressed in volume or value, are the wood capital; and the hundredth stand is the interest or harvest or felling budget (the last stand representing as well the increments of one hundred years, as the one hundred increments of one year on the whole area) 
which may be cut; and if reproduced as cut, the continuity of similar harvests is assured.

If we call the annual increment of any one stand $i$, and instead of the one hundred years substitute the general term of years $r$ (rotation), the capital stock is the sum of the arithmetic series $i+2 i+3 i \ldots+r i$ which, according to wellknown mathematical laws, is $\frac{r}{2} \times(r i+i)$; or, since $i$ is relatively quite small, it may be neglected, and if we substitute for $r i=I$, i.e. the annual increment of all the stands, the form becomes $\frac{r}{2} I$, or in other words the capital stock of wood which must be maintained is the increment occurring on the whole forest through half the rotation. It stands to reason that, with every species and every soil, as well as with every rotation and system of management, the amount of $I$ changes, and hence the capital stock required.

It is evident that, for instance, in coppice forest, sprout lands, which are usually managed in rotations of not over twenty to forty years, the wood capital is much smaller than in timber forest, which requires from sixty to one hundred and twenty years and more to become mature.

Merely to give an idea of the relative amounts which different conditions may require, we will assume that 70 cubic feet of wood per acre represents the annual increment, then a coppice of 100 
acres in twenty-year rotation would require as wood capital $100 \times 70 \times 10=70,000$ cubic feet; while the same 100 acres managed as timber forest in one-hundred-and-twenty-year rotation would require a wood capital of $100 \times 70 \times 60=420,000$ cubic feet, or six times as much as the coppice in volume, and, to be sure, many more times in value, since in the timber forest higher-priced material is involved.

In actual practice in a large average (Bavarian and French forest departments), the disproportion is much greater, namely, the wood capital in the timber forest is eight to twenty-five times as large as in the coppice.

To give a few absolute figures which we can take from the elaborate yield tables of the Germans, a Scotch pine timber forest of 100 acres in one-hundred-year rotation would require, according to the character of the site, that 400,000 to 900,000 cubic feet of wood be maintained as wood capital; a spruce forest requires a wood capital of 560,000 to 1,540,000; and a beech forest under similar conditions managed for continuity would make it necessary to leave 500,000 to 700,000 cubic feet in round numbers, the lower figures for the poorer, the higher figures for the best soils.

Translated into money values, these quantities would vary from $\$ 100$ to $\$ 600$ per acre, and in the coppice, to be sure, not over \$10 per acre.

We see, then, that in a properly regulated for- 
est management for timber production, while the soil represents the smallest portion of the fixed capital, soil and wood capital combined exceeds the fixed capital needed in an intensive farm management, and on the whole two to ten times the capital required in agriculture is needed to carry on forest management for timber production.

Two most important deductions from the standpoint of political economy follow from this discussion.

First, that the time element, together with the large capital required in timber-wood production, renders the forestry business undesirable to private enterprise of circumscribed means; that long-lived persons, like the state and corporations, and large capitalists, can alone engage in it as a business by itself with hope of financial satisfaction.

This does not exclude the farmer's wood-lot as an 'adjunct to the farm, but he will finally find it more advantageous, if he figures correctly, to manage it as coppice, not as a timber forest.

Secondly, the fact that capital and interest, wood stock and harvest, are mixed together, the differentiation being made, not by the character of the material, but by voluntary economic considerations and self-imposed saving, and that, while in the lower age classes the capital is tied up without any possibilities of realizing on it, it is possible to liquidate portions of it in the older age classes at any time, making it readily available, to be turned 
into other channels - this ease of reducing the fixed capital without appreciable loss is one of the peculiarities of the forestry business, which sometimes may be of advantage, like a savings bank account, but also brings with it the danger of uneconomic anticipation of the harvest, of disturbing the systematic progress of a management for continuity, of returning to mere exploitation when there is an urgent need of money.

Hence, not only capital, but economic capacity and character and moral strength are required to maintain a systematic forest management and withstand the temptation to realize. Again the state, communities, and corporations, who have an interest in continuity, are most safely intrusted with a business that can be so easily unbalanced.

It is also evident that a profitable, well-regulated forest management for annual returns as a business by itself is only possible on a large acreage. This will appear readily from the consideration that German government forests net from $\$$ I to $\$ 4.50$ per acre per year (as against $\$ 24$ for farm lands); hence, to furnish $\$ 1000$ margin not less than 250 to 1000 acres are required, and to pay a competent manager's salary alone, without interest and profit on the business, requires at least 2500 acres, while, to be sure, he would not be fully occupied with less than 10,000 to 20,000 acres. And we must not forget that the results in these German forests are obtained now after a century of systematic manage- 
ment, and then are only possible by having very large areas under one management, when the good acres offset the loss on the poor acres. Under such conditions 35 to 60 per cent of the gross yield goes for labor and administration, one-third to onequarter for the former, one-fifth to one-seventh for the latter, leaving 40 to 65 per cent of the gross yield as profit, equivalent to a rate of 3 to 5 per cent on the wood capital from soil otherwise mostly valueless.

There are other consequences which follow from the character of the wood capital: the difficulty of determining what is capital, what interest makes the renting of woods for systematic forest management impracticable ; and such management is also unsuitable for stock companies, which are formed to make money fast and lack conservative spirit, however favorable such companies may be in conducting mere forest exploitation. On the other hand, it is conceivable that trusts could most advantageously carry on the forestry business, owing to the fact that large fixed capital is needed, and is most safely invested in forest growth, promising secure and steadily growing income, and that the more surely the larger the property under one management.

There are, to be sure, dangers to the wood capital from insects, storms, and fires $;^{1}$ but they can

${ }^{1}$ In Prussian forest districts in fifteen years 405 fires were reported, but only 191 acres in $1,000,000$ were damaged out of the $7,000,000$ acres involved. 
be reduced to a minimum of permanent injury, and the more easily the larger the property under one management.

All things in the production of which nature plays the important part have the tendency to rise in price, while those relying principally on labor and capital sink. That the price of wood is bound to rise is not only a matter of simple philosophy as long as forest area decreases and demand for wood increases, but also of history wherever natural resources have been reduced to the necessity of management. (See further on regarding rise in prices.) The financial results of German forest administrations are certainly most assuring as to the profitableness of a systematic forest management pursued during the last one hundred years, through all the changes of economic conditions which have characterized that century.

Evidences of the increasing profitableness of these administrations are given in the statistics contained in the Appendix. The increased yields and incomes there recorded do not, however, tell the entire story, for they do not show the additional improvement in the condition and earning power of the properties.

Taking, for instance, the Saxon forest property of only 430,000 acres, we find that, although the cut of wood had increased from 23,500 cubic feet in 1850 to 37,400 cubic feet in 1893 , an increase of 60 per cent, the timber wood per cent (wood of 
superior size not cordwood) had increased from 14 cubic feet to 54 cubic feet per acre or nearly 300 per cent, and at the same time the wood capital had increased nearly 25 per cent. While the net income during the earlier period, when wood was worth 5.6 cents per cubic foot, amounted to $\$$ I.I2 per acre, in 1893 the price had risen to 9.9 cents, or 76 per cent, but the net income had risen nearly 300 per cent, namely, to $\$ 4.37$ for every acre of the property, while the expenditures had been more than doubled.

When it is considered that Saxony has taken in about $\$ 200,000,000$ during the last fifty years from a small area of rough mountain land, a tract half the size of many a county in the United States, and that without diminishing, but rather increasing, its earning power, the advantage of a careful treatment of forest areas, at least to the state, the community, must be apparent.

Considering the net income as the interest of the value of the forest lands at a 3 per cent interest rate, it appears that, meanwhile, the capital value of these lands has increased from $\$ 100$ to $\$ 150$, whereas their deforestation would quickly convert them into poor alpine pastures, which would bankrupt their owners at $\$$ ro per acre.

To the uninitiated an interest rate of 5 per cent, which the appreciation of the investment and the continued revenue of 3 per cent represents, would appear unattractive; but when the conditions under 
which this rate is secured are considered, it would be difficult to find any other business that under similar non-speculative conditions and management could make such a showing.

It is the consensus of a large number of prominent financiers in the United States, ${ }^{1}$ that at the present time an absolutely safe, satisfactory long time investment in this country cannot net more than 3 to $3 \frac{1}{2}$ per cent, with a tendency to decreasing rates.

A number of reasons can be adduced for the claim that the forestry business is one of those which is entitled to a low interest rate. It is well known that the form of the capital varies the interest rate, besides those more general modifiers of the value of capital, such as the general safety, prosperity, and credit of a country, and the supply and demand for money. Among the features which render capital invested in forestry business of such a character as to satisfy a low interest rate, are the following:-

Like all landed property, the safety of the investment is great; moreover, since forest property under forestry management does not, as we have seen, lend itself to renting, but is usually managed on own account, no allowance need be made in the interest-rate it must bring for the premium for risk which loaned capital requires. As long as the

1 "Letters of Prominent Financiers on Interest Rates," Equitable Life Assurance Society, 1899. 
fire danger is as great as in this country, the safety of forest property under certain conditions (coniferous forest, dry regions) is, to be sure, greatly im. paired. That this danger does not need to exist is amply shown by European experiences, and as soon as forest properties are really managed and not only exploited, they will have the same safety.

In Prussia, with 7,000,000 acres, including large pineries on sandy plains, in 25 years (I868-1895) only I 400 acres, or 0.02 per cent, or I acre in 4500 , were burned over, and some years not more than $I$ in 8000 , a small percentage for so large and specially endangered properties. In the mountainous forests of Bavaria in 5 years (1877-188I) only I acre in 13,167 was lost by fire, less than 0.007 per cent of the $2,000,000$ acres, the loss representing 2 per cent of the gross yield. This state lost heavily by insects and storms, but such loss is usually of little consequence on large areas, only disturbing the regular management, and readily compensated. In 1868 to 1878 windfalls and damage by beetles made it necessary to anticipate the cutting of 400,000,000 cubic feet, and although thereby the regular cut was increased by 2.1 per cent, this increase remained without any influence on normal prices.

The permanency and continuity of the investment, the amenity and dignity of large landed property, recommend it to large capitalists; and since the nature of the business necessitates the 
employment of large fixed capital, the usual low rate prevails which accompanies large capital investments, safely placed and avoiding the losses incident to re-investment.

The promptness and absolute assurance with which the revenues may be expected, and also the advantage of being able to anticipate revenue when needed, have the same tendency. Finally, the general tendency to lower interest rates, and at the same time to higher prices for wood, promise an advantage in the future (especially in a country where, on account of extensive forest exploitation, prices are still comparatively low) which will make investments in forest property for continuous management show superior advantage to most other forms of capital of large size.

This rise of prices, of which we gave an example for the densely populated, industrial little state of Saxony, comes out still more strikingly in the larger, and more extensively managed Prussian forests. Here the average price per cubic foot nearly doubled in the 35 years from 1830 to 1865 , and from 1850 to 1895 it rose nearly 50 per cent, namely from 3 cents to $4 \frac{1}{3}$ cents per cubic foot, all together an increase of $1 \frac{1}{2}$ per cent annually for a period of 65 years.

In every case of the state forest administrations of Germany, we observe steady increase in material production, value production, expenditures, appre- 
ciation of investment, and net yield, as the table in the Appendix exhibits.

One important policy which has brought about this result, and which defines in general the financial requirement of forestry, has been that these state administrations were willing and able to forego present revenue for the sake of continued future revenues, to give up immediate momentary profits for the sake of making larger profits distributed in time.

Forest management means that some part of the forest, the wood capital, must be left, although it could be turned into cash, or that money be spent in establishing such a wood capital where it is deficient, waiting for the time of returns. No business realizes more than the forestry business that time is money, and time is what the small capitalist does not have. It is, therefore, not a business for the small capitalist, who must work for large margins. 


\section{CHAPTER VI.}

\section{NATURAL HISTORY OF THE FOREST.}

To understand the operations of the forester, it is necessary to have some knowledge regarding the life history of the object of his endeavor.

We have seen that the forest is not a mere collection of trees, but an organic whole, the result of evolutionary development, of adaptations and reactions to the environment, of interrelations between the components of the forest and the soil, climate, and lower vegetation, as well as between the components themselves.

While the forester must necessarily be thoroughly conversant with the development of the single tree and all the conditions influencing it, he cannot stop there, but must also know its behavior when placed in relation to associates in the community of companions, for it is his business to develop this community in such a manner, and bring all influences and elements of environment into such a relation to it, that it will produce a certain desired result. Acres of forest, not single trees, concern him.

The virgin forest and the forester's forest will 140 
necessarily differ, inasmuch as the former is merely the result of a natural evolutionary struggle among the different forms of vegetation, in which the "most fit" survivors may not be the economically desirable, while the forester substitutes artificial selection for natural selection, and makes sure of the protected survival of the most useful. Within limits, at least, he has it in his power to influence the seemingly lawless mixture of species which the virgin forest offers into a form more suitable for his purposes. The limits are set by the adaptability of the species to climate and soil, and by the skill of the forester in recognizing and utilizing the laws under which the natural forest develops.

Climatic factors, temperature and moisture conditions, determine, in the first place, the field of natural distribution of the various species. Different species are adapted to live within different ranges of temperature and of relative humidity, or the combination of both; hence, different types of forest occupy the different regions through which we pass from the tropics, with their palms and broad-leaved evergreen trees, through the deciduous-leaved forest of the middle latitudes, composed of oaks, hickories, chestnut, and tulip tree, to the northern latitudes, where birch, maple, beech, with pine, and hemlock, and finally, only aspen and spruce, can brave the wintry blasts. And beyond the last outposts of these, tousled and 
dwarfed, the esquimaux of tree growth, the treeless tundra is reached, where ice and snow abound all the year, the home of winter.

Similar changes in type may be traced by ascending some high mountain in tropic or subtropic regions. We may begin our journey under the palms. As we ascend 2000 or 3000 feet, we pass through the varied evergreen, broad-leaved forest, into the deciduous-leaved forest, not dissimilar to that of our middle latitudes. At an altitude of 8000 feet we enter the dominion of spruces and firs. At 10,000 to 15,000 feet the forest opens, the trees stand in groups, are dwarfed and tousled like their northern counterparts, hugging each other and the ground for protection against the winter storms; finally, the timber line is reached, where killing frosts occur every month in the year, and no persistent life can exist.

Again, variation in the relative humidity, in connection with temperature conditions, brings about changes in forest types; from the humid seashore to the drouthy interior of continents, we find different species adapted to the many possible combinations of temperature, humidity, and winds, which together influence that most important physiological function needful in the life of the tree, transpiration. Dry climates, like cold climates, tend to diminish growth, and reduce the number of species composing the forest.

Within the geographical range of the species 
thus limited, soil conditions vary, and again differentiate the distribution; the frugal pines being able to subsist on the deep, overdrained sands, the shallow-rooted spruces on the thin soils of alpine situations, the elms, swamp maples, tupelo, bald cypress, being indifferent to excess of moisture at their feet, the hickories, walnuts; and tulip trees seeking the rich, loamy soils, and others again being ubiquitous, adapted more or less readily to any kind of soil.

While, then, certain territory is assigned to the different tree species, which through eras of evolution have adapted themselves to the climatic and soil conditions, - and this is a very important economic fact, since usefulness of species varies, - yet the absence of a species from a given locality does not necessarily predicate its inability to exist and thrive in such a locality, since there are also mechanical barriers, like wide oceans and high mountain ranges, or there may be absence of suitable means of transportation for the seed, preventing its spread, and these difficulties man can overcome.

It is, therefore, not impossible to exchange and distribute artificially the useful species, as has been done in agriculture and horticulture. But in the case of plant material for forest purposes it is impracticable to give special protection to the introduced species through the long term of its growth to usefulness, as may be done in the case 
of animals or even of fruit-trees. Acclimatization, so called, in forestry is, therefore, practically confined to overcoming merely the mechanical barriers of distribution, i.e. to transport the species, where its means of transportation fail, and to give it a chance of showing its adaptation or lack of it.

As a rule, the forester relies on the species which he finds in the locality in which he is to operate, and introduces from outside only species which he has strong reasons to believe are adapted to his locality, and at the same time promise decided advantage over the native ones either in quality or quantity of product or in other silvicultural qualities.

Nor has much attempt been made to improve on the quality of the wood as nature produces it. While in agricultural products nature has been improved upon in nearly every case, in forest products very little attention has been given to this subject.

The forester, more than the agriculturist, follows and imitates the processes of nature; all that he attempts is to direct them to produce, in a degree, better form and larger quantity of the better kinds which he finds on hand.

While the presence of a species in the composition of the natural forest is, in the first place, due to climatic and soil conditions, its numerical distribution and the manner of its occurrence in the 
mixed forest depend primarily on two qualities in combination, namely, its relative rapidity and persistence of height growth, and its relative requirements for light, while the manner of seed production, seed transportation, and character of seed are additional factors.

In those natural forests which are composed mainly or entirely of one species, a comparatively rare occurrence, the presumption is that climatic or soil conditions are such that other species do not find them congenial, at least, not when they must contend for root and air space.

One, by a prolific production of seed, has an advantage over another which produces seed only every three or four years. The heavy nut of the walnut, or the acorn or beechnut, needs squirrels, mice, birds, and water to extend its territory, while the light-winged seeds of birch and poplar, carried by the winds, make these trees almost ubiquitous. The seed of the willow loses its power of germination within a few hours or days; hence it is confined mainly to the borders of streams, where favorable opportunities for sprouting exist. The acacia and others of the leguminous tribe, like the black locust, preserve their seed alive for many years; nay, the seed of the former will often lie buried in the ground for years, until a fire that destroys all other vegetation breaks their hard seed coat and calls to life the dormant germ: the cones of some pines remain closed, and release 
the seed only when fire, which has probably destroyed all competitors, opens them. The pecu- liarities of the seed, then, account for much in the distribution of plants.

Next comes the peculiarity of growth. The long-leaf pine, which, for the first four years, does not grow more than two or three inches above the ground, is at a disadvantage in that first period, - during which it has occupied itself with forming a stout root system; but thereafter, by virtue of this root system, it may endure what a fastergrowing neighbor could not. The quickly growing aspen covers large areas, but its reign is of short duration, for, as with most of the rapid growers, its life is short. The slower-growing spruce, which could support itself under the light shade of the aspen, remains on the field, the victor by sheer persistency.

Capacity to resist unfavorable weather conditions - frost and drought - will give the advantage to one species over the other, while liability to attacks by animals, especially insects, may also prove disadvantageous in comparison with the others. There is little doubt in the mind of the writer that the big trees, the Sequoias, owe their long life to their immunity from insects and fungi and to their resistance to fire, to which their competitors succumb. Finally, however, the two qualities first mentioned, relative height growth and relative light requirement, are determinative. 
While light is usually accompanied by heat and it is difficult to discern how much of the effect of it on plant growth is to be ascribed to the heat which causes transpiration, and how much to the light as such, yet it is now well known that light itself exercises various influences upon vegetation, some of which are still imperfectly or not at all understood. It is light which is indispensable in the formation of chlorophyll-the material which imparts the green color to plants; it is light, a certain degree of light, upon which the assimilation of carbonic acid in the chlorophyll and the formation of starch are dependent; it is light, together with other factors, which influences transpiration by the foliage, which determines the development of the crown and of the whole tree in direction and quantity of growth.

It has been observed that various plants show need of a greater or smaller amount of light for their development. Some plants always seek the shady places in the woods; others enjoy the full sunshine of the meadow. The dense spruce forest permits only a moss-cover on the soil, while the open-foliaged oak forest permits a host of shrubs and herbs to subsist. Just so, some trees are found thriving under the shade of others, while these are intolerant of the shade of their neighbors, or can endure it only a short time. So all important and so well known is the influence of light on the development of a forest crop that on the difference of 
light requirements of the various species are based the most important forestal operations. According to relative tolerance of shade, the species can be graded from the most tolerant to the least tolerant, into shade-enduring or light-needing. Those species which, like the beech or sugar maple, the hemlock or the fir or spruce, form dense crowns evidently need less light than those with lighter foliage, for the interior leaves of these crowns can grow and function in the dense shade. On the other hand, the light-foliaged, open-crowned larch or pine, aspen or poplar, ash or birch, show their extreme sensitiveness to the absence of light by the very openness of their crowns, by losing early the lower branches unless they are fully lighted, and in the forest by the inability of their seedlings and young progeny to endure the shade of neighbors or even of their own parent trees.

To offset this drawback in their constitution, they have usually some advantage in the character of the seed, and are mostly endowed with a rapid height growth in their youth, so that, at least when the competition for light starts with even chances, they may secure their share by growing away from their would-be suppressors. They can keep themselves in a mixed forest only by keeping ahead and occupying the upper crown level. The tolerant species, on the other hand, able to thrive in the shade of light-foliaged species, usually increase more slowly in height; but their capacity of 
shade endurance assures to them a place in the forest.

Many of them are characterized by a height growth which, though slow, is persistent; while the light-needing species, by falling behind in their rate of height growth, often lose in the end what they attained in their youth. As a result the shade endurers finally become dominant, and the light needers occur in the mixed forest only sporadically, the remnants or single survivors of groups, all the outside members of which have perished; and only when a wind-storm or insect pest creates an opening of sufficient size is a chance for their reproduction given.

Just as in the mixed forest the species are distributed according to their shade endurance, so in the pure forest of one species, or of species of equal tolerance, will the different-sized or differentaged trees develop side by side according to available light, each crowding the other, the laggards being finally killed by the withdrawal of light.

In a well-established young growth of white pine, the seedlings, some 50,000 to 100,000 on an acre, with their symmetrical crowns sooner or later form a dense crown canopy, excluding all light from the soil. After a few years the leaves of the lower branches, no longer able to function under the shade of the superior part of the crown and of their neighbors, fail to develop and the branchlets die and break off ; this natural cleaning, which secures 
the desirable clear boles, takes place during the period of rapid height growth, which occurs from the tenth to the thirtieth year. At the age of thirty years the trees are slender poles having a diameter of 3 to 5 inches, and a height of from 20 to 25 feet, with a few taller ones, the boles bearing a dense conical crown and beset for the greater part of their length with small limbs, the lower ones dead or dying. Not a few trees are seen to fall short of reaching the general upper crown level; the crowns of these laggards are shorter, more open, with fewer leaves on each twig. Others again will be found dead or scarcely vegetating, with crowns very poorly developed. In other words, we can recognize different vigor in development according to constitution and accidental opportunity, and can make a differentiation into development classes: the predominant, with their crowns 5 to 10 feet above the general level, which must finally make up the mature stand; the subdominant, still alive and; should accident remove some of the superior class, ready to occupy their air space ; and the dominated or inferior ones, hopelessly out of the race.

Of the tens of thousands which started only 2000 or 3000 are surviving, and as each tree tries to expand its crown, and secure for itself as much air space as well as root space as it can, the result is a continued diminution of the number of trees occupying the acre. 
This decimation is in exact mathematical relation, except for accidents, with the development of the dominant, especially in height growth. At the age of eighty, of the several thousand trees which started in the race, only a portion - not more than 400 to 500 - are left. Then the diminution proceeds at a slower rate, until finally only 200 to 300 occupy the ground, or as many as can conveniently fill the air space in the upper "story, the number varying according to soil and climatic conditions and species.

The time has arrived when the height growth is practically finished. The branches cannot lengthen any more to occupy the air space. After this a numerical change can take place only as a result of casualties, caused by fungi, insects, fires, or windstorms; these of course may also from the start interfere in the regular progress of adjustment which takes place under the effect of physiological laws.

In reality the conditions of soil, climate, and species in combination are so various that this process of evolution does not appear so simple, yet the seemingly lawless, yet actually law-directed, appearance of a forest growth explains itself by these few observations of the results of action and reaction of its surroundings and of the single components.

The factor of light is not only the most important one in bringing about the evolution of the natural forest, but practically almost the only one 
under control of man. With the knowledge of the light requirements and with the judicious use of the axe, the forester is enabled to stimulate or suppress one species or another, and to direct in quantitative and qualitative development the progress of his crop, and finally to secure the regeneration of entire forest growths with species that to him are most useful.

Not only is the composition largely a result of changes in light conditions, but the amount of production ceteris paribus is a function of the light, for the amount of foliage which the single tree can exhibit to the influence of light predicates the amount of wood it produces during the season, provided that food supplies are accessible.

The whole art of forestry, in its technical as well as in its financial results, is based upon the knowledge and application of the laws of accretion. Just as the manner in which composition and numbers arrange themselves is a result of recognizable laws of development, so the growth of the individual tree as well as the growth of the whole stand of trees in quantity and form is subject to laws which can be formulated. The mathematics of forest growth, developed by forest mensuration, ${ }^{1}$ reveal not only how, but how much, trees

1 The measurements to establish the progress of development are based upon the fact that trees grow annually in length at their tips by addition of shoots, and in circumference by the superposition of a layer of wood over those of former years, which in a 
and stands of trees grow, how much useful material they are capable of producing, and under what conditions the largest amount of the most useful material may be produced most quickly upon a given area, which is the principal aim of the forester.

As we recognize in the animal or in man certain periods of development which are each characterized by progress in certain directions, so we can in the tree individual recognize an infantile stage, the seedling first unfolding the characteristics of the plant, and occupied in forming organs of nutrition. This process continues more vigorously during the juvenile period or brush-wood stage, when the difference in inherited capacity is most pronounced, some species shooting rapidly upward - mostly light-needing species - while others first consume considerable time in developing a root system, a basis upon which the future persistent growth can establish itself. During this stage the difference in the rate of height growth of different species is greatest and we can speak of rapid and slow growers. After the juvenile period all species grow more or less alike during the brief adolescent or pole-wood period, the maximum rate of height growth occurring in the tenth to fifteenth year with the light-needing and in the twèntieth to fortieth year with the shade-enduring cross-section appear as the well-known annual rings, permitting a statement of relation of performance to time. 
species; then follows the even rate of the adult virile, or young-timber period, during which maturity and frequent seed production absorb part of the energy until the maximum height is reached, and in the senile or old-timber stage height growth stops altogether. The virile stage is of most uneven length, and here the "law of the lever" asserts itself often : those which grow most rapidly in their youth, as a rule, cease soonest to exert themselves, while the slow growers are persistent and finally overtower the rapid ones.

The diameter growth proceeds slowly until a fully formed crown and root system can elaborate the material to be deposited along the bole in annual layers. As these conditions improve during the adolescent period, so does the rate of diameter growth increase and the maximum rate does not occur until the fortieth to eightieth year, then very evenly declining into late life; but the area of a cross-section taken in any part of the bole, usually breast high, increases a considerable time after the diameter rate has begun to sink, as mathematical reasoning requires, the' deposit each year being made on a larger periphery.

Of greatest economic interest is the form development of the bole, which depends upon the manner in which the wood is deposited over the previous year's deposits. In well-fed trees, with fully developed crowns, standing in the open, so much food is elaborated that the lower portions. 
receive an excess, hence we find such trees with broad base tapering rapidly toward the crown; while trees of the forest, grown in denser stand, and having smaller confined crowns, elaborate less material, hence the lower portions do not receive so much, the result being a more nearly cylindrical form, or even taper.

In the volume development matters become more complicated, and we must differentiate it into parts, namely, the volume of the bole, and that of the branches, and brush wood, not to speak of the root growth, or, as is customary with foresters, we may consider the volume of the useful timber wood, namely, material over three inches in diameter, as differentiated from the brush wood, of smaller dimension.

In a tree grown in the open, the crown is apt, for a time at least, to develop at the expense of the bole, and the deposition of new material takes place more largely in the branches. At the same time, since under this condition the largest amount of foliage is at work, the largest amount of total wood is also produced by such single trees. In the forest the branch development is impeded by the neighbors, hence each single component of the forest not only produces less wood, but the distribution of the product is different, the valuable bole receiving more than the less valuable branches. Since open position secures quantity, dense position quality, we can conceive of such a position or density 
of stand that will secure the largest amount of deposit, compatible with the most useful form.

In general, the volume accretion of trees in full enjoyment of light experiences a constant increase in rate after the adolescent stage, and continues at such rate for a long time, of ten into old age.

Of course different soil and climatic conditions, as well as light conditions, influence the rate of growth, and the growth of different species also varies in amount. Here again the interesting law of the lever may be noted, namely, that on good sites the development is, to be sure, more rapid, but the culmination in the rate is also reached more rapidly, and the decline is more rapid. Similarly as regards species: those that start with a rapid growth usually reach their culmination sooner than the slower ones, and are apt to decline more rapidly in their rate, so that in the end the slow but persistent growers may outgrow the rapid ones in height, diameter, and volume.

In the forest, as we have seen, the individual trees experience an influence in their development from the shade of their neighbors, and as a result, a differentiation of trees into size classes, dominant and inferior growth takes place, and finally as a consequence the dying off of the latter, the diminution in numbers, which we have already discussed. Both height and diameter, as well as volume growth, of these various tree classes, together with the diminution in numbers, must be studied to determine 
the important question of volume development of stands. Hopeless as this would seem at first, it has been accomplished with tolerable success by German foresters, and a good beginning has been made for the species of the United States.

The general laws which have been deduced from the thousands of measurements made by the Germans are, within limits, applicable to our native species; they exhibit at least what the possibilities are under good management.

In the first place, these measurements show that, so far as weight of production is concerned, the same acre produces annually the same weight of dry material, with practically whatever species it may be grown, namely from 4000 to 8000 pounds per acre, according to the quality of the acre (see p. 123). In volume there is, to be sure, a considerable difference, due to the difference in specific weight of the wood of different species, and of the water contents; in other words, the trees with heavy wood would, ceteris paribus, produce less volume per year than the light woods. That the weight of vegetable product should be the same was logically to be expected, since on the same acre the active factors which produce assimilation and the potential energy of the soil remain the same, and the result in product must be the same. Nearly one-half of this product is represented by foliage and roots, and onefourth by brush wood and bark, leaving only about three-eighths available as useful wood material. 
According to climatic and soil conditions, which, in combination, are technically called "site," the annual production of available dry wood substance above ground, when the site is fully utilized, varies from at least 3500 pounds on the best sites to 1200 pounds on the poorest. This production remains the same, regardless of the number of trees participating in it, provided that the entire available light space be filled with active foliage, or, that, technically speaking, there is a full crown cover.

From this observation it appears that not the number of trees, but the density of crown cover, i.e. the intensity of utilization of the light, is the important factor in weight production, and, ceteris paribus, in volume production. In other words, there may be two and three times as many trees on the same area, and yet no difference in total volume. The difference due to numbers will appear in difference of the distribution of volume in more or less useful form; hence the proper gauging of numbers is one of the most important operations of the forester.

As we have seen before, in a dense young growth of nature's sowing, there may be 50,000 or more trees per acre, which, by natural thinning after the twentieth year, are reduced to 2000 or 2500 , and then diminishing steadily in number at a slower rate; at the end of the hundredth year only 200 to 250 occupy the upper crown level, or only ro per cent are left, 90 per cent having succumbed to the shading, or 
having become mere undergrowth. Hence, while on the whole the volume accretion has been increasing, there has been also a constant loss by the death of the inferior trees, a loss in volume which is equal to at least 30 to 40 per cent of the final harvest, and which, in part at least, can be saved by timely interference and utilization.

It is evident that, with the great variety of conditions possible, the rate of production of useful wood, i.e. wood of $\log$ and bolt size fit for the arts, varies greatly. Yet through painstaking analysis and classification of the collected measurements, it has been possible to construct for each species and site so-called yield tables, which under the premise of a fully stocked stand, i.e. full crown cover, and of proper practice in thinning out the dying trees, record the progress of volume accretion. These tables, then, are standards of measurement, with which the forester can compare his actual forest, to see how far he is away from the possible or normal conditions, and what he may expect to produce in the future. These state, for a given species and given site, usually in periods of ten years, the total amount of wood per acre which will have been produced every ten years, and possibly the different classes or sizes of wood, stated at least percentically, the number of trees to be present, their average height and diameter, and other similar information. For illustration such a table will be found in the Appendix. 
While in our natural unmanaged woods the final useful crop, which usually has accumulated over 200 years before it is considered fit for harvest, rarely exceeds 8000 cubic feet, in the managed German spruce forest, fully covering the ground, from which all useless species are eradicated, we may find at 30 years over 3000 cubic feet of wood, more than three times that amount at 60 years, and at 100 years 14,000 cubic feet of timber wood, having produced at the rate of 70 cubic feet during the first two decades, at the rate of 240 cubic feet in the third decade, reaching its maximum with 267 cubic feet in the fourth decade, declining after this decade so that in the ninth decade the rate may be only 100 cubic feet per year, and at 100 years the average rate for the whole period has become only 140 cubic feet. On poorer soils much less, down to one-half, of this production may be expected, and with other species, of course, the general progress of accretion and final result must differ; yet there is a remarkable regularity, a law of accretion observable in all conditions, upon which an analysis of the assiduously gathered data lets in a flood of light.

While the natural forest, if not interfered with by man or by accident such as fire, would follow, of course, the same laws, yet practically the result is a different one, because the economic point of view is left out, and tree weeds are mixed with the valuable species, thus naturally reducing the amount of useful production. 
But if we take the small stands here and there which occur in nature's forest, grown under similar premises as those of the tables, we will find, as would be expected, the same results; the stand has developed in the manner indicated by the tables.

These tables of normal forest yield can serve us as a goal which may be gained by a proper forest management; when the useful product of nature's forest can be trebled and quadrupled.

To illustrate the economic and practical value of the laws deduced from these tables we may state only a few of them. The so-called rapid growers, i.e. those trees which have'a rapid height growth in their youth, are, in the end, not the largest producers, if stout sizes are desired; the persistent growers, i.e. mostly the shade-enduring trees, produce relatively more in the long run. Hence, the rapid-growing aspen, which is near the end of its life at 80 years, may have then produced at best 7600 cubic feet to the acre, while the shady, slower, but persistent spruce has, by that time, accumulated over 12,000 cubic feet, and is still growing at the rate of over 80 cubic feet per year.

On good sites and with rapid-growing species, the culmination of the rate of volume growth occurs earlier than under opposite conditions, and then declines more rapidly, influencing, therefore, the most opportune time for harvest. For the Scotch pine the highest rate of production may be 
found on good sites between the twentieth and fortieth year, with over 160 cubic feet per acre, and on poorer sites a decade later; while the slowgrowing beech shows its culmination between the fiftieth and seventieth year, with 190 cubic feet per acre.

In general, the volume of a stand progresses much more slowly than that of a single tree, and much more regularly, since it expresses all the variable conditions. It is a matter of simple mathematical demonstration that the maximum average accretion occurs when it is equal to the current accretion, i.e. equal to the accretion of the particular year. In other words, when the accretion which has occurred through a series of years, divided by the number of years, happens to be as large as the accretion of the current year, the highest average production per acre and year has been attained. This occurs mostly before the fiftieth year with light-needing species and on good sites, later on poor sites and with shade-enduring species, but, to be sure, the value accretion, which depends upon the amount of large-sized material, culminates very much later.

If a group of some hundred trees have grown together in dense stand, they develop so regularly and interdependently that the following relations will prevail: the contents of the average tree will be found to equal very nearly one-tenth of the volume of the three stoutest and the seven slimmest 
trees which participate in the upper crown level, and the volume of the whole stand may then be closely approximated by multiplying this amount by the number of trees involved:

$$
\text { (vol. of stand } \left.=n \times \frac{3 \text { max. }+7 \mathrm{~min} .}{\text { IO }}\right) \text {. }
$$

If the trees are arranged in size-classes from the stoutest down, the average tree will be found to be at about 40 per cent from the stoutest. For instance, in 500 trees, the 200th tree, counting from the stoutest, will be the average tree. Moreover, if these trees arranged in size-classes are divided into five groups, the first fifth will contain 40 per cent of the total volume, the second fifth 24 per cent, the third 17 per cent, the fourth 12 per cent, and the last, the slimmest, will represent only 7 per cent of the total volume of all the trees.

These interesting deductions from the yield tables, which could be multiplied, are cited merely to impress upon the reader the fact that the forest grows under the influence of recognizable laws, just as the single tree does. If we differentiate the volume into the different sizes of material, logs of given diameter, cords of certain character, etc., expressed in quantities or relative proportions, and apply market prices, we can come to a conception of the value accretion of a stand at any particular time, and then can discuss upon a tangible basis the results of a forest management which may change at will the growth conditions and de- 
velopment of a forest stand to secure certain results in a given time.

Instead of computing total quantities, we can express the relationships in percentic proportions, conceiving the stand of trees as a capital, and the accretion as the interest on such capital, and speak of the accretion per cent as basis for the more complicated finance calculations. 


\section{CHAPTER VII.}

\section{METHODS OF FOREST CROP PRODUCTION : SILVICULTURE.}

THERE is nothing that needs to be more strongly emphasized and impressed upon the American public, and even upon the young professional forester, than that the main business of the forester is expressed in the one word "reproduction"; his main obligation is the replacement of the crop he has harvested, whether produced by unaided nature or otherwise, by as good, if not a better crop of timber than he found.

Silviculture, the technique of the growing of wood-crops, a branch of the broader subject of arboriculture, is the pivot upon which the whole forestry business turns.

As the farmer sows and reaps, so the forester harvests and replaces, although the methods of the two have little in common. Nor are the methods employed in other arboricultural pursuits applicable, such as the orchardist uses where the fruit is the object, or the landscape gardener, who looks for æesthetic effect, or the roadside planter, who desires the shade. 
The tree which satisfies these arboriculturists does not at all satisfy the requirements of the forester, for his point of view, his aim, is a different one and hence his methods are his own. In fact, single trees are not his object any more than the single grass blade is the object of the farmer; the largest amount of wood in the most salable or profitable form is his aim, logs rather than trees, and the financial results from their harvest. The final aim of the silviculturist is, therefore, attained only when he has removed the old trees and replaced them by a young crop. He grows trees in masses and for their substance. Not only does he deal with trees in masses, but with trees in natural conditions, being by financial considerations often limited in the use of artificial aids and methods, such as the other arboriculturists and the farmer in his crop production may employ.

Restricted as he is, or finally will be, to the poorer soils and conditions, those least favorable to agricultural production, he is forced to the most conservative management of the natural conditions in order to secure a desirable result without too much expenditure, which his long-maturing crop cannot repay.

The simplest method of harvesting the crop of nature and replacing it is to cut clean or clear the ground and plant or sow the new crop, the farmer's method. This is called "artificial reproduction" or "reforestation," and is largely practised in Europe. 
It is, of course, the only method applicable where the forest crop is to be started anew on abandoned fields, on the forestless prairies and plains, on the burnt areas which have grown up to useless brush, in short, where no old crop of desirable species is on the ground. Where an old crop of desirable kinds is already on the ground, the same method of clearing followed by artificial reforestation may be employed, but there is also a choice of producing the new crop by seeds falling from the trees of the old crop, by "natural regeneration."

This method is the one by which nature maintains the forest. As trees grow old, decay, and fall, an opening is made into which the neighboring trees throw their seeds and fill up the gap with a new seedling growth. The forester profits from this observation, and with the recognition of the laws under which forest growth develops, as detailed in the preceding chapter, he gives merely direction to this development in such a manner as to reduce the unfavorable and increase the favorable conditions of development for whatever kinds he may desire to propagate, avoiding the use of the planting tool, and managing to secure the reproduction and development of the young crop by the mere use of the axe in the old crop. But he uses the axe differently from the lumberman.

The lumberman, the first exploiter of the mixed virgin forest, treats it like a mine from which he 
takes the pay ore, culling the best kinds and cuts, and abandoning the rest to its fate, which is usually made hazardous by fires running through the forest, fed by the debris he has left.

If these fires have not killed the remaining growth, he may come back after a few years, and may find some of the smaller trees of the useful kinds, which he had left standing, grown to such a size as will pay to cut and transport to market ; these he calls "second growth." Possibly he may repeat this culling process several times; but finally the desirable kinds are cut out, and there is left a growth of undesirable kinds, of weeds which he has helped in their struggle with their rivals of useful kinds, by the removal of the latter.

Meanwhile, wherever an opening is made by the cutting of trees, seeds from the neighboring growth fall to the ground and sprout, giving rise to some aftergrowth, but this is apt to be preponderantly of the undesirable kinds which were left; moreover, this young growth under the shade of the old trees, being deprived of the desirable amount of light, develops slowly and poorly. As a result of these operations, then, not only the present composition of the growth is deteriorated, but also its future. Thus, in Kentucky, where the valuable white oak used to form 40 per cent of the forest, the aftergrowth contains hardly 5 per cent; and in Michigan, Wisconsin, and Minnesota, where the white pine has been culled out severely, its absence 
4

in the young growth has led to the curious belief among lumbermen that it does not propagate itself by seed.

The forester, on the other hand, treats the forest as a permanent investment and as a crop. All his operations keep in mind continuity and permanency for the future. Reproduction not only, but reproduction of the most useful kinds ${ }^{1}$ and superior quality is his aim.

The forester, instead of culling out the best kinds first, as the lumberman does, would take out the undesirable ones first, and thus improve the composition of his crop. The material which results from these so-called "improvement cuttings" may sometimes not directly pay for the labor spent on them, but they are cultural operations, designed to put the property in more useful condition for the future, and hence they are at least indirectly profitable.

When in this way the desirable kinds have been given the advantage (or sometimes simultaneously with the improvement cuttings), a gradual removal of these takes place, either of single individuals here and there, or of groups of them, making larger or smaller openings; or else more or less broad strips are cleared, on which the seed falling from the remaining neighboring growth can find lodgement,

1 Of the nearly 500 species native to our country, only about 70 furnish wood of sufficient size and quality to deserve the attention of the forester. 
and sprout; and, as the young seedlings require more light for their development, gradually more of the older timber is removed, or the openings are enlarged for new crops of young growth, and thus the reproduction is secured gradually, while harvesting the old crop.

Finally, when the last stick of old timber has been removed - and in a well-developed forestry system every stick is expected to be utilized a young growth composed as far as possible only of the more useful kinds has taken the place of the virgin forest, to grow until it becomes profitable to harvest again, when the same methods will secure another reproduction, and so on.

To be sure, these operations are not quite so simple as they appear from this statement, for considerable knowledge of the requirements of each species and judgment of the needs of the young crop for its best development are needed to secure a successful regeneration, two requisites secured by study and experience, which, for American species and conditions, are still lacking to a large extent.

The progress and manner in which the natural regeneration by seed is secured give rise to variously named methods and to various results in the appearance and development of the young crop; but in all of these so-called natural regeneration methods the young crop is secured by seed falling from the mother trees on or near the ground to be re- 
cuperated, and the old crop is removed more or less gradually, to make room for the young crop, the main difference being in the rapidity with which the old crop is removed.

The choice of method depends upon financial as well as silvicultural considerations.

In protection forests and luxury forests, in which the financial questions become secondary and the requirement of a continuous soil cover may be paramount, the choice of method is circumscribed by this consideration. Here, methods in which the old crop is very slowly removed and replaced by the new crop are indicated, even if financial and silvicultural results would make other methods desirable.

In supply forests, the cheapest method which secures desirable proportionate results in the crop is to be chosen. This must vary according to local conditions. Climate, soil, and species to be dealt with call for silvicultural considerations; the relative cost of planting and of logging or harvesting under different methods influence the financial results.

The clearing process followed by artificial replacement entails a money outlay for the latter from year to year; the gradual removal methods with natural seeding avoid, to be sure, this outlay, but, since to secure the same amount of harvest, a larger territory must be cut over, they entail large initial investment for means of transportation, which 
must be maintained for all the years of removal, and they occasion also otherwise greater expenses in the harvest than the concentrated logging in the clearing system, which may be done over temporary roads. Where, as in Germany, most forest districts are provided with well-built permanent road systems, gradual removal methods are often probably the least expensive; but in the United States, in most places, unless water transportation can be relied upon, a gradual removal system means heavy initial outlays for roads, which may make the clearing followed by planting the cheaper method. It is in most conditions also the surer; for a complete success of the young crop can, in most cases, be forced. In the natural regeneration methods there are elements of uncertainty, the seed years may not come when expected; in a mixed forest, which, for many reasons, is the most desirable form, the species seed irregularly, have different requirements of light, so that the composition cannot be very well controlled; the damage and loss occasioned in the young crop by the removal of the old crop must be discounted in the final result; and besides, where the removal is very slow, the young crop is impeded in its development by the shade of the old crop. These systems, therefore, are better adapted to shade-enduring species than to light-needing. The main argument and the most important in favor of these methods is that they furnish protection to the soil, preventing its 
deterioration under the influence of sun and wind, to which the soil is liable in a clearing system, and giving also protection to the tender seedlings of such species as are subject to frost or drought. Under such conditions, therefore, i.e. where protection of soil and young crop are necessary, the gradual removal methods will be chosen.

Over 80 per cent of the forests of Germany are managed under a clearing system and rapid removal systems, and only 20 per cent under slow removal and other systems.

Where, as in our culled forests, the valuable species have been removed and the weed trees have been left in possession, it stands to reason that no natural regeneration method will reëstablish the better species; they must be restored by artificial means. Finally, where conditions permit, a combination of natural and artificial methods may be resorted to in order to secure the best result.

The crudest, least intensive method is an improvement on the method of the lumberman, who culls the best trees here and there, the so-called method of selection. The improvement over the lumberman's practice, who is concerned only in the removal of the useful timber, consists in looking somewhat after the fate of the young growth, protecting it against competing species, giving it light as soon as practicable by further culling, and improving the composition by reduc- 
ing the weed trees and also leaving more. seed trees.

The result is a forest in which all ages and sizes are scattered over the entire area, coming nearest to the conditions of nature.

This system, in which the young crop has a poor chance to develop, and which is applicable to shade-enduring species only, is recommended for protective forest areas. In Germany it is applied only on small areas and on the steepest slopes, less than Io per cent of the German forest area being managed under it, and in the Prussian state forests, less than $\frac{1}{2}$ per cent.

The continuous soil cover, to be sure, is a feature which is its greatest recommendation, but this is secured at great expense and loss in accretion.

To permit a better chance for the young growth, the so-called "group method" has been lately devised, in which not single trees, but groups of trees, are removed and the opening is expected to be seeded by the neighboring trees. From time to time, as soon as the young growth is well established, the opening is enlarged and additions of young growth secured in the form of an irregular ring or band around that of preceding years.

An older method, similar to the last, consists in making the opening in the form of a narrow strip at right angles to the prevailing winds, and as the ground is seeded to clear a new strip toward the 
windward side. This "strip method," just as any method which relies upon the seed furnished by a neighboring growth, is more successful with those kinds which have light-winged seeds, easily carried by the winds over the area to be seeded, and which do not require any protection in their infantile stage. It is a method which, on account of the greater concentration in harvest, is probably advisable in many cases in the United States.

For heavy-seeded kinds like oaks, beech, hickories, and other nut trees, the more complicated method of "regeneration under shelter wood or nurse trees" becomes necessary ; this consists in a series of severe preparatory thinnings of the old crop which is to be reproduced, beginning a year or more before the time when a full seed crop is to be expected, seed years recurring more or less periodically. These preparatory thinnings are made for the purpose of exposing the soil to atmospheric influences, which hasten the decomposition of the litter, thereby securing a serviceable seed bed. Enough trees of the kind to be reproduced are left on the ground to secure full seeding and shelter and protection of the young crop. When the latter has come up, the nurse trees are gradually removed to give the young seedlings the required light. The whole operation, until the last nurse trees are removed and the young crop is established, may take from three to ten and more years, according to kinds, soil conditions, climate, and success 
in securing the seeding. The greatest nicety of judgment is required to direct these operations, taking into account the requirements of the species and the conditions and progress of development of the young crop.

To secure a full crop by this natural method often requires, not only careful manipulation, but patient waiting for years, since trees do not bear seed every year and the young crop may from this or other causes fail to establish itself wholly or in part, when another seed year must be awaited, or the "fail" places filled out artificially by planting.

The artificial reforestation may be made either by sowing the seed or by transplanting seedlings secured from nurseries or from the woods. This planting or sowing is done after more or less careful preparation of the soil, the preparation and manner of planting depending on soil conditions, species, and financial considerations.

Simple and effective as these artificial methods are, there are certain dangers connected with them, which follow their injudicious application. The exposure of the soil may lead to its deterioration, the sun-warmed areas are apt to breed insects, the standing timber, exposed to sweeping winds, may be thrown when the opening is large.

Where in a natural seeding a hundred thousand seedlings would cover the soil and quickly replace the shelter removed in the old growth, economy will permit the planting of only a few thousand 
(usually 2500-5000 per acre), and it requires years before the crowns of the young growth close up to shade the ground thoroughly, meanwhile weeds and grass sapping its strength and retarding the development of the crop. Nevertheless, by a judicious application, making the openings small, utilizing the shelter of some left-over trees for partial protection, increasing the number of plants, or sowing a cheap nurse crop, these dangers may be avoided.

Theoretically, however, the regeneration under shelter wood with a short period of removal is considered the most efficient.

While all these methods rely upon a reproduction of the new crop by seed, directly or indirectly, there is another mode of reproduction possible, owing to the capacity of some trees to reproduce new parts from buds, forming shoots from the stumps after the old tree is. cut. These stool shoots, or sprouts, grow into trees, and by the mere harvest of the old crop, the new crop is secured. This, in turn, may be cut, and the stump will produce again and again new sprouts. This simplest and crudest system of reproduction, called "coppice," which results involuntarily when the old hardwoods are cut, is applicable only to the broad-leaved trees which are capable of producing valuable shoots in this manner; the coniferous trees, like pines, spruces, etc., are practically excluded, although some possess the capacity of sprouting in inferior degree. 
Even in broad-leaved trees the capacity for sprouting is possessed in different degree by the different species, and is more or less lost by all in old age; and especially after repeated harvests the stumps become exhausted and die, so that the forest is apt gradually to deteriorate in composition as well as in density, unless fresh blood is added by reproduction from seed.

Thus in Pennsylvania, where the system has been in vogue for a century and more to furnish charcoal for the iron furnaces, the valuable white oaks and hickories have been crowded out by the chestnut, which is a superior sprouter; similarly, in Massachusetts the inferior white birch replaces the more valuable kinds in the coppice, as their stocks weaken and fall a prey to rot.

Another disadvantage of this coppice system under which the woodlands of deciduous trees in almost all New England and the Atlantic States are reproduced is that, although the sprouts develop much faster than the seedlings from the start, they soon fall off in their growth, and are capable merely of furnishing small dimensions and fire wood. The coppice, therefore, is useful only for certain purposes, but cannot be relied upon to furnish material for the great lumber market.

The deterioration consequent to the continued application of the coppice is best studied in Italy and in certain parts of France, where serviceable 
timber is almost unknown, and fagots of small fire wood are precious articles.

To avoid this objection a mixed system has been practised, by which part of the crop (the so-called standards) is allowed to grow up and be reproduced by seed, while the other part is treated as coppice; but in this so-called standard-coppice (Ger. Mittelwald, Fr. taillis composé) the standards, unimpeded in their branch development, do not form serviceable trunks, and in addition, by their shade injure the coppice growth.

While, then, these methods are of limited use, the only method of reproducing the forest which is to serve as a basis for the supply of the enormous quantities of saw timber required in the markets is the so-called timber forest, the high forest, Hochwald of the Germans, or futaie of the French, which is reproduced by seed, and grows to full size and maturity, to be again so reproduced.

As in the natural methods the axe is the only tool which is used to secure the regeneration, so is the axe the only tool which cultivates the young crop, such cultivation consisting in the judicious removal of surplus trees by the so-called thinnings, by which the quantity and quality of the crop is increased. To understand this, it is necessary to know that trees form wood by the function of the foliage under the influence of light.

Hence a tree with much foliage and unimpeded access of light is bound to make much wood. 
These conditions are fulfilled when the tree is allowed to grow in open stand, as on a lawn, without close neighbors, who would cut off some of the light supply.

But trees under such conditions grow mostly into branches, the crown being developed at the expense of the bole, which remains short and more or less conical in shape, of little commercial or technical use, except for firewood; when the trunk is sawn into boards every branch appears as a defect, known as a knot, which makes it unfit for use in the better class of work, and thus, while the total quantity of wood in the tree is increased by the open stand, it is done at the expense of quality.

The object of the forester, however, is not simply to grow wood, but to produce wood of such form and quality as is useful in the arts. The ideal tree for him is one with a long, cylindrical, branchless trunk, bearing its crown high up, which when cut into lumber produces the largest amount of material clear of knots, of straight fibre, and giving the least amount of waste or fire wood.

His aim, therefore, must be to so place his trees that, while the largest possible amount of wood shall be produced, it shall be deposited in the most useful form also.

By a close position, when each tree cuts off the side light from the neighbor, the formation of branches is prevented, or the branches which were 
formed, being overshadowed, soon lose their vitality, die, and finally break off, leaving the shaft smooth, and, if this clearing was effected before the branches had reached considerable size, the amount of clear lumber is increased.

But again, if the trees are kept too close, if too many trees are allowed to grow on the acre, each one having the smallest amount of foliage and light at its disposal, the amount of wood produced by the acre may be fully as large as it is capable of producing, but it is distributed over so many individuals that each develops at the very slowest rate, and hence does not grow to useful size in the shortest time.

To secure his object, producing the largest amount per acre of the most useful wood in the shortest time, the forester must know what number of trees to permit to grow, so as to balance the advantages and disadvantages of close and open position.

This number differs not only according to the species composing his crop, but also according to soil and climatic conditions and to the age of the crop, as we have seen in the preceding chapter.

Some trees, having considerable capacity of enduring shade, like the beech, sugar maple, or spruce, may require many more individuals to the acre than the more light-needing oaks or pines; on richer soils fewer individuals will produce 
satisfactory results, when on poorer soils more individuals must be kept on the acre. The question of the proper number of trees to be allowed to grow per acre at different ages is one of the most difficult, on which practitioners differ widely. In general, however, the practitioner has recognized the necessity of preserving a dense position for the first twenty to thirty years of the young crop, sacrificing quantitative development to quality and form. The close stand secures the long, branchless, cylindrical trunk, which furnishes the clear saw-logs of greatest value. Then, when the maximum rate of height growth has been attained, a more or less severe thinning is indicated, in order to secure quantitative development, and these thinnings are repeated periodically, to give more light as the crowns close up, and also to utilize such of the trees as are falling behind in this wood production.

As a result of judicious thinnings, the rate at which the remaining crop develops may be doubled and quadrupled, the heavy, more valuable sizes are made in shorter time, and, where the inferior material removed in the thinnings is salable, a much larger total product is in the end secured from the acre, for many of the trees which were removed and utilized would have died, fallen, and decayed in the natural struggle for existence.

In German forest management the amount utilized in thinnings amounts to 25 per cent and more of the final harvest yield. 
Other considerations also influence these operations, such as the preservation of soil moisture, which is the most essential contribution of the soil to tree growth, and which requires the soil to be kept shaded.

In fact, there is nothing that a forester guards so jealously, next to the light conditions at the crown, as the soil conditions: a soil cover free of weeds and grass, and covered as amply as possible with a heavy mulch of decaying leaves and twigs, and if this best protection of the soil moisture be deficient, a cover of shrubby undergrowth which requires less water than weeds and grass - this is the character of a desirable forest floor.

Altogether it will have appeared that the entire silvicultural requirements of the crop resolve themselves into one, namely, proper management of light conditions, which is secured by the judicious use of the axe.

While in field crops it is customary to grow only single species, in pure stands, the forester has discovered that, as a rule, not only better results, both in quantity and quality, but better protection of soil conditions and especially safety against many dangers from insects, frosts, and storms, etc., can be secured by mixed plantations, and hence he gives preference to mixed crops, although such crops, composed of several species, require more skill in their management.

While the crop is developing, it is, of course, 
necessary to protect it against damage of various kinds. The young seedlings of some species are apt to suffer from frost or drouth, which is avoided by growing them under shelter of older trees, by draining wet places, securing opportunity for cold air to draw off, etc., - mostly preventive measures. In prairie and plain it may'be possible to assist their resistance to such damage by cultivating the ground as the farmer does, but in the real forest country such means are excluded by the character of the ground, and the expense. Altogether the only practical remedies lie in the direction of foreseeing the damage and guarding against it.

Animals, and especially insects, are frequently injurious to the young crop, and insects also to old trees, by their defoliation. This damage, too, can be largely obviated by preventive measures.

Since many, if not most, injurious insects are monophagous, i.e. feed on one species, or at least one genus, mixed forests resist their damage better, since the number of host plants is reduced and the intermixed trees impede progress and development of the pest. Fewer insects develop in the dense shade and on vigorous, healthy plants, hence they can be kept in check to some extent by keeping the crop dense and in vigorous development, when it can resist the attacks; and also by keeping the woods clean of débris, dead and dying trees, in which insects develop; finally, as ultima ratio, 
positive measures must be resorted to for collecting and destroying the broods of insects before they have time to do damage. Considerable amounts of money are spent in this direction in European forest management, amounting in ordinary times to from one-half to one cent per acre, but, from time to time, the pests break out in such numbers that no remedies will avail. ${ }^{1}$ Some loss must be sustained, which is, however, of less moment if the crop had already developed to suitable size and can be harvested when the trees have been killed.

Wind-storms are a danger to older timber, especially of shallow-rooted species, like the spruce, and on soft soils and exposed slopes or mountain tops. Here care must be taken in keeping the stand well thinned, so that the trees may get accustomed to the swaying of the winds in more open stand. In this way they are induced individually to form a better root system and become wind-firm, while in the dense stand their strength was only in the union with neighbors.

Under conditions where damage from windfall is to be expected, it becomes necessary to arrange the felling areas so that no stand of old timber be suddenly exposed to the prevailing winds by the

1 In Bavaria, in one year ( 1891$), \$ 500,000$, or 20 cents per acre of property and $\$ 1.80$ per acre infested, were spent in combating one insect, the nun, without much effect. The premature harvesting of $60,000,000$ cubic feet was the result of the damage. 
removal or harvest of a neighboring stand. Since the prevailing winds in the northern zone come mostly from the western direction, it is sought to secure an arrangement of the stands of different age in series (a "felling series"), so that the old and tall timber is found at the eastern end, the age classes grading off to the west, the youngest at the western end, and the tops of the series of stands ideally appearing like a roof slanting down from east to west. It is apparent that, under such an arrangement, the old timber can be harvested and reproduced without exposing any stands to the force of the wind, and the young timber is growing up under the influence of winds and becomes windfirm.

The greatest danger to forest properties, however, is fire, and the protection against this most unnecessary evil, resulting mainly from man's carelessness, absorbs a large part of the energy of the forester. Proper police, but also silvicultural measures, reduce the amount of danger and damage.

The damage which fire occasions is very variable, according to a variety of conditions. Most forest fires are confined to the forest floor, running in the litter and young wood, scorching the older trees merely; yet, under favorable conditions, the fire may run up the trees, becoming a crown fire and propagating itself from top to top and throwing firebrands and sparks to the ground, often for long distances. 
Young crops, during the seedling and brushwood stage, are readily killed, while older timber may stand scorching without much or any damage. Different species behave differently in this respect. The giant trees, or Sequoias, covered with a dense bark more than a foot thick, and their wood hardly inflammable, the Douglas fir, with a similar protection, are less liable to be damaged than the thin-skinned firs or spruces, beech or white birch and aspen. The green, succulent foliage and wood of broad-leaved trees is more resistant than the dry resinous foliage and wood of conifers. Drouthy conditions and dry soils are more likely to induce danger from fire damage than the opposite conditions. Finally, the presence or absence of an undergrowth, or débris, of dead and dry branches of trees, and the character of the forest floor, must make a difference in the ease with which a fire may start and run, the amount of heat it develops, and the consequent damage.

The damage may consist in the total loss of the crop, which is usual until the pole-wood stage is reached. In pole wood and young or old timber the trunks may be only blackened, but more often the cambium layer below the bark is partially or entirely killed, causing either the death of the tree, especially when recurring fires accumulate the damage, or secondary damage results through rot or insects which develop, especially in the weakest trees. 
A damage even greater than the loss of the crop is experienced in the loss of the soil cover, the litter and duff, which is the forester's manure. This loss may become irreparable in localities where only a thin layer of mineral soil overlies the rock, and the opportunity for starting a new crop. may be entirely destroyed. The fire danger in the United States is so great that in many localities it almost prohibits the practice of forestry; for who would want to invest money and energy in a property which is exposed to extra risks from fire by the absence of proper legislation, or by the lack of police and moral support on the part of the community in enforcing it, by the unpunished negligence or malice of incendiaries, and by the populational conditions of the country, which prevent the economical disposal of the débris from logging operations.

The last-mentioned difficulty is perhaps the most important, because practically almost impossible to avoid. There must, especially in our virgin woods, always result from the harvest of the useful material a large amount of débris, tops, branches, brush, and other waste, which cannot be marketed; and this not only impedes the development of a young crop, but adds to the danger from fire until decay has reduced the débris, which often requires many years, even decades.

The proposition has been made to burn the débris after the logger. This is not as simple and 
inexpensive as it appears, when care is to be taken not to damage the remaining growth and especially when natural regeneration is to be practised, or a young crop, already in part provided by nature, is to be saved.

Where the culling is made light, only here and there a tree being taken, especially in the mixed forest, the amount of débris also is small and it may be left to natural decay, with the only precaution that the branches of the top are lopped so as to have the whole mass come into as close contact with the ground as possible, when the decay proceeds more rapidly.

But where the culling is severe, as is often called for in pure woods and also in mixed stands, and a large amount of débris results, even this lopping of tops is of no avail; the fire risk continues for many years. Incessant watching during the dangerous season is necessary, and even this proves futile, for a fire, easily started by the slightest carelessness or by lightning, ${ }^{1}$ will run in the débris so fast that no human power can stop it.

1 Although undoubtedly most fires are the result either of malice, foolishness, or carelessness, namely, by smokers, campers, farmers in clearing brushlands, and others using fires, locomotives throwing sparks from smoke-stacks and ash-pits, the writer can attest that lightning is occasionally the cause of fires. The old "snags," dead trees, the result of previous fires, are especially liable to be struck by lightning, and being dry, they burn, and propagate the fire either by the flames burning down to the ground, or else by sparks and burning limbs falling to the ground; but the writer has also seen live 
Partial burning and piling of the brush reduce the danger somewhat, but hardly in proportion to the expense. The readiest remedy, where forestry is to be practised under such conditions, is to make a clean sweep, that is, clearing, burning up the débris, and replanting, or else, if natural regeneration is to be relied upon, adopting the strip system, when the opportunity of burning the débris totally is still possible.

The danger from the débris continues longer in coniferous woods than in the deciduous-leaved, the wood of -which decays more readily in contact with the ground, although usually, in these latter, larger amounts of débris result. For instance, in the hardwood forests of the Adirondacks, the merchantable $\log$ material presents only one-third of the total amount of wood, two-thirds being cordwood and débris. The only hope here, in the absence of a paying home market for fuel from this inferior material, is to establish chemical works for its conversion on a large scale into charcoal, acetic acid, wood alcohol, and other useful manufactures.

trees, even of hardwoods, blaze when struck by lightning, and propagate the fire in spite of a pelting rain. Of 509 fires occurring in the Bavarian state forests during 6 years, 4 were demonstrably accredited to lightning and 7 to locomotives. Of 156 conflagrations in the Prussian state forests during 1o years, 3 were the result of lightning and only 4 from locomotives, 7 years out of the ro being without any record of fire from this last cause, and that on a property of $7,000,000$ acres, over half of which was stocked with pine on dry sandy soil 
In fact, the application of silviculture, i.e. the systematic production of wood-crops as a business proposition, in our culled, mismanaged woodlands throughout the United States is, in most cases, possible only where the means exist of utilizing this inferior material; for the risks from fire are too great, or else the cash which would otherwise have to be spent in making room for the young crop will surely exceed reasonable proportions. Only the state or other long-lived corporations can afford to spend money now in the hope of adequate returns in a distant future.

That it is finally possible to reduce the fire danger to a minimum by proper police regulations and by silvicultural measures, and by proper management and organization, is attested by the forest fire statistics of the German forest administrations, to which we have already referred on pp. 137 and 190.

To these we may add that in any given longer period within the last 25 years the acreage destroyed in Prussia or Bavaria (about 10,000,000 acres) rarely exceeds .005 per cent of the total forest area under state control. In a recent report ( I 896) we read of "very considerable damage by fire" occurring in the Prussian state forests, referring to the burning over, not total loss, of 2500 acres. One fire is reported as destroying 1000 acres of a "hopeful" pine and spruce plantation 20 to 25 years old. In the next year (1897) the entire loss 
was not over IOO acres. This comparative immunity is due to both administrative and police regulations.

The Indian forest administration, under circumstances not much less difficult, nay, perhaps more difficult, than those prevailing in the United States, refutes the assertion that forest fires may not be suppressed.

Not only have the people of all timbered parts of India practised the firing of woods for many centuries, for purposes both of agriculture and pasture, but the natural conditions in many of the Indian forests are such as to discourage the most sanguine.

The forest in most parts is a mixed growth, of which a considerable portion is valueless and is left to die and litter the ground with dry and decaying timber, furnishing ready fuel. A dense undergrowth, largely composed of giant grasses and bamboo, covers the ground, green or dry, to which is added a mass of creeping and climbing vegetation. It is a dangerous forest, with hot, dry winds to fan the flames; and yet the forest department fights and prevents fires, and succeeds in a measure. The efficiency of protection has constantly increased with perfection of methods, and the expenses have never exceeded \$IO per square mile in any year on an area of over 30,000 square miles, of which, in 1895 , not more than 8 per cent experienced damage. The police regulations 
which lead to such results will be discussed in a succeeding chapter.

Here the preventive silvicultural measures and arrangements in the forest, which are designed to reduce the fire danger, are to be only briefly enumerated.

The experience that deciduous-leaved woods are less liable to danger suggests the maintenance of mixed forest; the fact that old timber is comparatively safer, and that on large wind-swept areas the heat and the rapidity of progress of a fire is increased, leads to distributing the felling areas, and that means the areas of young crop, isolating them, making them smaller, and having them surrounded by older timber. Removal of the dead and dying trees by systematic thinnings wherever possible, and the disposal of the slash from logging operations, are obvious means of reducing the danger.

In German forest districts, more especially those unduly exposed to fire danger, a subdivision of the forest into blocks surrounded by avenues, or socalled rides, of 8 to 40 rods width, is made. These rides, kept free from inflammable material by annual burning, or perhaps by sowing to grass, serve the purpose of confining the fire within the block, and furnishing a base from which to fight a fire, for which the frequent roads may also be utilized.

But these openings are worse than useless unless kept in proper condition, and unless the forces to 
fight the fire are on hand, for if débris is allowed to accumulate on them, this dries out more readily, and, in addition, the draft of air along the rides only increases the fury of the fire. In older deciduous-leaved woods the shade keeps the ground moist, the fire runs more slowly, and a wider opening would in most cases prove undesirable.

The same may be said regarding rights of way for railroads. The wide swath usually made, and usually not kept clear, but rather accumulating inflammable débris, exposes the soil to the drying effects of sun and wind, and besides, creates drafts of air, fanning the sparks into flame. There would be more safety in a narrower opening, which the shade of a dense stand of timber, especially if of deciduous-leaved trees, would keep moist, with a tendency to extinguishing the sparks. The objection that the falling of trees would impede and endanger the traffic might be overcome by gradually removing those liable to fall.

Through specially endangered districts, i.e. in coniferous forest, safety strips running along the right of way may be maintained. On these, on both sides of the track, a strip of ground 25 feet wide is entirely cleared of all inflammable material, which may, if practicable, be used for farm purposes; this is skirted by a strip of woods 50 to 60 feet wide, which remains wooded, acting as a screen for the sparks from locomotives, but is also kept clear from inflammable materials by annual raking 
and burning. Where this is not sufficient, a ditch 5 to 6 feet wide and a foot or so deep is opened on the outside of this strip toward the endangered woods, the soil being thrown toward the track side and possibly planted with a light-foliaged, deciduous-leaved species; cross ditches through the safety strip every 300 feet add further to the safety by confining any fire within reasonable limits. The whole arrangement requires not over 200 feet, and that mostly usefully occupied, while furnishing almost absolute security.

Such a system would be applicable in many cases in our own country. It would, with some slight changes, be perfectly feasible, and in the end profitable, for railroad companies to grow their tie timber in this way, using such light-foliaged rapid growers as black locust, catalpa, etc.

Forest crop production as a business, silviculture, will become practicable and profitable in this country only when reasonable forest protection is assured by proper exercise of state functions.

Until this is secured, lumbermen will continue to exploit the natural forest without much regard to its fate after they have secured its present valuable stores, for they cannot afford to assume the hazard of the fire danger.

Before positive silvicultural methods are applied by them, they may find it advantageous to cut the virgin forest more conservatively, they may find that it pays in the long run better not to cull too 
closely, that it is advantageous to leave more of smaller sizes, i.e. to limit the diameter to which they remove trees, so that they may return sooner for a second cut, and also to avoid unnecessary damage to the young volunteer crop. At present the limitation of size to be cut or to be left uncut is based upon calculations of immediate profits to be derived, and does not take into account any future considerations, since the lumberman does not cut with a regard to the future, but attempts to secure the largest present gain. He views the forest as a mere speculation. To curtail his present revenue for the sake of a future revenue by abstaining from cutting all that is marketable is the first step toward changing this point of view, introducing the idea of continuity, and treating the forest as permanent investment.

It must be understood, however, that the limitation of the size of trees to be cut or to be left uncut has not necessarily any bearing on the replacement of the crop; it is not silviculture. It is in the main a financial measure, it being demonstrable that it pays better to leave small-sized trees to accumulate more wood before utilizing them, or else a device to prevent overcutting of a valuable ispecies, so that it may not be eradicated too soon, a wise measure wherever systematic attention to positive silviculture çannot be given. 


\section{CHAPTER VIII.}

\section{METHODS OF BUSINESS CONDUCT: FOREST ECONOMY.}

As in every technical industry concerned in production, so in forestry the methods of the technique - the technical art - are distinct from the methods of the business conduct. Silviculture represents the technical art of forestry; while under the comprehensive term forest economy we may group all that knowledge and practice which is necessary for the proper conduct of the business of forestry.

Besides the purely technical care in managing the productive forces of nature to secure the best attainable quantitative and qualitative production of material, - the highest gross yield, - there must be exercised a managerial care to secure the most favorable relations of expenditure and income, the highest net yield, a surplus of cash results without which the industry would be purposeless from the standpoint of private enterprise and investment. Moreover, an orderly conduct and systematic procedure to secure this revenue is necessary. 
Carried on by government activity for reasons of general cultural advantages, the net yield or money profits may be considered secondary, or perhaps may be dispensed with. It may even appear rational to carry on forest management at a loss, for a time at least, just as is done in many other forms of public works, because of the indirect benefits derived from it, and for internal improvement. Nevertheless, even in that case it would be desirable to organize and to carry on the business of forest cropping systematically, with a view of bringing into relation results and efforts, i.e., of counting the cost.

It is possible, also, to practise the art of silviculture incidentally, as the farmer does, or can do, on his wood lot, without special business organization and elaborate planning, the owner harvesting and reproducing and tending his crop whenever needful; but the case is different if forest growing is to be carried on as a business by itself with a view to continued and regular procedure, to continued and regular revenue; in that case more elaborate planning becomes necessary.

The one peculiarity which distinguishes the forestry business from every other business is the time element. The forester cannot harvest annually what has actually grown (the current increment); the forest crop, as we have seen, must accumulate the accretions of many. years before it becomes mature, i.e. of sufficient size to be useful; 
hence, unless special provisions are made in the management of a forest property, the crop and the revenue would mature and be harvested periodically only, and that in long periods; from twenty to a hundred years and more would elapse from the sowing to the reaping.

The farmer may be satisfied to practise on his wood lot attached to his farming business what is technically called an "intermittent." management, harvesting and reproducing from time to time without attempting to secure regular annual returns. But when forestry is to be practised as an independent industry, it becomes desirable, as in any large mercantile establishment, to plan, organize, and manage the business so as to secure, continuously and systematically, a regular annual income nearly equal or increasing year by year.

The lumberman or forest exploiter also plans and organizes his business for annual returns, not, however, to be derived continuously from the same ground; he seeks a new field, he changes his location as soon as he has exhausted the accumulated stores of his forest property, which he then abandons or devotes to other purposes than woodcropping.

The forester's business is based upon the conception of what is technically called the "sustained yield" (Ger. Nachhaltigkeitsbetrieb, Fr. Possibilité), a continued systematic use of the same property for wood-crops, the best and 
largest possible; this is secured by proper attention to silviculture, reproducing systematically the harvested crop. Finally, when the industry is fully established, he is annually to derive this "sustained yield" as far as practicable in equal or nearly equal amounts forever, under an "annual sustained yield management." This is secured by means of forest regulation, the principal branch of forest economy, ${ }^{1}$ which comprises the methods of regulating the conduct of the business so as to secure finally the ideal of the forester, - a forest so arranged that annually, forever, the same amount of wood product, namely, that which grows annually on all his acres, may be harvested in the most profitable form.

- As in every business there is an ideal, a standard in conduct and condition, which the manager more or less consciously recognizes and follows, or seeks to establish, yet, on account of uncontrollable circumstances can never quite attain, so is the ideal of the forester never quite attainable, although it is his obligation to attempt and approach it as far as practicable.

The ideal conduct of the management " for annual sustained yield" is possible only under the ideal

${ }^{1}$ For this branch of forest economy a number of terms have been used, such as "forest organization," "forest valuation," "working plan," "yield regulation," "forest management," which either linguistically are not commendable, or else single out a part of the work of the "forest regulator" to designate the whole. 
condition, which the forester recognizes in the "normal forest," the standard by which he measures his actual forest and to which he desires, as nearly and as quickly as circumstances permit, to bring his actual forest. The latter will usually be found abnormal in some one direction, or in several directions, and hence make the ideal conduct impossible. The object of forest regulation, then, is to prepare for the change of an abnormal forest into a normal forest.

In simplest terms, the normal forest is a forest in such condition that it is possible to harvest annually forever the best attainable product, or to secure continuously the largest possible revenue. The conception and schematic description of the normal forest we have already elucidated on p. I $28 \mathrm{ff}$. It was there shown that such a forest must contain as many stands, varying in age by years or periods, as there are years in the rotation ( $r=$ normal felling age) i.e. normal age classes must be present, so that an annually equal normal felling budget $(r i=I)$ might be harvested, the reproduction being looked after, and the best possible, i.e. normal accretion (i), being secured by silviculture. As a result of these two conditions the normal stock $\left(S_{n}\right)$ would be present, which would permit the desired annual sustained yield management. We found that the normal stock, varying in actual amount, of course, according to species, site, silvicultural system, and especially length of rotation, is found by summing up 
the arithmetical progression represented by the accumulated increments of the age classes, and that it assumes the general expression $S_{n}=\frac{r I}{2}$; that is to say, half the accretion which takes place throughout the rotation forms the normal stock, which must be maintained for a sustained yield management, the other half furnishes the harvest or yield during the rotation. On p. I 30 examples of the actual volume and value of normal stock under different conditions were given.

While we have assumed, for the sake of simplicity of conception, that the stands of different age, the age classes, are separate in area one from the other, it is readily conceivable that all, or some of them, may be mixed together, on the same area as in the selection forest, where all age classes, from the seedling to the mature timber, are mingled; and if there are enough trees in gradation from the older to the younger, allowing for losses, so that the younger age class can replace in amount the older as it is removed or is growing out of its class, we would have arrived at normal condition for the selection forest.

In the actual forest some one condition or all conditions will usually be found abnormal. The normal accretion may be deficient, because the area is not fully stocked or the timber is past its prime, old timber growing at an inferior rate, or rot offsetting increment. The age classes are usually not 
present in proper gradation and amount; some of them are probably entirely lacking, others are in excess, either too many stands of older or of younger timber, so that even if the normal stock of wood in amount be on hand, it may be in abnormal distribution.

The normal accretion can, of course, be established only by silvicultural methods. The other two conditions are attained or approached by regulating the felling budget in area and amount, so that gradually the age classes and the normal stock are established. Various methods are employed to determine the actual felling budget, which will gradually lead to the final possibility of the normal felling budget.

The simplest method would be to divide the forest into as many areas as there are years or periods in the rotation, and cut one, or the equivalent in volume, every year or during every period, when after one rotation the age classes are established. If proper attention has been given to the reproduction and to keeping the reproduced areas fully stocked, the normal conditions are attained after the forest has been once cut over, i.e. during the first rotation. But this would burden the present generation with the entire cost of securing the normality; at the same time necessitating not only unequal felling budgets, as better or poorer stands are cut, but also requiring that the harvest of timber past its prime be deferred, if the forest 
is largely composed of old age classes, or that immature timber be cut prematurely, if young age classes predominate, - in either case a financial loss. Indeed, the greatest practical difficulty which confronts the forest regulator is found in gauging the sacrifices which the present must make for the sake of the future.

To overcome the difficulty of unequal felling budgets in part, the so-called "allotment methods" were invented, which try to distribute the felling areas so as to equalize the budget, the area allotment providing for equality of felling areas, the volume allotment for equality of volume, and the combined allotment securing both, the main stress of these methods being laid on the establishment of normal age classes, from which finally the normal stock results. The simplest form of these methods, which is now in practice in Saxony and elsewhere, determines the felling budget only for the next decade in such a manner that the future will find a sufficient amount of stock on hand to secure an approximately sustained felling budget, determined from decade to decade.

The most logical, although practically not always readily applicable, methods of budget regulation, which lay main stress on the existence of normal stock in proper amount, are the so-called normal stock or formula methods. These compare the actual stock $\left(S_{a}\right)$ with the normal stock $\left(S_{n}\right)$ which should be on hand, and determine the period $(e)$ 
during which the difference in stock is to be equalized and the normal stock is to be secured either by saving of increment, if there be a deficiency, or by removing any surplus during the period of equalization; the establishment of the proper series of age classes being left to the future.

The felling budget $(b)$. which will secure this equalization may be expressed by formula :-

$$
b=I \pm \frac{S_{a}-S_{n}}{e}
$$

The choice of the period of equalization $(e)$ is to be made with due consideration of the financial aspects of the property and the owner's financial capacity.

Altogether, the principle of the "owner's interest " must be the guiding one in the management of any property; and it would first have to be demonstrated that a sustained yield management, either annual or intermittent, and sacrifices of revenue in the present for the sake of a future improved revenue are in his interest. For it must always be remembered that financially forestry means foregoing present revenue or incurring present expenditure for the sake of future revenue; it involves gauging present and future advantages, and the time element, as we have seen, is the prominent element in its finance calculations.

Before an annual sustained yield management will appear profitable in the United States, many 
changes in economic conditions will have to take place, among which we may single out reduction of danger from fire; opportunity for utilizing inferior material; increase in wood prices by reduction of the natural supplies on which no cost of production need be charged; the development of desire for permanent investments instead of speculative ones; an extension of government functions in the direction indicated in the first chapter, leading to the practice of forestry by state governments on a large scale.

Meanwhile all that can be expected from private forest owners is that they may practise more conservative and careful logging of the natural woods, avoiding unnecessary waste, and as far as possible paying attention to silviculture, the reproduction of the crop, leaving to the future the attempt to organize a sustained yield management. Only governments and perpetual corporations or large capitalists can afford to make the sacrifices which are necessary to prepare now for such a management.

In order to secure the data upon which the felling budget may be regulated, a forest survey is necessary, which will embrace not only an area and topographic (geometric) survey, serving for purposes of subdivision, description, and orderly management, but also a quantitative survey, an ascertainment of the stock on hand in the various parts of the property, and of the rate of accretion 
at which the different stands are growing. Besides this stock taking ${ }^{1}$ and measurement of accretion, accompanied by a description of the forest conditions of the different parcels or stands, all of which exhibit the present status of the forest, the construction of so-called "normal yield tables" is needed. These are the result of measurements on the most perfect, normally stocked stands of various species, stating what the contents of such stands should be at different periods of life, generally from ten to ten years, giving, therefore, by decades the progress of accretion under normal conditions for the area unit. With the aid of these tables (see Appendix to Chap. VI) the summation of which permits a statement of the normal stock required for different rotations, the sustained yield can be ascertained by comparing with the actual conditions, and gauging the felling budget as intimated in the formula given above.

In order to translate the statements of volumes recorded in the yield tables into values, which is needed to permit finance calculations, the progress of accretion, or of accumulation of stock in size or assortments of different value, must be ascertained. This leads to the construction of financial yield tables, which give the value from period to period either of the unit measure of wood (cubic feet, feet B.M.) or of the unit measure of area (acre) nor-

1 For this quantitative survey, the term "valuation survey" has been adopted by English writers with doubtful etymologic propriety. 
mally stocked, or else the statement is made in percentic relation.

When all these data have been laboriously gathered, with an attempt at a degree of accuracy greater or less according to the intensity of the proposed management, the formulation of a working plan and the ascertainment of a proper felling budget can be begun.

After having determined upon the general policy of management, with due consideration of the owner's interests and of market conditions, general and local ; and after having decided upon the silvicultural policy, including choice of leading species in the crop for which the forest is to be maintained, and silvicultural method of treatment, as coppice or timber forest, under clearing system or gradual removal or selection system, - the most important and difficult question to be solved is that of the rotation, the time which is to elapse between reproduction and harvest, or the normal felling age, that is the age, or so far as age is in relation to size, the diameter, to which it is desirable to let the trees grow before harvesting them.

In the United States, among the enthusiastic propagandists of the necessity of forest preservation, there exist the crudest notions on this subject, which it may be well here to set right. There is no maturity of a forest crop as we know it in agricultural crops; wood does not ripen naturally, and trees do not even usually die a natural death 
at a given period, but death is with them a gradual process of decay, the result of exterior damage, of insect and fungus attacks; trees actually die by inches in most cases, and it may take hundreds of years before the trunk is so weakened that its own weight or a wind-storm may lay it low. It is, therefore, not practicable, as has been proposed, to harvest when death is approaching. Besides, the poetry and the picturesqueness of the forest might perhaps be subserved by leaving trees to grow until they die, allowing mighty giants to mingle with the younger generations, as in the virgin woods of nature, until they are past usefulness; but it would be abhorrent to economic thought thus to waste the energy of nature. The question of ripeness, of the proper felling age, wherever forest growth is an object not of mere pleasure, as in a luxury forest, must be determined by economic considerations.

There is more sense in the proposition that the felling age be determined by a diameter limit below which timber is to be considered immature ; in fact, the forester bases his calculations of the rotation in part, at least, upon size of crop. But the proposition, frequently advocated, to restrict a forest owner to an arbitrary diameter limit, below which he is not to cut his crops, anywhere and everywhere, is not only unsound as an exercise of state policy, but also mistakes the economic questions involved in the determination of that limit, and entirely 
misjudges the value of the limitation as far as silvicultural results, the perpetuation of a valuable forest, are concerned. In fact, from this last and most important point of view it might be wiser, under certain conditions, to impose upon the owner the cutting out of everything below a given diameter. For, as we have seen in nature's mixed forest, valuable timber and weed trees are growing side by side; the diameter restriction indiscriminately applied might prevent the removal of the objectionable portion, the weed growth, putting a premium upon the decimation of the more valuable portion. Without silviculture, i.e. attention to systematic reproduction, a diameter restriction is of little value. With silviculture it is not necessary, for even the entire removal of the whole crop - denudation - and its replacement by planting or sowing would accomplish the object sought, namely, the continuity of the forest, and in many cases might be preferable to other methods. Arbitrary diameter restriction is merely a device to prevent a too rapid reduction of a valuable species before the time when its reëstablishment by silvicultural methods becomes practicable. Otherwise a diameter limitation has justification only when it can be shown that it is more profitable and in the owner's interest to leave trees below the diameter limit uncut for a longer time.

In other words, the determination of the rotation or felling age, or of the felling size, is largely a 
matter of financial calculation. This calculation is, however, influenced by silvicultural and technical, as well as purely financial, considerations. The fact that the stocks in a coppice lose their vigor if sprouts are left too long uncut, or that frequent and full seed years do not occur until a certain period in the life of the crop, sets limitations to the length of rotation; the technical value of the product, salability, and market requirements for special materials (firewood, poles, mining timber, railroad ties, saw timbers) may influence the choice, but finally quantity of product and money yield are determinative.

From the standpoint of political economy it was supposed that the largest volume of product per acre per annum, the rotation of maximum volume, should be the aim of forest management, and the rotations chosen for state forests in Germany, which lie mostly between 90 and 140 years, were supposed to be based upon this principle. Lately, however, it has been shown that the largest average product of wood per acre and year occurs much earlier, and usually before much of the crop has attained to desirable size.

Since the accretion of a stand varies from period to period, gradually increasing in rate from its early stages to a given age and then again sinking, there must be a time when the average of all the different rates, the average accretion, attains its maximum. If, for instance, a fully stocked acre of spruce contained at 120 years IO,200 cubic feet of 
wood, it would have produced an average per year of $\frac{10200}{120}=85$ cubic feet; if a stand at 80 years contained 6880 cubic feet, it would have produced an average per year of $\frac{6880}{80}=86$ cubic feet; hence from the standpoint of volume production a rotation of 80 years would be preferable.

It will be readily admitted that value production rather than volume production should be the aim, and since with age the size and with it the value increases, the year of maximum volume production will be of interest only as denoting the lowest limit of a rotation based on value accretion. If the price of 80-year-old wood averaged for all sizes 3 cents per cubic foot, and of I 20-year-old wood 4 cents, then in the above example the average value accretion in the one case would be $\frac{10200 \times 4}{120}=$ $\$ 3.40$ per year, while in the second case it would have been $\frac{6880 \times 3}{80}=\$ 2.58$ per year, hence the longer rotation would appear more favorable:

But even the rotation of maximum value production will not satisfy any private investor, since it leaves out of consideration the expenditures necessary to secure the result. The annual expenditures for planting, taxes, administration, which are necessary to secure the annual harvest, should at least be deducted, and since these vary with the 
length of rotation, that rotation should be found at which the surplus of the annual values derived from the harvest over the annual expenditures is greatest, the so-called rotation of the highest forest rent. Finally, even this method of calculation cannot satisfy a strict financier, for it neglects to take account of the capital invested and the relation of the revenue to this capital, it neglects the interest account.

The true financial rotation is that which brings the highest rate of interest on all the capital invested in soil and stock of wood, or, as it is technically known, the rotation of the highest soil rent or "soil expectancy value" (Ger. Bodenerwartungswerth).

As we have seen (p. I29), the amount of stock of wood which must be maintained as capital for a sustained yield management increases with the length of rotation. In our example, in order to bring the stock corresponding to an 80-year rotation to the amount needed for a 100-year rotation would require that the owner should abstain from harvesting for about 20 years. The question then arises whether this saving will prove profitable, whether the accumulation of values to the Iooth year, which can only then be harvested, will exceed the results which could be had by harvesting in the 8oth year and investing the proceeds. Here appears for the first time the need of that branch of forest economy which may be truly called for- 
est valuation, or better, forest finance and forestry statics. This branch concerns itself, not only with the ascertainment of the present value of a single stand, and with the future value to which it is growing, but also with its value as a part of a regulated forest management, in which for all time to come it is an inherent necessary member as a producer of values. It also occupies itself with comparisons of the financial results of different kinds of management.

It is here that the foremost peculiarity of forest economy, namely, the time element, comes most prominently to expression. The inability of withdrawing annually the interest on the invested capital makes compound interest calculations necessary, and since the investment in the young plantation, for instance, will have to be left untouched, accumulating upon itself the interest for fifty, one hundred, or more years, the question as to what interest rate it is fair to assume for compounding on such a long time investment, becomes important. It is well known that every business, every employment of capital, according to its character, works with a different interest rate. There are many reasons why the forestry business should work with a low rate of interest. Compounding for such a long time, the general tendency of sinking interest rates must be taken into account, while, on the other hand, history has shown and philosophy sustains the expectation that prices for wood are 
likely to rise, as natural supplies are exhausted, and the demand for the better soils for agricultural use limits forest growing to the poorer, absolute forest soil. Forest properties, with the exception of the danger from fire, which will be greatly reduced when systematic management is begun, are in general safe properties and easily managed, requiring little labor. Hence, if safe long time investments in the United States, such as savings and trust companies favor, are bringing now only 3 and $3 \frac{1}{2}$ per cent, it is justifiable to use no higher, possibly a lower, interest rate in forestry calculations.

If now we inquire what the "soil expectancy value," i.e. the value of the soil expressed by its expected yields, is, and how it is calculated, we must first conceive that every stand in a regulated forest management is expected to be harvested every $r$ years (years of rotation) forever; the income is therefore in the nature of a periodic or intermittent interminable rent or revenue $(R)$, the capital value of which at present $\left(C_{0}\right)$ being found by well-known mathematical methods in the expression $C_{0}=\frac{R}{\mathrm{I} \cdot \mathrm{O} p^{r}-\mathrm{I}}$. The rent or revenue is composed of the final harvest yield $\left(Y_{r}\right)$, and of intermediate incomes by thinning $(T)$, occurring in the years $a, b$, etc., the values of which have to be extended for purposes of comparison to the same time in which the harvest yield occurs, namely to the year $r$. The expenditures which have to be offset are the out- 
lay for planting (c), if any, occurring at the beginning of the rotation, and hence to be extended to the end of the rotation, in order to bring it into relation with the yield, and the annual expenditures for administration, which can be expressed as a capital $(A)$, furnishing yearly forever the needed amount. With these items we can then express the soil rent value -

$$
S_{e}=\frac{Y_{r}+T_{a} \mathrm{I} \cdot 0 p^{r-a}+T_{b} \mathrm{I} \cdot 0 p^{r-b} \cdots+T_{q} \mathrm{I} \cdot 0 p^{r-q}-c \cdot \mathrm{I} \cdot 0 p^{r}}{\mathrm{I} \cdot 0 p^{r}-\mathrm{I}}-A .
$$

By entering values which correspond to different rotations, that one may be found in which the soil rent value appears as a maximum, the true financial rotation.

It will readily appear that, while theoretically this is the only correct financial method of calculating, practically it is difficult, almost impossible, to determine values for the various items, on account of varying prices and uncertainty of interest rate for the future. Although all calculations in forestry must necessarily be approximations, such calculations may serve as a guide for a time, to be recalculated with change of conditions.

Where, as in well-established state forest administrations, the question is not one of strict financial business, and where absolute forest soils, which could not be used for other purposes, are involved, the simpler forest rent calculation is probably more satisfactory. It is of historical 
interest to state that for nearly forty years a fierce literary battle as to the propriety of applying either one or the other method has been waged in the German forestry literature between the adherents of the forest rent and the soil rent theory of finance calculation.

Where, as in the selection forest, the harvest is made by selecting trees here and there, as they grow to suitable size, instead of determining a rotation which covers the whole time from the seedling to the harvest stage, a calculation may be made which determines only the last part of the rotation, namely, the time which is required by trees near cutting size to grow from one diameter class into the next higher, and then choose that diameter limit for cutting which appears most profitable - the exploitable size. Since this method of ascertaining a conservative felling budget is advocated and used in the so-called working plans prepared by the United States Bureau of Forestry, it may be well to elucidate it more fully. It was first taught in 1746 by the German forester Oettelt, and adopted with various modifications by the French Code forestier, and later by the Indian Forest Department, as paving the way for better methods.

By a forest survey, the number and contents of trees of different diameters near felling size found on the average acre is ascertained; by a series of measurements (stem analyses) the rate at which one diameter class grows into the next higher is 
determined, and upon this basis a yield table is constructed which shows the amount of material obtainable from decade to decade according to the difference of felling size. That diameter limit then is chosen which in the long run appears most profitable.

If, for instance, the actual survey showed of the exploitable species an average per acre of -

28 trees above Io inches diameter,

23 trees above 12 inches diameter,

18 trees above 14 inches diameter,

and it is ascertained that it requires 12 years for an 8-inch tree to grow into the Io-inch diameter class, I6 years for a ro-inch tree to grow to 12 -inch, and I4 years for a 12 -inch tree to grow to 14 -inch diameter, then if a ro-inch standard were adopted the present cut would remove the 28 trees above Io-inch diameter, and no exploitable size will again be found before I2 years; while if the I2-inch standard were adopted, the return for another harvest based on the same standard could not be made before 16 years, and the 14 -inch standard would permit a return in 14 years. These data would then permit a tolerably accurate finance calculation, to determine which the profitable size in the long run would be. This calculation the Bureau of Forestry does not make, but instead ascertains and compares merely volume production by constructing a yield table.

In a given case the yield table approximately 
corresponding to the above enumeration shows as follows (rounded off) :-

\begin{tabular}{|c|c|c|c|c|c|c|}
\hline \multirow{2}{*}{$\begin{array}{l}\text { Diameter limit to } \\
\text { which cut is made. } \\
\text { Inches. } \\
\text { IO }\end{array}$} & \multirow{2}{*}{$\begin{array}{c}\begin{array}{c}\text { Actual stock } \\
\text { on hand, } \\
\text { M ft. B.M. }\end{array} \\
4.6\end{array}$} & \multicolumn{5}{|c|}{$\begin{array}{l}\text { Amount of cut obtainable after } \\
\text { ro | 20 | } 30 \text { | } 40 \text { | } 50 \text { years. } \\
\text { M ft. B.M. }\end{array}$} \\
\hline & & .40 & I. .04 & 2 & 3.22 & 4.85 \\
\hline 12 & 4. & .44 & I. 24 & 2.48 & 4.14 & \\
\hline 14 & 3. & .76 & I. .84 & $3 \cdot 32$ & & \\
\hline
\end{tabular}

This table shows that, while the cut to ro-inch yields of course a larger harvest, the same harvest in amount can then only be again had in about 50 years; while the harvest is replaced in less than 30 years if the cut is made to I4-inch, and the average annual production is then largest, namely, $\frac{3 \cdot 32}{30}=$ I 10 feet B.M. per year.

The report of the bureau nevertheless chooses the I 2 -inch limit because "the present yield to a 14-inch limit is not large enough to justify the construction of logging roads, the building of camps, and other expenses necessary for lumbering."

In other words, these calculations serve only as a general guide to direct the judgment. And especially with this method caution is necessary, as it is based upon the assumption, probably not of ten correct, that reproduction will take place, and that younger age classes in sufficient number and amount are in existence to take the place of the older; 
when, as is often the case in the virgin uncut woods, most of the trees are of exploitable size, this assumption and with it the method of regulating the budget fails entirely.

An improvement of the method and a closer approach to true finance calculation could be made by basing the exploitable size on the highest net value per unit of volume in connection with the time it takes to replace it. In this connection it must be understood that, although one and the same stumpage price ${ }^{1}$ per thousand feet board measure is paid for all sizes, the price per unit of volume as it grows in the tree is by no means the same, for the board foot measure as applied to round logs is not a unit of volume in the same sense as the cubic foot, a deduction variable according to log size being made from the true volume to allow for loss in sawing.

The following table based on one of the accepted rules of measurement(Doyle's) will elucidate this :-

\begin{tabular}{c|c|c|c}
\hline $\begin{array}{c}\text { Diam. of log } \\
\text { (length ro feet). }\end{array}$ & $\begin{array}{c}\text { Real Contents. } \\
\times \text { ro }\end{array}$ & $\begin{array}{c}\text { Contents in } \\
\text { lumber at mill. }\end{array}$ & $\begin{array}{c}\text { Stumpage value of } \\
\text { forest grown material } \\
\text { per cubic foot if price } \\
\text { per M ft. }=\$ 5.00 .\end{array}$ \\
\hline Inch. & Cubic feet. & Feet B.M. & Cents. \\
10 & 65 & 23 & 1.8 \\
14 & 127 & 62 & 2.4 \\
18 & 211 & 122 & 2.9 \\
24 & 376 & 250 & 3.3 \\
30 & 588 & 422 & 3.6 \\
\hline
\end{tabular}

1 Stumpage is the amount of exploitable material; stumpage price is the price paid for the wood leave, or the wood as it stands in the forest. 
The value of the unit volume increases, therefore, with the size of a log, yet in a decreasing ratio; if, now, the time required to produce the cubic foot is put in relation, a nearer approach to the profitable exploitable size may be made.

A further improvement, designed to secure more surely a sustained yield, requires that the number of trees (at least the dominant) of different diameter classes which are present be ascertained, and the number which should normally exist be determined, when, if necessary, enough trees of the higher or lower diameter class can be left, or else the excess be removed, to bring the number to standard.

Whatever method of budget regulation is adopted, it must never be forgotten that the approach to normality can only be gradual, and can be secured in shorter or longer time, depending on the owner's interests ; in other words, while the regulation of a budget is primarily based on mathematical measurements of accretion, yield, and values, in practical application it must be modified by judgment, which makes allowance for changing conditions; for forest regulation only points the way, sets up an ideal which in practice we may never approach closely; it gives us merely a standard, a measure, a check upon our business. It may even be to the best interest of the owner to defer entirely the attempt. at a sustained yield management, leaving it to a more favorable future to regulate the budget accord- 
ing to its requirement. Finally, silviculture, replacement of the crop, is the much more important obligation, assuring continuity of crops, and this can in many cases be practised without the elaborate organization of the ideal business conduct.

Of as much and even more moment than the budget regulation for the orderly conduct of the business is the organization of the property into units of management, forest districting. This will be more or less elaborate according to the intensity of the management.

In Germany, a manager's district, which may comprise from 5000 to 25,000 acres, is divided into compartments of 50 to 100 acres, and sometimes more in each, which form the units of management, being numbered consecutively, and sometimes named. In the level country it is usual to locate these compartments, not only on the map, but in the field, by dividing the property into rectangular blocks separated from each other by openings (rides) running north and south, east and west, so that on the map the subdivision looks like an American city street system. ${ }^{1}$ In the mountainous country the subdivision is an irregular one, the division lines following the contours of the slopes, valleys, and roads, and usually the division lines are not opened.

${ }^{1}$ The rides are used for roads and serve in the pineries also as fire guards. 
This merely geometric subdivision serves the purpose of easy orientation; it enables the forest regulator in his working plan to properly ascertain and describe the stock, and to plan the treatment of each compartment, and it enables the manager readily to locate and apply the prescriptions of the working plan. A number of these units may then again be combined into subdistricts or ranges for purposes of administration, fire patrol, etc., while all those which are to be managed under one silvicultural system are, at least in the working plan, segregated as working blocks or working sections, from those to be managed under another silvicultural system (coppice or timber forest, etc.), or under another rotation.

These various subdivisions are all noted on maps, as is also, by colors, shadings, and signs, such descriptive matter as is desirable to present a clear, comprehensive picture of the actual forest conditions, and to indicate the changes which are to be attempted.

One of the important prescriptions in the working plan, especially wherever clear cutting systems are to be applied, or where species liable to windfall are involved, is the establishment of a proper sequence or collocation of felling areas-felling series (Hiebsfolge). (See p. I 86.)

Since danger from fire threatens the young crop more than old timber, especially in pineries, it is desirable to decrease the risk by making the fell- 
ing areas small and so distributing them that they are interrupted by old timber; the same risk exists with regard to insect damage, and the same plan disruption of the age classes - reduces that danger. Again, older timber grown up in the close company of a dense stand is wind-firm, and resists both windfalls (uprooting) and wind breakages (breaking of stems), but when, by felling operations, portions of the interior are opened up and exposed to the force of winds, the trees are liable to be thrown, especially if of shallow-rooted species, or on shallow soils. To avoid this damage it is desirable, not only to make the felling areas narrow, so that the wind has less force, but to locate the fellings with regard to the prevailing winds (mostly westerly), so that the older age classes lie in the lee, the younger to the windward, the roof of the forest or the felling series ideally rising from west to east, the fellings progressing from east to west.

Where it becomes necessary to cut on the windward side, opening up timber unaccustomed to wind exposure, a wind mantle is left on the windward side, which is also a commendable prescription for small wood lots of farmers, to keep the drying winds out. Or else, in due time, ten to twenty years before the necessity for harvesting timber so located, a severance felling is made, a small opening which will induce the formation of a wind-firm mantle. 
While these, considerations of future danger make a distribution of felling areas desirable, present considerations of logging expenses dictate consolidation of felling areas, for the concentrated logging can be done more cheaply than the distributed logging, since temporary means of transportation may answer the first plan, while permanent roadways become necessary in the latter plan.

Here, again, we see that the forest regulator is constantly called upon to compromise between the exigencies of the present and the benefits for the future ; he must weigh the desirability and the financial ability of present investment or present loss for the sake of future gain. The general working plan, then, - the result of the investigations of the forest regulator, - is more than a mere budget regulation; it furnishes the broad basis, the principles and policies, for the entire management in all directions for a long time to come, taking into consideration present as well as future contingencies, and serving as a guide to the manager.

Since, during the long time which such a plan contemplates, all sorts of changes, unforeseen and uncontrollable, take place, changes in economic conditions and changes in forest conditions as well as growth in experience, it is useless to make detail prescriptions beyond a short period, leaving to the future a readjustment and revision of the working plan and the formulation of new policies. 
The detail prescriptions for the first decade or so are laid down in a periodic working plan, based upon the general working plan, in which the areas to be cut, and to be replanted, and the improvements to be made, are specifically designated. For the felling plan the areas that must first be cut are designated, namely the old and decrepit stands which are deteriorating, - a dead capital not growing in value, - and all the open stands which do not utilize the soil to full satisfaction; next are chosen such parcels as need to be cut to secure a desirable felling series in the future; and if more is needed to fill the required felling budget, areas near the desired normal felling age are added.

Where practicable, the areas are prescribed in which thinnings are to be made for the improvement of the crop, and an estimate made of the probable amount secured by such thinnings, which is added to the main felling budget. Whatever planting operations may become desirable are detailed in a special planting plan.

For the administration of a large and complex forest management, a thorough organization and bookkeeping are of course essential. These offer no especial peculiarities that need here be discussed, except to state that besides the financial bookkeeping and the cost-keeping accounts, it is necessary to keep account of the results of the operations upon the forest conditions. For this purpose a ledger account is opened for each com- 
partment, in which the changes are noted to furnish a basis for the revision of plans for the future.

It will have become clear that the business conduct of a forest management is, as every other business, influenced by the economic conditions, general and local, surrounding it. Much that is possible under the settled conditions of such countries as Germany and France will not be practicable under our conditions, until they have become more fixed and stable.

But the technical art - silviculture - which is the more important since it furnishes the basis for any kind of forest management, being based mainly on natural laws, is applicable everywhere, just as in Germany or France, where its methods have been developed and practised for centuries. 


\section{CHAPTER IX.}

\section{PRINCIPLES AND METHODS OF FOREST POLICY.}

THE expositions of the preceding chapters will have made it clear that the forest cover is of more importance to the household of a nation than many other of its resources, that it bears a peculiar relation to national prosperity, and also that its management for continuity offers various unique and peculiar aspects, which call for special active interest by the community at large and by its representative, the state.

Briefly summarizing the arguments for such special interest and exercise of governmental activity, we recall that the forest is a natural resource which answers simultaneously three purposes of civilized society: it furnishes directly materials used in very large quantities and almost as needful as food; it forms a soil cover which influences, directly and indirectly, under its own cover and at a distance, conditions of waterflow, of soil, and of local climate ; it has, in addition, an æsthetic value, furnishing pleasure and recreation and benefiting health.

The exploitation of this resource for private 228 
gain is apt to lead to its deterioration or eventual destruction, especially in a country where population is relatively small and unevenly distributed, when only the best kinds and the best cuts can be profitably marketed. Hence, since profit is the object of private enterprise, exploitation must under • such conditions be by necessity wasteful. By the removal of the useful kinds and of the desirable individuals, leaving the ground to be occupied by tree weeds and runts, the reproduction of the desirable and useful is prevented, and since the forest by changing its composition and quality is deteriorated in value, the future is injured as far as material interests are concerned.

Since, with the removal of the marketable timber, the interest of the individual in the forest is gone, it is naturally neglected, and conflagrations which follow the wasteful exploitation, with the accumulated debris left in the woods, kill or damage, not only the remaining old timber, but more especially all the young growth. Even the soil itself, often formed only by the mould from the decay of leaves and,litter accumulated through centuries, is destroyed, and thus, not only the practicability, but the possibility, of restoration is frustrated. In many localities the consequences of such destruction are felt in deterioration of climatic conditions, and in uneven waterflow, floods and droughts being exaggerated; in this way damage is inflicted on portions of the community far 
removed from its cause and unable to protect themselves. The private individual can hardly be expected to appreciate these distant interests of his own motion in the management of his forest property, hence the state must guard them.

- To insure a conservative treatment and continuity of the resource, - a sustained yield management, - it is necessary to curtail present revenue or to make present expenditures for the sake of a distant future, since the crop takes many decades to mature. This time element is the peculiar feature in forest management which renders the use of the soil for such production undesirable for private enterprise concerned in immediate results. The fact that the capital invested in the soil and in the gradually accumulating wood growth must be tied up for many decades, and exposed to many dangers, before the harvest returns interest, and that hence finance calculations and financial transactions with such kind of property become complicated, renders the safety of this resource in private hands doubtful, and points to the desirability of permanent, stable, long-lived ownership.

The desire to get the largest present profit from his labor, which is the only incentive of private enterprise, will be also a constant incentive to curtail the wood capital necessary for a sustained yield management, and to let the future take care of itself.

The interest in the future lies with the state; the 
state must interfere, therefore, wherever the interests of the future clearly demand it.

What form shall this interference take? What shall be the policy of the state in regard to the forest resources?

The answer will vary according to our conceptions of government functions, according to practical considerations of expediency, and according to the character and location of the forest areas.

In the first chapter we have endeavored to develop a conception of governmental functions based upon the logical proposition that the state is to protect the broad interests of the many, the community, against the inconsiderate use of property by the few; and we laid special stress upon the necessity of including the interests of the future community in this consideration, calling for the exercise of providential functions on the part of the state.

While in principle this position may be regarded as a self-evident logical sequence of the state idea everywhere in application under differently developed conditions of government, the manner and extent of exercising its functions will, of course, vary. In the densely populated monarchical countries of Europe, with relatively scanty resources, a much more direct and strict interference is called for than in a country which has still plenty of elbow room, with plenty of resources; here it may be expedient to leave adjustment to future con- 
sideration and action, there expediency calls for prompt and vigorous assertion of state rights and obligations.

How inconsistently in actual practice the principles of state function may be applied can nowhere be studied better than in the United States. While, as a principle, we are inclined to demand restriction of state interference and insisting upon personal liberty to circumscribe and minimize in many directions the sphere of governmental action and authority, we actually find paternalism rampant, almost to the verge of despotism, in other directions, as in the liquor laws and oleomargarine laws, offering restrictions which no European would tolerate. Surely expediency has here dictated almost the annihilation of principle. We can, therefore, not expect to have the policies which satisfy one country, although based on sound principles, transferred and applied in the same way in another country.

It may be conceded that the truly socialistic conceptions (much ventilated in forestry literature), which consider it a duty of the state to take care that the materials necessary or desirable for the comfortable existence of its society be produced in sufficient quantity and economically, are either antiquated and buried with the rest of physiocratic teachings, or are not yet accepted as true democratic doctrine. In mercantile pursuits, generally speaking, individual effort and responsibility are certainly 
preferable to government action and authority, which must often be arbitrary, indirect, uneconomical, and ineffective. Hence, as far as forest areas serve only the one object of furnishing supplies, and form the basis of industrial activity, we may, for a time at least, allow our general modern industrial policy of non-interference to prevail, which is based upon the theory, only partially true, that self-interest will secure the best use of the means of production.

There is, however, one great generic difference between the forestry business and all other productive industries, which places it after all on a diferent footing as far as state interest is concerned; it is the time element, which we have again and again accentuated, and which brings with it consequences not experienced in any other business.

The result of private activity which is supposed to come from self-interest is closely connected with the working of the well-known economic law of supply and demand which regulates the effort of the producer. This law and the self-interest can be trusted to bring about in most cases a proper balance rapidly, but in the forestry business this balance works sluggishly; before a shortage in supplies is discovered and appreciated, stimulating to productive effort, years will have elapsed, years which are needed to prepare for a supply to become available in a distant future. How difficult it is to get conditions of forest supplies recognized and appre- 
ciated, we have experienced in regard to our white pine supply. It has taken twenty years to force this realization upon the producers, in spite of the fact that the federal government made a creditable effort to ascertain and publish the facts. And even now, when there is no more doubt of the fact that these most important supplies are bound to be practically exhausted in a short time, there is no very extensive self-interest aroused to adjust the balance of supply and demand, and to anticipate the shortage, simply because self-interest works only for the present and does not concern itself with a distant future.

We must, then, admit that, even with regard to supply forests, the position of the state may be properly a different one from that which it would be proper and expedient to take toward other industrial activities.

When, in addition to the mere material function, the immaterial benefits of a forest cover enter into the question or become paramount, there can be no doubt that both principle and expediency call for timely exercise of state activity. The so-called protection forests, therefore, which by virtue of their location on steep mountain slopes or on sand dunes, or wherever their influence on soil conditions, waterflow, and climatic factors can be shown to be superior to their material value, must claim a more intimate and direct attention by the state; for here protection of present 
interests, as well as of future well-being, demand the application of the old Roman law: Utere tuo ne alterum noceas; here the police power of the state is invoked, extended according to our wider horizon and fuller conception of the need and direction to which the protective function of the state is required, as developed in the first chapter. In the exercise of this protective function, the state performs merely the primary logical duty of its existence, namely, securing for each of its members the maximum opportunity to do for himself, preventing interference, direct or indirect, by others ; it is not doing for the individual what he could have done for himself, and it is not liable to the charge of paternalism.

In practical application of this principle, the question must, to be sure, be settled either in general or in each case, as to whether injury is being done or is to be anticipated by the unrestricted use of the property, and what form the interference by the state is to take.

There are three generically different ways in which the state can assert its authority and carry out its obligations in protecting the interests of the community at large and of the future against the ill-advised use of property by private owners : namely by persuasive, ameliorative, or promotive measures, exercising mainly its educational functions; by restrictive measures or indirect control, exercising police functions; and by direct con- 
trol, i.e. ownership and management by its own agents.

Basing our conception of state function on the fundamental postulates, that the state has primarily the object to increase the freedom of the individual in personal and economic relations, and to promote the possibilities of individual effort; that the sphere of governmental action and authority in circumscribing individual action and responsibility should be minimized to absolute necessity; and that the state should undertake to do only whatever by its character it is better fitted to do for the community than the individual members can do for it, - our choice of method will be in the order named.

As a general principle, only when persuasive and promotive measures fail or are insufficient, recourse is to be had to restrictive measures; only when even these are inefficient or inexpedient is the state to own and manage properties.

In the first category we have to discuss educational measures, taxation and tariff duties, bounties, and other aids in promotion of private industry.

The educational function of the state is now recognized as one of the most prominent and beneficial in all civilized nations, although the degree and generality of its application still vary. In the United States we rely, as regards the higher and professional education, still largely on private charity and effort, with results comparatively satis- 
factory, yet by no means as efficient, as state institutions could make them. If, as is the case with some of our western state universities, the state provides the means of supporting the institution by a certain proportion of the tax rate independent of political changes, the institution is relieved of the necessity of keeping up the competition for favor, which disadvantageously besets most of our private institutions of learning, and is destructive to the competition for scholarship and true scientific efficiency.

A state institution, thus well endowed and independent of numbers and of undesirable rivalry, can at least promote efficiency with a freer hand. Charity is generally conceded to be undesirable where it can be avoided, and in educational matters the interest of the community ought to be sufficiently well recognized to repudiate support by charity.

In the old countries the educational function of the state is so well established as to have almost eradicated private schools, except in certain specialties and primary institutions.

The forestry schools of Germany, all of which are now state institutions, originated, however, in private undertakings, the so-called " master schools," when a practitioner assembled around him young men and taught them all he knew. Such schools arose in large numbers during the last half of the eighteenth century, - the first in 1763 in the Harz Mountains, - but were usually of short duration, 
the change to well-organized state institutions taking place in the first decades of the nineteenth century. In the United States the state of New York was the first to recognize its obligation in this direction by instituting a College of Forestry in 1898, administered by Cornell University, a private institution. Almost simultaneously a "master school" was instituted on the Vanderbilt estate at Biltmore, N.C., and by private endowment a third school arose in connection with Yale University, while a number of other institutions attempt, at least, to keep abreast with the times by represénting the subject in some fashion in their curricula.

We believe that finally, in each of the forested states, it will be considered a part of proper forest policy for some public institution of learning to furnish instruction in forestry. This does not necessarily mean university or higher professional education; there is as much need for the lower grade education, of underforesters, logging bosses, etc., such as Berea College, Kentucky, has so auspiciously inaugurated.

The only danger is, that multiplication in number rather than increase in efficiency of a few such institutions will be the rule of the day, when the fever sets in.

In the European forestry literature a lively discussion has continued for years as to whether the higher education in forestry should be given at 
separate special academies or forestry schools, or whether these should be connected with universities. There are advantages and disadvantages in either arrangement; but the better facilities which can be had at a university, with its concentrated intellectual and laboratory apparatus, give the preference to the latter.

In the United States propagandists have been loud in advocating the introduction of the subject into the primary public schools. While it is desirable that our young citizens should become acquainted in a general way with all the varied interests of the world, and should have some general intelligence regarding them, such as well-educated teachers can impart incidentally in reading lessons and otherwise, it would, indeed, be mistaking the object of primary education to introduce any special systematic teaching of professions or practical arts. Expediency, if not principle, forbids it, for with equal rights every other branch of economics and every professional art might claim recognition.

Besides the establishment of schools, there are other means open for the state to exercise its educational functions. The endowment of scholarships, especially travelling scholarships, has been of greatest value in increasing capacity and intelligence for promoting communal interests. As long as the practice of forestry does not exist, or is poorly developed in the United States, it is 
desirable to give opportunity to competent students for observing its practice where it is well developed. A year's, or even a half-year's, travel through the well-managed forest districts of Germany or France gives more insight into the possibilities, advantages, and methods of forest management than a lifetime spent in wrestling with the problems without having seen a practical solution elsewhere.

Next, no more efficient means of education in practical arts which, like forestry and agriculture, rely still largely on empirics can be devised than the establishment of experiment stations. Experiments always imply the expenditure of means and energy for an uncertain result, by which, to be sure, the experimenter may profit, but, unless the experiment is carried on in the quiet of a laboratory, he is not alone benefited; the observer, who does not share in the expense, shares in the benefit. Hence, while the principle of self-interest will lead to experimentation, expediency makes it desirable, in some directions at least, to broaden the field of experimentation, and to make the results fairly and openly accessible to the whole community. This is especially so where the use of a limited resource, like the soil, to its greatest efficiency, is of benefit to the whole of society.

If, as has been practically conceded, experimentation in agricultural lines is best done by state institutions, this is still more true in forestry lines, 
on account of the time element involved in most forestry experiments. In agriculture the answer to an inquiry may be often secured in inexpensive ways, and may be given in one season; while in forestry, years of patient waiting and observation, wholesale methods or measurements, large areas, and a large number of cases, are required to permit generalization. In both directions the activity of the private investigator is at a disadvantage. To conduct investigations that must be continued for decades, and in a large way, a systematic plan and organization is needed, such as only a public institution usually has at command. Moreover, comparability of results can be secured only when uniformity of method has been assured, and this again is more likely secured by coöperation between state institutions, or even by the character and organization of a single state institution.

The advantage of connecting such experiment stations with institutions of learning needs hardly any argument ; the mutual increase of educational facilities and opportunities is patent. These educational means can, of course, be extended by proper methods of publication of results, by organization of meetings for their discussion, by so-called university extension, and finally, by the promotion of associations which have for their object the increase of application of knowledge in the actual forestry practice. Such associations give opportunity of impressing and driving home 
what is desirable in practice, and also of finding out what are the needs of the private owner, and what the state should do to further his interests. The state of Minnesota has, for more than a quarter of a century, supported the efforts of such an association with considerable satisfaction by yearly appropriations. The countenancing of such private endeavor in educational directions is certainly good state policy.

A more direct and far-reaching influence upon private activity, still of an educational character, is properly exercised by the state in securing and publishing statistical information. Statistics, intelligently gathered and presented, form the necessary basis for a safe judgment of existing conditions and past progress of development, and also for forecasting the future tendencies of development and possibly directing its progress; they give clews, and are guides, not only for rational legislation, but also for rational conduct of private business. While self-interest may be quite efficient to ascertain conditions of supply and demand in daily, weekly, or monthly business for the sake of private business use, for the sake of the prosperous development of the community at large and of giving general direction to private endeavor, it is desirable that a state institution ascertain periodically the condition of a whole industry and its relation to other industries.

Such ascertainment is done with satisfaction 
only by the machinery of the state, which can make inquiries uniform, compel answers, and has no special interests to represent which might influence the reliability of the statements. In forestry statistics especially, the difficulties of ascertaining conditions of supply are beyond the capacity of individual inquiry, owing to the complicated nature of the object of inquiry. If there is difficulty in determining quantity and value of standing merchantable timber, which is within the actual vision of the estimater, how much more difficulty must be found in judging the prospective quantity and value of the unperfected crop, the promise of the future; and this is the essential knowledge upon which is to be based, private as well as state activity with reference to this resource.

We may only briefly indicate what kind of statistical knowledge would be desirable in order merely to direct public policy. ${ }^{1}$

In the well-ordered state the soils most fit for agriculture should be devoted to systematic food production, but just so should the non-agricultural soils, the absolute forest soils, be devoted to the systematic production of wood-crops; moreover, as we have seen, the forest in certain situations exercises a potent influence on cultural conditions. Hence

${ }^{1}$ For a fuller discussion see "Considerations in gathering Forestry Statistics," by the author, in Quarterly Publications of the American Statistical Association, 1898. 
the knowledge of the extent of forest area of a country is by itself meaningless; the character of the soil the forest occupies, its topographical location, and its relation to the hydrography of the country, must be known to permit an estimate of cultural conditions, to prognosticate likely change in area and the desirability of interference in its use.

To get an idea of the amount and value, present and prospective, of the existing resource, there must be known the composition, i.e. relative occurrence of merchantable kinds and conditions as to density, age, and character of growth, damage by fire, etc., and, most difficult of all to ascertain, conditions and stages of development of the young crop. Only forestry experts can so ascertain such statistics as to give them value. The other side of the question, market conditions and statistics of wood-consuming industries, offers some peculiarities, but no difficulties.

Furthermore, when forest management is once established, not only the condition of the resource, but the methods of its management, call for statistical inquiry.

In addition to these educational methods which incite private activity in the right direction by indirect means, namely, by increase of knowledge, there are more direct ameliorative or promotive methods to be found in bounties which are given to aid private endeavor in the pursuit of private industry. 
These may take the form of assisting by money gifts, by furnishing plant material, by giving land as in our timber claim planting, by making working plans or otherwise specifically assisting in private forest management beyond the giving of general information, and finally by tax release and tariff duties.

We are approaching in these methods closely to paternalism, when the state is doing for the individual what the individual could or should do for himself, when the state is doing more than providing opportunity for individual activity; at least the danger of transcending proper policy and abusing public interest is always present with these methods.

It is, therefore, necessary to scrutinize much more carefully the conditions under which proper policy is subserved by them. Curiously enough, these paternal methods have found much more favor and are more extensively used in our country than in the European countries, which are usually charged with the opprobrium of paternalism; and in spite of the fact that the results have been rather disappointing, the advocates of these methods continue successfully to impress their opinions upon legislatures.

The fact that these methods have failed before does not, to be sure, argue that with a change in conditions and with more circumspect supervision they may not be employed with better results. yet 
the past experiences should serve at least the purpose of exercising caution in their employment.

In the years 1868 to 1873 a wave of legislation for the encouragement of timber planting, either under bounty or with exemption from taxation, went through the country from Maine to Nebraska, culminating in the so-called timber culture acts by the federal government in $1873-1874$. All of these laws proved practically ineffective, or at least the results were inadequate except in taking money out of the treasuries.

Yet only in 1899 the State of Indiana revived the idea in a law "for the encouragement of forestry," with an attempt at specifications which in themselves are devoid of tangible principle. This law provides that any owner may declare oneeighth of his property as a permanent forest reservation, this portion to be assessed at one dollar per acre, provided he either plant and maintain for three years, or, if natural woods, have on hand, not less than 170 trees per acre; he must keep out cattle, sheep, and goats until the trees are four inches in diameter; and whenever any of the 170 trees die or are removed, he must replace and maintain the number and protect them until they are four inches in diameter, and he may never cut or remove more than one-fifth of the trees in any year.

A reference to the chapters on "Natural History of the Forest" and on "Silviculture" will show how futile and inadequate this encourage- 
ment of forestry must prove to be in a timbered state like Indiana.

In Pennsylvania, according to a legislative act of 1897 , the owner needs to have only 50 trees to the acre, which must, however, measure at least 8 inches in diameter 6 (!) feet above ground; as long as he keeps these in sound condition, in "consideration of the public benefit to be derived from the retention of forest and timber trees," he is to have 80 per cent of the tax on such lands refunded, provided that this be not more than 45 cents per acre and that no more than 50 acres are entitled to such release. From this last restriction one would suppose that a larger acreage would not be a public benefit; one fails also to see the rationale of the other measurements and numbers required, nor is it apparent what benefit to the public any 50 acres with 50 trees to the acre without special reference to its location might bring.

The timber culture acts of the federal government, which had in view the amelioration of cultural conditions in the treeless territory of western prairies and plains, a very proper concern of government, conferred title to 160 acres or smaller amounts of the public domain, if 40 acres or a proportionate smaller acreage was set out to trees. The crude provisions of the law and lack of proper supervision led to its abuse, and the results have been mostly disappointing, leading to the repeal of the law in $189 \mathrm{I}$. 
The federal government also practised the method of furnishing plant material; this was done, however, with inadequate means and without proper discrimination.

The writer himself, when in charge of the Forestry Division, United States Department of Agriculture, was enjoined by law to distribute plant material, and did so long enough to convince himself that the size of the country and the number of people with equal rights to this bounty, as well as the practical difficulties in handling such plant material, which must necessarily vary in kind according to locality, forbid the practice, or, at least, do not promise adequate results, except possibly in planting a few shade trees.

Yet, in connection with other methods of state action and with proper organization, this method has proved satisfactory in the European countries, namely, when the state enforces, and, by technically educated officials, supervises reforestation of alpine locations, barrens, and waste places, and when the distribution of plant material is made, not to private owners, but to associations and communities, free, or at cost of production and on an adequate scale. It may, of course, under similar conditions and with similar judicious supervision, but only then, be employed successfully in our country.

Within the last few years the federal government of the United States has inaugurated through 
the Forestry Bureau of the Department of Agriculture another method of encouragement, which is also practised in the old countries, namely, to give to private owners 'specific advice as to the management of forest properties, the government bearing the larger share of the expense of securing the data for these so-called.working plans. But for the educational feature involved, this would be a violation of our principle that the state should not do for the private citizen what he could do for himself. If, however, the benefit to be expected for the community at large is thereby secured, expediency would lend countenance to such a method. The probability, however, is that in the absence of an obligation to follow the working plan, and in the absence of technical supervision in its execution, the results will be hardly commensurate.

The one principle under which the community can properly be called upon to tax itself - directly by paying bounties, or indirectly by refunding or reducing taxes and by imposing import duties - in order to encourage private industry is that the community will thereby secure extraordinary benefit. But the benefit must be specific, demonstrable, adequate, and, moreover, it must be evident that mere private self-interest will not be sufficient to secure incidentally the desired benefit.

The power of adjusting taxes is a mighty lever to industries, which can be used scientifically or unskilfully, for good or for evil; and those who 
advocate the use of the taxing power to encourage the forestry industry are perfectly justifiable, provided it is used in a reasonable way.

As a matter of fact, taxation of woodlands is at least in most forested states of the Union most unscientifically applied, and in such a manner as to encourage forest destruction and discourage forest management. Moreover, the quid pro quo for which taxes are primarily exacted, namely, protection of the property of individuals, is most inadequately performed by the community.

It is customary to assess forest property by including the value of the standing merchantable timber; in other words, not only the apparatus of production, but the product itself, the crop, is taxed. If the same principle were applied to agriculture, if the farmer were not only assessed on the value of the land, buildings, and machinery, but on the value of the growing crop itself, it would certainly appear absurd, and discourage him from all efforts to secure the highest values in his crops.

To be sure, as long as the forest crop is a mere gift of nature, bought and exploited like a mine, the crop idea does not present itself forcibly; as soon, however, as forest management, continued systematic forest crop production, is contemplated and practised, a more equitable principle of taxation must be introduced, namely, the assessment of the soil alone, the value being gauged by its 
capacity for producing the lowest value of marketable wood.

But since the harvest cannot be secured annually, since it must accumulate for the length of a rotation before a return for the expenditure of tax and otherwise comes to the owner, a compound interest calculation on returns as well as on the annual tax must be made to come to a rational assessment rate.

An example may make it clear how an equitable valuation of a growing forest crop could be made without going into much finesse.

If an acre produce annually at the average rate of one-half a cord of salable wood, and it takes 30 years before the crop is ripe for harvest, and the I 5 cords then harvested brought a stumpage value or wood leave of 20 cents per cord or $\$ 3.00$ per acre, the soil rent upon which the assessment should be established would figure, according to well-known interest calculation (if a 5 per cent interest rate be acceptable for such investment, which would be fair for the present time in many places), as $\frac{3 \times .05}{1.05^{30}-\mathrm{I}}=4 \frac{1}{2}$ cents, and the value of the soil as wood producer under the conditions named would be $\frac{4.5}{.05}=90$ cents per acre.

And if, as is usual with real property, only 60 per cent of the value is taxed, the taxable value of such an acre would be 54 cents. This would be 
fair if the county or state did its part of the contract, namely, furnished adequate protection against fire risk. This calculation leaves out any allowance for cost of protection and administration, and, on the other hand, also of the possibility of harvesting higher-priced materials. Since it is usual to tax the "wrecking value" rather than the true value, it would probably be fair to assess upon the assumption of this lowest value production or even still further reduce the assessment to allow for risk and cost of protection.

How do we find forest property actually taxed? For an example we may cite a definite case from Wisconsin, a state where values are naturally still unsettled, but stumpage is probably lower than that assumed above. Here, for an aggregate of tracts of hardwood lands from which the valuable pine has been removed, the taxes for a number of years have varied from 3 cents to 40 cents per acre a year without any reference to changes in condition or value, and have averaged about Io cents per acre, that is to say, 20 to 30 per cent of what probably is the year's production must be paid to the tax gatherer. On a virgin growth, with the pine left, the taxes were never below 50 cents. It is safe to say that no other property is so heavily taxed. It is a premium on deforestation, after which the land, worth $\$ 6$ to $\$ 7$ per acre for agricultural purposes, will be more reasonably treated. And these examples of irrational taxa. 
tion can be multiplied from every part of the Union. No wonder that lumbermen argue the necessity of escaping as quickly as possible from this extortion, and are discouraged from considering the advisability of adopting forestry practice, which even under more rational methods of taxation offers as yet only doubtful inducements.

Just as the direct tax can be regulated to encourage or deter private enterprise, so tariff legislation, as is well known, has had the protective feature added to its fiscal objects.

Import duties have been designed to reduce or deter the importation of wood materials and to encourage home industry by this artificial raising of prices, as in the United States and in Germany, and export duties have been placed, as in Canada, on raw forest products in retaliation or to prevent reduction of raw materials and to insure their preservation for use in home industry. In both cases the argument has been brought forward that such duties encouraged the practice of forestry.

Theoretically, plausible reasons may be adduced for such an expectation; practically, no such results can be noted. An increase in the price of wood materials simply stimulates the forest exploiter to increased effort in reaping the benefit while it lasts; he pockets the difference, and the increased margin only reduces the necessity of applying more economical methods of utilization until home competition, induced by the increase of price, counter- 
balances the benefit; and even then the effect is rather to greater wastefulness in the exploitation, to forest destruction, or increase of effectiveness in the existing wood-working business, than to the establishing of a new industry, the forestry business. A duty which prohibits or essentially curtails importations, the demand remaining the same, can only tend to increase the cut, and more rapid decimation of our own resource.

In other words, the encouragement is toward greater consumption of existing forest products as far as the exploiter can bring it about, rather than toward efforts at their renewal.

The reason is clear, if we recall our discussions on the nature of forest growth and on the nature of the forestry business.

The larger part of the harvest of a nature-grown wild woods is inferior material, which is either unsalable or unprofitable to handle. If the tariff, therefore, stimulates wood consumption, or by the exclusion of foreign-grown material necessitates a larger output from the native woods, this waste by necessity must be also increased. A rational tariff, which had in view the benefit and conservation of the natural forest resource, would put a premium on the importation of the better grades, and would absolutely prohibit the importation of the poorer grades, when the disparity of poor and good grades in the home exploitation might be somewhat alleviated, a closer utilization made 
possible, and at least conservative lumbering would appear more profitable.

Export duties, if placed high enough to prevent practical exportation, would appear a more reasonable method of influencing exploitation; but when we consider that, for instance in the United States, the value of forest products exported hardly exceeds 5 per cent of the value represented in home consumption, and is counterbalanced to at least one-half more by importations, it would appear that the influence of an export duty, at least for this country, could hardly have any appreciable effect in establishing forestry practice.

But all such devices influence only the present or short future, while the interests of the forestry business are in a distant future. We must never forget that financially forestry means foregoing present revenue, or making present expenditures for the sake of future revenue.

To induce private owners to begin such a conservative policy is hardly to be attained by tariff legislation, unless a definite obligation is laid upon them to spend a part of the increased earning in that direction.

The case is entirely different when a systematic forestry business is actually established and in competition with importations from a country where crude exploitation of virgin forests is still practised, which threatens to make the home enterprise unprofitable. 
While in general mercantile business it may then be argued that the unprofitable business had best be abandoned, the forestry business, as we have seen, occupies an exceptional position, both in the time element required to secure working capital of standing timber and establish the systematic industry, and in its general cultural significance, so that, aside from mercantile considerations, interference from outside competition is harmful to national prosperity.

Such is the case in European countries with wellestablished forestry systems, when brought into competition with countries which are still mainly exploiting natural resources.

Yet a prominent writer on the subject of import duties on wood ${ }^{1}$ discusses the influence of such on German forestry as follows :-

"The question as to whether high prices, especially as a result of tariff, encourage to reforestation and forestry practice or to forest devastation, is for Germany, according to the latest statistics, of no import. Deforestations on a large scale and excessive overcutting without reference to the future are here neither induced by high prices nor prevented by low prices, but are the regular concomitant of general economic crises and unsound speculation periods."

The motives for tariff legislation in the old countries were at first fiscal ones, then fear of a

${ }^{1}$ Schwappach, "Forstpolitik," 1894, p. 16 r. 
timber famine (intelligible by the absence of means of transportation), resulting in export tariffs as early as the sixteenth and continued through the seventeenth and eighteenth centuries. To this motive was then added the mercantilistic one of desiring to produce everything in the home country, thus giving rise to protective import duties. Finally, the liberation from these economic fallacies, or perhaps, I should say, the changes in commercial economic conditions, and especially the influence of railroad building since $\mathrm{I} 860$, led, for Germany at least, to a total abolishment of all duties in 1865 . Now, however, Germany as well as almost all European countries, those which export a surplus as well as the importing ones, have protective import tariffs, the object being, as aforesaid, to foster the well-established forestry business and to protect it against competition from virgin sources.

In Germany this protective legislation was enacted in 1879 , when the opening up of the virgin woods of eastern Austro-Hungary, which are simply exploited, not managed, had brought destructive competition to the forest administrations.

The specific duties amounted then to about 3 per cent on the value of unmanufactured logs and timber, and 4 per cent on manufactured lumber, .60 and $\mathrm{I} .50 \mathrm{mk}$. respectively per cubic metre (70 cents per 1000 feet B.M.), - with the result of reducing importations, of the latter at least, by 40 per cent; but the railroads equalized the difference, 
and in 1885 an increase in duties of 6 per cent and 12 per cent respectively was inaugurated, which, in I892, was again modified and reduced by special treaties.

In the United States and countries similarly situated the problem is quite a different one. Forest management is not in existence. Our only competitor on the lumber market is Canada. In both countries the virgin forest is simply exploited ; the protection afforded by a tariff would, therefore, not be of that general economic import. A duty which prohibits or essentially curtails importations, the demand remaining the same, can, as has been said, only tend to increase the cut and more rapid decimation of our own resource. A duty which does not prohibit or curtail essentially importations is not likely to benefit the forest, but only to reduce the profit of the Canadian lumberman, and possibly to put a part of the difference into the pocket of his American competitor.

The one promotive action of the state, which is preëminently required to establish a proper forest policy, the propriety of which cannot be questioned for a moment, and which arises from the primary function of the state, its police function, is to afford protection to forest property, at least equal to that afforded to any other property and adequate to the peculiarities and needs of such forest property.

Such protection is the unquestioned right of the forest owner, and without it he cannot be expected 
to maintain a "sustained yield " management which requires maintenance of a large wood capital subject to depredations and to destruction by fires unless properly guarded.

Forestry as a business is practicable, nay, thinkable, only under the assumption of civilized, stable conditions, and the first requisite of civilization is reasonable safety of property.

There are, to be sure, especially in only partly developed countries or sections of country, special difficulties in enforcing laws and preventing crime; nevertheless, the obligation of the state is to make an adequate effort.

It is not sufficient for the state to legislate, but, at least wherever broad communal interests are at stake, it must provide the machinery to carry out this legislation. The impotency of the laws designed to prevent forest fires is too well known to need comment. In this respect, in police organization and the proper means of executing the laws and of preventing damage, even the states which have attempted to remedy the evil of forest fires are wofully backward. We can learn from Canada and from the British India forest department, how a large amount of this damage can be prevented, even in countries which as yet lack a systematic, thoroughly established forestry system. Such protection is a conditio sine qua non, the first step to a state forest policy, and the beginning of forestry practice. 
Our present conditions in that respect discourage, and rightly so, all efforts to provide for future crops, and encourage rapid exploitation in order to secure the value of the existing crop before the fire has swept it away.

The principles most needful to keep in view when formulating legislation for protection against forest fires ${ }^{1}$ are :-

(I) A well-organized machinery for the enforcement of the laws must be provided, in which the state must be prominently represented, since the damage done by forest fires extends in many cases far beyond immediate private and personal loss.

(2) Responsibility for the execution of the law must be clearly defined, and must ultimately rest upon one person, an officer of the state; but every facility for ready prosecution of offenders must be at command of the responsible officer.

(3) None but paid officials can be expected to do efficient service, and financial responsibility in all directions must be recognized as alone productive of care in the performance of duties, as well as in obedience to regulations.

(4) Recognition of common interest in the protection of this kind of property can come only by a reasonable distribution of financial liability for loss between the state and local community and the owners themselves.

Only when the state has made ample and reason1 See Appendix for draft of a forest fire law. 
ably efficient provisions to protect forest property may the community impose obligations upon the owner and restrict him in the use of his property, so that the protection can be made reasonably practicable; and only then and for such purpose may regulations in the use of the property, interference by the state in its unrestricted management, be adjudged admissible even in those forests which we have designated as supply forests, i.e. those which have mainly or only an industrial and commercial significance. In other words, we conceive as a primary condition for the application of restrictive measures, in the use of private property, that the state furnish a quid pro quo, a compensation, direct or indirect.

It has frequently been proposed in the United States to force the lumberman to burn his débris in order to reduce the fire danger. This prescription may be practicable and expedient in some cases, but not in others; in its generality it would be both impracticable and inexpedient, unless specific precautions and supervision accompany it, as pointed out on pp. I $88 \mathrm{ff}$. Here also the practical objection would be properly raised that, unless all the states, or at least a group of states under similar conditions, exact such precaution, the lumberman's industry in the one state which exacts it would be placed at a disadvantage as compared with the neighboring state which neglects it. In such case, it would appear equitable that 
at least part of the burden should be borne by the state or local community.

In European countries the existence of wellorganized state forest administrations renders the execution of legislation for the protection of forest properties much easier, since there is a machinery of officials whose functions can be readily extended.

These officials, as well as those employed by private owners under prescribed conditions, are under oath, uniformed, and endowed with sheriffs' power, and can, therefore, act readily. Even the forest owner has, in Prussia, the right to call out assistance to fight fires, which assistance is obligatory on every citizen.

Curiously enough, regarding property rights, the mediæval idea, that the forest is more or less common property ("quia non res possessa, sed de ligno agitur"), dominates still the modern laws of Europe, which look with more leniency upon depredations on forest property than upon other common theft, and the proceedings and amount and character of punishment are also special. Among the latter obligatory work in the forest is a significant one. But the punishment for incendiaries is so much severer. The German code makes wilful incendiarism punishable by penitentiary up to ten years, and negligent incendiarism by prison up to one year. Railroad companies are obliged to maintain safety strips as described on p. 194, and are enjoined to take other precautions. 
With the efficiency of the state organization in protecting forest properties comes also the increased ability of the private interest to help itself, and finally the propositions for a forest fire insurance on the principle of mutuality, such as have been lately ventilated, especially in the Prussian province of Hanover and in Saxony, may become practicable.

As we have seen in the chapter on silviculture, there are, besides the fire danger, insect pests and wind-storms to be feared, and hence they call for measures of a police character. To insure against excessive damage by insects, coöperation on the part of private owners may be enforced, as is done in most German states. To protect a neighboring forest against windfalls, the removal of the adjacent forest growth is prevented in Austria, a rather doubtful exercise of restrictive functions.

Generally speaking, restrictions and supervision of private forest industry have proved themselves mostly undesirable and impracticable; their only justification would appear when protection of neighboring properties or of general communal interests demonstrably require them.

The mediæval attempts at legislation which forestry reformers in the United States have made or proposed, in their mistaken belief that the old countries furnish a precedent, namely, restricting private owners in the size of trees which they may be allowed to cut, or requiring them to plant a 
tree for every one cut, will appear rather ludicrous to those who have read the three preceding chapters.

How averse even European governments are to restrictive measures may be learned from the manner in which the Prussian law works; where only minor local interests are at stake, the principle "de minimis non curat prator" prevails. Whenever a property owner thinks or fears that the mismanagement of his neighbor's property is endangering his own property he may call for a jury to view the case, and the state will interfere according to the verdict, either forbidding absolute clearing, or prescribing the manner in which the property may be utilized; the loss which, if any, may accrue to the forest owner from this curtailment of the free exercise of property rights may be assessed on the complainant who is benefited, as well as the cost of proceedings.

For fiscal reasons only, a supervision over the management of forest properties belonging to communities, villages, and cities is exercised on the same principle which is applied in preventing communities from incurring debts beyond certain iimits determined by the state. This supervision consists usually in the requirement that no permanent clearing be made without special permission, that the plans of management be submitted for sanction by the government, and that approved skilled foresters be employed. 
Wherever else supervision or interference with the free exercise of property rights exists on the part of the state, it is not based on questions of supply, but of protection to threatened interests of some magnitude.

In this respect, as we have seen, forest property assumes a peculiar position.

The recognition of the fact that the removal of the protecting forest cover may give rise to shifting sands and sand dunes, which may encroach and despoil larger areas beyond, is sufficient call for the exercise of the police functions of the state to prevent such damage, if we admit the providential character of such functions.

The experience that the deforestation or even bad management of the forest cover, forest devastation, on mountain tops and hills, leads to excessive water stages, to destructive floods, filling channels, thereby impeding navigation and silting agricultural soils, damaging neighboring or distant interests, again makes the exercise of the police function of the state, in the wider sense in which I have defined it, necessary in order to prevent the consequences of mismanagement of the protective forest cover in such particular situations.

The sugar planter in Louisiana, whose crop is endangered or destroyed by overflows due to causes a thousand miles away, has a right to protection through the government. The city mer- 
chant, the mechanic, the laborer, the professional man, are either directly or indirectly interested in the success of the agriculturist, and hence whatever disturbs the peaceful prosecution of the business of the latter is a matter that affects everybody and calls for public concern. He who is in safety is as sure to feel the losses as he who is directly in the path of the flood. Hence we should consider the protection of our watersheds as much a national problem as the improvement of our waterways, and even more so.

No new functions are called into play, simply the primary function of all government, the police function, only extended according to our present knowledge of the relations of things.

Logically, to be sure, if it is once admitted that the state is justified in preventing the mismanagement of a property, when by such mismanagement damage is inflicted upon neighbors, the further suggestion lies near, that it may enforce the placing in proper condition of a property which in its improper condition is a menace to other interests. Here, however, the innocence of the owner in the creation of these unfavorable conditions may modify the aspect of things, and we must appeal from the police function to the wider socialistic function which imposes upon the state the duty, not only to maintain social existence, but to assist social progress by coöperation, or, as Lester F. Ward puts it, "to render harmless those forces which 
now seem to be working evil, and to render useful those now running to waste."

In this way we come to the function of internal improvement. As a matter of fact, these principles have found expression in the forest policies of various European nations, as we shall see in the next chapter.

The forcible reforestation of denuded mountain slopes by the owners with the financial aid of the state, as carried on in France, Italy, Switzerland, and Austria, is an admission of this double obligation, namely, that of the owner to keep his property in proper condition and that of the state to secure internal improvement. Such improvements, to be sure, must be palpably of public benefit and not of advantage to individual interests only; where forest growth would be simply useful, the state may employ ameliorative measures, indirectly encouraging private enterprise, but where a forest growth is indispensable to the public welfare, its duty is farther reaching, and coercion or other interference is called for. It will appear at once that the distinction is one which must be made in each individual case. The adequacy of the interest for which the state enters must be apparent.

As to the methods and manner of applying these principles, a variety may be suggested. The determination as to the protective quality and necessity of maintaining the forest property as such, and the quality of the state's interference, may be pre- 
scribed generally, as in the law of Italy, or specifically in each case, as in the law of Bavaria. The interference may consist in simply forbidding an absolute clearing, or else prescribing the manner in which the property may be utilized.

Where, on account of the smallness of separate holdings, a good forest management could not be maintained, coercive coöperation, the management of all the parcels as a unit, may recommend itself, or else the state, having a well-officered forest administration, may undertake the management for the owner, at least for a time. Where reforestation becomes necessary, it has usually been recognized incumbent upon the state either to reimburse, or at least to assist and alleviate, the burden of reforestation by relieving from taxation, for a given time, the land to be reforested, as is done in France for thirty years, and in Austria for twenty-five years, or by the granting of bounties on plantations, as practised in Austria and Prussia and also in the United States. Or else supplies of plant material have been granted, or part of the cost of planting is borne by the state, or else loans at low interest have been given to ease the burden of replanting. This very judicious assistance was given by the province of Hanover during the years 1877 to 1883 ; in order to encourage the planting of the Luneburg heath, the sum of nearly $\$ 100,000$ was loaned to nine associations, ten cities, and thirty-one private landowners, by means of which 
about ten thousand acres of this hitherto barren and almost useless part of the province became productive.

Finally, however, it will be found that control and supervision of private property is an unsatisfactory, expensive, and only partially effective method of securing conservative forest management, where the necessity of maintaining a forest growth may exist and the financial margin that can be had from it is but small. Experience in the old countries has shown that, in spite of the much more perfect machinery for enforcing laws, and in spite of the much more ready disposition to submit to laws, than we are accustomed to see in this country, the attempts to control private property have been largely without the desired result. It then becomes preferable for the community to own and manage such forest areas.

Such ownership may rest either in the state or else in the county, the town, or other political subdivision which seems most nearly interested in the maintenance of the protective cover. To obtain possession, if it cannot be had by purchase, the necessity of exercising eminent domain may arise. Such eminent domain is now exercised in most civilized states where public objects, public safety, or public utility require it; usually, however, the objects for which this power may be called into requisition are definitely stated by law.

If the question of protection of forests be once 
recognized as of importance to the general welfare, there is no reason why it should not be declared by law to justify the exercise of this power. And while usually the right to expropriation is reserved to the state, and presumably the objects are supposed to be an advantage to the whole, there can be no logical reason why this right may not be exercised for any parts of the state, or for any consid. erable portion of the community, provided the interest to be subserved is communal and not individual. Where the interests are of less range or significance, the maxim "de minimis non curat pretor" may place the matter in that class of cases which must be adjusted by appeal to jury and by simple police regulation, as provided by the Prussian law.

In practice the expropriation of forest property as a protective measure has found expression in France, Italy, Switzerland, and Austria.

In France, according to the law of I860, private woodlands could be expropriated when the owners refused to reforest or keep in forest, but restitution could be demanded within five years; this very improper clause was abolished in $\mathrm{I} 882$.

In Switzerland the canton is empowered to, and at the request of the owner must, expropriate.

In Italy the state, province, or community can exercise this right for the purpose of reforesting slopes to secure stable soil conditions and to regulate waterflow. 
In Austria a limited right to expropriate exists at the instance of the owner who cannot or does not desire to submit to regulations.

We may now summarize briefly the results of this discussion.

A rational forest policy requires a distinction into supply forests and protection forests.

The former may be largely left to the free exercise of private enterprise, the state affording only the general protection accorded all property, and also the more specific protection which the peculiarities of forest property demand.

In addition, the educational functions of government may be called into play by giving opportunity to acquire the needed technical knowledge, and such other ameliorative action may be resorted to as will assist and make possible a conservative management of forest property. This action is of more import in the forest industry than in other industries, because of its peculiarities, as pointed out. In certain given cases, temporary exemption from taxation, supplies of plant material, or better, financial assistance, may prove beneficial when the low rate of interest which the state commands will benefit the forest owner and enable him to reforest waste places, while tariff legislation, as far as it is to protect not exploitation, but to make possible a conservative forest management, may become necessary. Ownership of portions of the forest resource by the state, either as a fiscal 
measure, or, with much better reason, for the pur. pose of equalizing forest supplies and also for educational reasons, may be extended to supply forests, but probably these objects can be attained by the ownership of protection forests alone.

In the case of protection forests the degree and extent of their influence must determine the quality of state control. The police function, either in its restricted sense or else extended in its meaning to assume a providential character, lies at the base of such control. Interference in or control of private forest management may suffice in cases where merely individual interests must be protected. Financial assistance and partial assumption of . costs may be the proper policy where internal improvement is sought, where unavoidable disasters are to be remedied, or where the interests of the community must be protected and the owners are not able to comply with the requirements. Where far-reaching communal interests require the maintenance of a forest cover and its conservative management, especially on poor mountain soil, sand-dunes, etc., the ownership by the community, the state, or smaller subdivision becomes unavoidable, since they can afford to forego revenue on the investment and manage with the single view to the general welfare.

The freedom of private forest ownership has in Germany, and especially in Prussia, led not only to forest dismemberment and forest devastation, but 
also to inconsiderate clearing. On good soils this clearing may lead to something permanently better; on mediocre and poor soils the result has been that agriculture, after the fertility stored up by the forest is exhausted, impoverishes the deluded farmer. These soils are now utterly ruined wastes, and can be made useful by reforestation only.

Finally, when the ideal, the socialistic, coöperative, most highly organized state will have developed, the policy will be that the community shall own or control and devote to forest crops all the poorest soils and sites, leaving only the agricultural soils and pastures to private enterprise. 


\section{CHAPTER X.}

\section{FOREST POLICIES OF FOREIGN NATIONS.}

THE conditions which a hundred years ago influenced the policies of European nations in regard to their forest policies, - namely, the necessity of looking out for continuance of domestic supplies have long ago changed. At that time the fuel question was still the important one, for coal had not yet become an established substitute, and, in the absence of railroad transportation, home supplies were a necessity.

The many ordinances and laws, therefore, which attempted to assure continued home supplies have fallen into disuse, although the desirability of fostering home production and of securing the advantages of a general economic character which come from forest management - notably the employment of labor in winter time, which the forest industries offer - have still an influence upon the policy of governments, or are at least academically discussed as properly establishing a government interest even with regard to supply forests.

In the main, however, the state forest policies of the European governments are based upon the 
protective value of the forest cover, and the recognition that private interest cannot be expected or is insufficient to secure proper regard to this feature in its treatment of forest areas.

It cannot be said, however, that a finally settled policy exists in any of the states, not even in Germany, but only that it is in a highly advanced stage of formation, with the tendency of increasing governmental interference.

All the various methods of giving expression to state interest are employed; the educational function, the police function, and finally state ownership, being brought into use.

State ownership of forest areas, which in the beginning of the century began to decrease under the influence and misapplication of Adam Smith's teaching and the doctrine of individual rights, urged to its extreme consequences after the French Revolution, is now on the increase. Thus France, during and after the Revolution taking the lead in this dismemberment of the forest property, which the monarchy had maintained (then nearly 12 million acres), sold during the years I 79I to I 795 nearly one-half of the state forests, and continued to reduce the area until there remained in 1874 but one-fifth of the original holdings. Since then a reversal of the policy has been in practice, the area of state holdings is being increased, besides financial assistance in reforesting on a large scale being given to private owners and communities. 
In the budget for 1902 , of $\$ 2,800,000$ appropriated for the state forest department, $\$ I, 000,000$ was set aside for the extension of state forests and necessary improvements in those now existing. The state now owns about 2,800,000 acres, - somewhat over 12 per cent of the total forest area, managed by a staff of 700 officials and protected by 3500 guards.

In addition, private forest property is absolutely controlled as regards clearing; no clearing may be done without notice to the government authorities, and in the mountain districts not without special sanction by the same.

This control is especially stringent with reference to the holdings of village and city corporations, which represent over 27 per cent of the forest area. These must submit their plans of management to the state forest department for approval, and are debarred from dividing their property, thus insuring continuity of ownership and conservative management.

The necessity for such control became apparent in the first quarter of the century, when, as a consequence of reckless denudation in the Alps, Cévennes, and Pyrenees, whole communities became impoverished by the torrents which destroyed and silted over the fertile lands at the foot of the mountains. Some $8,000,000$ acres of once fertile soil in twenty departments were involved in these disastrous consequences of forest destruction on 
over $1,000,000$ açres of mountain slopes. The work of recovery was begun under the laws of 1860 and I 864, and a revised law, the reboisement act, of 1882 . Under this law the state buys and recuperates the land, or else forces communities or private owners to do so with financial aid from the government.

Since the operation of this law the state has spent in purchases of worn-out lands, in works to check the torrents and in reforesting, nearly $\$ 20,000$,oo, not including subventions to communities and private owners. It is estimated that more than $\$ 30,000,000$ more will have to be expended before the area which the state possesses or will possess, probably some 800,000 acres in all, will be restored.

The work of fixation of sand-dunes, which has occupied the attention of foresters in all states bordering the sea-coast, has been prominent in France since the beginning of the nineteenth century, especially in the Department of the Gironde, where during the years 1802 to 1864 a round $\$ 300,000$ were spent in coöperation between the state, the municipal corporations, and private owners to fix the 250,000 acres of sand-dunes and turn them into pine forest, which now, together with I, 500,000 acres of forest planted in its protection during the last century, yields a constant revenue and occupation for the poor population.

A state forestry school at Nancy educates the officers, and is among the best on the Continent.

Englaind, in the home country, has had little 
need of a forest policy on account of -its insular position and topography, although one-quarter of the country is waste, on which it would pay to cultivate wood-crops. It imports nearly all its needed wood supplies with over \$100,000,000. Of the $3,000,000$ acres of woodlands, mostly devoted to purposes of the chase or to parks, 2 per cent are state forests, and so encumbered with rights of adjoining commoners as pasture or for wood supplies that no rational management is possible. But in India there is a well-organized state forest administration, and the government there exercises itself also in promoting private forestry. The policy here differs from those in existence on the Continent of Europe, in that it is based on the supply question rather than the protective value of the forest cover.

In the past the native people of India, as far as known, never realized the importance of their forests. They were mostly more or less common property, or else belonged to the rajas. They were cleared, destroyed, mutilated at all times and in all places, and the use of wood seems never to have formed an important factor in Hindoo civilization.

With the advent of foreign commerce, exploitation for the more valuable export timbers received a new stimulus, and the forests were culled regardless of the future either of forest or people. This exploitation was aggravated by the construction of railways, which, in themselves large consumers, 
also offered a premium on all that contributed to increased traffic. When at last it was noticed that the demands of timber for public works in some localities could no longer be supplied without costly transportation, the matter received the tardy public attention.

The present effective organization of a forest department and forestry service, covering now a forest property of nearly 100,000 square miles, was established under the guidance of German thought and German methods, and for nearly half a century the heads of the state forest department were German foresters. ${ }^{1}$

Although the conditions surrounding the problems of the Indian forest department are quite dissimilar from those with which we have to deal in our country, it will nevertheless be of interest, and suggestive for our own efforts in establishing forestry practice, to give some space to a brief account of what has been established in India.

In 1859, Dr. (now Sir) Dietrich Brandis was appointed superintendent of forests for Pegu; in I 862 he was charged with the duty of organizing a forest department for all India, and in 1865 he was appointed the first inspector-general for the forests of India under the first Indian Forest Act. During the forty years of its existence this department has steadily and rapidly grown in the

${ }^{1}$ Refer to the excellent account of this movement in B. Ribbentrop, "Forestry in British India," Calcutta, 1900, 245 pp., 8vo. 
area managed, the number of men employed, and the revenue derived for the state. In 1898 this forestry department had control of about 90,900 square miles of forest, nearly half of all the forests, and about ro per cent of the entire area of India. Of these state forests, nearly 82,000 square miles are "reserve" or permanent state forests, while the rest are held as "protected" and "unclassed," and will become reserve or permanent forests as fast as the necessary surveys and settlement can be made.

The area of protected reserved forests is constantly varying, for although new areas are taken up, others are changed into reserves. About 28,000 square miles of forest property of the empire remain still unclassed. On page I I4 we have given an account of the personnel required in the management of this largest and youngest forest department of the world and its financial results.

More than half of India lies within the Tropics, and over 60 per cent is farther south than New Orleans, the latitude of which is $30^{\circ}$. From this it is apparent that the climate is generally hot, but, owing to diversity of elevation and peculiarities of the distribution of rainfall, it is by no means uniform.

The rains of India depend on extraordinary sea winds, or "monsoons," and their distribution is regulated by the topography of land and the relative position of any districts with regard to the 
FOREST POLICIES OF FOREIGN NATIONS. 28I

mountains and the vapor-laden air currents. Thus excessive rainfall characterizes the coast-line along the Arabian Sea to about latitude $20^{\circ} \mathrm{N}$., and still more the coast of Lower Burma, and to a lesser extent also the delta of the Ganges and the southern slope of the Himalayas. A moderately humid climate, if gauged by annual rainfall, prevails over the plateau occupying the large peninsula and the Lower Ganges Valley, while a rainfall of less than fifteen inches occurs over the arid regions of the Lower Indus. In keeping with this great diversity of climate, both as to temperature and humidity, there is great variation in the character and development of the forest cover. The natural differences in this forest cover are emphasized by the action of man, who for many centuries has waged war against the forest, clearing it permanently or temporarily for agricultural purposes or else merely burning it over to improve grazing facilities or for purposes of the chase. Thus only about 20 per cent of the entire area of India is covered by woods, not over 30 per cent being under cultivation, leaving about 50 per cent either natural desert, waste, or grazing lands. The great forests of India are in Burma; extensive woods clothe the foot-hills of the Himalayas and are scattered in smaller bodies throughout the more humid portions of the country, while the dry northwestern territories are practically treeless wastes. In this way large areas of densely settled districts are 
so completely void of forest that millions of people regularly burn cow dung as fuel.

In the greater part of India the hardwood forest (conifers are scarce and confined in locality) consists not of a few species, as with us, but is made up of a great variety of trees unlike in their habit, their growth, and their product, and if our hardwoods offer on this account considerable difficulties to profitable exploitation, the case is far more complicated in India. In addition to the large variety of timber trees, there is a multitude of shrubs, twining and climbing plants, and in most forest districts also a dense undergrowth of giant grasses (bamboos), attaining a height of 30 to 120 feet. These bamboos, valuable as they are in many ways, prevent, often for years, the growth of any seedling tree, and thus form a serious obstacle to the regeneration of valuable timber. The growth of timber is usually quite rapid; the bamboos make large, useful stems in a single season. Teak grows into large-size saw-timber in fifty to sixty years. But in spite of this rapid growth and the large areas not now in forest but capable of reforestation, India is not likely - at least within reasonable time - to raise more timber than it needs. In most parts of India the use of ordinary soft woods, such as pine, seems very restricted, for only durable woods, those resisting both fungi and insects (of which the white ants are specially destructive), can be employed in the 
FOREST POLICIES OF FOREIGN NATIONS. 283

more permanent structures, and are therefore acceptable in all Indian markets.

With the irregular distribution of forests, the peculiarities of Indian affairs, and the unsurveyed wild, and difficult conditions of the forests themselves, it is but natural that the work thus far has been chiefly one of organization, survey, and protection, and to a far less degree an attempt at improvement by judicious cutting and reforestation.

Over 23,000 square miles have been surveyed for forest purposes since I874, at a cost of over $\$ 1,500,000$.

Work of establishing and maintaining boundary lines, which is often a very difficult and costly matter in the dense tropical jungles, involved during one year, I894, an expense of over $\$ 40,000$, and there are at present over 93,000 miles of such boundary lines maintained. Besides this survey work proper, there is a large force constantly at work to ascertain the amount and condition of timber supplies and to prepare suitable plan for their exploitation and improvement, so thá over 20 per cent of the entire forest area, or about 20,000 square miles, is by this time managed with definite working plans as to amount of timber to be cut, the areas to be thinned, reforested, etc.

The work of protection is chiefly one of preventing and fighting fires. This protection, with present means, cannot be carried on over the entire forest areas, of which large tracts are not even 
crossed by a foot-path, and in a land where the regular firing of the woods has become the custom of centuries, and where, in addition, intensely hot and dry weather, together with a most luxuriant growth of giant grasses, render these jungle fires practically unmanageable. In all forests near settlements the forest must be isolated by broad "fire traces" or otherwise. In the jungle forests these traces must be broad; the grass, often taller than an elephant, must be cut and burned before the grass on either side is dry enough to burn. Similarly, the traces in the longleaf pine forests must be very wide and first converted into grass strips, cut or kept clean by burning. In spite of the unusual difficulties there were, in 1898 , over 32,000 square miles protected against fire, and on only 8 per cent of this area did the element succeed in doing any damage. In this work, too, great progress has been made during the last twenty years; the efficiency has steadily increased, and the expense, about \$10 per square mile in 1883 , has been reduced to less than half, or 2 per cent, of the gross revenue.

In the protection against unlawful felling, or timber stealing and grazing, the government of India has shown itself fully equal to the occasion by a liberal policy of supplying villagers in proximity to the forests with fuel, etc., at reduced prices or gratis. Over $\$ 2,000,000$ worth was thus disposed of in $1894-1895$, the incentive to timber 
stealing being thereby materially reduced. A reasonable and just permit system of grazing, where again the needs of the neighboring villagers are most carefully considered, not only brings the government a yearly revenue of nearly $\$ 800,000$, but enables the people to graze about $3,000,000$ head of animals in the state forests, without doing any material damage to tree growth.

Though the forests of India are now, and will continue for some time, little more than wild woods, with some protection and a reasonable system of exploitation, in place of a mere robbing or culling system, yet the work of actually improving the forests steadily increases in amount and perfection.

In the large teak forests of Burma, as well as other provinces, care is taken to help this valuable timber to propagate itself; the useless kinds of trees are girdled, huge climbers are cut off, and a steady war is waged against all species detrimental to teak regeneration. Where the teak has entirely disappeared, even planting is resorted to. Thus in Burma over 35,000 acres have been restocked with teak by means of taungyas, or plantations, where the native is allowed to burn down a piece of woods, use it for a few years as field (though it is never really cleared) on condition of planting it with teak, being paid a certain sum for every hundred trees in a thrifty condition at the time of giving up his land. 
Similarly, the department expends large sums in establishing forests in parts of the arid regions of Beluchistan, and, on the whole, has spent on cultural operations, in different years, from 2 to $5 \frac{1}{2}$ per cent of its gross revenue, namely, at the rate of about \$I25,000 per year, over I00,000 acres having been planted since 1880 .

In disposing of its timber the government of India employs various methods. In some districts the people, paying a small tax, get out of the woods their needs. In other cases, the logger pays for what he removes, being neither limited in quantity nor quality of product. The prevalent systems, however, are the permit system, where a definite amount is to be cut and paid for, and the contract system, where the work is more or less under control of government officers, and the material remains governmental property until paid for. To a limited extent the Forest department carries on its own logging operations. In spite of many difficulties, a poor market (no market at all for a large number of woods), wild, unsurveyed, and practically unknown woodlands, unusual and costly organization and protection, the forestry department has succeeded, without curtailing the timber output of India, to prepare for an increase of output in the future, and at the same time has yielded the government a steadily growing revenue which bids fair before long to rank among the important sources of income. 
The growth of both gross and net revenue is illustrated in the following figures, rounded off, and figuring the rupee at one third of a dollar. ${ }^{1}$

\begin{tabular}{l|c|c|c|c}
\hline & $\begin{array}{c}\text { Gross } \\
\text { Period. }\end{array}$ & Expenditure. & Surplus. & $\begin{array}{c}\text { Proportion of } \\
\text { Expenditure to } \\
\text { Revenue. }\end{array}$ \\
\cline { 2 - 4 } & \multicolumn{3}{|c|}{ M dollars. } & Per cent. \\
\cline { 2 - 4 } $1865-67$ & 1,200 & 740 & 460 & 61 \\
$1868-72$ & 1,540 & 1,100 & 440 & 71 \\
$1873-77$ & 2,180 & 1,470 & 710 & 67 \\
$1878-82$ & 2,360 & 1,630 & 730 & 67 \\
$1883-87$ & 3,560 & 2,280 & 1,280 & 64 \\
$1888-92$ & 4,750 & 2,700 & 2,050 & 56 \\
$1892-97$ & 5,700 & 3,120 & 2,580 & 55 \\
$1897-98$ & 5,930 & 3,400 & 2,530 & 57 \\
\hline
\end{tabular}

This steady rise in revenue in response to a rise in expenditures, is one of the best arguments of the efficiency of the administration, brought about by a liberal policy in paying for efficient administration, including a generous pension system - a policy which in its results compares most favorably with the stingy, niggardly policy which usually prevails in the United States in the employment of public officers. The inspector-general receives about $\$ 8000$, and the conservators about $\$ 5000$ per annum.

${ }^{1}$ The figures given on p. II5 differ on account of different value used in translating rupees. 
In the expenditures it is of special interest to note that fire protection absorbs less than 2 per cent of the gross revenue, namely, about $\$ 100,000$ per year, and about as much is expended on cultural operations, while the superior staff absorbs a little over 13 per cent and the subordinate staff with office establishments 14 per cent.

The forest laws of India were, like those of most countries, a matter of growth and adaptation, with the important difference, however, that the welldefined object of preserving a continuous supply of the all-essential timber was from the beginning steadily kept in mind. The principal acts are those of 1865,1869 , and especially the "Indian Forest Act" of 1878, with secondary legislation applying to particular localities, such as the act of I 88I for Burma and of 1882 for Madras, and others.

In general, these forest laws provide for the establishment of permanent or "reserved" state forests, to be managed according to modern forestry principles. They provide for a suitable force of men, give the forest officers certain police powers, prohibit unwarranted removal of forest products, the setting of fires, or otherwise injuring the forest property. The laws also regulate grazing and the chase by permit systems, and prescribe rules by which the work of the department is carried on, as well as the manner in which officers are engaged, promoted, etc. Since the peculiar circumstances require men specially fitted 
and trained, schools were established to furnish the recruits for this steadily growing service. There is one at Cooper's Hill, England, where a thorough course is intended to prepare men for the superior staff positions, and the Imperial school at Dehra Dun, which is to supply the great number of the executive staff, the young men starting in usually as guards or rangers at a pay of about $\$ 25$ per month, working their way up to places worth $\$ 50$ per month, and if well suited, eligible for further promotion. In the Dehra Dun school and the executive staff, the native element is fast making itself felt, and there is little doubt that the men of India will soon be able to manage the forests of their own native land.

In most of the English colonies, there exist also beginnings of a forest policy, and in several of them, at least, forestry departments, albeit inefficient or impotent, as in New South Wales, whose timber wealth, originally enormous, is now rapidly deteriorating under a loosely managed license system, although the department of agriculture and forestry employs some 350 "foresters" and assistants on the 5,500,000 acres of forest land belonging to the government.

Similarly in Western Australia, the conservator of the department of woods and forests is apparently powerless to extend any improved system of utilization over the $20,000,000$ acres of woodlands to which the magnificent Eucalypts, especially the 
Jarrah, Karri, and Red Gum, lend special value. The government merely controls the cutting by issuing licenses under certain reservations, and by collecting the revenue.

In South Australia, which is mostly a forestless plains country, a forest department was instituted in 1876 for two purposes, namely, to plant and administer state forest reservations, and to grow trees for free distribution. In 1890 there were about 2 I 5,000 acres planted and in reservations, and during the fourteen years some 4,500,000. seedlings had been distributed; the expenses above receipts having been $\$ 120,000$ during the period.

Cape Colony seems to be similarly situated, mainly forestless, and hence merely interested in tree planting, which is done in a small way by four conservators, who are directly under the Minister of the Colony. Here the government also assists municipalities in covering their watersheds by contributing half the expense.

Even in the Soudan we note a beginning, a report for a plan having lately been at last called for.

The Germans in their African possessions have also begun to introduce their painstaking forestry methods with success.

Two years ago Egypt also entered the ranks of states with a forest policy, encouraging reforestation by relief of taxes on planted land.

The country which, next to British India, can claim to have the largest forest area under one 
policy is Russia. Although one of the export countries, with $\$ 30,000,000$ to $\$ 35,000,000$, and largely in the pioneering stage, Russia in Europe, well wooded with $500,000,000$ acres in forest, although much in poor condition, has a well-devised forest policy, developed within the last thirty or fifty years, which consists not only in maintaining government forests to the extent of about $300,000,000$ acres, divided into 1500 districts under tolerably good management, and I 5,000,ooo acres of Crown forests, personal property of the royal family, but in restricting private owners ( $110,000,000$ acres in large domains and $75,000,000$ in lands of small owners) from abuse of their property, where the public welfare demands, while in the prairie country in southern Russia large amounts of money are spent by the government in planting forests and in assisting private enterprise in the same direction.

With the Siberian forests and those of the Caucasus added, the area of government forest may reach the large figure of $600,000,000$ acres, which, though not yet all placed under management, is sooner or later to come under the existing forest administration.

The restrictive policy dates from a very elaborate law passed in $\mathbf{I} 888$, and extended greatly in I900, in which the democratic spirit in the constitution of the body controlling the exercise of property rights is interesting. The approval of working 
plans, or of clearings on private property, is placed in the hands of a specially constituted committee for each county, which includes the governor, justices of the peace, the county council, and several forest owners, and the government itself must secure the approval of this committee for its operations.

By this law, throughout European Russia, woodlands may be declared "preserved forests" on the following grounds: That they serve as preventives against the formation of barrens and shifting sands, and the encroachment of dunes along seashores or the banks of navigable rivers, canals, and artificial reservoirs; that they protect from sand drifts towns, villages, cultivated land, roads, and the like; that they protect the banks of navigable rivers and canals from landslides, overflows, or injuries by the breaking up or passing of ice ; that when growing on hills, steep places, or declines, they serve to check land or rock slides, avalanches, and sudden freshets; and that they protect the springs and sources of the rivers and their tributaries. One hundred million acres of private forest have thus come under supervision.

In these preserved forests, working plans are made at the expense of the government, and in the unpreserved forests at the expense of the owners. In each province the government maintains an inspector-instructor, whose duty is to advise those who apply to him in forest matters, 
and as far as possible he is to superintend on the spot all forestry work. The government has established nurseries, from which private owners can obtain young trees and seeds at a low price. The owners are allowed to employ as managers of their forests the trained officials of the forest administration, while medals and prizes are given yearly to private owners for excellency in forest culture and management. Two higher and thirty lower schools of forestry are also maintained by the government.

The forest institute in St. Petersburg, with a staff of 15 professors and instructors, and about 450 students, and one at New Alexandria, near Warsaw, supply the superior staff. But the most important and characteristic feature in educational direction are the 30 silvicultural schools, in which the rangers or under-foresters are educated, almost entirely at government expense. There are usually 3 teachers employed, and forestry officials having also other duties, for the 20 students at each of these schools. The total expense of such a school is about $\$ 3300$, of which the state contributes about $\$ 2500$.

Another characteristic feature is a method, revived in 1897 , from German precedent of I 50 years ago, and also practised in France, to secure reforestation of cut-over lands. The wood-merchant who cuts timber on government lands, especially in the pineries, is obliged to clear the ground of débris, 
replant it, and hand it back to the government in satisfactory condition. To insure compliance with this condition, a deposit of $\$ 2$ to $\$ 4$ per acre is exacted. Results are not as yet on record.

Russia's small neighbors at the southwestern frontier, Bosnia-Herzegovina and Roumania also can boast of quite effective forest administration. In the former, which is to the extent of 50 per cent forested, the state has, since 1878 , instituted an orderly management on its 5,000,000 acres of forest property, while Roumania, since $\mathrm{I} 88 \mathrm{I}$, has not only a forest administration for its $2,500,000$ acres of state lands, but has also a very efficient and strictly enforced forest protection law, under which 84 per cent of all the forest lands, the total forest area being $6,800,000$ acres, are declared protection forests, and their plans of management must be sanctioned by the state authorities. Since 1892 , there is also established a forest melioration fund, to which the state contributes 2 per cent of the gross revenue from its forest property, for the purpose of encouraging reforestation.

In Ausiria, which is wooded to the extent of 30 per cent, and which exports over $\$ 40,000,000$ in excess of imports, the disastrous consequences which the reckless devastation and abuse of her mountain forests by their owners has brought upon whole communities, have led to a more stringent and general supervision of private and communal forests than anywhere else. In I 868 a 
law was enacted which released reforested areas from taxes for Io years, and under some conditions for 25 years; the effect seems to have been mainly a moral and educational one. Since 1883 there has been in progress a work of recuperation similar to the French reboisement work, in which, up to I 894, nearly $\$ I, 500,000$ had been spent, the state contributing variously from 25 to 100 per cent toward covering the expense, the state itself having reforested over 200,000 acres of waste lands. A fully organized forest department manage the government forests, 2,500,000 acres, or Io per cent of the total forest area, which are gradually being increased by purchase.

Nearly 2,000,000 acres are declared protection forests, and the state exercises the right to expropriate or place under supervision private property for protective purposes. Lately (I 898), for the purpose of directing the government's policy regarding the use of its soil resources, a Land: wirthschaftrath (agricultural council), composed of 75 members, has been instituted, consisting of farmers, foresters, miners, and others. One higher and several lower schools supported by the state provide instruction.

Austria's sister state, Hungary, also has a wellestablished forest administration, and since 1879 has had a law providing for supervision of private forest lands and for reforestation of waste lands, with the assistance of the state. 
Italy has long suffered from the effects of forest devastation by droughts and floods, but the government was always too weak to secure effective remedies. Densely populated, with one-third of its area unproductive and one-quarter almost beyond redemption, no country offers better opportunities for studying the evil effects of deforestation on soil and waterflow. The state owns only 1.6 per cent, or I 16,000 acres of forest, the balance of $7,000,000$ acres belonging to communities and corporations or to individuals. Yet by the laws of I877, revised in 1888, the policy of state interference is clearly defined. Excellent though the law appears on paper, it has probably not yielded any significant results, since owing to the financial disability of the government there has not even been general enforcement. This law placed nearly half the area not owned by the state under government control, namely, all woods and lands cleared of wood on the summits and slopes of the mountains above the upper limit of chestnut growth, and those that from their character and situation may, in consequence of being cleared or tilled, give rise to landslips, caving, or gullying, avalanches and snowslides, and may to the public injury interfere with watercourses or change the character of the soil or injure local hygienic conditions. Government aid is to be extended where reforestation appears necessary.

Of the 76,000 acres which required immediate re- 
forestation for reasons of public safety, only 22,000 were reforested in twenty years up to $\mathrm{I} 886$, the government contributing $\$ 85,000$ toward the cost.

In the revised law of 1888 , as a result of the past experiences, an elaboration of the same plan was attempted by creating further authority to enforce action. It is now estimated that 534,000 acres need reforesting at a cost of $\$$ I $2,000,000$, of which two-fifths is to be contributed by the state.

Expropriation proceedings may be instituted where owners refuse to reforest, with permission to reclaim in five years by paying, with interest, the cost of work incurred by the state.

The latest addition to the inefficient means of coping with the evil is an Arbor Day imported from the United States. .

A forestry school at Vallombrosa furnishes all needed opportunity to learn the necessary forestry methods.

Our little sister republic, Switzerland, has had a long struggle during the first half of the nineteenth century to come to a rational forest policy, although the damage done by its absence was clearly enough seen. Only in I 898 has the federal government finally succeeded in becoming the executor of the protective laws in all cantons. These laws prohibit clearing in the high Alps without sanction by the federal authorities. With the assistance of the bund reforesting is done where needed. A forestry school in Zürich educates the staff. 
Sweden and Norway have been the great forest exploiters and exporters of wood materials of the last fifty years, supplying especially England with most of her needs. A comparatively large forest area (over 60,000,000 acres) accessible to water transportation by the many fiords and streams in-

- vited this exploitation, the product of which, to the extent of over 60 per cent, goes to England and France and amounts now to nearly 2,000,000,000 feet, B.M.

In Sweden, which contains nearly three-fourths of the forest area, crude beginnings of government interest are recorded from about the year I 500 . In the year 1720 a director of forests was appointed, the germ of the present Government Forest Department. It was then that the previous lax policy of the government gave place to a somewhat sentimental solicitude. "It is rather amusing to read the jeremiads that were given utterance to both inside and outside the Riksdag by the men of light and leading of that age with regard to the question of forest exhaustion, when only the fringe of the woodlands had been touched and forest property had scarcely a nominal value as a realizable asset . . the champions of a policy of restriction originated equally as much in an apprehended deterioration of climate as in an actual scarcity of wood. Both these apprehensions proved groundless, and we have the testimony of one of the foremost public men of Sweden that the 
climate of Norrland, especially, has been much improved the last sixty years by the partial cutting down of the forests." 1

In the first part of the nineteenth century laws were passed to restrict clearing, determine the minimum size of logs to be cut, and, in some parts (Lapland), where climatic deterioration was specially feared, preventing all cutting without permission from the government. The more systematic administration of government forests, some $18,000,000$ acres, dates from the year 1860, and with it a more conservative policy in the exploitation generally. The success of this administration seems not to have been conspicuous, due partly, perhaps, to an ultra conservative management, partly to the license system under which much of the State forests are cut over by lumbermen. Continuous agitation and troubling prophesies concerning the future of the timber trade led, in I 894, to a special investigation of the subject by a commission sent out from the University. As a result of this inquiry it appears that Sweden is fully able to continue her present cut, or even increase it, without exhausting her resource, provided it is sufficiently protected to permit its renewal and the cutting is done conservatively.

The simplicity of the composition of the forest, namely, pine and spruce with oak almost exclu-

1 "The Wood Industries of Sweden," Timber Trades Journal. 1896. 
sively, insure the renewal with valuable species, although it appears that the spruce is gaining over the pine. Replanting has been begun even by private forest owners; in some cases on large areas. Towns and country districts and parishes own extensive forest tracts. The parish of Orsa is an example of several in similar condition, realizing a fund of $\$ 2,500,000$ from its forest lands, which does away with the need of taxes. These areas are under the management of a local committee, with the governor of the province as chairman, a crude selection system only being practised.

The country which has attracted the greatest interest in all matters pertaining to forestry, because the science of forestry is there most thoroughly developed and applied, is Germany.

It may, therefore, be of interest not only to describe the forest policies of Germany more fully, but briefly to trace their historical development.

Although as early as Charlemagne's time a conception of the value of a forest as a piece of property was well recognized by that monarch himself, and crude prescriptions as to the proper use of the same are extant, a general, really well-ordered system of forest management hardly existed until the beginning of the eighteenth century. Sporadically, to be sure, systematic care and regular methods of reproduction were employed even in the thirteenth and fourteenth centuries. 
FOREST POLICIES OF FOREIGN NATIONS. 3OI

To understand the development of the present forest policy in Germany, one must study the peculiar conditions and development of property rights that led to it. Germany was originally settled by warriors, who had to keep together in order to resist enemies and conquerors on every side, and to be ready to move and change domicile at any moment. The soil which was conquered was, consequently, not divided, but, owned as a whole, was managed by and for the whole tribe. It is only in the sixth century that signs of private property in woodlands are discernible. Before that time it was res mullius, or, as it is expressed in legal manuscripts, "quia non res possessa sed de ligno agitur."

Wood being plentiful and yet needed by everybody, it appeared not a crime to take it unless it had been already appropriated or bore unmistakable signs of ownership, such as being cut or shaped. But severe punishments were in earliest times inflicted for incendiarism and for damage to mast trees, since the seed mast for the fattening of swine was one of the most important uses of the forest.

There was not much need of partition, especially of the forests. The community, to which all the land of a district belonged, and which was managed by and for the aggregate of society, was called the "mark," a communistic institution of most express character, and every "marker" or 
shareholder was allowed to get the timber needed by him for his own use without control.

This early communal ownership of forest land undoubtedly explains the fact that even to-day over 5 per cent of the forest is owned by communities, cities, or villages. Gradually the necessity of regulating the cutting of the wood became apparent, as the best timber in the neighborhood of the villages was removed; and we find quite early mention of officials whose duty it was to superintend the felling, removing, and even the use of the timber. By and by even the firewood was designated by officials. Manufacturers received their material free of charge, but only as much as was needed to supply the community. Occasionally there were rules that each man had to plant trees in proportion to his consumption. So that by the end of the fourteenth century quite a system of forest management had been developed.

Meanwhile the Roman doctrine of the regal right to the chase had also begun to assert itself by the declaration of certain districts as ban forests, or simply forests, in which the king exclusively reserved the right to chase. The kings again invested their trusted followers and nobles with this right to the chase in various districts, thus gradually dividing the control of the same.

While at first these reservations did not bring with them restrictions in the use of the timber or pasture or other products of the forest, these uses 
were gradually construed as exercised only by permission, and the former owners were reduced to holders of "servitudes," i.e. holders of certain rights in the substance of the forest. The fact that the feudal lords frequently became the obermarkers, or burgomasters, of the mark community lent color of right to these restrictions in the use of the property, besides the assertion that the needs of maintaining the chase required and entitled them to such control.

It is interesting to note that through all the changes of centuries, these so-called servitudes have lasted until our own times, much changed, to be sure, in character, and extended by new grants, especially to churches, charitable institutions, cities, villages, and colonists. Such rights, to satisfy certain requirements from the substance of an adjoining forest, were then usually attached to the ownership of certain farms, and involved counter service of some sort, usually in hauling wood or doing other forestry work.

Sometimes when the lordly owners of large properties exercised only certain prerogatives to show ownership, these, in the course of time, lapsed into the character of servitudes, the forest itself by occupation becoming the property of the community. With changes in value and other changes in economic conditions, these rights often became disadvantageous and more and more cumbersome to either or both sides. 
The present century has been occupied with the difficult labor of relieving this state of things and making equitable arrangements by which the forests become unencumbered and the beneficiaries properly satisfied by cession of land or a money equivalent.

This chapter of the history of forest policy is especially interesting to us, as a tendency, nay the practice, exists of granting such right to the public timber to the settlers in the western states, which by and by will be just as difficult to eradicate when rational forest management is to be inaugurated.

Over 5,000,000 marks and several hundred acres of land were required in the little kingdom of Saxony to get rid of the servitudes in the state forests. The Prussian budget contains still an . item of $1,000,000$ marks annually for this purpose ; and although over 22,000,000 marks and nearly 20,000 acres of land have been -spent for this purpose in Bavaria, the state forests there are still most heavily burdened with servitudes.

The doctrine of the regal right to the chase, as we have seen, led to the gradual assertion of all property rights to the forest itself, or at least to the exclusive control of its use. This right found expression in the fifteenth and sixteenth centuries in a legion of forest ordinances, aiming at the conservation and improvement of forest areas, and abounding in detailed technical precepts.

At first, treating the private interest with some 
FOREST POLICIES OF FOREIGN NATIONS. 305

consideration, they gradually more and more restrict free management. Prohibition of absolute clearing, or at least only with the permission of the government; the command to reforest cleared and waste places; to foster the young growth; limiting the quality of timber to be felled; the prevention of devastation by prohibiting the pasturing of cattle in the young growth, rules in regard to the removal of the forest litter, of pitch gathering, etc., were among these prescriptions, with many others, such as prescribing the manner and time of felling, the division into regular felling lots, determination as to what is to be cut as firewood and what as building timber. Then, with the increasing fear of a reduction in supplies, followed prohibitions against exportation, against sale of woodlands to foreigners, against speculation in timber by providing schedules of prices, and from time to time entire exclusion from sale of some valuable species. Even the consumer was restricted and controlled in the manner of using wood.

In mediaval times, besides private forests of the king and lords, only the communal forest (allmende) was known, and small holdings of farmers were comparatively rare until the end of the middle ages.

The Thirty-years War and the following troublous times gave rise not only to extended forest devastation, but also to many changes in owner- 
ship of woodlands. With the growing instability of communal organization of the "mark," division of the common property took place, and thus private ownership by small farmers came about, reducing the communal holdings. Colonization schemes by holders of large estates also led to dismemberment.

A very large amount of the mark forest came into possession of the princes and noblemen by force, and later the possessions of the princes were increased by the secularization of the property of monasteries and churches. Until the end of the last century these domains belonged to the family of the prince, just as the right to the throne or the governing of the little dukedom, thus contributing toward the expenses of government.

But when, as a consequence of the French Revolution and the Napoleonic wars and subsequent changes, the conception of the rights of the governing classes changed, and in some states, like Prussia, much earlier, a division of domains into those which belonged to the prince's family as private property and those which were state forests was effected, so that now the following classes of forest property may be distinguished:-

(I) State forests, which are administered by the government for the benefit of the commonwealth, each state of the confederation owning and administering its own.

(2) Imperial forests, belonging to the empire 
and administered for its benefit, situated in the newly acquired province of Alsace-Lorraine.

(3) Crown forests (Fideicommiss), the ownership of which remains in the reigning family, which are administered by state government, but the revenues of which are in part applicable to government expenses.

(4) Princely domains, which are the exclusive and private property of the prince.

(5) Communal forests possessed by and administered by village and city communities, or even by provinces as a whole for their own benefit.

(6) Association forests, the remnants of the old "mark" forests, possessed by a number of owners, the state sometimes being part owner.

(7) Institute and corporation, school or bequest forests, which belong to incorporated institutions, like churches, hospitals, and other charitable institutions.

(8) Private forests, of larger or smaller extent, the exclusive property of private owners.

The proportions of these classes of property which existed in the beginning of the century experienced considerable changes by the sale of state forests, the sales being due partly to financial distress, partly to a mistaken application of Adam Smith's theories, which supposed that free competition would lead to a better management and to the highest development of the forest industry as well as of other industries. 
This tendency, however, was checked when the fallacy of the theory became apparent, especially with reference to a property that demands conservative treatment and involves such time element as we have seen.

The hopes which were based on the success of individual efforts were not realized, and although control of private action had been retained by the state authorities, this could not always be exercised, and the necessity of strengthening the state forest administration became apparent. The present tendency, therefore, is not only to maintain the state forests, but to extend their area by purchase, mostly of devastated or deforested areas and by exchange for agricultural lands from the public domain. Thus, in Prussia, the increase of state forest area has been at the rate of 14,000 acres per year since I867; during the decade I89I-I900 I 70,000 acres of waste lands were added at the average cost of $\$ 10$ per acre, and the budget of I 900 contained $\$ 800,000$ for that purpose. Bavaria spent about $\$ 6,000,000$ in such purchases during the last 50 years.

In districts where small farmers own extensive areas of barrens a consolidation is effected; the parcels of remaining forest and the barrens are put together, the state acquires these and pays the owners either in money or other property.

In Prussia, during the decade I882-I 891, 30,000 acres were in this way exchanged for 17,000 acres, 
FOREST POLICIES OF FOREIGN NATIONS. 309

and in addition some 200,000 acres, waste or poorly wooded, were purchased at an expense of $\$ 3,500,000$, round numbers. During the same decade the reforestation of 80,000 acres of waste lands was effected, while nearly 75,000 acres in the state's possession remained to be reforested.

The annual budget for these, reforestations of waste lands has been $\$ 500,000$ for several years.

The area of barrens and poor soils in Prussia, fit for forest purposes only, is estimated at over $6,000,000$ acres, which it is the policy of the State gradually to acquire and reform.

The present distribution as regards property classes of the round $35,000,000$ acres of forest in the whole empire is about as follows, varying, to be sure, very considerably in the single states of the confederation :-

State and Crown forests (of which the Crown owns less than

2 per cent) . . . . . . . . . . 32.7

Imperial forests . . . . . . . . . . . . . . I

Communal forests $(5,000,000$ acres $)$. . . . . . I5.2

Association forests . . . . . . . . . . . 2.5

Institute forests . . . . . . . . . . . . I.3

Private forests . . . . . . . . . . . . 4883

Half of the forest area consists of small holdings, below 2500 acres, while 15 per cent is in over I 2,000 acre domains. In Prussia, the private forest property comprises 53 per cent, with many large domains, while the state and Crown forests represent $3 \mathrm{I}$ per cent, the communal forests I2.5 per cent, the balance being institute forests. 
The state and Crown forests are all under wellorganized forest administrations, sometimes accredited to the minister of finance, sometimes to the minister of agriculture. These yield an annual net revenue of from $\$ 1$ to $\$ 5$ per acre of forest area, with a constant increase from year to year, which will presently be very greatly advanced when the expenditures for road building and other improvements cease.

In the state management the constant care is to avoid sacrificing the economic significance of the forest to the financial benefits that can be derived, and the amount cut is most conservative.

The Imperial forests are of course managed in the same spirit as those of the several state forests.

While the present communities, villages, towns, and cities are only political corporations, they still retain, in some cases in part, the character of the "mark," which was based upon the holding of property.

The supervision which the princes exercised in their capacity of Obermaerker or as possessors of the right to the chase, remained, although based on other principles, as a function of the state, when the "mark" communities collapsed; the principles being that the state was bound to protect the interest of the eternal juristical person of the community against the present trustees, that it had to guard against conflicts between the interest 
of the individual and that of the community in this property, that it should secure permanency of a property which insures a continued and increasing revenue. The principle upon which the control of these communal holdings rests is then mainly a fiscal one.

The degree of control and restriction varies in different localities. Sale and partition and clearing of communal forest can usually take place only by permission of the state authorities, and is generally discountenanced except for good reasons (e.g. too much woods on agricultural soil).

With reference to 5.6 per cent of communal forest property, this is the only control, entirely of a fiscal nature. The rest is more or less closely influenced in the character of its management, either by control of its technicalities or else by direct management and administration on the part of the government.

Technical control makes it necessary that the plans of management be submitted to the government for sanction, and that proper officers or managers be employed who are inspected by government foresters. This is the general system, under which 49.4 per cent of communal forests are managed (as also in Austria and Switzerland), giving greatest latitude and yet securing conservative management. To facilitate the management of smaller areas several properties may be combined under one manager, or else a neighboring govern- 
ment or private forest manager may be employed to look after the technical management.

Where direct management by the state exists, the state performs the management by its own agents with only advisory power of the communal authorities, - a system under which 45 per cent of the communal forests are managed (also in Austria and France).

In Prussia this system exists in a few localities only, but since 1876 it is there provided as penalty for improper management or attempts to avoid the state control.

This system curtails, to be sure, communal liberty and possibly financial results to some extent, but it has proved itself the most satisfactory from the standpoint of conservative forest management and in the interest of present and future welfare of the communities. Its extension is planned both in Prussia and Bavaria.

Sometimes the state contributes toward the cost of the management, on the ground that it is carried on in the interests of the whole commonwealth. A voluntary coöperation of the communities with the state, in regard to forest protection by the state forest guards, is in vogue in Würtemberg, as also in France. Institute forests are usually under similar control as the communities.

The amount of state influence, and especially the control of private forests, is extremely varying from state to state, even for the same state 
in different districts. A direct state control of some kind is exercised over only 29.7 per cent of the private forest, mostly in southern and middle Germany, while 70.3 per cent of the private property is entirely without control.

As far as the large land-owners are concerned, this has mostly been of no detriment, as they are usually taking advantage of rational management; but the small peasant holdings show the bad effects of this liberty quite frequently in the devasted condition of the woods and waste places. As a competent writer puts it: "The freedom of private forest ownership has led in Prussia not only to forest dismemberment and devastation, but often to change of forest into field. On good soils the result is something permanently better; on medium and poor soils the result has been that agriculture, after the fertility stored up by the forest has been exhausted, has become unprofitable. These soils are now utterly ruined and must be reforested as waste lands."

Need, avarice, speculation, and penury were developed into forest destruction when in the beginning of this century the individualistic theories led to an abandonment of the control hitherto existing, and it was found out that the principle so salutary in agriculture and other industries was a fatal error in forestry.

According to the character of state control, the entire forest area may be classified as follows:- 
(I) Managed by state authorities as state property, I I,360,000 acres, which is 32.7 per cent.

(2) Managed by the state authorities, but the property of corporations, villages, towns, etc., a little over 2,2 I2,000 acres, which is 6.3 per cent.

(3) Under strict government control, the plans of management and the permissible cut having to be approved by state authorities (corporation property), 3,875,000 acres, which is I I. I per cent.

(4) Under supervision of the state, not only as common property but as special property, subject to inspection and, in part, to control of state forest authorities (nearly all private property and that partly belonging to large estates), 4,767,000 acres, which is 13.7 per cent.

(5) Without any government control or supervision beyond that of common property, I I,490,ooo acres, which is 33 per cent. These forests may be divided, sold, cleared, and mismanaged, except under the certain cases before mentioned. Here belong all private forests of Saxony and Prussia and part of the corporation forests of Prussia and all those of Saxony.

Where control of private forests exists it takes various forms :-

(I) Prohibition to clear permanently or at least necessity to ask permission exists in Würtemberg, Baden, and partially in Bavaria. (Protection of adjoiners!)

(2) Enforced reforestation within a given time 
after removal of the old growth and occasionally on open ground where public safety requires.

(3) Prohibition of devastation or deterioration a vague and undefinable provision.

(4) Definite prescription as to the manner of cutting (especially on sand-dunes, along river courses, etc.).

(5) Enforced employment of qualified personnel.

In addition to all these measures of restriction, control and police, and enforcement, there should be mentioned the measures of encouragement, which consist in the opportunity for the education of foresters, dissemination of information, and financial aid.

In the latter direction Prussia, in the decade I 882-I 892, contributed for reforestation of waste places by private owners $\$ 335,000$, besides large amounts of seeds and plants from its state nurseries. Instruction in forestry to farmers is given at twelve agricultural schools in Prussia. In nearly all states permission is given to government officers to undertake for compensation at the request of the owners the regulation or even the management of private forest property.

For the education of the lower class of foresters there may be about twenty special schools in Germany and Austria, while for the higher classes not only ten special forest academies are available, but three universities and two polytechnic institutes have forestry faculties. 
Besides, all states have lately inaugurated systems of forest experiment stations; and forestry associations, not of propagandists but of practitioners, abound. As a result of all this activity in forestry science and practice, not less than twenty forestry journals in the German language exist, besides many official and association reports and a most prolific book literature.

Germany, as constituted at present, has an area of $133,000,000$ acres - about one-fifteenth of our country, - a population of about $47,000,000$, or less than 3 acres per capita, or only one-tenth of our per capita average. Its forests cover $34,700,000$ acres, or 26 per cent of the entire land surface. A large portion of the forests cover the poorer, chiefly sandy, soils of the North German plains, or occupy the rough, hilly, and steeper mountain lands of the numerous smaller mountain systems, and a small portion of the northern slopes of the Alps. They are distributed rather evenly over the entire empire. Prussia, with 66 per cent of the entire land area, and also of the entire forest area, possesses 23.5 per cent of forest land, while the rest of the larger states have each over 30 per cent, except small, industrious Saxony, which lies intermediate, with 27 per cent of forest cover.

In spite of the care bestowed upon the management of this resource, which is constantly yielding larger returns as the properties get into regular working order, - the output now is probably 1500 
million cubic feet of wood over 3-inch, or nearly 40 cubic feet per acre, - Germany is next to England the largest importer of wood materials, with $\$ 70,000,000$ excess of imports over exports, adding 25 per cent to her home product.

The condition of the forests depends largely on the amount of control exercised by the state authorities. It is best in all cases in the state forests, it is almost equally as good in the corporation forests under state control, and is poorest in the private forests, particularly those of small holders.

The control of the corporation forests is perfect in a few of the smaller states only, notably Baden, Hesse, and Alsace-Lorraine; also in some districts in Prussia where the corporation forests are managed by the state authorities, the wishes of the villagers or corporate owners being, however, always duly considered. In a large portion of Prussia, in Würtemberg, and in Bavaria the corporation provides its own foresters; but these, as well as their plans of operation, must be approved by the state authorities, so that here the management is under strict control of the state, and favorable forest conditions are at least partially assured. In Würtemberg the corporation is given the choice of supplying its own foresters or else of joining their forests to those of the state. This has led to state management of nearly 70 per cent of all corporation forests. Only the corporation for- 
ests of Saxony and those of a small part of Prussia are without any supervision. Of the private forests, those of Prussia and Saxony, involving 69 per cent of all private forests of the empire, are entirely free from interference. They can be managed as the owner sees fit, and there is no obstacle to their devastation or entire clearing and conversion into field or pasture. The remainder of the private forests are under more or less supervision. In most districts a state permit is required before land can be cleared. Devastation is an offence, and in some states, notably Würtemberg, a badly neglected forest property may be reforested and managed by state authorities. In nearly all states laws exist with regard to so-called "protection forests," i.e. forests needed to prevent floods, sand blowing, land and snow slides, or to insure regularity of water supply, etc. Forests proved to fall under this category are under special control, but as it is not easy in most cases to prove the protective importance of a forest, the laws are difficult to apply and not always enforced.

An increase of state supervision over private forests has been attempted in Prussia by the establishment of a law previously referred to, which renders the owner of a forest liable for the damage which the devastation or clearing of his forest property causes to his neighbor. This law, however, is so difficult to apply, and puts the plaintiff to so great expense, that so 
far it has not been enforced to any extent except where the government itself is the injured party.

Lately, ași a result of destructive floods in Prus- " sian rivers, extension of supervision by the state is urged again,

Altogether we can distinguish the South German policy which has been always inclined to be restrictive and coercive, from the North German tendencies which have only lately developed in this direction. The difference is perhaps due to the fact that South Germany is mainly mountain country, North Germany mainly plain.

The unusual floods in the Prussian rivers, especially the Oder, during the last decade, which occasioned over $\$ 2,500,000$ damage, led to the appointment of a commission - just as this year in the state of New York - to propose remedies. In the two reports made in 1896 and 1898 , the influence of forest cover on retardation of snowmelting, and of the forest floor on retardation of run-off are admitted, but forest conditions are found tolerably satisfactory. Nevertheless, new legislation is proposed to supervise private forest management so as to preserve existing conditions, the following points being made :-

I. The forest areas which are of importance to the watershed must be definitely determined.

2. A prescription for their management is only to be made, and if the management is found un- 
satisfactory by the county president, an appeal may be made to the courts.

3. Clearing may be forbidden, subject to appeal.

4. If unpermitted clearing is made, reforestation may be enforced, but there is no right to force reforestation of lands now not in forest.

5. The ploughing of slopes may be forbidden, and regulation of drainage channels ordered, but in that case the corporation, for whose sake this is done, must pay the cost or damage to the owner.

6. The state is to give financial aid in securing this work.

Quite different in tone is the Bavarian law of I 852, revised and accentuated in 1896, which absolutely forbids clearing, as well as any severe thinning, except by permission, in all protection forests, namely, on tops of mountains and ridges and steep slopes, on the high Alps where danger from land and snow slides is to be anticipated, or on sand-dunes, and wherever waterflow is influenced. The forest administration, either at the request of the owner or, on its own motion and final decision, by the forest courts, is to decide whether or not a forest property falls in this category. The plans of management for such properties must be submitted for sanction by the government under penalty of $\$ 20$ to $\$ 300$, and even $\$ 600$, per acre for any disobedience. Nor does the state recognize any obligation to compensate the owner for such restriction in the use of his property, although 
a proposition is now under discussion to give a tax release for 20 years for reforested tracts, provided the owner foregoes all use of it for that period.

The two smaller states of Baden and Würtemberg seem to have succeeded better than any other states in their restrictive policies. Würtemberg began proper measures, which have remained fundamental, as early as $16 \mathrm{I} 4$, remodelling them in 1875 and 1879 .

The "forest police law" of I 879 decides :-

(a) Clearing of forest requires a state permit: illegal clearing is punished with a fine.

(b) A neglected piece of forest shall not become waste land; the state authority sees to its reforestation with or without help of owner, the expenses to be charged to the forest.

(c) If the state forester is convinced that a private owner cuts too much wood or otherwise mismanages his forest, he is to warn the owner, and if this warning is not heeded, the forest authority may take in hand and manage the particular tract.

(d) Owners of small tracts of forest can combine into associations and can place their properties with municipal or even state forests for protection and management. In the latter case they share the advantages of part of the municipal or communal forests which are managed by state authorities.

The law of 1875 relating to the management 
and supervision of forests belonging to villages, towns, and other public corporations, about onethird of the forest area, places all the forests under this category under direct state supervision; there being a special division of corporation or municipal forests in connection with the state forestry bureau. The law demands that all corporation forests be managed in accordance with the principles of a continued supply, the same as the state forests. The corporation may employ its own foresters, but these must be approved by the forestry bureau and are responsible for the proper execution of the plans of management. These plans are prepared by the foresters and must be approved by the state forest authorities. If preferred, the corporation may leave the management of its forests entirely to the state authorities. This is always done if a corporation neglects to fill the position of its forester within a certain period after it becomes vacant. Where the state forest authorities manage either corporation or private forest, the forest is charged with eight cents per acre and year for this administration. This fee is generally less than it costs, so that the state has been really making a sacrifice so far in providing a satisfactory management for these forests.

The forest policy of Baden has also been conservative for a long time, and there is no state in Germany where the general conditions of the 
forests are better. Since all municipal and corporation forests are under direct state control, being managed by the state forest authorities, about 910,000 acres, or over 60 per cent of all forests, enjoy a careful, conservative treatment, which insures to them the largest possible return in wood and money. But even the private forests, representing another third of the forest area, are under the supervision of the state authorities, and though the private owner may use his forest very much as he pleases, he can in no way devastate or seriously injure it. Clearing requires a permit, even a complete clearing cut, which latter is permitted only if the owner guarantees the reforestation of the denuded area within a given time. Bare and neglected spots in forests must be restocked, and failure of private owners to comply with the forest rules and laws leads to temporary management of the forest by the state authorities, such management never to continue less than ten years.

It is evident that the existence of thoroughly organized, efficient state forest administrations make the execution of the laws regarding the use of forest properties comparatively easy, and from the technical point of view the supervision competent. Moreover, the good example which the forest management of the state sets is of most salutary influence, especially in showing that such management pays. 
By good management for "sustained yield" the yearly cut has been increased, in some cases doubled, since the beginning of the century, and the income has increased of course in greater rate, partly due to advance in prices for wood, which for a long series of years has not been less than $I \frac{1}{2}$ per cent annually, partly to increase in the quality of the output, but largely to improvements in transportation, for which large sums have been expended, especially during the last fifty years. The future promises even greater returns, when all the properties are in working order and covered with road systems.

Moreover, it is believed that the state administrations are now less profitable than they might be, as they are managed with great conservatism and without an attempt at greatest financial results, the economic objects being kept foremost.

The following tables give most briefly an insight into the financial aspect of forest management of the leading states. They show that the financial results vary considerably for the different administrations, owing largely to differences in market conditions; they also show the increase of revenue from 1890 to 1897 . The figures for the whole country are in part rounded-off estimates for all the state forests. The record of the city of Zürich is added to show how an intensively managed small forest property under most favorable conditions of market compares with the more ex- 
FOREST POLICIES OF FOREIGN NATIONS. 325

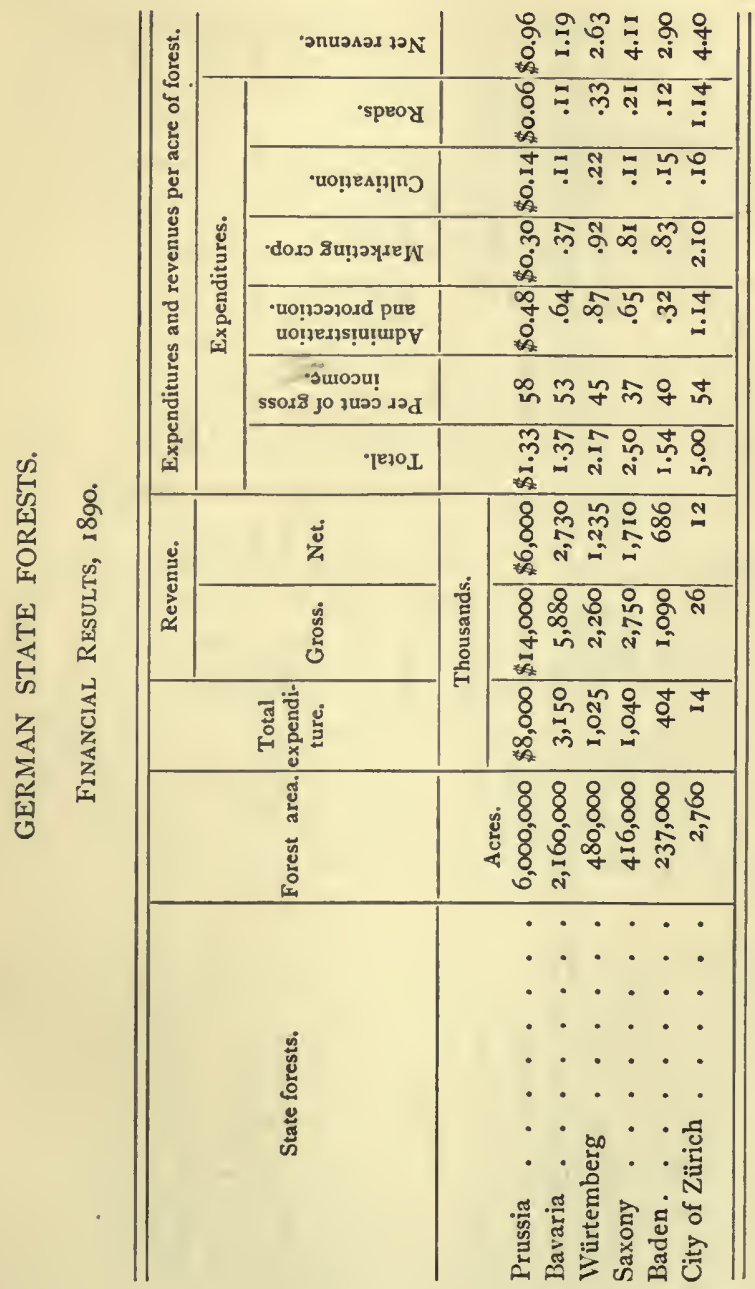


FOREST POLICIES OF FOREIGN NATIONS.

Percentic Distribution of Main Expenditures, 1897.

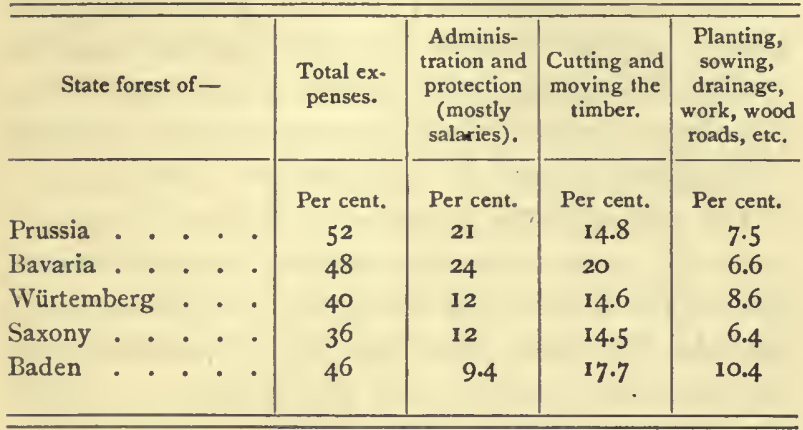

tensively managed larger forest areas. Judging from the results of the state administrations, it can be assumed that Germany produces annually wood values equal in amount to England's consumption, namely, somewhat over $\$ 100,000,000$, or $\$ 3.00$ gross and probably $\$ 1.75$ net per acre, from soils that are mostly not fit for any other use, and which by being so used contribute to other favorable cultural conditions.

This net income, figured at 3 per cent, would make the capital value of soil and growing stock nearly $\$ 60$ per acre, and the value of the entire forest resource of Germany 2000 million dollars.

The revenues have apparently risen with the increase of expenditures. In 1850, when Prussia expended only 37 cents per acre, her net income was 46 cents; in Igor her expenditure had increased to $\$ I .43$ and her gross revenue to $\$ 2.87$, 
although wood prices for the entire Prussian cut of $300,000,000$ cubic feet have in that period advanced only 37 per cent ; while Saxony expended 80 cents per acre in the beginning of the century and netted 95 cents, to-day she spends three times the amount and has increased her revenue nearly fivefold.

The table of the distribution of expenditures is especially interesting, showing that even in Saxony, the very state where the timber is usually cut clean and the land restocked entirely by planting with nursery stock, the item of planting, etc., uses up the smallest portion of the income.

From this brief outline it will be apparent that forestry in its modern sense is not a new, untried experiment in Germany, but that care and active legislative consideration of the forest wealth dates back more than four centuries; that the accurate official records of several states for the last one hundred years prove conclusively that wherever a systematic, continuous effort has been made, as in the case of all state forests, whether of large or small territories, the enterprise has been successful; that it has proved of great advantage to the country, furnished a handsome revenue where otherwise no returns could be expected, led to the establishment of permanent woodworking industries, and has given opportunity for labor and capital to be active, not spasmodically, not speculatively, but continuously and with assurance of success. This rule has, fortunately, not a single exception. To be 
sure, isolated tracts away from railroad or water, sand-dunes, and rocky promontories exist in every state, and the management of these poor forest areas costs all the tract can bring and often more; but the wood is needed, the dune or waste is a nuisance, and the state has found it profitable to convert it into forest, even though the direct revenue falls short of the expense.

The unsatisfactory condition of many of the private forests and their uneconomic exploitation, due to the speculative spirit developed after the Franco-German War, are deplored, exposed, and discussed with a view of extending state supervision. In Bavaria, in spite of severe prescriptions and in spite of the assistance given by the state, which distributed I27,000,000 plants during the years 1893-1 899, deforestation is in excess of reforestation, and the private forest diminishes. Similarly in Prussia during the last twenty years over 75,000 acres were deforested by private owners, although the state here too is exhausting all ameliorative and persuasive means, which, however, remain ineffective. Hence the state buys the half-wastes, restocks them at great expense, and thus public money pays for public folly in not restricting ill use of forest properties.

Of extra-European countries and nations, we should at least mention Japan, as one that has had a forest policy earlier than any of the European nations, and has now as efficient and modern ap- 
paratus to carry it into effect as any, Germany hardly excepted.

It is interesting to note that the historical development of this policy considerably resembles Teutonic development under the feudal system. During the first century after Christ, and repeatedly during later ones, frequent edicts were issued to enforce the planting of watersheds to alleviate floods, and the state representatives, the provincial princes, from early times took active interest and supervised the fellings. ${ }^{1}$

The forests thus protected by strict laws remained in comparatively good condition, so that in 1867 , when the great modern change in the government of Japan took place, they came into imperial hands nearly unimpaired. A department of forestry, instituted in 1874 , in the department of the interior, has the management of the state forests, which comprise $17,500,000$ acres, or 30 per cent of the total forest area of 57,000,000 acres. Some of the private forests, namely, those declared protection forests, are under supervision. A forest academy, according to German models, and at first manned by German foresters, was established in I 882, which in 1890 was incorporated with the University at Tokio.

${ }^{1}$ See an interesting historical sketch in Zeitschrift für das gesammte Forstwesen, 1900. 


\section{CHAPTER XI.}

\section{FOREST CONDITIONS OF THE UNITED STATES.}

IF considered simultaneously from botanical, geographical, and economic points of view, the forests of North America are unique in the world.

The forests of the tropics are richer in species; there are contiguous forest areas of greater extent in other parts of the world, and other countries possess forests of as high economic value. But it may be fairly truthfully claimed, that in no part of the world is to be found in combination under the ownership of one nation, a forest area of so large extent, of so high economic value, furnishing such a large number of species of such varied usefulness and in such accessible form and condition.

Geographically and botanically we must differentiate the country into two absolutely unlike types, namely the Atlantic and the Pacific type.

Practically the entire surface on the Atlantic side - west to a meandering line, which follows more or less closely the Mississippi Valley and runs nowhere beyond the ninety-ninth degree of longitude - was originally a vast continuous forest comprising somewhat over one million square miles, or 
about 700 million acres, ${ }^{1}$ of which less than 40 per cent, or less than 300 million acres, have been turned into farm lands, and an unknown acreage has been culled of its valuable stores of timber, ravaged by fire, or turned into useless brush lands.

The area to the west, almost twice as large, I 200 million acres, - is mainly a forestless, often treeless area into which stretch like narrow peninsulas of varying width from the north the forested mountain ranges of the Rockies, not exceeding roo million acres of woodlands and the forest of the Sierras and coast ranges of the Pacific with nearly the same acreage.

The Atlantic forest occupying the humid regions of the United States and covering both valleys and mountains, composed of a large variety of broadleaved species with conifers intermixed, gradually changes to the westward into the prairie country, practically forestless, although not treeless, where trees and forests of an inferior character are capable of growing, but where the grasses are able to compete successfully with the arborescent flora.

To the west of the prairie belt lie the plains and semi-arid regions, including deserts, irrigable

${ }^{1}$ The figures used in this chapter lay no claim to statistical accuracy but are merely rough approximations, sufficient to give a general idea of relationships, such as the economist needs. There are no accurate data at hand; when not even the areas of the different states are accurately known, official authorities differing widely, it is useless to attempt anything but rounded-off figures. 
valleys, forestless plateaus, and mountains, where tree growth is entirely absent or stunted, unless artificially fostered. It is into this type of country that the Rocky Mountain forest protrudes, of coniferous composition, for the most part of inferior development, except in the more northern portion; and similarly, paralleling the coast from north to south, extends the Pacific forest along the mountain slopes of the Cascades, Sierra Nevada, and Coast Range, practically almost wholly composed of conifers, often of most magnificent development, with only few broad-leaved species.

For the purposes of this volume it is not necessary to consider the forest conditions of the newly acquired outlying dependencies and of the far-removed Alaskan territory, except to state that the interior of Alaska, being in the main an arid country with a short season of vegetation, is forested in the manner of such countries, the tree growth mostly stunted and open, while the Alaska coast forest partakes of the character of the Pacific coast forest, with fewer species of conifers (mostly only hemlock and spruce) of inferior development.

The distribution then of forest country and open country is most uneven; three-fourths of the woodlands being concentrated on one side of the continent, the remaining fourth being collocated in two parcels on the two great mountain systems of the other side of the continent. 
This distribution is, of course, mainly due to climatic conditions; low relative humidity of the air and deficiency of water supplies in the soil having much to do with the absence of forest cover over the larger part of our domain.

The economic significance of this condition comes with the realization that the bulk of the best agricultural soils of the United States lies within the forestless region, and also that eventually the irrigable portion of the arid regions is destined to be the richest, dependent on a rational management of water supplies, i.e. of the forest cover. On the other hand, while undoubtedly the productive timber area of this region may be artificially extended in a small degree, the main timber production of the country will have to be secured where nature originally placed it, namely on the east side of the continent, where climate favors forest growth, and diversity of surface conditions differentiates farm and forest soils. Here, where the centre of population lies, and with it the bulk of consumption, the problems of forestry and of timber production need foremost attention.

So far, of the vast domain of the United States ( $I, 900,800,000$ acres) not one-fourth is occupied by farms; in most sections of the forest country the farm area ${ }^{1}$ falls below 50 per cent and in no state does it exceed 84 per cent. A vast area, there-

${ }^{1}$ The Census of 1900 gives the farm area as $841,201,000$ acres, of which, however, only 49.3 per cent are reported as improved. 
fore, is not yet appropriated to any particular use, being wild lands, waste, or under forest.

The acreage given above would indicate a forested area of not exceeding 650 million acres, namely, the 900 million acres as given above, less the improved farm area in the forest country, which amounts to about 250 million acres; but it should be well understood that this represents merely woodlands, areas covered with woody growth, which must be very considerably reduced if we apply the economic point of view and include only areas that contain or can without human aid produce timber useful for the arts, - if we discuss, in other words, the forest area not as a natural condition, but as a national resource.

Not only are large areas, especially in the western country, occupied by trees incapable of growing to valuable size or quality, but in the eastern forest country there are large areas from which all valuable growth has been removed by axe and fire. These are sometimes turned into actual barrens or are occupied by useless brush growth, which effectually prevents the reëstablishment of valuable forest growth without human aid, and hence they are for the present withdrawn from useful production.

Trustworthy statistics of the actually productive forest area are not in existence, although figures have been presented as such by statisticians without capacity to interpret their mean- 
ing. We can only attempt rough approximations, applying to the data at hand personal knowledge and impressions gathered in the field with professional insight. We can readily admit that these figures are often far from correct, yet not so far but that they give a true conception of the general condition of things.

Applying proper economic considerations, we may at once halve the figures given for both the Rocky Mountain and the Pacific forest, and reduce that of the Atlantic forest, after deducting the actually enumerated farm area by only io per cent, a small allowance to make for actual waste lands. ${ }^{1}$ We thus arrive at an area of round 500 million acres as representing the real forest resources of the country, a near enough ap-

I Some basis for such reductions may be found in information of the following kind: -

The nearest approach to a statistical statement for one of the Pacific Coast states, Washington, is made in the Twentieth Report of the U.S. Geol. Survey, 1900, Part V, from which it appears, that while the area reported as forest by the chief geographer is 47,700 square miles, only half that acreage is found to contain merchantable timber, of which two-thirds is located in the western one-third of the state. Here, of $15,85^{8}$ square miles, formerly covered with merchantable timber, 20 per cent are reported cut and nearly 23 per cent destroyed by fire.

For the state of Oregon the same report upon rather insufficient data reduces the reported woodland area of 54,300 square miles to 45,441 of timbered, i.e. economically valuable area.

A similar survey of one of the Atlantic forest states, Wisconsin, described in Bulletin 15, Forestry Division, U. S. Dept. of Agriculture, 1898 , reduces the woodland, reported by the census of 1880 , 
proximation for all practical purposes of the economist.

The larger portion of this area of 500 million acres is, however, not to be conceived as filled with standing timber ready for the axe, but consists of "culled" forest, which means that the merchantable timber of the better kinds has bẹen removed more or less closely.

How nearly this assertion must be true we may learn from the simple contemplation of the fact, that the constantly increasing population of the United States has drawn its wood supplies from this area originally of less than 700 million acres, without systematic attention to reproduction. If we assume that the consumption per capita has not been quite as large as it is now ( 350 cubic feet), although there is not much reason for such assumption, and add up the population annually calling for such supplies since the year 1780 only, we find that not less than 2,500 million people have had their annual requirements satisfied; that means a total of not less than 600 to 700 billion cubic feet.

from 31,750 square miles to about 26,904 , of which nearly 50 per cent is "cut over, largely burned over and waste brush lands, and one-half of this as nearly desert as it can become in the climate of Wisconsin."

From such statements it will appear that the method of arriving at the forest acreage, used by Mr. Gannett, chief geographer, in the Nineteenth Report of the U.S. Geol. Survey, namely to deduct the farm area of twenty years ago from the total land area, leads to no useful result for purposes of the economist. 
Taking into consideration the wasteful use of timber, - the log-rolling fires in clearing for farm use, owing to the lack of market, - we may assume that less than half of this consumption was secured from these farm areas, the other part necessitating the culling of certainly 300 million acres, so that hardly 200 million acres containing merchantable timber may remain, even if we make allowance for aftergrowth. Comparing this probability calculation with the amount of standing timber, given on page 52 , as an extravagant estimate, this area would have to contain an average of 10,000 feet B.M., or 2000 cubic feet of such wood as we use, which is not likely to be the case, or at least questionable.

This area, moreover, is continually reduced by fire and by clearing for farm purposes, as the change of improved farm areas in the forested states from census year to census year shows, namely, an increase of about 25 million acres each decade in round figures. Some abandoned farms in New England, and in the South, to be sure, are gradually returning to forest growth, but these additions are small in proportion to the farm increase: Nevertheless, taking the forested area actually grown or growing to timber, in good, bad, or indifferent condition, it represents in the forest country of the Atlantic side still 40 to 45 per cent of the total land area, while about 20 to 25 per cent may be set down as waste lands. 
The productive forest area of the western country may be stated as not exceeding 14 per cent. For the whole country the woodland area according to the United States Chief Geographer, whose discussions on these questions contain many misstatements and misconceptions, represents 37 per cent; according to the writer's conception of what may be considered forest area, it is not much over 26 per cent. This acreage of round 500 million acres under proper management would barely be capable of supplying continuously the present annual wood consumption of the people of the United States, which, as we have seen on page $5 \mathrm{I}$, amounts to about 25,000 million cubic feet; while we estimated that the virgin supplies still standing may be able to satisfy the present consumption for perhaps 40 to 50 years.

The immediate inauguration of conservative treatment, of recuperative measures, and of proper economies in the use of wood may, therefore, be able to avert serious discomforts to be expected from a shortage in wood supplies, provided there be no increase in consumption, or perhaps even a proportionate reduction, as the population increases, which as we have seen in Chapter II. is possible. So far the census statistics record an increase of wood consumption, in values at least, of a round 30 per cent for every decade, and hence the economies, as well as the conservative and recuperative treatment, should be begun now. 
The ownership of the forest area will largely determine how far such conservative treatment may be expected.

Governments, which are logically conservative managers of their properties, own in the United States as yet only an insignificant acreage. Thanks to the forest reservation policy, inaugurated in I89I, the federal government has reserved and continues to reserve and exclude from sale or other disposal some of the public domain, which still comprises over $500,000,000$ acres.

It is uncertain how much of this acreage is forest covered. There are somewhat over 10,000,000 acres still held in the Eastern states, largely swamp lands and forest, while for the Western states, Mr. F. H. Newell, a few years ago, ${ }^{1}$ estimated the public lands open for entry as follows :-

$$
\begin{aligned}
& \text { Brush lands . . . . . 96,000,000. } \\
& \text { Timber forest . . . . . . 70,000,000. } \\
& \text { Desert . . . . . . . 69,000,000. } \\
& \text { Grazing land . . . . . 374,000,000. }
\end{aligned}
$$

Since under the existing construction of the land laws, the timber lands on the Pacific coast may be entered as agricultural lands, and since the lumber business of that region in the last few years has been greatly extended, it is fair to assume that by such entries the timber forest area of the public domain has been considerably reduced from that estimate.

The forest reservations made by the federal 1 U. S. Geol. Survey, Ann. Rep. I 894. 
government to July I, I902, comprise an acreage of nearly 60 million acres, hardly more than I per cent of the public domain, but it is well known that a considerable portion of these reservations is not timber land; they include brush lands, grazing lands, and desert.

In fact the examinations by agents of the United States Geological Survey indicate that of about I2 million acres examined, not more than 30 per cent contains merchantable timber, and the amount of such timber is estimated at not to exceed 24 billion feet B.M. In other words, on this vast area cannot be found one year's requirement for the whole United States, or six years' supply for the mills now operating in the Western states. There is no reason to suppose that the rest of the federal reserves are much better timbered, for the examined portions seem to represent fairly well average conditions; hence, the forest reservation policy of the government, as far as the supply question for the country at large is concerned, has not, and indeed cannot, alleviate matters very much. Even if all the timber lands now in possession of the federal government were withdrawn from entry, - and it is a shortsighted policy not to have done so long ago, - such reservation would bear on local conditions of supply only. But, indeed, for the welfare of the Western states, the inauguration of the forest reservation policy is of the utmost importance; not only from the timber supply point of view, but especially with 
regard to the question of water supply. The valleys of the West being, for the use of their almost inexhaustible fertility, dependent upon irrigation waters, the water conserving capacity of a wellkept forest cover is indispensable, and in this direction even the brush lands are of value.

It would be only rational that the extensive plans for the development of irrigation systems in the West should include the rapid withdrawal from entry of all the mountain forest and brush lands, and their rational treatment with the main object of preserving the soil cover.

In the Eastern states, the single state governments alone may carry out a similar reservation policy, and indeed the beginnings have been made here and there.

The state of New York owns nearly one and one-quarter million acres with the avowed purpose of increasing the acreage of state forest; the state of Pennsylvania has entered upon the policy of acquiring state forest, and several other states are at least discussing the propriety of such ownership. But the majority of the states have not yet waked up to their obligation in this respect, and communities, like villages, towns, cities, counties, which so often in Europe derive acceptable income from forest properties, have not yet considered such a policy, hence the forest areas are nearly entirely in private hands.

As to the character of this private ownership and 
the distribution among different classes of owners, we are without data. The census of 1880 gave a statement of the ownership by farmers of 200 million acres in wood lots. This would mostly represent a conservative ownership, although farmers do not always treat their timber lots as intelligently as they might; but it is quite certain that much of this acreage has since passed into the hands of lumbermen and wood-working establishments. ${ }^{1}$

Among these we must discern between the jobbers, who merely buy stumpage, i.e. the timber without the land, who, therefore, take no interest in the future of either, and hence are least conservative in their treatment of the forest, and the land-owning class, who are apt to take more thought of what may become of their holdings. It is, however, only very lately that this interest extends in the direction of conservative lumbering and of keeping the forest as such productive; in most cases the policy of "skinning" is still the usual one, that means culling out the merchantable material, with a very variable result as regards the condition in which the forest is left. Sometimes, as when the spruce or pine is cut out from the mixed hardwood forest, its absence may be hardly noticed by the layman, the forest cover is little interrupted, and the scattered débris sooner or

1 The value of wood products, cut on farmers' wood lots, was found by the census of 1900 to amount to less than 120 million dollars. 
later decomposes, but the composition is surely altered in the old timber as well as in the young aftergrowth. Where the soft woods, which are the most valuable and the most easily removed by water transportation, had occupied a larger portion of the mixed forest, or were found in pure stands, or where hardwoods are lumbered, the case is less hopeful for the future, the accumulation of débris prevents largely a reproduction of valuable species, and the succession is of inferior kinds and shrubs, especially as the valuable seed trees have been either entirely removed or greatly reduced. Sooner or later fires run through the slashing, and if repeated may destroy not only all the struggling aftergrowth, but the humus, the soil itself, and so render the land practically useless for generations.

Sometimes a fire at the right time may, however, have done good by reducing the slash, and, if seed trees were left uncut in the neighborhood, a desirable aftergrowth may have established itself, which but for a repetition of the fire would grow into desirable timber.

In late years the severity of the culling process has greatly increased, since with improved means of transportation and reduced supplies smaller sizes have become marketable; as a result the chances of a valuable aftergrowth are greatly diminished, and most of the logged areas of to-day, differing from those of twenty or thirty 
years ago, are doomed to non-productive condition for generations.

The owners of expensive permanent mill establishments, relying on timber supply, are naturally more interested in a continuity of local supplies than those who can readily change their location when the supplies in one locality, are exhausted.

Hence such manufactures as the paper-pulp industry will become or are already interested in more conservative use of their holdings.

Lately, as in all commercial enterprises, a tendency has developed in the lumber industry to consolidate forest properties and form trusts, which own many thousands or even millions of acres of forest land.

Such trusts may be and probably are mostly formed for the immediate financial advantages accruing from combination, but they could, and, if they consulted their true interests, would, practise a more conservative treatment of their timber and introduce forestry methods, which would prove in the end the wisest continual financial policy.

Trusts, therefore, properly organized for continuous business, may prove next to governments the most hopeful agencies for practising forestry, since they can control large areas under uniform and continuous policy.

Another class of conservative owners of forest property is coming to the fore, namely, wealthy capitalists, who can see the financial advantages of 
the future in forest properties, and are able to hold such properties until developments surrounding them will make their conservative use under forestry methods possible.

Others, including sporting associations, are owning forest properties for other than economic purposes. These, too, are naturally conservative, and when forestry practice is established in this country, will probably learn that their pleasure need not suffer by applying such practice to their properties and deriving financial benefits from them as well.

As we have seen in previous chapters, forestry is profitable only in the long run and on large areas; it is a business which contemplates continuity for a long period, hence the more our forest - resources pass into the hands of perpetual corporations and wealthy owners, the more hopeful is their fate.

For a thorough understanding and discussion of the economic aspects of our forest areas, we ought to know, not only the extent of forest cover, and the character and condition of the forest growth, but its distribution over the different soils and topographic conditions, when it may be determined what areas are naturally to be kept in forest, and what areas must by necessity be turned into farm lands; where the protective feature requires greater care in their management, or where they may be left to their fate.

It will have appeared that in speaking of the 
forest areas from the supply point of view, we keep in mind that not only the old crop, the virgin timber ready for the axe, but also the young crop, the aftergrowth of valuable kinds, should be considered as timber-producing area, and even the bare soil itself, if it is only left in condition to recuperate, and to reproduce naturally valuable species in a reasonable time.

As far as mere soil cover is concerned, the valueless species and even the brush lands may suffice to furnish protection and perform the functions, at least in part, of the timber forest; yet even here, in order to make the best use of the soil in the household of a nation, it becomes necessary to eradicate the weeds and favor the useful species.

As we have intimated before, there are weeds among trees as well as among the lower vegetation. Indeed, of the 500 species of arborescent growth of which we can boast in our woods, there are hardly more than 70 which deserve the forester's attention, although we may expand the number of useful ones to 100 or more, since in the absence of some better material, even the poor Lodge-pole Pine of the West, covering thousands of square miles, the Black Jack of the barrens, and the Scrub Pines of the sandy coast become valuable, at least for firewood.

In the markets, where the finer botanical distinctions into species are neglected, it would be difficult to find as many as fifty native woods quoted. 
Some of these, which we now use simply because they can be had, since nature grew them without counting the cost or considering that a better material might have been grown with as much ease, will be discarded by the forester. They will not be grown again consciously by man's aid. Nevertheless, with all these eliminations, there remains a large number of highly valuable species for which the chances of perpetuation are to be prepared by the forester.

The most important furnishers of timber are the conifers: pines, spruces, firs, hemlocks, cedars, larch, and cypress, usually in commerce called soft woods in contradistinction to the broad-leaved trees, designated as hardwoods, ${ }^{1}$ although both groups contain both hard and soft woods.

Our flora excels especially in a great variety of pines, those most useful trees of the temperate zone, of which we can boast at least ten timberproducing species, three softwooded white pines and seven hardwooded yellow pines, besides not less than twenty-five scrub-pines, useful to occupy the least favorable dry soils.

Of other conifers the Red and Black Spruce of the Northeast, the Bald Cypress of the South, and the Douglas or Red Fir, Redwood, and Sugar Pine of the West are the most prominent staples, the others being of minor importance.

Among the hardwoods the oaks are perhaps the

1 This distinction has received sanction in the courts. 
most useful, and here again we can boast of a great variety, classified botanically and according to their wood in two groups, the white oaks and black oaks, of which not less than a dozen are large-sized timber trees, and some twenty or thirty perform similar service as the pines in covering barrens. Next in importance may be placed the ashes, two important species, the hickories with five interchangeable timber species, the maples with four marketable species, and the Tulip Tree or Whitewood, the giant tree of the East, besides Chestnut, Red Gum, Basswood, elms, birches, and the rarer Walnut and Cherry for ornamental woodwork, with a number of others.

The relative importance of these woods, and hence of the forest regions in which they are found, may be learned from the estimated distribution of the annual cut as it appeared in the census year 1890.1 This total annual cut, including all material requiring bolt or log size, estimated at round 40,000 million feet B.M., ${ }^{1}$ was approximately made up of the following kinds and quantities:-

$$
\begin{aligned}
& \text { Billion feet } \\
& \text { B.M. } \\
& \text { White Pine . . . . . . . . } 12 \\
& \text { Spruce and Fir . . . . . . . } \quad 5
\end{aligned}
$$

1 These figures are not census statistics, which are always short of the truth, but estimates based upon census data and other information, rounded off to include unenumerated amounts; they approximate relative conditions averaged for a series of years. The present actual cut must be somewhat larger than this approximation, since the Census of 1900 places the sawed product alone at 35,000 million feet B.M. 


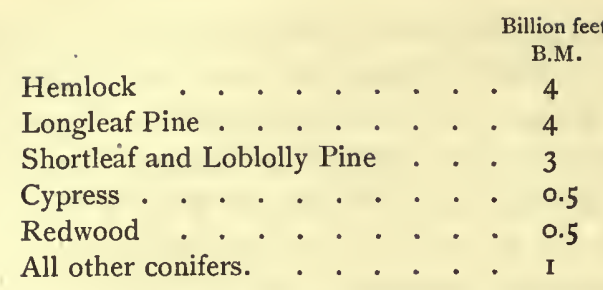

or altogether 30,000 million feet of coniferous material, leaving for all the hardwoods 10,000 million feet, of which the oaks furnished 3000 million feet. The largest part of the cut was furnished by the Southern states and the Lake Region, each with I 3,000 million feet, New England and the North Atlantic states furnishing 6000 million, the hardwood region of the Central states 5000 million, the Pacific states 4000 million, the rest, of 2000 million feet, coming from scattered localities.

Since that time the general relation of the different regions has remained the same, but the relative amounts have changed, the White Pine cut of the Lake Region has been considerably reduced owing to waning supplies, the Southern and Pacific coast cut has been increased. (For further statistics, see Appendix.)

Our principal and most important supplies, then, are found in the White Pine of the lake states and the yellow pines of the Gulf and South Atlantic states.

The Atlantic forest, as we have stated, is essentially a forest of deciduous-leaved trees, in which the conifers occur mixed or in small bodies. Only 
where the soil becomes sandy, the drainage being rapid, are to be found extensive pineries composed of these frugal species to the exclusion of the more fastidious hardwoods. In the rich loamy soils of the central agricultural states - Ohio, Indiana, Illinois, Kentucky, Tennessee, and Missouri- the conifers are of less importance or mostly entirely absent, the hardwoods in greatest variety and most excellent development occupying the ground exclusively. The North Atlantic forest, north and east of this purely hardwood region, originally contained everywhere the valuable White Pine among the oaks and maples, Beech, and Basswood, to which farther north the Yellow Birch, replacing the oaks, is associated. But now the merchantable pine areas of importance are confined to the northern part of Wisconsin and Minnesota, with a remnant in Michigan, although some scattered pine, especially young growth, is found in all the other Northeastern states, and small bodies of old timber on the Alleghanies even as far south as North Carolina. Similarly, hemlock is distributed over the whole area, but the large bodies are mainly confined to western New York and Pennsylvania, soon to be exhausted, while the spruce, so much prized for paper-pulp, is found in quantities mainly in the northern New England states and the Adirondacks of northern New York.

The northern parts of this white pine region furnish also a valuable yellow pine, the so-called Red or Norway Pine, which is often included in the 
estimates of White Pine, although its quality is quite different.

So important a part does the White Pine play in our timber supply that speculation as to the amount available has occupied the mind of the lumber world for many years. The census of 1880 attempted to secure an estimate of timber standing at that time ; the estimates then published indicating twenty years' supply at once showed their influence upon price for stumpage and upon standards of merchantable material.

By reduction of this standard, by increase of means of transportation, by more careful cutting, sawing, grading, and handling, and partly by new growth, the supplies have been considerably lengthened, so that in 1897 the writer, compiling later estimates, ${ }^{1}$ could still find in the three main whitepine-producing states nearly 40,000 million feet, which with a greatly reduced cut will last a few years longer, when the king of the woods will have been reduced to an inferior rank.

In the same document the supplies of all coniferous interchangeable material, standing ready for the axe in the Northern states, was estimated at a round 100,000 million feet, while the annual cut at that time was placed at round $\mathrm{i} 8,000$ million feet. Since then the conception of what is merchantable timber has greatly changed, small-sized

${ }^{1}$ See Senate Document, No. 40, 55th Congress, ist session, I897, "White Pine Timber Supplies." 
logs and small-sized trees have become salable, the cut, at least of White Pine, has been considerably diminished, and hence supplies will last still for years to come. In addition, on the areas which in earlier years had been culled less severely, the trees that were left have put on growth sufficient to become marketable (second growth!); and occasionally also natural volunteer reproduction has come, furnishing new supplies.

Nevertheless, even if the estimates were doubled and quadrupled, the time of practical exhaustion of this resource will be upon us before recuperative measures have been fairly started.

The Southern forest, although showing greater variety and number of species, does not add many hardwood species of economic value, which are not represented in the Northern forest. But in coniferous species it furnishes invaluable supplies by a group of hardwooded yellow pines, the Bald $\mathrm{Cy}$ press, and to a lesser extent the Pencil Cedar or Juniper.

The sandy soils in which the Southern states along the Atlantic and Gulf coast abound are occupied by vast pineries, in which for hundreds and thousands of square miles the hardwood species are almost absent except in the loamy hummocks and river-bottoms. The most important and valuable of these pines is the Longleaf or Georgia Pine, which predominates over the largest area in a belt paralleling the coast from North Carolina to eastern 
Texas, varying in width from 60 to 150 miles. In its southern range it is joined by the Cuban Pine, of equal or even greater value, although in the market not differentiated, and by the Loblolly Pine; in its northern range it extends into the mixed forest which covers a belt of 20 to 60 miles more, in which the Longleaf Pine is associated with Shortleaf Pine, in the market called North Carolina Pine, with Loblolly or Oldfield Pine (called Virginia Pine), and with hardwoods.

North of this belt of mixed forest the pine area is increased by the Shortleaf Pine, occasionally associated with the Loblolly, occupying the sandy soils. Although the Longleaf and Cuban pines are superior in quality, the other two have not much less value and application in the arts, being often substituted; and hence we can consider the whole pine belt as a unity, an area of about $150,000,000$ acres, within which these pines do or did occur in merchantable quantities. Deducting the farm area and making allowance for hardwood areas interspersed between the pineries, the pine-producing area is probably not quite two-thirds of the area of distribution, or round $90,000,000$ acres. The available supplies of standing timber were estimated by the writer seven years ago at between 200,000 and 300,000 million feet. At that time the annual cut exceeded 7,000 million feet, and as it has constantly and rapidly increased, the waning whitepine supplies stimulating the Southern lumber in- 
dustry, it is probably safe to reduce this stand by at least 70,000 million, so that at best, less than the lower estimate is remaining to satisfy a demand of now over 10,000 million feet annually.

We must again and again accentuate that these figurings are neither mathematics nor statistics in the sense of the enumerator, but are calculations of possibilities or probabilities sufficiently close to give an insight into the general situation. By changing standards, by cutting more closely, by avoiding waste in logging and sawing, by avoiding extravagance in the use of the materials, we may lengthen the time during which these stores may last, but unless they are replaced by reproduction, they must give out within much less time than it takes to grow a log tree, for the timber which we now cut is mostly 150 to 300 years and more old, and none of these pines make suitable sawlogs in less than 60 to 120 years.

What under prevailing practices the chance for spontaneous natural reproduction and the condition of the cut-over areas are, may be learned from reading the excellent monograph on "The Southern Pines," by Dr. Charles Mohr. ${ }^{1}$ The practice of annual firing of the woods, to improve the grazing, has in most places effectually prevented renewal of the pines.

One of the forest industries using a by-product,

1 "The Timber Pines of the Southern United States," Bulletin No. I3, Division of Forestry, U. S. Dept. of Agriculture, I896. 
which is derived from bleeding the Longleaf Pine, the naval store industry, producing now values to the amount of $\$ 20,000,000$ per annum, has also done much to reduce supplies and reproduction. While it might have been carried on, as it is in France, without injury to timber or young growth, the crude methods employed have destroyed much timber before the saw miller was ready to use it, and much more has fallen a prey to the destructive fires which have followed the turpentine gatherer.

Besides the pines there is found in the swamps of the Southern states another valuable conifer, the Bald Cypress. The area occupied by this species is naturally small, and with an annual cut which may now be much more than 5,000,000 feet, it can be soon exhausted, and the reproduction, which is naturally less ready on lands under water for several months in the year, may be counted as nil.

Of hardwoods we have large areas throughout the entire Atlantic forest, and as our consumption is relatively small, and the hardwoods reproduce readily, their future is easily provided for. In the more settled parts of the New England and North Atlantic states and on the northern Appalachians of Pennsylvania and New York, the timber forest of hardwoods has mostly been supplanted by the coppice, producing only firewood and small dimensions, but it will be an easy task to change it back into timber forest. 
It is in the coniferous materials that we are most concerned, for they form three-fourths of our consumption, and their reproduction in competition with the hardwoods and the fires is not promising.

Some ignorant people - ignorant both as to requirements of the wood industries and as to the condition and character of our forest resources have claimed that the natural growth of young trees, without any attention, following the operations of lumbermen, would suffice to replace that which is removed and would continue to furnish the required material.

The observant student, not to speak of the professional forester, can readily see that culling the valuable kinds and leaving the inferior tree weeds in possession of the soil almost entirely prevents in many cases reproduction of the valuable species. In other cases where the production of valuable kinds does take place, as, for instance, with the Southern pines, whenever the young growth is not killed by fires, the development is so unsatisfactory, that where with proper attention a new crop might be available in seventy to a hundred years, twice the time will be required to make clear timber of quality. In most cases recurring fires retard this natural re-growth still further or prevent it altogether.

Of the character and conditions of the Western forests we have almost more detailed information than of the Atlantic forest, thanks to the various 
government surveys and railroad-land cruisings, and the examinations of the federal forest reservations by agents of the United States Geological Survey.

These forests are all coniferous, the broad-leaved trees playing an insignificant part, although the Pacific Coast forests contain some valuable oak, ash, and maple. The Western forests are mainly confined to the mountain slopes, varying in character with latitude and altitude, i.e. with the variation in moisture and temperature conditions. We have seen that probably 50 per cent of the woodland area may be ruled out from consideration as timber producing, so that roughly only round 100,000,000 acres remain for that purpose, onehalf on the Rocky Mountains, the other half on the Pacific coast. If this were all untouched, we might have found for the Rocky Mountain forest a stand of not exceeding 200,000 million and for the Pacific coast forest $1,000,000$ million feet, but from these stores during our occupation of these territories at least $200,000,000$ people have drawn their annual requirement of probably not less than 500 feet, and that in a wasteful manner; a large amount of material has been exported to neighboring states and across the sea, and a still larger amount has been destroyed by fire, so that, gathering indications from the reports of the Geological Survey, the amount of standing timber, according to present standards and under present methods of utilization, will probably be less than 
700,000 million feet. It must be understood, that especially on the Pacific coast, where lumbering is carried on not merely to supply local wants but for export, the most wasteful use of the timber is forced upon the lumberman by the destructive competition, the distance from market, with high freight rates, reducing the material actually marketable by 50 to 80 per cent and more below Eastern standards, the merchantable diameter limit in the Puget Sound regions being at present twenty-two inches. Even in the Black Hills, in lumbering the pine of the forest reserve, mostly for local use, it has been estimated that 50 per cent of each tree cut for lumber is left in the woods, fully one and onehalf cord for every thousand feet utilized.

Throughout the Rocky Mountain forest the hardwooded Yellow or Bull Pine is the most important tree, often occurring in pure stands as on the plateau forest of Arizona. To this are joined the Douglas or Red Fir, becoming more prevalent and better developed toward the north, the Engelman Spruce and several other inferior spruces and firs, and occasionally a hemlock.

Toward the north, in Idaho, where the timber improves in development and the forest in density, a white pine, the Silver Pine, and a larch of prodigious dimensions, form most valuable stands, together with the Giant Cedar. Thousands of square miles are covered with the Lodge-pole Pine in pure stands almost entirely useless for timber,

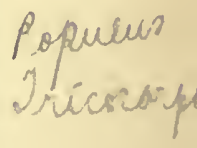


although furnishing fire wood and small dimension material. Thousands of square miles of the high elevations are occupied by the Subalpine Fir and scrubby pines of no commercial value; in addition fire has not only damaged but destroyed thousands of square miles.

The following figures abstracted from the United States Geological Report cited are illustrative. In the Priest Forest Reserve, which comprises about I000 square miles, of which 850 were found timberproducing, at least 70 per cent of the timber once standing is estimated as destroyed by fires during the last thirty years, a loss in value of over $\$ 100,000,000$. "Excepting a small area of about 1600 acres along the Lower West Fork, there is no body of timber of 1000 acres or even 500 acres extent not scorched by fire. In the lower zones there are over 200,000 acres on which the destruction is practically complete. In the subalpine zone at least 40,000 of the 60,000 acres have been more or less injured by fire."

In the Bitterroot Reserve, which contains over $4,000,000$ acres, of $1,000,000$ acres examined only 60 per cent was found wooded, half with the comparatively valueless Lodge-pole Pine, 20 per cent with inferior Red Fir, and only 30 per cent with the valuable Yellow Pine, over 20 per cent of the original stand having been destroyed by fire in the last forty years.

On the east slopes of the Cascades and Sierras 
and throughout the Interior Basin arid conditions prevail, and hence wherever forest areas occur, the trees stand open and are stunted, and generally of no commercial value. Yet the open pine forest of the Blue Mountains, of the slopes and plateau of eastern Oregon, made up of Bull Pine, furnishes at least a welcome local timber supply; and the northern part of Washington, where moisture conditions improve, shows the effect in permitting an extension of the Rocky Mountain forest type of northern Idaho, with Bull Pine and Silver Pine of commercial value accompanying the comparatively valueless Lodge-pole Pine.

The Pacific coast forest presents four types. The northern type, covering the west slope of the Cascade and the Coast ranges through Washington and Oregon, derives its value mainly from the Douglas or Red Fir, and is characterized both by density of stand and individual development and by dense undergrowth in response to the great humidity of the climate. Associated with the fir is found a hemlock of not much inferior development, but at present left unused, and the Giant Cedar. In the higher elevations some excellent true firs, Silver Pine, Engelman, and other spruces add variety, and along the seashore the Sitka Spruce and Port Orford Cedar of limited distribution, while Yellow or Bull Pine occupies the sandy flats and drier slopes. In its extension over the Coast Range of California the type changes somewhat, although 
the same species are present and the density is alike, but the Redwood, congener to the Big Tree, is added, and, in its narrow, long belt of distribution from Oregon to the Santa Cruz Mountains, replaces in importance the Douglas Fir, which seems to lose in value in its more southern range.

The extension of the Cascade forest over the Sierra Nevada shows a much greater change, although the same species continue in the composition with the same magnificent development, but the Sugar Pine, a congener of the Michigan White Pine, of ponderous development, is added and becomes the main and most valuable timber tree, and the forest grows open, the undergrowth more scanty. Here the giant Big Trees occur in occasional groves, of historic interest more than of commercial value.

Toward the south, both on the Coast Range and on the Sierra, the value of timber growth greatly diminishes, becoming reduced in size, the stand opening more and more; finally, in the southern ranges of the San Gabriel, San Bernardino, and San Jacinto mountains, the timber of value, Yellow and Sugar Pine and Red Fir, occurs only in groves among the brush and chaparral which covers most of the dry slopes.

We have seen that the timber-producing area of this Pacific coast forest may not be estimated at more than round $60,000,000$ acres, containing somewhat over 600,000 million feet of merchantable timber. Upon the basis of a compilation of 
timber cruisings of railroad companies, the United States Chief Geographer has for the states of Washington and Oregon placed the merchantable timber at less than 350,000 million feet on $38,000,000$ acres, which appears to us a rather low estimate even with the high standard at present prevailing. Timber cruisings' are usually from 20 to 50 per cent below the actualities.

The writer still believes that it would be perfectly safe for purposes of this general discussion to raise this estimate 20 per cent, and, applying the same stumpage for California on a timber-producing area of $18,000,000$ acres, to arrive at the above figure, leaving 180,000 million feet of the amount credited to the Western states on page 52 to be found in the Rocky Mountains and scattered regions of the West.

Indeed, with a change in standards and in logging practice, and especially with a more rational utilization of all the useful timber, this estimate may readily be doubled or even trebled, as the writer had done in the Senate document cited, when comparing supplies with the consumption of the whole country.

Since the cut of lumber in the Pacific coast states does not exceed at present $5,000,000,000$ feet, no immediate apprehension regarding supplies would be justified. Yet, when we find that the value of the mill-product of the three states increased according to the census from $\$ 8,000,000$ in 
I 880 to $\$ 30,000,000$ in 1890 , and to $\$ 54,000,000$ in 1900 , the security for the future is not as assured as the mathematical statistician figures out from the given data, especially since it is well known that forest fires keep in check useful reproduction and also consume or make useless considerable quantities of standing timber. (See note on page 336.)

Unsatisfactory as is our statistical knowledge of our forest resources, it is sufficient to arouse most serious apprehension as to future supplies. We have, in the forests of the United States outside of Alaska, a supply of coniferous material most unevenly distributed and not exceeding I,200,000 million feet to satisfy a demand of at present 30,000 million feet per annum and constantly growing. Even if the estimates of supplies were doubled, and if fires were stopped, it must be evident to any student of the field that the reproduction, left to nature alone, cannot replace in time our requirements.

The argument for the adoption of immediate recuperative and conservative measures from the supply point of view, in which the writer for a quarter century has used his breath and pen with indifferent result, would appear well sustained.

Small beginnings toward the solution of the problems which arise from this condition of things have been made, but the importance of the forestry 
movement has by no means been fully and generally realized, as we shall see in the next chapter; the difficulty of changing existing usages, lines of procedure, and modes of thought require unusual effort and require time.

For the future, it is in the end of much more importance to know the acreage available for timber growing and the capacity of production of that acreage than the actually available supplies. These, no matter how large, every intelligent man will admit, must sooner or later be exhausted, and we must rely upon the reproduction. The present acreage must, to be sure, change until all agriculturally available lands have been turned into farms and all lands unfit for farming have been turned back into forest growth.

But if we accept as mere indications of possibilities the present acreage of timber land on the Atlantic side as 400,000,000 acres, and assume that it can be made to produce at the same rate as the German forests under good management, it would be able to supply continuously the present consumption of $25,000,000,000$ cubic feet.

The most important, most immediately needful change in thought and practice, without which forestry, the provision for future supplies, cannot be practically applied, is that in regard to forest fires. Forest fires are the bane of the forests of the United States - the most destructive agency; for while, with the exception of the Western forests, 
the yearly conflagrations destroy comparatively small amounts of standing timber, they kill the young growth, the hope of the future, and destroy even the soil, the fertility, an accumulation of centuries of decaying leaf-mould.

In comparison with our figures of bona fide consumption the direct loss of material through fires would appear, from such incomplete statistics as are at hand, as a small matter, perhaps 2 to 3 per cent of the total value of forest products, but the indirect loss can hardly be overestimated; besides, the seeming impotency of coping with this destructive agency discourages more conservative forest management on the part of forest owners, who are, under the circumstances, naturally induced to shorten the risk and turn into cash as quickly as. possible what is valuable in the forest growth, leaving the balance to its fate.

That, with the reckless exploitation of our virgin woods, accompanied by these forest fires, which have become notorious throughout the world, not only timber supplies have been decimated, but the protective function of the forest cover on mountain slopes has been considerably injured in many places, goes without saying.

Although it is even more difficult to adduce definite data regarding this influence, the argument of the pernicious influence of forest destruction on waterflow and loss of soil has found much more ready ears among the public. 
Indeed it is often used in the most absurd, extravagant, and unintelligent manner.

In the Eastern forest, especially the mountain forest, wholesale denudation is comparatively rare, since the lumberman usually culls merely; reproduction at least of a shrubby vegetation is most rapid, and there would be little danger of losing the protective cover through lumbering operations if the fires were kept out.

Even if a fire goes. through the slash, it is not many years before a new vegetation has established itself, and only repeated fires can produce a real denudation.

The effects are, of course, variable according to a variety of circumstances and conditions, the time of occurrence of the fires, the amount of débris to feed the flames, the character of the soil and its cover, etc.

While the mountain forests on the Atlantic side show only here and there really serious detriment to soil and soil cover due to lumbering operations and fires, injudicious clearing for farm use and improper management of farm lands are much more frequently the causes of undue erosion and soil washes.

Signs of the deleterious influences of undue deforestation are visible in all parts of the Eastern United States, and a chapter could readily be filled with detailed descriptions of regions which have especially suffered. 
Sand-dunes have been created by forest removal on all parts of our sea-shore; uneven water stages have been aggravated in all the older parts of the Union; soil washes can be seen in all the mountain and hill country, especially in the Southern states, with their abandoned or mismanaged farm lands.

In the Western mountains, where fires are more destructive on account of the coniferous composition and the dry climate, and where the pasturing of sheep in the forests prevents ready reëstablishment of vegetation, the results are even more readily observed.

We are experiencing droughts, we are suffering from floods, we have uneven seasons; but how much of these conditions is to be ascribed to our forest conditions, how much to general cosmic causes, nobody can determine. At any rate these conditions can be discussed and corrected only for definite local points. We have, perhaps, nowhere as yet come to such state of affairs as those reported from the high Alps of France, Switzerland, Austria, and Italy, but a continuance of our present disregard of the soil cover must inevitably lead to them.

Meanwhile the supply question is the more important, and attention to this, leading to the practice of silviculture, will naturally also incidentally correct the evils of denudation. 


\section{CHAPTER XII.}

\section{THE FORESTRY MOVEMENT IN THE UNITED STATES.}

FROM the very beginning of the settlement of the country some wise heads recognized that attention to satisfactory forest conditions is as necessary as attention to other economic conditions. William Penn, the founder and first legislator of Pennsylvania, as early as 1682 , stipulated in his ordinances, regarding the disposal of lands, that for every five acres cleared of forest growth one acre should be left to forest. In 1640, only two years after its settlement, the inhabitants of Exeter, N. H., adopted a general order for the regulation of the cutting of oak timber, then a most valuable export material, a precaution which other towns followed. In I 70I, the governor of New York reports 40 mills in the province of New York, and referring to one working with 12 saws, he adds, "A few such mills will quickly destroy all the woods in the Province at a reasonable distance from them." And he recommended that each person who removed a tree should pay for planting four or five young trees, as the Russians do to-day. 1

1 See "History of the Lumber Industry in the State of New York," by Colonel W. T. Fox, 6th Rept. of F. F. G. Com., Igor. 
In I708, the provincial assembly of New Hampshire forbade the cutting of mast trees on ungranted lands under a penalty of $£$ Ioo, and at that early time the province had a surveyorgeneral of forests, appointed by royal authority, for the purpose of preventing depredations upon the timber. No doubt this early regard to the timber supplies in the face of plenty came largely through the momentum of education, suggested by the usages and methods of the mother countries, where forest protection had already become an established policy, and even forestry practices existed.

A century later, real want seems to have appeared, or at least anticipation of it. For, in I795, the Society for the Promotion of Agriculture, Arts, and Manufactures published a report on the best mode of preserving and increasing growth of timbers, an outcome of an inquiry by circular letter issued in I79I; and in I804, the Massachusetts Society for the Promotion of Agriculture offered prizes for successful forest plantations; while the federal government, between the years 1799 and I83I, appropriated money for the purchase and passed legislation for the protection of liveoak timber, suitable for navy purposes, under which acts it acquired some 250,000 acres in Alabama, Florida, Louisiana, and Mississippi, — not as a matter of general forest policy, but to secure sufficient supplies of a special material, restricted 
in amount, and supposed to be a continued necessity for building war ships. ${ }^{1}$

We can now smile at the concern expressed so early by writers in public prints, with regard to the threatened exhaustion of forest supplies. But it must be understood that the extent of our forest domain was then entirely unknown, the population was confined mainly to the Eastern coast country, and in the absence of railroad communication, only the supplies adjacent to rivers and sea were available, and, just as in Europe, the fuel question was uppermost, as long as coal had not yet been developed; hence location of supplies close to centres of civilization was of more moment.

With the rapid development of the country, and the opening up of means of transportation, such as the Erie Canal, the apprehensions regarding supplies seem to have vanished. During the active period of expansion, from 1820 to 1860 , when the population more than quadrupled, over one and a half million farms were established, mainly hewn from the forest, the timber in the absence of a ready market being largely burned in the log pile; and with the necessity of constantly having to subdue tree growth, not only a feeling of inexhaustible resources and hence of carelessness, but almost a real pleasure in destruction

1 Laws to punish malicious and wilful incendiarism and sometimes also careless firing of the woods were about this period enacted in almost every state. 
seems to have been inculcated in the early settlers. Then came the period of railroad building and the settling of the Western prairies and plains, after I 860, and then only the enormous lumber business, as we know it to-day, came into existence.

The difference in the volume and character of the business of forest exploitation is most readily seen by comparing the census figures at different periods. In 1840 , there were reported 31,560 lumber mills, with a total product valued at $\$ 12,943,507$, or a little over $\$ 400$ per mill. Small country mills, run like gristmills and often in connection with such, sawed to order for home consumption, or sent material to the mouth of the river, to be carried by vessel to home and foreign markets. By 1870 , a change had already become apparent, when the product per mill was $\$ 6500$, which in 1890 had grown to $\$ 19,000$, or about three times the value of 1870 with only $2 I$,OI I mills reported.

In 1865, the state of New York still furnished more lumber than any other state; it now is seventeenth in the list with less than one billion feet. In I 868, the golden age of lumbering had arrived in Michigan, and this state is still second with over three billion feet; in I87 I, rafts filled the Wisconsin River, and the state of Wisconsin is now the largest producer; yet the 30 mills of Eau Claire, 20 mills at Marathon, 20 mills at Fond du Lac, which in I 875 cut millions of feet, are now all gone. 
Besides the concentration of the lumber business into large establishments which these figures show, there are other interesting changes indicated in the census figures, which have a bearing upon the question of the need of a forest policy and the cause for its development. While in 1890 the efficiency of the single mill establishments had increased to three times what it was in 1870 , and to nearly fifty times that of 1840 , the total product had also increased in the last twenty years nearly three times, but the capital employed in the lumber industry had increased four and one-third times; and while capital became less efficient with concentration, the unit product of labor also became less efficient in spite of the improvement of machinery, every dollar of capital producing less result by over 40 per cent in I890, in the value of the product, and every dollar of wages producing less result by over I 2 per cent, but the cost of raw material had increased over I6 per cent, - all these are signs pointing to the deterioration and exhaustion of supplies at least in the principal producing regions. The census of 1900 is, at present writing, not accessible in a form permitting such comparisons, except that we can note an apparent increase in value of product of nearly 30 per cent over that of 1890. (See Appendix for further details.)

It would be difficult to set a date or mark an event from which the change in the methods of the lumber industry, now such a stupendous factor 
in forest decimation, might be reckoned; it came as gradually or as fast as railway systems developed, and made accessible the vast fields of supply in the northwestern Lake states just as the supplies of the Eastern states began to weaken. ${ }^{1}$

By 1882 the Saginaw Valley had reached the climax of its production, and the lumber industry of the great Northwest, with a cut of eight billion feet of white pine alone, was in full blast. Southern development began much later to assume large proportions; but by the present time the lumber product of the Southern states has grown to proportions equal, if not superior, to those of the Northern states.

No wonder that those observing this rapid decimation of our forest supplies and the incredible wastefulness and additional destruction by fire, with no attention to the aftergrowth, began again to sound the note of alarm. Besides the writings in the daily press and other non-official publications, we find the reports of the United States Department of Agriculture more and more frequently calling attention to the subject.

In the report issued by the Patent Office as early as 1849 , we find the following significant language in a discussion on the influence of forests on waterflow and their rapid destruction :-

"The waste of valuable timber in the United

I See "American Lumber," by B. E. Fernow, in "One Hundred Years of American Commerce," D. O. Haynes \& Co., 1895. 
States, to say nothing of firewood, will hardly begin to be appreciated until our population reaches $50,000,000$. Then the folly and shortsightedness of this age will meet with a degree of censure and reproach not pleasant to contemplate."

The report of the Department of Agriculture for I 860 contains a long article by J. G. Cooper on "The forests and trees of northern America as connected with climate and agriculture."

In 1865 , the Rev. Frederic Starr discussed fully and forcibly the "American forests, their destruction and preservation," in which, with truly prophetic vision, he says :-

"It is feared it will be long, perhaps a full century, before the results at which we ought to aim as a nation will be realized by our whole country, to wit, that we should raise an adequate supply of wood and timber for all our wants. The cvils which are anticipated will probably increase upon us for thirty years to come with tenfold the rapidity with which restoring or ameliorating measures shall be adopted."

And again :-

"Like a cloud no bigger than a man's hand just rising from the sea, an awakening interest begins to come in sight on this subject, which as a question of political economy will place the interests of cotton, wool, coal, iron, meat, and even grain beneath its feet. Some of these, according to the demand, can be produced in a few days, others in 
a few months or in a few years, but timber in not less than one generation. The nation has slept because the gnawing of want has not awakened her. She has had plenty and to spare, but within thirty years she will be conscious that not only individual want is present, but that it comes to each from permanent national famine of wood."

The article is full of interesting detail, and may be said to be the starting basis for the campaign for better methods which followed.

Another and unquestionably most influential official report was that upon "Forests and Forestry of Germany," by Dr. John A. Warder, United States commissioner to the World's Fair at Vienna in I873. Dr. Warder set forth clearly and correctly the methods employed abroad in the use of forests, and became himself one of the most prominent propagandists for their adoption in his own country. About the same time appeared the classical work of George P. Marsh, our minister to Italy, "The Earth as Modified by Human Action," in which the evil effects of forest destruction on cultural conditions were ably and forcibly pointed out.

The census for 1870 for the first time attempted a canvass of our forest resources, and the relatively small area of forest became known. All these publications had their influence in educating a larger number to a conception and consideration of the importance of the subject, so that 
when, in I873, a committee on forestry of the American Association for the Advancement of Science was formed, and its memorial calling for the creation of a commissioner of forestry to gather information was presented to Congress, there existed already an intelligent audience; and, although a considerable amount of lethargy and lack of interest was exhibited, Congress could be persuaded, in 1876 , to establish the agency in the United States Department of Agriculture out of which grew the Division of Forestry now designated as Bureau of Forestry.

While these were the beginnings of an official recognition of the subject by the federal government, private enterprise and the separate states started also about the same time to forward the movement. In I 867 , the agricultural and horticultural societies of Wisconsin appointed a committee to report on the disastrous effects of forest destruction. In 1869, the Maine Board of Agriculture appointed a committee to report on a forest policy for the state, leading to the act of 1872 "for the encouragement of the growth of trees," exempting from taxation for twenty years lands planted to trees, which law, as far as we know, remained without result. About the same time a real wave of enthusiasm with regard to planting of timber seems to have pervaded the country, and especially the Western prairie states. In addition to laws regarding the planting of trees on high- 
ways, there were enacted laws for the encourage. ment of timber planting, either under bounty or exemption from taxation, in Iowa, Kansas, and Wisconsin in I 868, in Nebraska and in New York in I869, in Missouri in 1870, in Minnesota in 1871 , in Iowa in 1872 , in Illinois in 1874 , in Nevada, Dakota, and Connecticut in 1877 , and finally the federal government joined in this kind of legislation by the so-called timber culture acts of 1873 and I874, amended in 1876 and 1877 .

For the most part these laws remained a dead letter. The encouragement by release from taxes, except in the case of the federal government, was not much of an inducement, nor does the bounty provision seem to have had greater success, except in taking money out of the treasuries. Finally these laws were in most states repealed.

The timber culture act was passed by Congress on March 3, 1873; by this act the planting of timber on 40 acres of land, or a proportionate area in the treeless territory, conferred the title to 160 acres or a proportionate amount of the public domain. This law had not been in existence ten years when its repeal was demanded, and this was finally secured in I89I, the reason being that, partly owing to the crude provisions of the law and partly to the lack of proper supervision, it had been abused and had given rise to much fraud in obtaining title to lands under false pretences. It is difficult to say how much impetus the law gave to bona- 
fide forest-planting and how much timber growth has resulted from it. Unfavorable climate, lack of satisfactory plant material, and lack of knowledge as to proper methods led to many failures, and on the whole the expected results were not realized. Private interest of homesteaders and settlers without these aids has probably been more effective. In this direction the establishment of arbor days throughout the states has, been a stimulating influence. From its inception by Governor J. Sterling Morton and first inauguration by the State Board of Agriculture of Nebraska in 1872 , it has become a day of observance in nearly every state, and its adoption as a national holiday may be shortly expected.

While, with the exception of the so-called treeless states, perhaps not much planting of economic value is done, the observance of the day in schools as one set apart for the discussion of the importance of trees, forests, and forestry, has been productive of an increased interest in the subject.

Nevertheless, arbor days have had also a retarding influence upon the practical forestry movement in leading people into the misconception that forestry consists in tree-planting, in diverting attention from the economic question of the proper use of existing forest areas, in bringing into the discussion poetry and emotions, which have clouded the hardheaded practical issues and delayed the earnest attention of practical business men. 
The amount of tree-planting performed on the prairies, plains, and Western valleys, although aggregating thousands of acres, is infinitesimal, if compared with what is necessary for climatic amelioration; and it may be admitted, now as well as later, that the reforestation of the plains must be a matter of coöperative, if not of national, enterprise.

Indeed, as a result of an experiment instituted by the writer in 1890 to prove that the sand-hills of Nebraska could and should be planted to conifers, the federal government has lately reserved 200,000 acres for such planting, out of the I $5,000,000$ acres comprised in this sand-hill region.

Private efforts in the East in the way of fostering and carrying on economic timber-planting should not be forgotten, such as the prizes offered by the Society for the Promotion of Agriculture, the planting done by the private landholders at Cape Cod, in Rhode Island, Virginia, and elsewhere.

There have also been, here and there, farmers bestowing care on the manner of cutting their woodlots; lumbermen and other forest. owners have, now and then, not only made special efforts to protect their forest properties against fire, but have done their cutting conservatively and with care for the existing young growth.

Yet, altogether, these efforts have been sporadic, unsystematic, and not on any scale commensurate with the destruction of virgin resources, as may be 
learned from an article in the Year-book of the United-States Department of Agriculture, for 1899, in which an attempt is made to collect the facts regarding these efforts and place them in the most favorable light. While perhaps conservative culling has been practised by lumbermen in more cases than is known, actual forestry practice with a view to securing reproduction has been rare and only very lately introduced in a few conspicuous cases, the Forestry Bureau of the United States Department of Agriculture being instrumental in most of them; this bureau offering to prepare socalled "working plans" for private owners, in which some rules for the cutting of mature timber are laid down, intended to insure a succession of young growth. It is stated, that owners of nearly $2,000,000$ acres have asked for such advice. With the increase of educated foresters able to make and carry out such working plans, and with the appreciation by the forest owners of the possibility of securing continuous revenues by a conservative treatment of their properties under such plans, these small beginnings promise to bring about the much-needed reform, especially with the owners of extensive tracts, who are financially able to forego the present revenue from closer cutting for the sake of better future returns, which may be derived from more conservative lumbering.

Most of the efforts to engage state governments in establishing forest policies originated in associa- 
tions formed for the purpose of making the necessary propaganda.

The first forestry association organized for the purpose of advancing forestry interests was formed on January I2, I876, in St. Paul, Minn., largely through the efforts of Leonard B. Hodges. This association was aided by state appropriations, which enabled it to offer premiums for the setting out of plantations, and also to publish and distribute widely a Tree Planters' Manual. Revised editions are issued from time to time, and a distribution of plant material is also occasionally attempted, the state aiding to the extent of $\$ 1000$ to $\$ 2000$ annually.

In 1875 , Dr. John A. Warder issued a call for a convention in Chicago to form a national forestry association. This association was completed in I 876 at Philadelphia, but never showed any life or growth.

In 1882 , a number of patriotic citizens at Cincinnati called together a forestry congress, incited thereto by the visit and representations of Baron von Steuben, a Prussian forest official, when attending the centennial celebration of the surrender of Yorktown.

A very enthusiastic and representative gathering, on April 25, lasting through the week, led to the formation of the American Forestry Association. This association, holding yearly and intermediate meetings in different parts of the states, has 
become the centre of all private efforts to advance the forestry movement. Twelve volumes of its proceedings contain not only the history of progress in establishing a forest policy, but also much other information of value on forestry subjects. It now publishes a monthly journal, The Forester, (since 1902 called Forestry and Irrigation). It is unaided by government, its efforts being entirely borne by private means and the annual dues of its membership, its officers doing gratuitous work. It has been especially instrumental in bringing about the establishment of the federal forest reservation policy, which we will note further on in detail.

Other local or state forestry associations were formed more or less under the lead of the national association, and exist now in Massachusetts, Connecticut, New Hampshire, New York, Pennsylvania, New Jersey, North Carolina, South Carolina, Ohio, Indiana, Minnesota, North Dakota, Colorado, Utah, and Washington, while several other societies, like the Sierra Club, the Water and Forest Association, and the Mazamas of the Pacific coast, and state horticultural societies in various states, make the subject one to be discussed and to be fostered.

The most active of these associations, publishing also, since its formation in 1886 , a bimonthly journal, Forest Leaves, is the Pennsylvania State Forestry Association, which has succeeded in thoroughly committing its state to a proper fores': policy, as far as official recognition is concerned. 
Usually, as a result of this associated private effort, various states have appointed forestry commissions or commissioners. These commissions were at first for the most part instituted for inquiry and to make a report, upon which a forest policy for the state might be framed. Others have become permanent parts of the state organization with executive or educational functions. Such commissions of inquiry were appointed at various times in Maine, New Hampshire, Vermont, Massachusetts, New York, New Jersey, Pennsylvania, North Carolina, Ohio, Michigan, Wisconsin, North Dakota, Colorado, California; while commissioners or commissions with executive duties exist now or did exist for a time in Maine, New Hampshire, New York, Pennsylvania, Michigan, Wisconsin, Minnesota, Indiana, Kansas, North Dakota, Colorado, and California.

Maine has an efficient forest fire law (chap. 26 of Revised Statutes) based on that of the state of New York, and a forest commissioner (created in I89I, Public Laws, chap. I00) - the state land agent of the state being ex officio designated as such - to look to its execution. $\mathrm{He}$ is also to create an interest in forestry and furnish useful information on the subject.

Two very interesting and instructive reports on the growth of the spruce and on allied subjects are the result.

New Hampshire had a temporary commission of 
inquiry, appointed in $188 \mathrm{I}$ and reporting in $\mathrm{I} 885$; and another such commission in 1889 , reporting in I 893, when the permanent forestry commission was created (March 29, I893) with a paid secretary, who publishes an annual report. The main function of the commission is one of inquiry and suggestion, besides partial supervision of the forest fire law. The acquisition of public parks, if private munificence should be found willing to furnish the necessary funds, is also made a part of the function of the commission. Two small areas have been donated for this purpose. Within the last year (I9OI) the Society for the Protection of New Hampshire Forests was formed, which, through the employment of a forester, attempts to secure increased practical interest.

In Massachusetts no special public officers are charged with the care of forestry interests, and hence the otherwise useful existing legislation in the interest of forestry is probably of only partial effect. Its best feature is perhaps that of encouraging communities to become owners of forest. tracts (chap. 255, acts of I882). The city of Boston has made special efforts in this direction, having set aside more than 7000 acres for forest parks. The State Board of Agriculture was, in I 890, ordered to inquire "into the condition of the forests of the state, the need and methods of their protection," and report thereon, which order did not produce anything of value. A bill to se$2 \mathrm{c}$ 
cure such forest survey, introduced into the legislature in the year 1897, failed of passage.

In Vermont a commission of inquiry was instituted in I882, reporting in I884 without any practical result, the proposed legislation remaining unconsidered.

In New York a law was passed in I 872 naming seven citizens, with Horatio Seymour, chairman, as a state park commission, instructed to make inquiries with the view of reserving or appropriating the wild lands lying northward of the Mohawk, or so much thereof as might be deemed expedient, for a state park. The commission, finding that the state then owned only 40,000 acres in that region, and that there was a tendency on the part of the holders of the rest to combine for the enhancement of.values should the state want to buy, recommended a law forbidding further sales of state lands, and their retention when forfeited for the nonpayment of taxes.

It was eleven years later, in 1883 , that this recommendation was acted upon, when the state through the nonpayment of taxes by the owners had become possessed of 600,000 acres - the nucleus of the later state forest preserve.

In I 884, the comptroller was authorized to employ "such experts as he may deem necessary to investigate and report a system of forest preservation." The report of a commission of four members was made in 1885 , but the legislation 
proposed was antagonized by the lumbering interests. The legislature finally passed a compromise bill formulated in part by the writer, entitled "An act establishing a forest commission, and to define its powers, and for the preservation of forests."

This legislation, afterward amended, is the most comprehensive of that of any state in the Union.

The original forest commission, appointed under the act of May I 5, 1885, was superseded in I 895 by the Commission of Fisheries, Game, and Forests (now designated " Forest, Fish, and Game Commission ") under the law of April 25, I895. This law is a comprehensive measure in which allied interests are brought under the control of a single board. Under this law the commission consisted of five members appointed by the governor with consent of the senate, the term of office being five years.

By later changes, the number of commissioners was reduced to three, two of whom are to discontinue with the year 1903 , so that then a single commissioner will be in charge. The commission has full control of the Adirondack Preserve, with a staff of officials which includes a superintendent of forests, three expert foresters (since 1900) who are graduates of the State College of Forestry, and some forty "fish and game protectors and foresters," i.e. not technically educated guards.

The duties of the commission besides publish- 
ing annual reports are described in the laws of I 895, namely, to (I) have the care, custody, control, and superintendence of the forest preserve; (2) maintain, protect, and promote the growth of the forests in the preserve; (3) have charge of the public interests of the state in regard to forestry and tree-planting, and especially with reference to forest fires in every part of the state; (4) possess all the powers relating to the preserve which were vested in the commissioners of the land office and in the comptroller on May I 5, I 885 ; (5) prescribe rules and regulations affecting the whole or any part of the preserve for its use, care, and administration, and alter or amend the same; but neither such rules or regulations nor anything contained in this article shall prevent or operate to prevent the free use of any road, stream, or water as the same may have been heretofore used, or as may be reasonably required in the prosecution of any lawful business ; (6) take measures for the awakening of an interest in forestry in the schools and the imparting of elementary instruction on such subject therein, and issue tracts and circulars for the care of private woodlands, etc.; (7) print and post rules for the prevention and suppression of forest fires.

In singular antagonism to these duties, especially that which calls for the promotion of the growth of forests in the preserve, stands a provision in the state constitution, which was inserted in 1893 , 
after the commission had existed for 8 years, barring the rational use and the application of any forest management in the preserve in the following language :-

Article VII : "The lands of the State constituting the forest preserve now fixed by law shall be forever kept as wild lands. They shall not be leased, sold or exchanged, or be taken by any corporation, public or private, nor shall the timber thereon be sold or removed or destroyed."

This certainly forbids the practice of forestry as explained in the chapter on "Silviculture," and would seemingly exclude even the planting of waste lands, although the commission during the present year, stimulated by the example of the College of Forestry, has set out a large number of trees on such lands. Repeated efforts to remove this constitutional bar to forestry practice on state lands have been made, but the people have so far refused to reconsider the injunction, partly because of mistrust of the commission's technical ability, partly because of ignorance or misconception of what forestry means, partly because of the influence of wealthy property owners, who desire to keep these woods in the wild condition for their pleasure; and there are perhaps good reasons why this economic loss should be endured until more education in forestry matters is secured and the forest preserve in its entirety is established and a comprehensive plan can be formulated. 
In 1897 , legislation, providing for an increase of the state forest preserve, was passed by instituting the Forest Preserve Board, whose function it is to purchase lands with appropriations made from time to time. Nearly $\$ 2,000,000$ have been spent on such purchases, and the preserve now contains over I,250,000 acres, which, if properly administered under forest management, should at least produce the amount of about $\$ 150,000$ annually for supporting the Forest, Fish, and Game Commission.

The state of New York was the first to inaugurate this forest reservation policy (even before the federal government), as well as the first comprehensive effective forest fire law, with an organization for its execution, and furthermore took the first steps to provide for the technical education of foresters, by establishing in 1898 the New York State College of Forestry, to be administered by Cornell University, together with a demonstration forest of 30,000 acres, located in the Adirondacks. The demonstration area was designed to give a practical object lesson of the manner in which a forest may be managed for reproduction and for profit; the college, to educate the foresters, who may eventually become the technical advisers for the management of the forest preserve. A four years' course, leading to the degree of Forest Engineer, as full and complete as any of the European forestry schools, is offered. During the first four years of its existence, the number of 
students has increased to 65 (fall, 1902), and the I 8 graduates and special students, who have been sent out from this first professional school, have found ready employment in the federal and state service or with private employers.

The state which, next to New York, has most progressed in the direction of a forest policy is Pennsylvania. Through the efforts of the State Forestry Association, a commission of inquiry was first created in I893, and before its report was published, in I 895, provision was also made for a commissioner of forestry as an organic division of the newly created department of agriculture. Through the effort of the commissioner, Dr. Rothrock, important legislation was had in 1897 , and in I90I the division became a separate department of forestry, and a state forest reservation commission was created.

The most important legislation of 1897 , besides improving the forest fire laws, and relieving forestlands under certain conditions from taxation (see p. 247), is that "authorizing the purchase by the Commonwealth of unseated lands for the nonpayment of taxes, for the purpose of creating a state forest reservation," and another act, providing for the immediate establishment of three definite reservations in the three large drainage areas of the state. Under these acts, some 400,000 acres have been reserved. A second state had recognized the propriety of state forests. 
The third state falling in line is Michigan. It began in 1887 by constituting the State Board of Agriculture a forestry commission of inquiry, but the report of the commission, published in 1888 , remained without immediate effect. In I899, a permanent forestry commission of three was appointed, whose duty was in the first place also merely one of inquiry, with the requirement to submit in I9O I a bill "to carry out the objects for which this commission is appointed," but also empowering the commission to have withdrawn from sale, temporarily, 200,000 acres of "state tax homestead lands and swamplands belonging to the state," and to receive from private owners donations of land. The commission presented a most admirable bill to carry out the forest reservation policy, but the bill was defeated, largely through the farming element. Nevertheless, the commission secured a forest reservation of 70,000 acres, and the progress of this policy is well assured, although progress will probably be slow on account of ignorant or selfish obstructionists.

In Minnesota a law was enacted in I90I, setting aside as a state forest reserve all lands unfit for agriculture that reverted to the state through delinquent taxes before I89I ; but legislation, having in view the creation of forest boards and forest reserve areas under rather unique conditions, which was introduced in the legislature in I897, failed to become law. 
In consequence of the terrible warning by the forest fires of 1894, which destroyed nearly three quarter million dollars' worth of property, and several hundred lives, Minnesota created the office of chief fire warden, acting under the state auditor as forest commissioner, in charge of an organized service to combat forest fires. The chief fire warden is also required to furnish annual reports, with suggestions relative to the preservation of forests and the prevention of forest fires. The four or five reports issued, show that the protective service is tolerably effective in spite of deficient appropriations, and the fact that the questions of forestry are systematically kept before the public is bound to result sooner or later in more comprehensive action.

The third of the three great lumber states, Wisconsin, was also scared by the forest fires of 1894 into enacting a forest fire law, similar to the Minnesota law, which followed the principles of organization first inaugurated in the New York law of I 885. Here the chief clerk of the state land office, and his deputy, were made forest wardens without additional salary. Towns are limited to \$IOO per year expenditure in extinguishing fires. It is easy to judge what the efficiency of such service may be. An attempt, through a commission of inquiry created in 1897 , to commit the state further has so far failed.

In the first year of the new century, two other 
states recognized their responsibility, namely Indiana and Connecticut. Indiana entered the list of states with a forest policy by the establishment of a state board of forestry and the enactment of a law exempting certain forest lands from taxation (see p. 246). Connecticut appointed a state forester under the board of control of the Agricultural Experiment Station, and enacted a law "concerning reforestation of barren lands," making a small appropriation for the purchase and planting of such lands.

A few other states show feeble beginnings, some dating back a long time, without visible progress.

In New Jersey, North Carolina, and West Virginia the state geological surveys have had the forestry interests in charge for several years, publishing from time to time useful information. A well-devised bill providing for a forest commission and state forest reserve failed of passage in the legislature of West Virginia in 1897.

In Ohio a forestry bureau was instituted in 1885 , its functions being of an educational and advisory nature. It published four or five annual reports containing information on a variety of subjects, but for a number of years these reports, and probably the bureau, have been discontinued.

In North Dakota the office of commissioner of irrigation and forestry was created in I890, seemingly mainly for educational purposes. In Kansas for some time the educational campaign for timber- 
planting of the State Horticultural Society was supplemented by the state in the establishment of two experimental tree stations, from which plant material is distributed to intending planters through a forest commissioner.

The state of Colorado was the first to recognize in her constitution the existence of a duty on the part of the government with regard to her forestry interests.

Article XVIII of the constitution, adopted in convention March I4, I876, contains the following clauses:-

"SEc. 6. The general assembly shall enact laws in order to prevent the destruction of and to keep in good preservation the forests upon the lands of the State or upon lands of the public domain, the control of which shall be conferred by Congress upon the State.

"SEc. 7. The general assembly may provide that the increase in the value of private lands caused by the planting of hedges, orchards, and forests thereon shall not, for a limited time, to be fixed by law, be taken into account in assessing such lands for taxation."

The constitutional convention also presented a memorial to congress asking for the transfer of the public timber lands in the then territory to the care and custody of the state, which remained, however, without attention.

The intentions of the constitution to take care 
of the forestry interests of the state were, however, not carried into effect until 1885 , when a law was passed creating the office of a forest commissioner and constituting the county commissioners and road overseers throughout the state, forest officers in their respective localities, to act as a police force in preventing depredation and fire, and to encourage and promote forest culture. But the provisions to carry out this laudable work were from the start insufficient, and the office of forest commissioner finally remaining without a salary became vacant, the law ineffective. A new departure, however, was made in 1897 . In that year a department of forestry, game, and fish was created. The salaried officers provided are a commissioner and three wardens, and the commissioner may appoint deputy wardens without pay. Section 9 of the law provides that -

"Said commissioner shall, as much as possible, promote the growth and extension of the forest areas of the state, and encourage the planting of trees and the preservation of the sources of water supply, but nothing in this act contained shall authorize the commissioner to interfere with the use of timber for domestic, mining, or agricultural purposes, in accordance with existing laws. He shall have the care of all woodlands and forests which may at any time be controlled by the state, and shall cause all such lands to be located and recorded in a book to be kept for the purpose." 
Section Io prohibits the appointment to any office created by this act of any person directly or indirectly engaged in the manufacture of lumber, railroaad ties, telegraph poles, or any business requiring a large use of wood. The law makes it a misdemeanor to cause fires to be set without a guard, or to cut coniferous timber from public or state lands for shipment outside the state. The remainder of the law provides for the protection of fish and game.

California began its course for the establishment of a forest policy in the most promising manner in $r 885$ by creating a state board of forestry. At first it was mainly a commission of inquiry with educational functions; police powers were conferred upon it in I887 "for the purpose of making arrests for any violation of any law applying to forest and brush lands within the State, or prohibiting the destruction thereof," with an appropriation of $\$ 30,000$ for the two years following, but by 1891 political complications and perversion of the moneys appropriated undid the good work of . the first board, and the office, as well as the functions, were abolished. Besides three valuable reports on the forest conditions and forest trees of the state, the board left as an inheritance two experiment stations, where exotic trees are being tested, now under charge of the University of California. Lately the state appropriated $\$ 250,000$ to purchase the remnant of the great Redwood 
forest in the Santa Cruz Mountains for a public park; such reservation, however, is only distantly and indirectly a part of forest policy.

We have again and again referred to the first and foremost obligation of the state and the most urgent and important need of reform in the treatment of our woodlands, namely protection against fires. There is so far no state as yet fully doing its duty in this direction, although tolerably effective beginnings have been made in several states. The first comprehensive forest fire law, drafted by the writer, was enacted in New York in 1885 in connection with the establishment of a forest commission. This law for the first time recognized the need of officers responsible for the execution of the law and of a well-organized army of fire wardens throughout the state. The states of Maine, New Hampshire, Pennsylvania, Wisconsin, and Minnesota followed, with some modifications, this example of New York. The most complete forest fire law is probably that of Minnesota, enacted in 1895 , which is, like the others, however, only partially effective on account of deficient appropriations and limited functions of the commissioner or fire warden. ${ }^{1}$

It would appear from all experience now accumulated by the officers in charge of the execution

1 For a full discussion of this phase of forest policy, with reprint of the Minnesota law, see H. R. Doc. No. I81, 55th Cong. $3 \mathrm{~d}$ sess. pp. $183-189$. 
of this law, that the reduction in forest fires is largely a matter of education and the development of morals, which must come in time. Moreover, when real forestry is begun, when waste lands are not any more abandoned as useless, but planted to valuable timber, when forest properties are really managed for continuity, in short, when forestry is practised, both the necessity and the desire for careful protection of a valuable piece of property will bring about a cessation of incendiarism; and the practice of forestry will soon come, when educated foresters can be had to practise it.

For the education of such, provision is being rapidly made by the establishment of special forestry schools or of courses in forestry in existing institutions. Here again the state of New York recognized its educational function by establishing, in I898, the State College of Forestry at Cornell University. With the establishment of this first professional forestry school, we may say that the art of forestry was removed from the mere field of discussion, and engrafted on our educational system, insuring a new era for rational forestry methods.

In the following year, Yale University established such a school, and a private school was established about the same time on the Vanderbilt estate at Biltmore, N.C. Before this time and since, the land-grant colleges of several states had introduced at least courses on subjects touching 
on forestry, without attempting professional train. ing, the object being mainly to give a general idea of the natural history of forest growth and the meaning and importance of forestry, and promoting public interest in forest protection and silviculture. Within a few years, however, it is to be expected that professional courses will exist in many of these institutions, and the flood of education will pour its beneficent influence over our neglected woodlands.

A sufficient number of professionally educated foresters, it appears, have gone forth from these schools and are now at work in the United States (including the Philippines) to justify the publication of the first professional journal, the Forestry Quarterly, which made its appearance in the fall of I902, published by students, alumni, and faculty of the New York State College of Forestry.

In this connection we should perhaps make also special mention of the effort of Berea College in Kentucky to furnish instruction in forestry to a class of rangers. Indeed, there is now more need to provide for this class of instruction, to rangers, logging bosses, under-foresters, etc., than for a multiplication of higher grade schools, nevertheless the latter is evidently contemplated by a number of colleges.

In all these movements throughout the states, the efforts of the American Forestry Association and of the state associations may be recognized, 
and the actions of the federal government no doubt had also an indirect educational influence.

With the establishment of the Division of Forestry in the United States Department of Agriculture (1876-1885) an official centre was created for supporting the forestry movement, and through the organization of the American Forestry Congress (changed later to American Forestry Association), in which the officers of the Division of Forestry naturally took a leading part, the sphere of influence was greatly enlarged. These two agencies have moulded public opinion through the past twenty or twenty-five years and brought about the interest now taken in forestry matters. The history of the establishment of these two agencies may be read in the repeatedly cited public document (H. R. Doc. No. 18I, 55th Cong. 3d sess.) and in the publications of the American Forestry Association.

The main tangible result of the educational campaign of these agencies for a federal policy was the inauguration of the forest reservation policy.

The first suggestion of such a policy appeared in 1876 with a bill (H. R. No. 2075) "for the preservation of the forests adjacent to the sources of navigable rivers and other streams," which never progressed farther than the pigeonhole of the Public Lands Committee.

Similar bills, introduced from time to time, experienced the same fate in the same or other 
committees, until more definite reservations were called for. An act to establish a forest reservation on the head waters of the Missouri and Columbia rivers passed the Senate in 1884, and again in 1885 , but died in the House Committee; in the same year a general act providing for forest reservations was reported favorably in the House. After this, hardly a year passed without a number of legislative propositions to the same effect being introduced, the titles of the bills filling several quarto pages of the above-cited document.

Hardly any kind of legislation which could be suggested was overlooked, from the creation of forest commissions to investigate the subject to providing for fully organized forest administrations and the establishment of forestry schools.

The American Forestry Association presented a comprehensive bill drawn by the Chief of the Forestry Division in I888, providing for the withdrawal from entry or sale of all public timber lands not fit for agricultural use, and for their proper administration under technical advice. (S. 1476 and S. I779, 5oth Cong. Ist sess.)

Modifications of this bill were introduced from year to year, and their enactment urged with small success.

Finally, in the Fifty-first Congress, through the earnest insistence of Secretary of the Interior John W. Noble, who was fully imbued with the necessity of some action such as was advocated by the asso- 
ciation, the following section was added to the act entitled "An act to repeal timber culture laws, and for other purposes," approved March 3, I891 :-

"SEc. 24. That the President of the United States may, from time to time, set apart and reserve, in any State or Territory having public lands bearing forests, any part of the public lands wholly or in part covered with timber or undergrowth, whether of commercial value or not, as public reservations, and the President shall, by public proclamation, declare the establishment of such reservations and the limits thereof."

It is upon this feeble "rider," attached to a bill hardly germane to the subject, that the forest reservation policy of the federal government is based, that the federal land policy, which before considered only disposal of the public domain, was changed, the government becoming a landowner for continuity.

Acting upon this authority, Presidents Cleveland and Harrison established seventeen forest reservations, with a total estimated area of $17,500,000$ acres previous to 1894 .

The reservations were established usually upon the petition of citizens residing in the respective states and after due examination, the forestry association acting as intermediary.

Meanwhile the legislation devised for the administration of the forest reserves, existing or to be established (H. R. II9), specially urged by 
Representative McRae, chairman of Public Lands Committee, failed to be enacted, although in the Fifty-third Congress it was passed by both Houses, but failed in conference. Forest reservation without forest administration threatened to make the whole policy unpopular.

Urged by the committee of the Forestry Association, which hoped to secure thereby potent influence for the proposed legislation, Secretary Hoke Smith, of the Department of the Interior, impressed with the importance of devising some adequate system of protection and management of the forests, both within the reserves and in the public domain, under date of February I 5, 1896, requested the National Academy of Sciences, the legally constituted adviser of the government in scientific matters, to investigate and report "upon the inauguration of a rational forest policy for the forested lands of the United States."

Under date of February I, I897, the academy submitted to Secretary Francis a preliminary report recommending the creation of thirteen additional forest reserves with a total area of 2 r,379,840 acres. These reserves were proclaimed as recommended, without examination, by President Cleveland, February 22, 1897. On May I, 1897, the president of the academy submitted his complete report (Senate Doc. No. 105), recommending substantially the legislation so long urged by the Forestry Association. 
A storm of indignation broke out in Congress over the precipitate action of the President, the repeal of the entire forest reservation policy was demanded by the Western senators and representatives, who felt insulted by the lack of consideration, and the laboriously achieved first step threatened to be lost. A compromise was, however, effected.

The sundry civil appropriation bill passed June 4, 1897 (see Senate Doc. No. IO2), set aside only the proclamations of February 22, I 897 , suspending the reservations which were made upon the recommendation of the committee of the academy until March I, I 898, presumably to give time for the adjustment of private claims and to more carefully delimit the reservations. For this purpose an appropriation of $\$ 150,000$ to survey the reservations under the supervision of the Director of the Geological Survey was made. The provisos attached to this appropriation embody the most important forestry legislation thus far enacted by Congress. These provisos had been in the main formulated in the above-cited bill known as the McRae Bill, which was passed by the House of Representatives and the Senate of the Fifty-third Congress - without, however, becoming a law; and again had passed the House in the Fifty-fourth Congress, it being the legislation advocated by the American Forestry Association as a first step toward a more elaborate forest administration of the public tim- 
ber lands. Excluding minor items, the law provides that -

"All public lands heretofore designated and reserved by the President of the United States under the provisions of the act approved March third, eighteen hundred and ninety-one, the orders for which shall be and remain in force and effect, unsuspended and unrevoked, and all public lands that may hereafter be set aside and reserved as public forest reserves under said act, shall be as far as practicable controlled and administered in accordance with the following provisions :-

" No public forest reservation shall be established, except to improve and protect the forest within the reservation, or for the purpose of securing favorable conditions of water flow, and to furnish a continuous supply of timber for the use and necessities of citizens of the United States; but it is not the purpose or intent of these provisions or of the act providing for such reservations to authorize the inclusion therein of lands more valuable for the mineral therein or for agricultural purposes than for forest purposes.

" For the purpose of preserving the living and growing timber and promoting the younger growth on forest reservations, the Secretary of the Interior, under such rules and regulations as he shall prescribe, may cause to be designated and appraised so much of the dead, matured, or large growth of trees found on such forest reservations as may be 
compatible with the proper utilization of the forests thereon, and may sell the same for not less than the appraised value in such quantities to each purchaser as he shall prescribe, to be used in the State or Territory in which such timber reservation may be situated, respectively, but not for export therefrom. Before such sale shall take place, notice thereof shall be given by the Commissioner of the General Land Office for not less than sixty days, by publication in a newspaper of general circulation, published in the county in which the timber is situated, if any is therein published, and if not, then in a newspaper of general circulation published nearest to the reservation, and also in a newspaper of general circulation published at the capital of the State or Territory where such reservation exists; payments for such timber to be made to the receiver of the local land office of the district wherein said timber may be sold, under such rules and regulations as the Secretary of the Interior may prescribe; and the moneys arising therefrom shall be accounted for by the receiver of such land office to the Commissioner of the General Land Office in a separate account, and shall be covered into the Treasury. Such timber, before being sold, shall be marked and designated, and shall be cut and removed under the supervision of some person appointed for that purpose by the Secretary of the Interior. not interested in the purchase or removal of such 
timber nor in the employment of the purchaser thereof. Such supervisor shall make a report in writing to the Commissioner of the General Land Office and to the receiver in the land office in which such reservation shall be located of .his doings in the premises.

" 'Upon the recommendation of the Secretary of the Interior, with the approval of the President, after sixty days' notice thereof, published in two papers of general circulation in the State or Territory wherein any forest reservation is situated and near the said reservation, any public lands embraced within the limits of any forest reservation which, after due examination by personal inspection of a competent person appointed for that purpose by the Secretary of the Interior, shall be found better adapted for mining or for agricultural purposes than for forest usage, may be restored to the public domain. And any mineral lands in any forest reservation which have been or which may be shown to be such, and subject to entry under the existing mining laws of the United States and the rules and regulations applying thereto, shall continue to be subject to such location and entry, notwithstanding any provisions herein contained.'"

The law authorizes the Secretary of the Interior to permit the use of timber and stone by bona-fide settlers, miners, etc., for fire wood, fencing, buildings, mining, prospecting, and other domestic purposes. It protects the rights of actual settlers 
within the reservations, empowers them to build wagon-roads to their holdings, enables them to build schools and churches, and provides for the exchange of such for allotments outside the reservation limits. The state within which a reservation is located maintains its jurisdiction over all persons within the boundaries of the reserve.

Under the above enactment, the commissioner of the General Land Office has formulated rules and regulations for the forest reservations, and a survey of the reserves is being made by the United States Geological Survey, the appropriations for such a survey having been continued from year to year, and the date for the segregation of agricultural lands and their return to the public domain open for entry having been deferred.

The appointment of forest superintendents, rangers, etc., although not with technical knowledge, to take charge of the reservations marks the beginning of a settled policy of the United States Government to take care of its long-neglected forest lands.

Gradually the people of the Western states, who were opposed to the reservation policy, believing it an interference of their rights and an impediment to settlement, have learned to appreciate the wisdom and the object of the reservations, especially in the irrigation districts. Annually new areas are being reserved and the administrative features developed. At present writing there are set aside $58,850,000$ acres in 56 reservations, in- 
cluding two in Alaska, varying in size from a few thousand to several million acres.

The administration of these reserves is still of the crudest kind, and forestry practice is as yet hardly attempted. In fact, the organization of the forestry service is still in embryonic condition. The administration of the reserves lies with the Department of the Interior, through a Forestry Division, under the Commissioner of the General Land Office. Meanwhile the technical knowledge is gradually developed in the Department of Agriculture.

The Forestry Division of the Department of Agriculture, dignified by being elevated to a bureau in rgor, is still without administrative function and occupies only an advisory position. But by an increase in appropriations (\$I $\$ 46,280$ for the year 1902) it has been able to extend its field considerably. It makes so-called working plans for the timber lands of private forest owners and planting plans, and investigates forest conditions, rates of growth, and other matters of interest, as before, only on an extended scale. It should, of course, be in charge of the public forest reservations, and introduce such technical management of the same as the case may permit.

To add to the curiosities and incongruities of the situation a third agency, the Geological Survey, has in charge the survey and description of the forest reservations with a view of delimiting the areas to 
be kept permanently as such. We have, then, three government offices, organically disconnected, albeit working in harmony as far as possible, intrusted with the forestry interests of the federal government. It is hoped that only a short time will elapse before logic will have its day, unity will be established, and a forest administration under the Bureau of Forestry will be inaugurated.

Curiously, too, we find that in one of our outlying possessions, the Philippine Islands, we are farther progressed in establishing a proper forest policy than at home. Here the Spanish Government had long ago established a forestry bureau to superintend the exploitation of the public timber lands. The United States fell heir to the lands, some 20 or 30 million acres, and to the bureau. By good fortune the administration of this bureau came into the hands of an army officer who had for some years interested himself in the forestry question, and under his efficient guidance the management of this part of the public domain promises soon to be on a rational basis.

We see then that the Federal Government has made a fair beginning toward establishing a definite forest policy, that a few states have also entered upon more or less definite plans to advance a state policy or secure private interest, and that the number of private owners who contemplate the advisability of practising forestry on their properties is rapidly growing. 

APPENDIX. 



\section{APPENDIX.}

NOTES TO CHAPTER I.

PAGE 6. Referring to Dearth of English Literature on Economy of Resources. - The conceptions and ideas contained in this chapter regarding the classification of natural resources and the relation of the state to them were first formulated by the writer in his Vice-Presidential Address before the Section of Economic Science of the Association for the Advancement of Science, entitled "The Providential Functions of Government, with Special Reference to Natural Resources," and printed in the volume of Proceedings for 1895 . The economics of natural resources have received only incidental and scanty consideration by English writers. The only publication known to the writer which discusses the subject in a broad manner is by G. P. Osborne, "Principles of Economics." The satisfaction of human wants in so far as their satisfaction depends on material resources. Cincinnati. 1893.

P. 9. - The fact that "emotion rather than reason, sentiment rather than argument, are the prime movers of society" has been most forcibly and convincingly argued by Lester F. Ward in his "Psychic Factors of Civilization" and "Dynamic Sociology."

P. I6. Eminent Domain. - In all modern states the right of eminent domain (dominium emineus), i.e. the right of the state to dispossess private owners or to restrict them in the use of their property for the sake of the common weal, and for public purposes, is well established. At first exercised only by specific legislation in individual cases, since the end of the eighteenth century the right of eminent domain has 
become a matter of constitutional provision and of genera. legislation. The modern legislation also fully recognizes the right of the owner to adequate compensation and provides methods of procedure.

In the United States the taking of land in invitum and the manner of ascertaining and securing the compensation is provided for in the statutes of each state. This right of eminent domain has been most frequently exercised for the purpose of roads, railioads, canals, bridges, etc., for the reason that, although these uses of land are usually accompanied by profits to individuals, they are primarily to serve a public use. There seems to be no reason why the same right should not be extended in favor of other public utilities, like forests.

The decision as to the public necessity of its exercise is in the United States, as in England, left to the courts, and the determination of the award for damage to a jury. In Germany these decisions lie with the administration. The exercise of eminent domain for the purpose of securing the protection of forest cover, as practised by European states, is discussed in Chapters $\mathrm{X}$ and $\mathrm{XI}$.

\section{NOTES TO CHAPTER II.}

P. 2r. Necessity of Wood Materials. - The necessity of wood for civilization, together with the constant increase in its use as industrial activity increases, is perhaps best illustrated by the statistics of imports of wood in European countries, which show the most remarkable increase of per capita consumption due to industrial development.

In Great Britain, a country which supplies itself almost entirely by importation, and hence uses wood probably least wastefully, during the decade $1856-66$ the import was 148 million cubic feet; during the following decade it had grown more than 60 per cent, namely, to 244 million feet. During 
the decade $1880-90$ the imports averaged round 300 million cubic feet, with an average value of $\$ 75,000,000$; and during the last decade the following changes in amounts and values took place :-

\begin{tabular}{|c|c|c|c|c|c|c|c|}
\hline \multicolumn{6}{|c|}{ Year. } & \multirow{2}{*}{$\begin{array}{c}\text { Million Feet. } \\
35^{\circ}\end{array}$} & \multirow{2}{*}{$\frac{\text { Million Dollars }}{78}$} \\
\hline 1891. & - & • & - & - & - & & \\
\hline 1894 . & - & - & - & - & - & 385 & 92 \\
\hline 1896. & - & - & - & - & - & 435 & 106 \\
\hline 1897 . & • & • & - & - & - & 500 & 127 \\
\hline 1898 & - & - & - & • & - & 455 & 117 \\
\hline
\end{tabular}

- an increase in forty years by over 200 per cent, while the population only increased 42 per cent.

In France, which is also relying upon imports to a very large extent (over 80 per cent in value), we find a still more striking increase of wood consumption, as may be judged from the statement of the values of wood imports, which were as follows : -

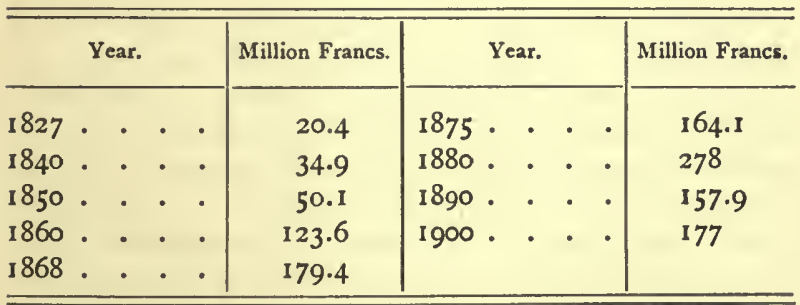

The wood exports increased during these seventy years from 4.5 million to 47 million francs, leaving, nevertheless, a total increase in excess of imports by over 700 per cent to satisfy the needs above home production, while the population increased about 20 per cent in that period, the home production slightly decreasing since 1870 . 
In the case of France, deforestation at home may account in part for this increase of imports, especially in the earlier decades. Not so in Germany, the land famous for its conservative forest management and thrift.

Germany, which until 1863 was an export country, its exports of wood exceeding its imports in that year still by 125,000 tons, after that year shows a constant increase of wood imports, and to-day Germany pays over $\$ 70,000,000$ for wood in excess of its exports and in addition to its own crop. The excess of imports over exports averaged per year as follows :-

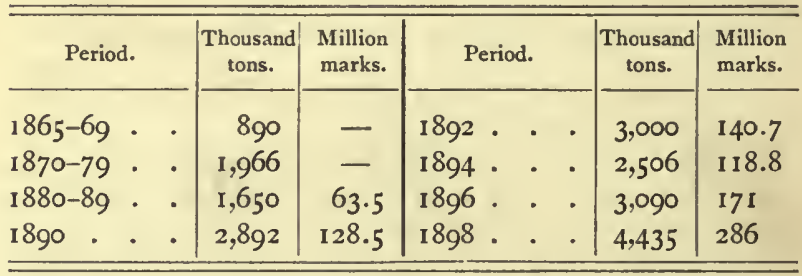

an increase in 40 years by 400 per cent in amount, in 20 years by over 350 per cent in values, besides a considerable increase in its home production, as is shown in Chapter X, while the population increased only by about $3^{8}$ per cent. These figures would indicate in general an increase of 5 to 10 times in per capita consumption; increase in prices accounting only to a limited degree for increase in the figures.

In spite of the substitution of iron and stone for timber wood and of coal for fuel wood, the wood consumption in Germany has increased from about 1,625 million cubic feet in 1872 to 2,051 million in 1898 . The consumption of fuel wood, to be sure, has lately decreased, but not in proportion to the coal mined, for the annual consumption of wood and coal per capita was as shown on opposite page. (This table leaves out importations, which add from 3 to 6 cubic feet, mainly to timber wood). 


\begin{tabular}{|c|c|c|c|c|c|c|}
\hline & \multicolumn{2}{|c|}{ Timber wood. } & \multicolumn{2}{|c|}{ Fuel wood. } & \multicolumn{2}{|c|}{ Coal. } \\
\hline & Cubic $\mathrm{ft}$. & Per cent. & Cubic $\mathrm{ft}$. & Per cent. & Tons. & Per cent. \\
\hline $1872-75$ & 13 & 100 & 27 & 100 & 1.062 & 100 \\
\hline $1876-80$ & 12.4 & 95 & 26.3 & 95 & 1.169 & I 10 \\
\hline $188 \mathrm{I}-85$ & 12.4 & 95 & 24.8 & 92 & I. 445 & 136 \\
\hline I $886-90$ & 13.4 & 103 & 23.8 & $88^{\prime}$ & I .686 & 159 \\
\hline $1891-95$ & 14 & 108 & 22.4 & 83 & 1.939 & 183 \\
\hline 1896 & 14.5 & III & 22 & 82 & 2.153 & 203 \\
\hline
\end{tabular}

P. 22. Proportion of Wood consumed for Necessities. - In this connection it would have been proper to point out that this consumption refers to the net wood product. The unavoidable very large waste, which occurs in the shaping of the raw.material for use, and which in most cases is a total loss, amounts to almost 50 per cent, - that is to say, of the cubic contents of a round average log only half the wood falls from the saw in useful size, the balance being turned into sawdust, slabs, edgings, etc., which only under special conditions can be made useful. In addition, a large amount of wood in the shape of top and branches is left in the woods unused, unless a dense population or special industrial development makes its use possible and profitable; this loss may amount to another 20-30 per cent, so that of the wood of a forest-grown tree often not more than 20 to 30 per cent appears in useful shape.

The following table shows how, in the usual mill practice, the loss varies with the size of material, and, at the same time, the value per cubic foot of forest-grown material increases with the size of $\log$, a financial argument against the cutting of the smaller trees and also an economic argument for the urgency of devising uses for the mill waste and forest waste. Much of this waste can be utilized, but is usually thrown aside through ignorance of its value, or lack of handling facilities. 
Value Accretion AND Waste of Wood.

\begin{tabular}{|c|c|c|c|c|c|}
\hline \multirow{2}{*}{$\begin{array}{l}\text { Diam. of log } \\
\text { ro ft. long. } \\
\text { Inches. }\end{array}$} & \multicolumn{2}{|c|}{ Contents in cubic feet. } & \multirow{2}{*}{$\begin{array}{c}\text { Waste per } \\
\text { cent. }\end{array}$} & \multicolumn{2}{|c|}{$\begin{array}{c}\text { Price at } \$ 6 . \infty \text { per } \mathrm{M} \text { ft. } \\
\text { B.M. }\end{array}$} \\
\hline & $\begin{array}{l}\text { Round } \\
\text { log. }\end{array}$ & $\begin{array}{c}\text { Mill } \\
\text { product. }\end{array}$ & & $\begin{array}{c}\text { Cost per } \\
\text { log. } \\
\text { Cents. }\end{array}$ & $\begin{array}{c}\text { Cost per cubic } \\
\text { foot. } \\
\text { Cents. }\end{array}$ \\
\hline 8 & 3.5 & 1.3 & 63 & 9 & 2.6 \\
\hline 12 & 7.9 & 4 & 50 & 30 & 3.8 \\
\hline 16 & 14 & 8 & 43 & 60 & $4 \cdot 3$ \\
\hline 20 & 21.7 & 14 & 35 & 132 & 4.8 \\
\hline 24 & $31 \cdot 3$ & 21 & 33 & 150 & 4.8 \\
\hline 30 & 49 & 35 & 28 & 253 & 5.2 \\
\hline 40 & 87 & 67 & 23 & 486 & 5.6 \\
\hline 50 & 136.2 & 110 & 20 & 993 & 5.8 \\
\hline
\end{tabular}

The second column gives the actual cubic contents; the third gives the feet board measure, as noted in the most favorable $\log$ scale translated into cubic feet by dividing by 12 ; the third column shows the amount of waste experienced at the saw; the last column shows what the cubic foot actually in the $\log$ has been paid for, if a stumpage price per $M$ feet board measure prevailed.

P. 27. Wood for Fuel in the United States. - The census of 1880 made a comprehensive canvass of the fuel wood consumption, which showed that $33,375,000$ persons used wood for domestic fuel at the rate of $4^{1}$ cords per capita, while the total consumption for domestic, railroad, steamboat, and manufacturing purposes was nearly 146 million cords, the total valued at $\$ 322,000,000$, or 2.9 cords per capita, nearly twelve times the German consumption. No statistics are at hand to estimate the present consumption of wood for fuel in the United States, but there are no reasons to assume that it has decreased appreciably in spite of the fact of the enormous increase in coal consumption, which is mainly due to indus- 
trial development. According to the United States Treasury Statistical Bureau's Summary, the world's production of coal rose from 144 million tons in 1860 to 450 million tons in 1883 , and to 86,6 million tons in I I 001 , an increase in 40 years of over 500 per cent, and since 1820 , when coal was first more generally recognized as fuel, the increase has been 4500 per cent. Five-sixths of the present consumption was furnished for the last 30 years by Great Britain and Germany, and Belgium, the largest consumer of coal per capita after Great Britain. The coal production of the United States, which in 1870 furnished but 15 per cent of the world's supply, has grown steadily until in IgOI it represented, with 295 million tons, 34 per cent, outstripping Great Britain and Germany.

What the substitution of coal for fuel means may be realized by translating the coal consumption into wood consumption. The fuel value of a ton of coal may be set equal to about 100 cubic feet of wood; hence the I70 million tons of coal now consumed per annum in the United States supplant 17 billion cubic feet of wood. To raise this amount of wood continuously not less than 300 million acres, more than half our present acreage (at 56 cubic feet per acre), would have to be kept under good forestry management.

P. 27. Cellulose and Wood Pulp Industry. - Wood pulp is either mechanically ground or chemically prepared, when it is called cellulose, or chemical fibre. Most of it is used for the manufacture of paper. The progress of the wood pulp industry in the United States has been marvellous, as shown by the growth in daily capacity of running wood pulp mills.

While in $188 \mathrm{I}$ this was less than $800,000 \mathrm{lbs}$, it had more than doubled in 1887 , and again more than doubled within two years in 1889 , increasing steadily from that time.

The following figures, taken from Lockwood's Paper Trade Journal, include both mechanical pulp and chemical fibre, but do not take into account small amounts produced by paper mills directly :- 


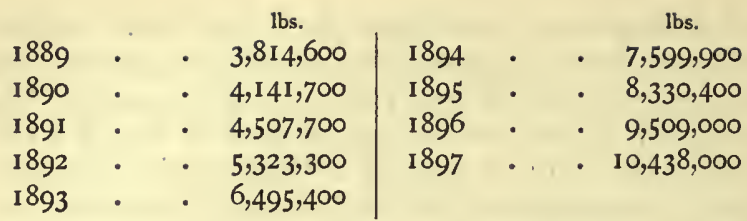

From data collected by the twelfth census the daily capacity for 1899 may be estimated at round 12 million pounds. In other words, in the last ten years the capacity of the mills has been trebled.

The census statistics unfortunately are not collected in a manner which makes those of one census comparable with those of others, as they either combine or separate paper and pulp, the raw and the finished product. This combination is explained by the fact that many mills produce their own pulp. Only the census of 1870,1880 , and 1890 separate the pulp business, showing respectively value of products of round $\$ 49,000,000, \$ 57,000,000$ and $\$ 79,000,000$ for wood pulp alone. For the census of 1900 , the manufactures of paper and pulp were reported together as representing a product of $\$ 127,326$,162, from 763 active establishments and 29 idle ones. There is no possibility of differentiating precisely how much of this value is to be credited to wood pulp, but apparently only $\$ 28,000,000$ are so credited as the cost of the wood materials to the manufacturers, while only $\$ 14,000,000$ represent other materials, and $\$ 27, \infty 00,000$ are for chemicals, fuel, etc. The total product of the wood pulp is given in amount as round I 180 tons, of which nearly one-half was produced by the establishments using it, about one-half of the total being ground, the other chemically prepared pulp. In another table it is reported that $1,986,310$ cords of wood were used by establishments using wood, and also 630,000 tons purchased wood materials, which may in part have been covered by importation.

The amount of other paper stock used is only $1,000,000$ tons, valued at $\$ \$_{5}, 000,000$, indicating that about one-half of our paper is made of wood. 
We may be safe from these figures to estimate the total wood consumption for this one manufacture, paper, as round $2 \frac{1}{2}$ million cords, in addition to a certain amount of fuel wood and an import, in spite of high tariff rates, of about 70,000 tons in excess of exports, worth between $\$ 2,000,000$ and $\$ 3,000,000$. The wood value of this industry is then over $\$ 30,000,000$.

Spruce constitutes about 76 per cent of all the wood used; in this amount, however, a considerable proportion of balsam fir, and lately hemlock, is included; 13 per cent is credited to poplar, and I I per cent to otherkinds. (For a brief but comprehensive description of the industry, see Report for 1890 , Division of Forestry, United States Department of Agriculture.)

To secure the round 2 million cords of spruce alone, almost entirely cut in the northeastern states, at least 200,000 acres of virgin mixed woods must be annually culled, and over 2 million acres in pure spruce stands would have to be maintained under good forestry management to secure this product continuously.

The growth of this industry in European countries is not - less remarkable, as may be seen from the fact that while in 1870 there were in Germany and Austria 92 wood pulp mills, in 1890 there were 836 reported, and 911 in 1896 . In Sweden the export of wood pulp rose from 9003 tons in 1881 to 133 ,889 tons in 1895 . In Germany the output of wood pulp consumes now over 500,000 cords of wood per annum, and, in the light of the anxieties which have lately been aroused in the United States regarding the enormous increase in this drain of our forest resources, it is significant to read the comment of one of the leading foresters of Germany: "The advantage of this industry for forest management is that the small sizes of coniferous wood, which could formerly be sold only as fuel wood at small prices or could not be sold at all, now have found a ready market, and by this competition the wood prices, especially for small wood, have risen. A profitable forest 
management for private owners has in many places become possible only through the wood pulp industry."

This would indicate that in Germany it is the small-sized material, the tops, which go into this manufacture, while with us the logs are used, the tops are left in the woods, and no provision for re-growth is made.

P. 28. Substitution of Other Materials. - Whatever the reasoning regarding the possible substitution of other materials for wood, the historical evidence so far has been the other way: new and more extensive use of wood has accompanied the development of these other materials.

The increase of wood consumption parallel with the increase of consumption of its substitutes, coal, iron, and stone, simply accentuates the influence of the great modern industrial development and increase of civilization, which means increase in wants.

P. 28. Tanning Bark. - The leather industry, which in the year 1900 produced, with a capital of over $\$ 356,000,000$ and a wage of over $\$ 105,000,000$, a product valued at over $\$ 615,000,000$, relies for the tanning, in spite of the increased use of substitutes, still mainly on the bark of two kinds of trees, namely, oak and hemlock. Of the amount spent for tan materials $(\$ 17,000,000)$, nearly $\$ 12,000,000$ is for such bark and bark extracts, denoting a consumption of about $\mathrm{I} \frac{1}{2}$ million cords of $\tan$ bark, as against about half that consumption in 1880 .

The consumption of hemlock bark is nearly three times as great as that of oak. Consequently the largest production is to be found in western Pennsylvania and New York, where the largest supplies of this material are to be found, these two States producing about half the cordage consumed. One ton of hemlock bark will tan about 300 pounds of sole and 400 pounds of upper leather. The usual harvest of hemlock bark averages 12 to I 5 cords per acre, worth $\$ 6$ to $\$ 7$ per cord. As long as the timber is used afterwards, which is now probably done in most places, this utilization of a by-product is one of the important economies in forest utilization. 
A very full account of the industry as far as its relation to forest supplies is concerned may be found in "Reports on Forestry" by F. B. Hough, Vol. III, I882, pp. 68 to 128 .

P. 29. The Naval Store Industry. - The naval store industry is confined to the pineries of the South, - Alabama, Florida, and Georgia being the principal producers. It supplies mainly materials used for the manufacture of varnishes, paints, soaps, and in the rubber and paper industries, besides tar and pitch, and has grown most unprecedentedly during the last decade. While from 1850 to 1890 the increase of value in products was only from less than $\$ 3,000,000$ to a little less than $\$ 8,000,000$, in the decade from 1890 to 1900 it rose, according to the census, to $\$ 20,344,888$. The capital employed and the wages paid trebled, while the value more than doubled. This great increase may be only apparent, the difficulty of gathering statistics in previous censuses having produced too low figures; nevertheless, increase in industrial development must account for a large part of the increase. Nearly all the rosin produced and nearly one-half of the spirits of turpentine are exported.

Through the investigations of the Forestry Division in 1890 to 1892 (see Report of Division of Forestry for 1892 for full description of this industry) it was established that this industry can be carried on without any necessary detriment to the forest and the timber product, but unfortunately the necessary precautions and methods for such harmless use of these by-products are mostly not practised.

P. 32. Relative Position of Forest Industries in $1890 .-$ Census statistics of the employment of capital, persons employed, and wages in the minor forest industries are either absent or more or less deficient. Moreover, in an industry in which many people are only temporarily or incidentally and for a part of the year engaged, the exploitation of the forests makes a close enumeration well nigh impossible. Hence, in comparison with other industries concentrated at centres of 
production or carried on with continuity, the forest industries lose relatively.

To get a closer approximation to the truth, and a more just appreciation of the comparative significance of the forest resource, the writer, upon the basis of census data of 1890 and other information, made an attempt in 1896 to supply these deficiencies by estimate. In this estimate all wood and other forest products, as railroad ties and timbers, telegraph poles, fence material, cord wood, bark, and other by-products are included, leading to the following result :-

\section{LEADING INDUSTRIES COMPARED.}

\begin{tabular}{|c|c|c|c|c|c|}
\hline Articles. & $\begin{array}{c}\text { Capital } \\
\text { in- } \\
\text { volved. }\end{array}$ & $\begin{array}{c}\text { Em- } \\
\text { ployees. }\end{array}$ & Wages. & $\begin{array}{l}\text { Raw } \\
\text { mate- } \\
\text { rial. }\end{array}$ & $\begin{array}{l}\text { Prod- } \\
\text { ucts. }\end{array}$ \\
\hline & $\begin{array}{l}\text { Mil- } \\
\text { lions. }\end{array}$ & $\begin{array}{l}\text { Thou- } \\
\text { sands. }\end{array}$ & $\begin{array}{l}\text { Mil- } \\
\text { lions. }\end{array}$ & $\begin{array}{l}\text { Mil- } \\
\text { lions. }\end{array}$ & $\begin{array}{l}\text { Mil- } \\
\text { lions. }\end{array}$ \\
\hline $\begin{array}{l}\text { Agriculture } \\
\text { Forest products, total }::\end{array}$ & 15,982 & 8,286 & ב & 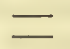 & $\begin{array}{l}2460 \\
1044\end{array}$ \\
\hline & 562 & $34^{8}$ & 102 & 245 & 446 \\
\hline $\begin{array}{l}\text { ated (estimated) } \\
\text { Manufactures using wood (see }\end{array}$ & + & + & + & & 598 \\
\hline table on opposite page). & 543 & 513 & 294 & $44^{2}$ & 907 \\
\hline $\begin{array}{l}\text { Mineral products, total } \\
\text { Coal }\end{array}$ & - & - & F. & - & 610 \\
\hline Goald and silver : : : & $\begin{array}{l}343 \\
486\end{array}$ & $\begin{array}{r}300 \\
57\end{array}$ & $\begin{array}{r}109 \\
40\end{array}$ & & $\begin{array}{r}160 \\
99\end{array}$ \\
\hline Pig iron - $\cdot{ }^{\circ} \cdot{ }^{\circ}$ & 134 & 34 & 16 & IIO & 146 \\
\hline $\begin{array}{l}\text { Manufactures of iron and steel } \\
\text { Leather }\end{array}$ & $\begin{array}{l}4 I_{4} \\
102\end{array}$ & $\begin{array}{r}176 \\
48\end{array}$ & $\begin{array}{l}96 \\
25\end{array}$ & $\begin{array}{l}327 \\
\mathbf{3} 36\end{array}$ & $\begin{array}{l}479 \\
778\end{array}$ \\
\hline $\begin{array}{l}\text { Leather manctures : : : } \\
\text { Leather manufact }\end{array}$ & 118 & $\begin{array}{r}40^{\circ} \\
186\end{array}$ & $\begin{array}{l}25 \\
88\end{array}$ & $\begin{array}{l}136 \\
153\end{array}$ & 289 \\
\hline Woollen manufactures. & 297 & 219 & 77 & 203 & $33^{8}$ \\
\hline Cotton manufactures $\cdot, \cdot \cdot \cdot$ & 354 & 222 & 70 & 155 & 268 \\
\hline
\end{tabular}

To secure the statement regarding the manufactures using wood, these were classified according to the estimated percentage of wood entering into their products and assuming that capital, labor, and value of products stand in the same proportion as the raw materials used. As a matter of fact, there is probably more labor employed in shaping wood than this percentage would indicate. 


\section{Forest Industries and Manufactures Using Wood.}

\begin{tabular}{|c|c|c|c|c|c|}
\hline Articles. & Capital. & $\begin{array}{c}\text { Em- } \\
\text { ployees. }\end{array}$ & Wages. & $\begin{array}{c}\text { Raw } \\
\text { material. }\end{array}$ & $\begin{array}{c}\text { Value } \\
\text { of product }\end{array}$ \\
\hline $\begin{array}{l}\text { Forest industries enu- } \\
\text { merated: }\end{array}$ & Thous'nds & Hundreds & Thous'nds & Thous'nds & s Thous'nds \\
\hline $\begin{array}{l}\text { Lumber and mill } \\
\text { products }\end{array}$ & & 2,862 & & $\$ 23 x, 556$ & $\$ 403,668$ \\
\hline $\begin{array}{l}\text { Timber products not } \\
\text { manufactured at }\end{array}$ & & & & & \\
\hline $\begin{array}{l}\text { mill } \\
\text { Naval stores : : : }\end{array}$ & $\begin{array}{r}6 \mathrm{r}, 54 \mathrm{r} \\
4,063 \\
\end{array}$ & $\begin{array}{l}46 r \\
\times 53 \\
\end{array}$ & $\begin{array}{r}1 x, 354 \\
2,933 \\
\end{array}$ & $\begin{array}{r}\mathrm{rI}, \infty 07 \\
3,506 \\
\end{array}$ & $\begin{array}{r}34,290 \\
8,077\end{array}$ \\
\hline Total . . . . & $56 x, 943$ & 3,477 & 102,o7x & 245,169 & 446,034 \\
\hline $\begin{array}{l}\text { Manufactures practi- } \\
\text { cally all wood: }\end{array}$ & & & & & \\
\hline $\begin{array}{l}\text { Cigar boxes } \\
\text { Packing boxes : } \\
\text { Carriage and wagon }\end{array}$ & $\begin{array}{r}3,374 \\
\times 3,018\end{array}$ & $\begin{array}{r}55 \\
\times 40\end{array}$ & $\begin{array}{l}2, \mathrm{r} 34 \\
6,477\end{array}$ & $\begin{array}{r}3,567 \\
\times 4,245\end{array}$ & $\begin{array}{r}7,092 \\
25,5 \times 3\end{array}$ \\
\hline stock & 13,028 & $r o g$ & 5,208 & $x, 388$ & $x 6,262$ \\
\hline $\begin{array}{l}\text { Carpentering }: \\
\text { Cooperage } \cdot \dot{\text { factory }} \\
\text { Furniture }\end{array}$ & $\begin{array}{l}8 \mathrm{x}, 543 \\
\mathrm{x}, 8 \mathrm{x} 7\end{array}$ & $\begin{array}{r}r, 409 \\
247\end{array}$ & $\begin{array}{l}94,524 \\
11,665\end{array}$ & $\begin{array}{r}137,847 \\
2,637\end{array}$ & $\begin{array}{r}28 \mathrm{r}, 195 \\
38,6 \times 8\end{array}$ \\
\hline products . & 66,394 & 639 & $34,47 x$ & 38,796 & $94,87 x$ \\
\hline Kindling wood & $\mathbf{x}, 300$ & $\begin{array}{r}18 \\
8\end{array}$ & $77^{2}$ & $x, 187$ & 2,402 \\
\hline Planing-mili products & $\begin{array}{r}907 \\
120,27 x\end{array}$ & $\begin{array}{r}8 \\
869\end{array}$ & $\begin{array}{r}572 \\
48,970\end{array}$ & $\begin{array}{r}331 \\
\mathrm{ro}, 9^{27}\end{array}$ & $\begin{array}{r}r, 239 \\
r 83,682\end{array}$ \\
\hline $\begin{array}{l}\text { Matches } \\
\text { Wood, turned and }\end{array}$ & $\mathrm{Y}, 94 \mathrm{Y}$ & r8 & 344 & 935 & 2,194 \\
\hline carved * . " & 7,826 & 84 & 4,267 & 3,947 & ro, 940 \\
\hline $\begin{array}{l}\text { Woodenware : } \\
\text { Wood pulp. }\end{array}$ & 2 & $3 I$ & 7 & 1,499 & 3,598 \\
\hline $\begin{array}{l}\text { Wood pulp. : } \\
\text { Wood carpet : }\end{array}$ & $\begin{array}{r}7,455 \\
333\end{array}$ & $\begin{array}{r}28 \\
3\end{array}$ & $\begin{array}{r}r, 229 \\
155\end{array}$ & $\begin{array}{r}2,005 \\
214\end{array}$ & $\begin{array}{r}4,028 \\
5 \times 2\end{array}$ \\
\hline Total . . . & 337,908 & 3,650 & 212,027 & 331,523 & $672,75^{\circ}$ \\
\hline $\begin{array}{l}\text { Manufactures in which } \\
\text { wood represents about } \\
\text { 50 per cent of the raw }\end{array}$ & & & & & \\
\hline $\begin{array}{l}\text { materials:* Total } \\
\text { Wood percentage }\end{array}$ & $\begin{array}{r}\mathbf{r} 69,983 \\
89,99 \mathrm{x} \\
\end{array}$ & $\begin{array}{r}1,356 \\
678 \\
\end{array}$ & $\begin{array}{l}71,460 \\
35,730\end{array}$ & $\begin{array}{r}114,383 \\
57,192 \\
\end{array}$ & $\begin{array}{l}229,408 \\
134,704\end{array}$ \\
\hline Manufactures in which & & & & & \\
\hline $33^{1 / 3}$ per cent: $\dagger$ Total & 321,059 & 2,143 & 123,588 & $148.57^{8}$ & 318.218 \\
\hline $\begin{array}{l}\text { Wood percentage } \\
\text { Manufactures in which }\end{array}$ & 107 & $7 \underline{4}$ & 41,196 & $\begin{array}{r}49.526 \\
\end{array}$ & 106,072 \\
\hline $\begin{array}{l}\text { Manufactures in which } \\
\text { wood represents about } \\
\text { ro per cent: } t \text { Total }\end{array}$ & & & & & \\
\hline $\begin{array}{l}\text { ro per cent: I lotal } \\
\text { Wood percentage }\end{array}$ & $\begin{array}{r}76,841 \\
7,684 \\
\end{array}$ & $\begin{array}{r}915 \\
92 \\
\end{array}$ & $\begin{array}{r}46,854 \\
4,685 \\
\end{array}$ & $\begin{array}{r}49,291 \\
4,929 \\
\end{array}$ & $\begin{array}{r}131,820 \\
13,182 \\
\end{array}$ \\
\hline $\begin{array}{l}\text { Manufactures of wood: } \\
\text { Total }\end{array}$ & 543,402 & 5,134 & $293,63^{8}$ & 443,170 & $23^{906,708}$ \\
\hline
\end{tabular}

* Includes carriages and wagon factory product, children's carriages and sleds, steam and street cars, coffins and burial caskets, chairs, wheelbarrows, sewing machine cases, artificial limbs, and refrigerators, and shipbuilding.

† Includes agricultural implements, billiard tables, railroad and street car repairs, furniture repairs, washing machines and wringers, organs and pianos.

† Includes blacksmithing and wheelwrighting, bridges, brooms and brushes, gunpowder, artists' materials, windmills, toys and games, sporting goods, lead pencils, pipes and pumps. 
The proportions in which the various kinds of products contribute toward the total of $\$ 1,044,000,000$ in value were figured as follows :-

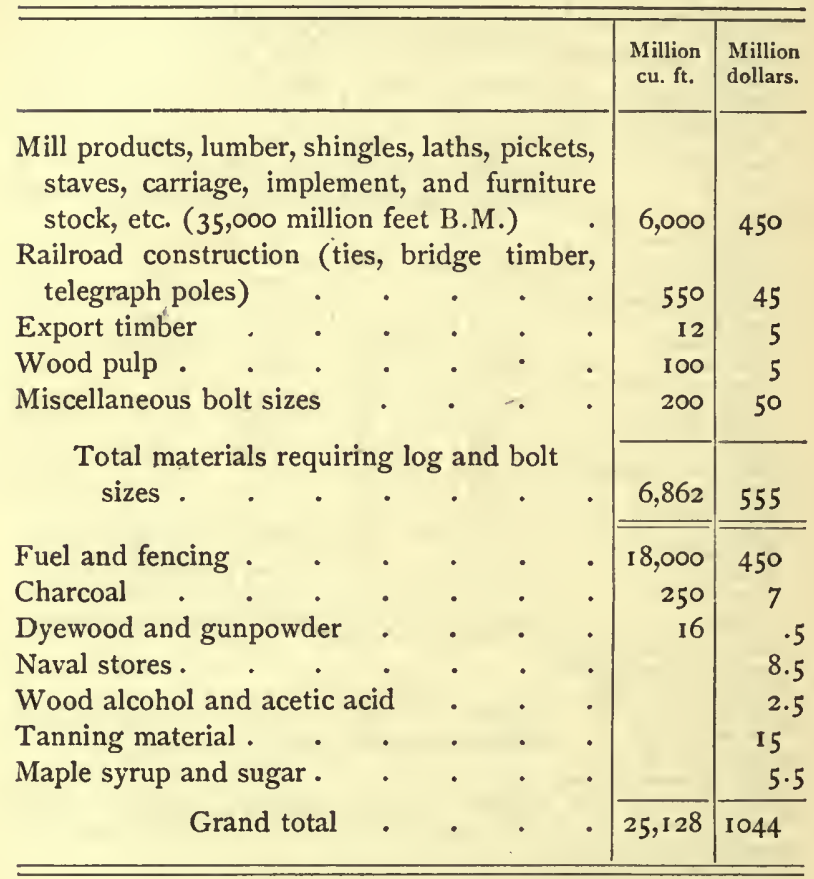

The cubic contents are estimates of the forest-grown material which might furnish the amounts of prepared materials at the given values. They give an insight into the possibilities and necessities of supply and its character. The fuel wood consumption in the above estimate has been assumed to have been somewhat decreased from that of the census of 1880 , the value per cord (\$2.20) to have remained the same. 
As will be seen in the notes to Chapter XI, the census of 1900 places the value of the mill products, including an uncertain part of the rest of bolt and $\log$ size material, at $\$ 566,832,984$, to which at least the wood pulp with round $\$ 28,000,000$ must be added, increasing this most important portion of forest products by about jo per cent. In the minor forest products the naval store industry has increased to over $\$ 20,000,000$, the wood alcohol industry to nearly $\$ 4,000,000$, the tanning materials being slightly reduced and the maple sugar industry slightly increased.

The present value of all forest products, at places of first manufacture or consumption, may then be safely placed at round $\$ 1,100,000,000$. The value of the wood manufacture has naturally also increased, increasing by so much the economic significance of our forest resource. To gain an insight into the importance of the forest resource in our industrial world the following comparison will serve, in which the manufactures requiring wood as an essential part of the manufacture, including sawmills, etc., are placed in opposition to all the manufactures of the country. In this comparison the reduction for wood value only as given in the table on p. 427 has not been made.

\begin{tabular}{|c|c|c|c|c|}
\hline \multirow{2}{*}{ I8go. } & Capital. & Product. & Employees. & Wages. \\
\hline & Million. & Million. & Thousand. & Million. \\
\hline $\begin{array}{l}\text { All manufactures } \\
\text { Manufactures dependent }\end{array}$ & 6,525 & 9,372 & 4,712 & 2,283 \\
\hline on wood . . . & $\mathrm{I}, 402$ & I,756 & $\mathrm{J}, 093$ & 542 \\
\hline $\begin{array}{l}\text { Wood manufactures repre- } \\
\text { sent of all manufactures }\end{array}$ & $21 \%$ & $19 \%$ & $23 \%$ & $24 \%$ \\
\hline
\end{tabular}


P. 33. Wealth of the Nation. - The total wealth of the United States was estimated, upon the basis of census data, in 1890 to be distributed about as follows:-

Real estate not in farms . $\quad$. $\quad$. 26.2

Farm property in land . . . . . . 13.3

Farm property in cattle and equipment . . $\quad 2.7$

Railways and telegraph lines . • • • 9.3

Capital in large manufacturing industries . . 6.5

Mines, quarries, and their capital stock . . $\quad 1.2$

Gold, silver, coin, bullion . . . . . I.I

All other property . . . . . . . 4.7

65.0

P. 35. Forest Area of the World. - As has been pointed out in various parts of this volume the forest area gives but an imperfect and unreliable basis for a discussion of the wood supply question; the contents and their condition and the accessibility to wood-consuming nations being the much more significant factors.

The table on p. $43 \mathrm{I}$ condenses information, more or less reliable, regarding some of the more important forest areas of the world. While these figures cannot claim absolute correctness, authorities varying more or less, they give at least approximate ideas of the relative position of the countries enumerated.

P. 51. Wood Consumption in United States. - Making allowance for the increases appearing in the census of 1900 , we may now roughly state our consumption at 26 billion cubic feet, one-third of which must be of $\log$ or bolt size, - a yearly harvest which could still be continuously supplied by our forest area of 500 million acres, if it were managed upon forestry principles, namely, as a crop harvested with due regard to its continuous reproduction, and if proper economy and differentiation of relative usefulness of material were practised. 
NOTES.

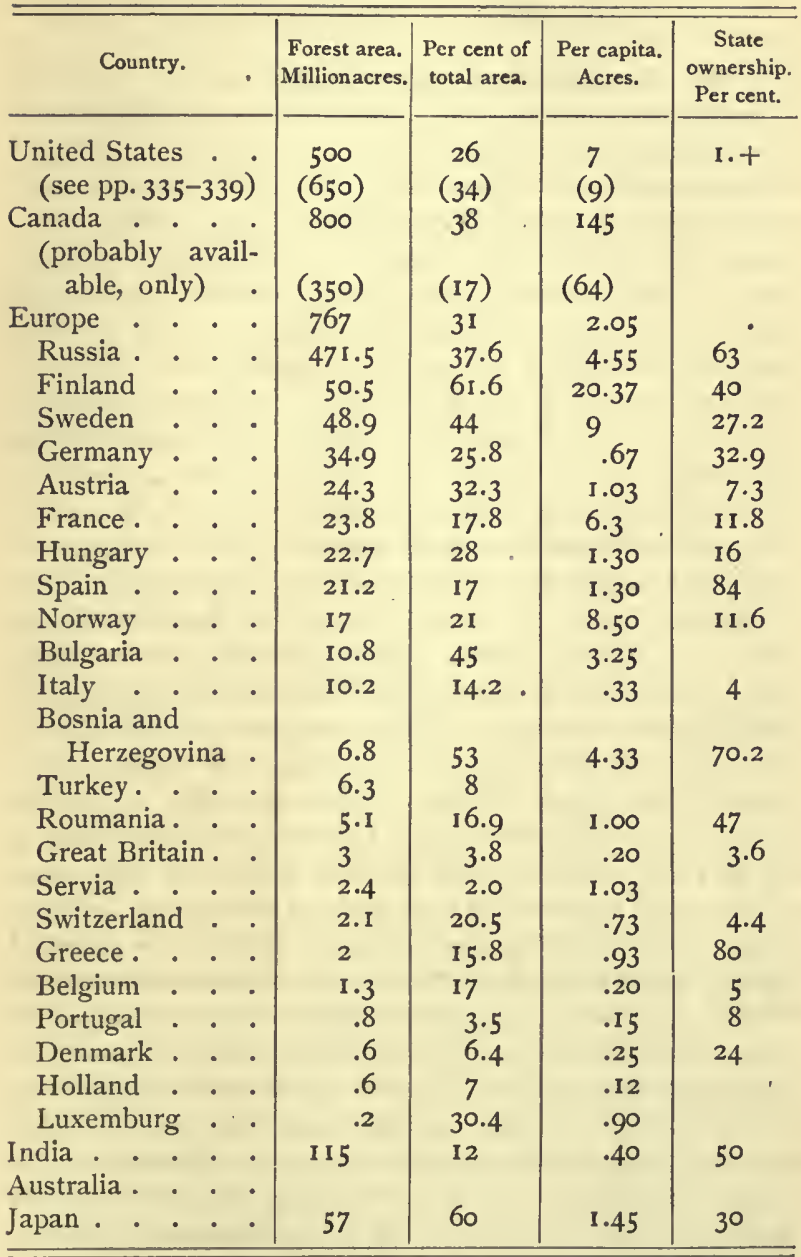




\section{NOTES TO CHAPTER III.}

P. 63. Investigations in Forest Meteorology. - The results of the Bavarian observations, as well as the methods pursued, were published by Dr. Ernst Ebermayer in "Die physikalischen Einwirkungen des Waldes auf Luft und Boden und seine klimatologische und hygienische Bedeutung," Berlin, 1873. A very full summary is to be found in F. B. Hough's "Report upon Forestry," Vol. I, Washington, Government Printing Office, 1878. A more complete discussion of the whole question and record of the investigations into "forest influences " is to be found in Bulletin 7, Division of Forestry, U.S. Department of Agriculture, 1887, with further additions to be found in H. R. doc. 181 , 55th Congress, 3d session, 1899 , from which sources the following data are reproduced.

P. 64. Inefficiency of Rain Gauges. - The inaccuracy of the rainfall measurements by the ordinary unprotected gauges is explained by Mr. Cleveland Abbe, in the Bulletin cited, as follows: "In the case of ordinary rainfalls we invariably have the air full of large and small drops, including the finer particles that constitute a drizzling mist and the fragments of drops that are broken up by spattering. All these are descending at various velocities which, according to Stokes, depend on their size and density and the viscous resistance of the air; the particles of hail descend even faster than drops of water, and the flakes of snow descend slower than ordinary drops. Now, when the wind strikes an obstacle, the deflected currents on all sides of the obstacle move past the latter more rapidly; therefore the open mouth of the rain gauge has above it an invisible layer of air whose horizontal motion is more rapid than that of the wind a little distance higher up. Of the falling raindrops, the larger ones may descend with a rapidity sufficient to penetrate this swiftly moving layer, but the slower falling drops will be carried over the leeward of the gauge, and, failing to enter it, will miss being counted as rainfall, although they go on to the ground near by. Evidently, 
the stronger the wind the larger will be the proportion of small drops that are carried past the gauge; or again, the larger the proportion of small drops and light flakes of snow that constitute a given shower, the more a gauge will lose for a given velocity of wind. In brief, the loss will depend both upon the velocity of the wind and the velocity of the descent of the precipitation; therefore, a gauge will, in general, catch less in winter than in summer; less in a climate where light, fine rains occur than where the rains are composed of larger, heavier drops; less in a country or in a season of strong winds than of feeble winds; less when exposed to the full force of the wind by being elevated on a post, than when exposed to the feebler winds near the ground. . . .

"The distinction between the effect of the winds in heavy rains and fine rains is very clearly brought out by Börnstein's classification of the catch on twenty-six days of fine rain and forty-three days of heavier rains; the percentages are shown in the following table" :-

\begin{tabular}{c|c|c|c|c}
\hline \multirow{2}{*}{ Wind force. } & \multicolumn{2}{|c|}{43 Heavy rains. } & \multicolumn{2}{c}{26 Fine rains. } \\
\cline { 2 - 5 } & No. of days. & $\begin{array}{c}\text { Deficit } \\
\text { per cent. }\end{array}$ & No. of days. & $\begin{array}{c}\text { Deficit } \\
\text { per cent. }\end{array}$ \\
\hline 0 & & & 4 & 23 \\
1 & 17 & 6 & 8 & 25 \\
2 & 13 & 13 & 6 & 18 \\
3 & 7 & 14 & 6 & 46 \\
4 & 6 & 17 & 2 & 52 \\
\hline
\end{tabular}

Rain gauges under trees do not record all the rain fallen. The percentage of precipitation recorded under trees of different kinds has been found as follows :-

\begin{tabular}{|c|c|c|c|}
\hline & & Entire year. & Warm season. \\
\hline General average. & . & 75 & 70 \\
\hline Average for deciduous trees & - & 74 & 65 \\
\hline Average for evergreens . & - & 77 & 74 \\
\hline
\end{tabular}


These data are the result of observations at sixteen stations for about I 50 years.

The table shows that in the warm season 30 per cent of the rainfall in the open fields fails to reach the gauges under the trees. Taking all seasons together, 25 per cent is intercepted. This deficit does not include the water which drips from the leaves, for this is fairly accounted for by the gauges. It is the water which moistens the tree and its various parts and that which flows down the trunk. The former is evaporated without reaching the soil ; the latter reaches the soil finally, and is measurable. Some experiments have indicated this amount to be about 8 per cent of the precipitation.

The same difficulties experienced with rain gauges are also found to attach to thermometers; the best thermometers placed side by side will vary by as much as $1.6^{\circ} \mathrm{F}$. and usually $0.7^{\circ} \mathrm{F}$, hence small differences of temperature may be merely inaccuracies, or due to non-uniformity of conditions, and cannot be argued as a result of forest influences.

P. 69. Details of Meteorological Conditions within and outside of Forests. - The following conclusions have been drawn from the German observations and are reproduced from the above-cited bulletin :-

Difference of Meteorological Conditions Within AND Wrthout the Forest.

(1) Soil Temperatures. - The general influence of the forest on soil temperatures is a cooling one, due to the shade and to the longer retention of moisture in the forest floor as well as in the forest air, which must be evaporated before the ground can be warmed. As a consequence, the extremes of high and low temperature within the forest soil occur much later than in the open, and both extremes are reduced, but the extreme summer temperatures much more than the winter temperatures.

The difference between evergreen and deciduous forests, which almost vanishes in the winter time, is in favor of the 
deciduous as a cooling element in summer and autumn, while during spring the soil is cooler under evergreens. The effect increases naturally with the age and height of the trees.

(2) Air Temperatures under the Crowns. - The annual range of air temperature is smaller in the forest than in the open; the effect upon the minimum temperature (i.e. the effect in winter) is less than on the maximum temperature (i.e. the effect in summer). The combined effect is a cooling one. The range of temperature is more affected than the average absolute temperature, or, in other words, the moderating infuence is greater than the cooling effect.

The monthly minima for middle latitudes are uniformly reduced during the year, and the monthly maxima are much more reduced during the summer than during the winter. On the average the forest is cooler than the open country in summer, but about the same in winter, with a slight warming effect in spring.

The difference between the mean monthly air temperatures in the woods and in the open varies with the kind of forest much more than is the case for soil temperatures. The evergreen forest shows a symmetrical increase and decrease throughout the year. The deciduous forest shows a variable influence which diminishes from the midwinter to springtime, but increases rapidly as the leaves appear and grow, becoming a maximum in June and July, and then diminishing rapidly until November. The annual average effect is about the same both for evergreen and deciduous forests.

Forests situated at a considerable elevation above the sea have sensibly the same influence on the reduction of the mean temperature as do forests that are at a low level.

Young forests affect the air temperature very differently from mature forests; in the former the minimum temperatures are always reduced, but the maxima are exaggerated. The observations on which this conclusion is based ought, perhaps, to be considered as pertaining rather to the case of temperatures in the tree tops. 
(3) Air Temperatures within the Crowns. - The mean temperature of the air in the tree tops, after correcting for elevation above ground, is rather higher than over open fields. The effect of tree tops does not appreciably depend upon the height of the station above ground. The effect upon the minima is generally greater than on the maxima, the total effect being a warming one. A tree-top station is in general intermediate, as to temperature, between a station near the ground in the forest and one in the open field.

Evergreen forests show less difference between the temperature in the crown and below, and altogether more uniformity in temperature changes throughout the year than deciduous growth.

The vertical gradient for temperature within the forest on the average of all stations and all kinds of forest trees is large, varying from $0.6 \mathrm{I}^{\circ} \mathrm{F}$. per 100 feet in April to $2.50^{\circ} \mathrm{F}$. in July.

A reversal of the vertical gradient, namely, a higher temperature above than below, occurs in the wood, especially in the summer time. It also occurs in the open air regularly at night, and may be three or four times as large as that just mentioned. In general, the action of the forest tends to produce a vertical distribution of temperature like that over snow or level fields on clear nights.

(4) Air Temperature above the Crowns. - The temperature, at considerable heights above the forest, appears to be slightly affected by the forest, and more so with evergreens than with deciduous growth. The vertical gradients of temperature within 30 feet above the tops of the trees are all reversed throughout the leafy season; the gradients are also greater above the tree crown than below, at least during the clear sky and calm air. The wind affects the temperature under and within the crowns, but makes little difference above them. The surface of the forest crown appears meteorologically much like the surface of the meadow or cornfield. It is as if the soil surface has been raised to the height of the trees. 
(5) Air Temperature in General. - From the preceding generalizations it appears that the forest affects the temperature just as any collection of inorganic obstacles to sunshine and wind; but as an organic being the forest may be also an independent source of heat. Careful observations of the temperature within the trunk of the tree and of the leaves of the tree show that the tree temperature is affected somewhat by the fact that the water rising brings up the temperature of the roots, while the food material from the leaves brings their temperature down, and the tree temperature, considered as the result of the complex adjustment, is not appreciably affected by any heat that may be evolved by the chemical processes on which its growth depends. It is not yet clear as to whether the chemical changes that take place at the surface of the leaves should give out any heat; it is more likely that heat is absorbed; namely, rendered latent, especially in the formation of the seed; the process of germination usually evolves this latent heat; the immense quantity of water transpired and evaporated by the forests tends to keep the leaves at the same temperature as that of the surface of water or moist soil.

(6) Humidity of Air. - The annual evaporation within the forests is about one-half of that in the open field; not only is the evaporation within a forest greatest in May and June, but the difference between this and the evaporation in the open field is also then a maximum, which is the saving due to the presence of the woods. The average annual evaporation within the woods is about 44 per cent of that in the field. Fully half of the field evaporation is saved by the presence of the forest.

The quantity of moisture thrown into the air by transpiration from the leaves in the forest is sometimes three times that from a horizontal water surface of the same extent, and at other times it is less than that of the water. The transpiration from leaves in full sunshine is decidedly greater than from leaves in the diffused daylight or darkness. The 
absolute amount of annual transpiration, as observed in forests of mature oaks and beeches in Central Europe, may amount to 50 per cent of the total annual precipitation and more; with conifers, only one-sixth to one-tenth of this.

The percentage of rainfall, evaporated at the surface of the ground, is about 40 per cent for the whole year in the open field and about 12 per cent for the forest, and is greater under deciduous than under evergreen forests.

The evaporation from a saturated bare soil in the forest is about the same as that from a water surface in the forest, other conditions being the same.

The presence of forest litter like that lying naturally in undisturbed forests hinders the evaporation from the soil to a remarkable extent, since it saves seven-eighths of what would otherwise be lost.

The total quantity of moisture returned into the atmosphere from a forest by transpiration and evaporation from the trees and the soil is about 75 per cent of the precipitation. For other forms of vegetation it is about the same or sometimes larger, varying between 70 per cent and 90 per cent; in this respect the forest is surpassed by the cereals and grasses, while, on the other hand, the evaporation from a bare soil is scarcely 30 per cent of the precipitation.

The absolute humidity within a forest exceeds that of the glades and the plains by a small quantity. The relative humidity in the forest is also larger than in the glades or plains by 2 per cent to 4 per cent. Forests of evergreens have from two to four times the influence in increasing relative humidity as do forests of deciduous trees.

The gauges in European forest stations catch from 75 to 85 per cent when placed under the trees, the balance representing that which passes through the foliage and drips to the ground or runs down along the trunks of trees, or else is intercepted and evaporated. The percentage withheld by the trees, and which either evaporates from their surface or trickles along the trunk to the ground, is somewhat greater 
in the leafy season, though the difference is not great. Deciduous and evergreen trees show but slight differences in this respect. More rain is usually caught by gauges at a given height above the forest crown than at the same height in open fields, but it still remains doubtful whether the rainfall itself is really larger over the forests, since the recorded catch of the rain gauge still requires a correction for the influence of the force of the wind at the gauge.

In such cases, where over a large area deforestation and reforestation have seemingly gone hand in hand with decrease and increase of rainfall, the possible secular change in rainfall must also be considered. Yet the experience of increased rainfall over the station at Lintzel, with increase of forest area, points strongly toward a possible interdependence under given conditions.

By condensing dew, hoar frost, and ice on their branches, trees add thereby a little to the precipitation which reaches the ground, and by preventing the rapid melting of snow more water remains available under forest cover.

The question as to the march of destructive hailstorms with reference to forest areas, which seems settled for some regions in France, remains in doubt for other, especially mountain, regions.

From these statements we would expect as a consequence of deforestation an effect on the climate of the deforested area in three directions, namely: (a) extremes of temperature of air as well as soil are aggravated, $(b)$ the average humidity of the air is lessened, and possibly (c) the distribution of precipitation throughout the year, if not its quantity, is changed.

\section{Influence of Forests upon the Climate of the SurRounding COUNTRY.}

(1) An influence of the forest upon the climate of its surroundings can only take place by means of diffusion of the vapor which is transpired and evaporated by the crowns, and 
by means of air currents passing through and above the forests being modified in temperature and moisture conditions; the mechanical effect upon such air currents by which they are retarded in their progress may also be effective in changing their climatic value.

(2) Local air currents are set up by the difference in temperature of the air within and without the forest, analogously to those of a lake or pond, cooler currents coming from the forest during the day in the lower strata and warmer currents during the night in the upper strata. The latter currents, being warmer and moister, can be of influence on the temperature and moisture conditions of a neighboring field by moderating temperature extremes and increasing the humidity of the air.

This local circulation is the one most important difference between forest and other vegetation. How far away from the forest this circulation becomes sensible is not ascertained. In winter time, when the temperature differences become small, no such circulation is noticeable.

(3) The general air currents in their lower portions are cut off entirely by the forest, which acts as a wind-break. This influence can of course be experienced only on the leeward side. How far this protection reaches it is difficult to estimate, but it certainly reaches farther than that of a mere wind-break, since by the friction of the air moving over the crowns a retardation must be experienced that would be noticeable for a considerable distance beyond the mere wind-break effect. Deforestation on a large scale would permit uninterrupted sweep of the winds, a change more detrimental where the configuration of the ground does not fulfil a similar function - in large plains more than in hilly and mountainous regions, and at the seashore more than in the interior.

In an experiment made by F. W. King in Wisconsin the evaporation increased with the distance from the woods up to 300 feet; the difference in the amount at a station only 20 feet from the protecting forest being over 66 per cent. Even 
behind a hedgerow, 6 to 8 feet high, a difference of 30 per cent was noted in the same distances. Extensive observations made by the Canadian Agricultural Experiment stations show very considerable differences in crop production due to the effect of wind-breaks.

The upper air strata can be modified only by the conditions existing near and above the crowns. At the same time they must carry away the cooler and moister air there and create an upward movement of the forest air, and thereby in part the conditions of this become also active in modifying air currents. The greater humidity immediately above the crowns is imparted to the air currents, if warm and dry, and becomes visible at night in the form of mists resting above and near forest areas. These strata pretect the open at least against insolation and loss of water by evaporation, and have also a greater tendency to condensation as dew or light rain if conditions for such condensation exist. This influence can be felt only to the leeward in summer time, and with dry, warm winds, while the cooling winter effect upon comparatively warmer moist winds is not noticeable. Theoretical considerations lead to the conclusion that in mountain regions only the forest on the leeward slope can possibly add moisture to a wind coming over the mountain, but this does not necessarily increase the precipitation on the field beyond. Altogether, the theoretical considerations are as yet neither proved nor disproved by actual observations, and as to rainfall, the question of influence on the neighborhood is still less settled than that of precipitation upon forest areas themselves. Wherever moisture-laden winds pass over extensive forest areas the cooler and moister condition of the atmosphere may at least not reduce the possibility of condensation, which a heated plain would do; but observations so far give no conclusive evidence that neighboring fields receive more rain than they otherwise would.

(4) With regard to comparative temperatures in forest stations and open stations that are situated not far apart from 
each other, it would appear that the forest exerts a cooliny influence, but that more detailed conclusions are hindered by the consideration that the ordinary meteorological station itself is somewhat affected by neighboring trees.

The study of the stations in Asiatic and European Russia seems to show that in the western part of the Old World the presence of large forests has a very sensible influence on the temperature. Similar studies for stations in the United States seem to show that our thin forests have a slight effect in December, but a more decided one in June. It appears also that our wooded regions are warmer than the open plains, but there is no positive evidence that this difference of temperature is dependent upon the quantity or distribution of forests or that changes in temperature have occurred from this cause.

(5) When a forest encloses a small area of land, forming a glade, its enclosed position brings about special phenomena of reflection of heat, local winds, and a large amount of shade. For such situations it is found that the mean range of temperature is larger in the glade than in the open; the glade climate is more rigorous than the climate of open plains; the glade is cooler and its diurnal range larger during the spring, summer, and autumn.

Favorable influences upon moisture conditions of the air are most noticeable in localities where much water is stored underground, with overlying strata which are apt to dry when our summer drought prevails. Here the forest growth is able to draw water from greater depths, and by transpiration return it to the atmosphere, thereby reducing the dryness and possibly inducing precipitation. In moist climates this action would be Iess effective or of no use. Hence in regions with oceanic climate, with moist sea winds, like England and the west coasts of Europe or of the northern United States, deforestation from a climatic point of view may make no appreciable difference, such as it would make in continenta' climates like the interior of our country, the Rocky Mountains, and Southern California. 
Whether large or small areas of forest and open fields alter. nating, or what percentage of forest is most favorable, can. not as yet be discussed, since we are not clearly informed even as to the manner and the amount of influence which forest cover exercises. In general we may expect that an alternation of large forested and unforested areas in regions which on account of their geographic situation have a dry and rigorous climate is more beneficial than large uninterrupted forest areas, which would fail to set up that local circulation which is brought about by differences in temperature and permits an exchange of the forest climate to the neighboring field.

More recent experiments tend to modify somewhat the conclusions arrived at heretofore, and indicate, as has been suggested, that the differences in temperature and humidity of woods and of open land that have been recorded are largely to be attributed to variability of instruments and of readings, and to nonconformity of conditions.

Even the well-planned Austrian experiments have produced neither striking nor consistent results. In 1893 Dr. Lorentz Liburnau concluded that forests did not cool the air of the surrounding country, and that temperature extremes were even heightened in the immediate vicinity of the woods. Concerning humidity, it was found that while with one set of stations this appeared increased by an uncertain trifle through the proximity of the forest, in another set no influence was observed, and in one case the air current from the woods was positively drier at noontime than that of the open country, and even though Lorentz Liburnau is still hopeful in the matter, he felt compelled to admit that a "distance effect" of forest influence was so far not demonstrated.

Schubert, in 1895 and again in 1897 , published results of extensive temperature measurements which point to an entire absence of influence in this respect, the air of the forest being in no case sufficiently cooler to warrant a decision. His experiments gave a difference of only $5^{\circ} \mathrm{F}$. in favor of the pine 
woods. This author came to practically the same con. clusion regarding the humidity of the forest and the open country.

\section{INFLUENCE of Forests upon Water and SoIL} Conditions.

(1) In consequence of deforestation, evaporation from the soil is augmented and accelerated, resulting in unfavorable conditions of soil humidity and affecting unfavorably the size and continuity of springs. The influence of forest cover upon the flow of springs is due to this reduced evaporation as well as to the fact that by the protecting forest cover the soil is kept granular and allows more water to penetrate and percolate than would otherwise. In this connection, however, it is the condition of the forest floor that is of greatest importance. Where the litter and humus mould is burned up, as in many if not most of our mountain forests, this favorable influence is largely destroyed, although the trees are still standing.

(2) Snow is held longer in the forest and its melting is retarded, giving longer time for filtration into the ground, which also being frozen to less depth is more apt to be open for subterranean drainage. Altogether forest conditions favor in general larger subterranean and less surface drainage, yet the moss or litter of the forest floor retains a large part of the precipitation and prevents its filtration to the soil, and thus may diminish the supply to springs. This is especially possible with small precipitations. Of copious rains and large amounts of snow water, quantities, greater or less, penetrate the soil, and according to its nature into lower strata and to springs. This drainage is facilitated not only by the numerous channels furnished by dead and living roots, but also by the influence of the forest cover in preserving the loose and porous structure of the soil.

Although the quantity of water offered for drainage on naked soil is larger, and although a large quantity is utilized 
by the trees in the process of growth, yet the influence of the soil cover in retarding evaporation is liable to offset this loss, as the soil cover is not itself dried out.

The forest, then, even if under unfavorable topographical and soil conditions (steep slopes and impermeable soils) it may not permit larger quantities of water to drain off underground and in springs, can yet influence their constancy and equable flow by preventing loss from evaporation.

(3) The surface drainage is retarded by the uneven forest floor more than by any other kind of soil cover. Small precipitations are apt to be prevented from running off superficially through absorption by the forest floor. In case of heavy rainfalls this mechanical retardation in connection with greater subterranean drainage may reduce the danger from freshets by preventing the rapid collection into runs. Yet in regions with steep declivities and impermeable soil such rains may be shed superficially and produce freshets in spite of the forest floor, and an effect upon water conditions can exist only from the following consideration.

(4) The well-kept forest floor, better than even the close sod of a meadow, prevents erosion and abrasion of the soil and the washing of soil and detritus into brooks and rivers.

This erosion is especially detrimental to agricultural interests as well as waterflow in regions with thin surface and impenetrable subsoils, and where rains are apt to be explosive in their occurrence, as in our western and southern country. The best soil of the farms is often washed into the rivers, and the water stages of the latter, by the accumulations of this soil, are influenced unfavorably.

(5) Water stages in rivers and streams which move outside the mountain valleys are dependent upon such a complication of climatic, topographic, geological, and geographical conditions at the head waters of their affluents that they withdraw themselves from a direct correlation to surface conditions alone. Yet it stands to reason that the conditions at the head 
waters of each affluent must ultimately be reflected in the flow of the main river. The temporary retention of large amounts of water and eventual change into subterranean drainage which the well-kept forest floor produces, the consequent lengthening in the time of flow, and especially the prevention of accumulation and carrying of soil and detritus which are deposited in the river and change its bed, would at least tend to alleviate the dangers from abnormal floods and reduce the number and height of regular floods.

Concerning the moisture of the soil the results of the most recent experiments differ. Ramann, in 1895 , published a series of results which indicated that the soil of the forest may be even drier than that of the neighboring open land. This view he finds strengthened by experiments made in small clearings within the forest, where he finds the soil of the sunny side of the clearing and that of the old forest itself decidedly drier than the soil of the shaded part of the clearing, though he also finds the soil under a young bush cover more moist than that under old timber.

Whether a forest cover aids in the accumulation of ground water by improving the permeability of the soil was made the object of an experiment by Wollny, in a series of inconclusive small pot experiments which led this investigator to the questionable result that bare land was more conducive to percolation than ground covered either by grass or trees. This would surely be true only if the bare ground, as in the experiments, is kept in an artificial, not natural, condition.

Attempts to deduce the influence of forest on waterflow from wholesale measurements and observations have been made in this country by Vermeule, of New Jersey (see Proceedings American Forestry Association, Vol. XI, pp. 130-137, and report of New Jersey Geological Survey, I 894). and Rafter, of New York (Proceedings of American Forestry Association, Vol. XII, pp. 139-165, and report of State engineer and surveyor of New York, 1896), the former claiming that no appreciable influence existed, the latter calculating the influ- 
ence of the forest to be equal in value to five or six inches of rainfall, this amount of moisture being saved by its presence.

Among recent papers which possess the highest value in describing the movements of water in the ground, and thus throw light on a most important phase of the whole subject, Bulletin 32 of the Experiment Station, Fort Collins, Colo., by Professor L. G. Carpenter, is noteworthy. Professor Carpenter shows that it is possible by mechanical means (ditches in this case) to prevent the rapid run-off in high-water time and thus produce a steadier flow of a stream and also raise the level of the ground water, as well as saturate large areas of otherwise arid land. In other words, he shows that in Colorado the work of irrigation has resulted in a rise in the level of the ground water, changing deep wells into shallow ones; that it has taken water out of the Platte and Cache la Poudre rivers, and saturated thousands of acres of formerly arid land, the seepage of which has changed dry branches into steady rivulets, and supplies already a steady inflow into the rivers, from which the water is taken above the fields. This inflow tends to make these rivers steady and uniform sources of water supply, and makes irrigation possible at points below where in former times such irrigation would have been out of the question.

P. 78. Sanitary Influence. - The theories of the development of the various pathogenic bacilli in the soil which were based on Pettenkoffer's authority have lately been discarded, and the origin of malaria has also experienced a different explanation by some authorities. The general statement that the forest soils, being removed from the contact with man's occupations, is usually less favorable to the propagation of pathogenic microbes remains true, and at least this indirect relation of soil conditions to malaria exists, namely, that the mosquito, which is considered the direct breeder of the disease, is dependent for its development on swampy conditions of soil, stagnant water, pools, etc. 


\section{NOTES TO CHAPTER IV.}

P. 8r. The etymology of the word "forests" is doubtful. It is only certain that it is not, as has sometimes been claimed, of Latin, but of Germanic origin, as is evidenced from a manuscript. of Zwentibold: "ut quandum silvam in bannum mitteremus et ex ea, sicut Franci dicunt, forestem faceremus."

The unquestionable connection between vor, first, fuirst and forst, which was originally written voorst (also vorst, vorëst, forest, foreht, foreis), suggests the meaning attached to the word originally, namely, a piece of property set aside for the use of the king or "Fürst."

Other etymologists have tried to relate the term foresta to ferce (wild animals), ferarum statio, and to foris (outside), referring either to game preserves or to location outside the range of the settled country. Lately again the word has been referred to the Latin forus, a subdivided area. It is claimed that the original meaning, namely, "restriction of the chase," was of Roman origin.

According to others the old German word signified "woodland," and only in the sixth and seventh century was specially applied to the woodland owned by the kings or masters, and gradually in the eighth and ninth centuries assumed the restricted sense of reserved woodlands, and finally of the mere legal condition and rights.

P. 83. Foresters (forestarii) and forest guards (custodes nemoris) are mentioned first under the Carolingians as having charge of the forest property of the kings or lords under the supervision of the majordomo; they had at first only police functions, and were often taken from the serfs. It was much later that their functions assumed a technical character.

P. 84. It is interesting to note the historical development of the forestry idea in England and in the United 
States by a comparison of the lexicographers from period to period.

Richardson's New Dictionary of 1846 defines a forest still as "a great and privileged wood or woody wilderness; some (Frenchmen) have generally interpreted it as a place whereto access and entry is forbidden by the owner unto others, and hence it seems that privileged fishing or large waters (wherein none but the lords thereof could fish) were also termed forests."

Webster's Dictionary in 1863 did not contain the word "forestry" at all ; "forester" was defined as (I) an officer appointed to watch a forest or chase, and to preserve game and institute suit of trespass; (2) an inhabitant of the forest; (3) a forest tree.

Forest was defined as (I) "an extensive wood or a large tract of land covered with trees. In America usually applied to a wood of native growth or a tract of woodland which has never been cultivated. It differs from 'woods' chiefly in extent." The second meaning refers to the legal term, as explained in the text.

The edition of 1880 gives essentially the same definitions for forest and forester, but contains also "Forestry: The art of forming or managing forests. (Rare.)"

In 1891 the rarity of the word "forestry" seems to have been overcome, the definition of forest remains the same; a forester has become "one who has charge of the growing timber on an estate," etc., and forestry is "the art of forming or cultivating forests; the management of growing timber."

Even the Standard Dictionary of 1895 finds it still necessary to explain that its definition, "forestry, the art of developing and managing forests," is based upon Professor Ely's use of the word when referring to New York state having acquired forests in the Adirondacks and having entered upon forestry, and that its definition of a forester as "one who has charge of a forest or of its timber, one who is versed in forestry," is 
based upon the use of the word in the Report of the U.S. Forestry Division for I 886. Nor is the definition of "forest" any more certain of its propriety, lacking in definiteness: "a large tract of land covered with a natural growth of trees and underbrush; a large wood, woodland, often with intervening spaces of open grounds."

\section{NOTES TO CHAPTER V.}

P. I13. Labor in Forestry. - The labor statistics of Germany for 1895 show one laborer employed to 3 ro acres in forestry and one to 10.6 acres in agriculture - a still greater labor-intensity in agriculture than indicated by the figures in the text, which were drawn from less complete statistics. Altogether 352,566 people were deriving their living directly or indirectly from forestry, besides 900,000 in sawmills and woodworking industries, while 17.8 millions were engaged in agricultural pursuits.

P. II6. Forest Labor in the United States. - In the United States, according to the census of 1900 , there were 382,840 wage-earners besides 14,333 clerks or other officials earning $\$ 153,000,000$, and 43,322 proprietors engaged in forest exploitation and sawmills and planing-mills, the wage-earners varying through the year from 350 to 650 thousand. In logging operations alone there were employed besides 2400 salaried officials and clerks on the average 121 thousand wage-earners, varying from month to month between 90 and 156 thousand, the largest number being employed in January and February, the smallest in July; the wages paid to these amounted to $\$ 46,000,000$. Translating the 35 billion feet, board measure, produced roughly into acreage, say 6 million acres representing the harvest area, there was one man employed for every 50 acres cut over, giving rise to a labor earning of over $\$ 7$ per acre; or, if we accept 500 million acres as the productive 
forest area, each 4000 acres of these furnish employment for one man in the harvest alone, for twice the number in the mills, and three times the number in woodworking establishments.

Pp. 116 and 131. The Farmer's Wood-lot. - The farmer's wood-lot has its unquestionable value to the farmer and to the farm, not only in furnishing fuel and repair material, and in giving occupation during the leisure of winter, but also in producing values from those portions of the farm which are unfit for agriculture, if he owns such, and in the indirect benefits from preventing soil washes, and from its wind-break effects, if properly placed.

Silviculturally the farmer's wood-lot is at a disadvantage, on account of its isolation and small size. It is, therefore, constantly wind-swept, and unless particular care is taken to maintain a wind-mantle on the outskirts, the soil is apt to deteriorate, reproduction is made difficult, and danger from windfall is intensified.

The time-element involved rules out the wood-lot from timber production; the coppice and standard coppice management for the production of fuel wood and small dimensions alone fits the small farmer's condition, and if in reach of a market for these, may prove very profitable. Timber production is practically not a business for small areas, although theoretically and under peculiar conditions in practice is not impossible.

P. 122. 'Provided the Litter is Left.' - The fallen leaves, twigs, bark, and other litter, decaying, form a mulch, which, covering the soil, preserves the soil water from being evaporated and keeps the soil in granular, permeable condition, most favorable to water conduction. Besides, the largest amount of the mineral constituents which the trees have pumped up from the soil is stored in these youngest parts, which are returned to the soil as the litter decays and forms the humus. In the average there are annually returned by the fall of leaves and litter in a dense forest from 1800 to 4500 
pounds per acre, containing, according to kind and condition of growth and soil, from 24 to 220 pounds of minerals, potash, phosphoric acid, magnesia, lime, etc., and 12 to 60 pounds of nitrogen, the whole equivalent to not less than 20 to 30 cents or more of fertilizer.

This accounts for the well-known fertility of fresh forest soils, which have accumulated these minerals in the surface layers.

A large literature on the subject of forest litter has been occasioned in Germany, owing to the conflicting interests of foresters and small farmers who desire to, and by necessity do, assist their scant crops by this forest manure, to the detriment of the forest crop.

P. 134. Results of Forest Management in Saxony, and other state forest administrations. - The most intensive management is possible in this densely populated and highly industrial portion of Germany. The periodic changes from 1817 , when a systematic forest management had only been begun, through the century are exhibited in the following tabulation, giving results per acre on about 430,000 acres.

\begin{tabular}{|c|c|c|c|}
\hline & $1817-26$ & $1854-63$ & 1884-93. \\
\hline Felling budget, cubic feet & $60^{\circ}$ & 70 & 90 \\
\hline Timber wood, per cent . & 17 & 48 & 79 \\
\hline Gross revenue, dollars . & 1.75 & 3.54 & 6.67 \\
\hline Expenditures, dollars . & .80 & 1.15 & $2 \cdot 30$ \\
\hline Net revenue, dollars & .95 & 2.39 & $4 \cdot 37$ \\
\hline $\begin{array}{c}\text { Revenue per } \$ \text { I expended, } \\
\text { dollars }\end{array}$ & 2.20 & 3.10 & 2.90 \\
\hline
\end{tabular}


The net revenues in all the other German state forest administrations have risen in similar manner, namely, in dollars per each acre under management :-

\begin{tabular}{|c|c|c|c|c|c|}
\hline Year. & Prussia. & Bavaria. & Saxony. & $\begin{array}{l}\text { Würtem- } \\
\text { berg. }\end{array}$ & Baden. \\
\hline 1830 & .44 & .46 & I. IO & .82 & I. $6 \mathrm{I}$ \\
\hline 1850 & .46 & .65 & 1.63 & I. I I & 2.96 \\
\hline 1870 & .87 & I .99 & 2.45 & 2.62 & 4.18 \\
\hline I 875 & 1.20 & 2.11 & $5 \cdot 4^{8}$ & $4 \cdot 22$ & 2.39 \\
\hline I 880 & .92 & I. 29 & 4.08 & 2.66 & 3.25 \\
\hline 1890 & $1 \cdot 30$ & I.90 & 5.17 & $3 \cdot 33$ & 3.70 \\
\hline 1895 & 1.03 & 1.74 & $4 \cdot 33$ & $3.8 \mathrm{I}$ & $4 \cdot 14$ \\
\hline I 897 & 1.19 & & 5.10 & 4.29 & \\
\hline
\end{tabular}

These figures show the influence of boom prices following the Franco-German war, but the agricultural depression of the last decade in Germany, although noticeable in its effects on wood prices, has hardly interrupted the constant increase in the net yields of forestry.

The gross yields of these forest properties contribute to the total gross budgets of the state administrations in Prussia, 4-5 per cent; Bavaria, 9-10 per cent; Saxony, 13-14 per cent ; Würtemberg, I 6 per cent; Baden, 8 per cent; Austria, 0.7 per cent; France, 0.7 per cent; Russia, I.6 per cent.

A further proof of the efficiency of forest management is to be found not only in the greater total wood production per acre, which has been secured in all states by careful management similarly to that recorded for Saxony on p. 453 , but also in the larger proportion of timber wood (over 3 inches diameter) which is coming to harvest, in part at least as a result of improved silviculture. 
This timber wood per cent increased as follows :-

\begin{tabular}{|c|c|c|c|c|c|c|c|c|}
\hline & \multicolumn{3}{|l|}{ Year. } & Prussia. & Bavaria. & Saxony. & $\begin{array}{c}\text { Würtem- } \\
\text { berg. }\end{array}$ & Baden. \\
\hline 1850 & . & - & - & 26 & 17 & 35 & 26 & 24 \\
\hline 1860 & • $\quad$ & - & - & 29 & 19 & 45 & 32 & 28 \\
\hline 1870 &.$\quad$. & . & - & 30 & 32 & $6 I$ & 40 & 34 \\
\hline 1880 & . & - & • & 29 & 32 & 75 & 39 & 35 \\
\hline 1890 & . & - & • & 47 & 48 & 80 & 54 & 42 \\
\hline 1895 & . & - & • & 50 & 50 & 79 & 53 & 44 \\
\hline
\end{tabular}

The total net income from all the German state forests is $\$ 1.80$ per acre, or $\$ 63,000,000$. Of this gross yield, 65 per cent is for timber wood, from 3-10 per cent for by-products, the balance for inferior wood materials.

How well deserved the reputation of the German forest administrations and financially how wise their maintenance has been may be judged by a comparison with other forest administrations. While in 1890 the German forest administrations showed a net revenue varying from $\$ \mathrm{I} .30$ to $\$ 4.46$ per acre, and in the average $\$ 1.80$, the state forests of the following countries yielded per acre in the period stated :-

\begin{tabular}{|c|c|c|c|c|c|c|c|}
\hline France & - & - & & . & 1897 & & $\$ 1.05$ \\
\hline Austria & . & . & & & $1887-1893$ & & .168 \\
\hline Hungary & $e^{\circ}$ & - & . & • & $1885^{-1} 894$ & • & .32 \\
\hline Russia & . . & . & - & - & 1896 & • & .02 \\
\hline Sweden & . & . & • & • & 1894 & ${ }^{\circ}$ & .48 \\
\hline Italy & . & . & • & • & 1893 & • & .33 \\
\hline Spain & . . & . & & . & 1892 & . & .172 \\
\hline
\end{tabular}

In France, which comes nearest to the German results, a decline of gross yields has been noticeable in the last 40 years. The decade of 1860-1869 showed a total yield of round 
$\$ 8,000,000$ average per year, while the following decades showed the averages of $7,5.5,5.4,5.7$, respectively; the cause of it being probably, in the main, the change from timber forest to coppice.

In Russia a constant increase in receipts during the last 15 to 20 years is the result of an improved forest administration; every increase in expenditures bringing more than a commensurate result.

This is brought out significantly by a comparison of yearly net yields and expenditures which were from 1885 to 1896 :-

\begin{tabular}{|c|c|c|c|c|c|c|c|}
\hline & \multicolumn{5}{|c|}{ Year. } & \multirow{2}{*}{$\begin{array}{c}\text { Expenditures. } \\
\text { Million Rubel. } \\
5.49\end{array}$} & \multirow{2}{*}{$\begin{array}{c}\text { Net revenue. } \\
\text { Million Rubel. } \\
8 .\end{array}$} \\
\hline I 885 & . & . & . & . & . & & \\
\hline I 886 & . & . & . & • & . & $5 \cdot 4^{8}$ & 8.2 \\
\hline I 887 & . & . & . & . & . & 5.60 & 8.5 \\
\hline I 888 & . & . & . & • & . & $5 \cdot 57$ & 10.4 \\
\hline 1889 & . & • & - & • & . & 5.80 & 12.8 \\
\hline 1890 & . & . & - & • & . & 6.09 & 12.1 \\
\hline 1891 & . & . & . & • & . & 6.24 & I I. 3 \\
\hline 1892 & - & • & . & " & - & $6.3 I$ & 13.1 \\
\hline 1893 & - & . & - & • & . & $6.5^{\circ}$ & I 5.9 \\
\hline 1894 & . & . & - & 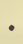 & . & 6.89 & 19.6 \\
\hline I 895 & - & . & . & - & . & $7 \cdot 35$ & 22.1 \\
\hline 1896 & . & . & . & - & . & $7 \cdot 76$ & 26.5 \\
\hline
\end{tabular}

The German administrations also show this relation of expenditure to net revenues. Not only has every increase in expenditure in each state produced greater efficiency (see p. 327), but the net results from state to state are almost in direct relation to the expenditure, as will appear when comparing the table of net yields with the following table of expenditures. The total expenditures are for the period from 1880 to 1896 , the expenditures for administration alone for 
the period from 1890 to 1896 , except for Prussia, for which the periods end in 1892 :-

\begin{tabular}{l|c|c|c|c|c}
\hline & Prussia. & Bavaria. & Saxony. & $\begin{array}{c}\text { Wiirtem- } \\
\text { berg. }\end{array}$ & Baden. \\
\hline $\begin{array}{c}\text { Total expenditures per } \\
\text { acre, dollars... }\end{array}$ & $1.10-1.30$ & $1.50-2.40$ & $2.10-2.70$ & $2.20-2.50$ & $2.10-2.80$ \\
$\begin{array}{c}\text { Per cent of gross } \\
\text { revenue..... }\end{array}$ & $50-57$ & $47-68$ & $32-39$ & $39-51$ & $48-65$ \\
$\begin{array}{c}\text { Administration expense } \\
\text { per acre, dollars. }\end{array}$ & .55 & $.87-.93$ & .95 & .70 & .56 \\
$\begin{array}{c}\text { Per cent of gross } \\
\text { revenue. . . . . }\end{array}$ & 21.5 & $20.5-26.8$ & 14 & 11.5 & 10 \\
\hline
\end{tabular}

In the expenditures there are absorbed by woodchoppers 15-18 per cent of the income from wood sales. For planting alone the following expenditures per acre of forest were incurred in 1894-1895: Prussia, 22 cents; Bavaria, 6.5 cents; Saxony, I4 cents; Würtemberg, I7.I cents; Baden, I8.8 cents. This means not per acre planted, but per acre under management.

P. 138. Rise in Wood Prices. - A very careful and exhaustive investigation into the movement of prices for wood and for agricultural products in Prussia, comprising the fifty years from 1830 to 1880 (by Dr. Fr. Jentsch in Zeitschrift fiir Forst- und Jagdwesen, 1887, pp. 91-108), during which time the price for wood (average) rose 74 per cent, namely, from $2 \frac{1}{2}$ cents to $4 \frac{1}{3}$ cents per cubic foot, brings out the following facts :-

I. The tendency of prices for agricultural products as well as for wood has been toward a rise.

2. Prices for wood have increased more rapidly than those of the staples wheat and rye (imports!), less rapidly than of potatoes, beef, and butter.

3. Prices for wood have risen more steadily than those for agricultural products. 
4. The relation between prices for wood and for wheat and rye shows a tendency in favor of greater rise in profits from forestry than from grain production.

5. Prices promise to rise further for an indeterminable time.

This last prediction seems so far to have proved correct, as the following records from Upper Bavaria show. As an average result of yearly sales, round timber, f. o. b. boat, brought in -

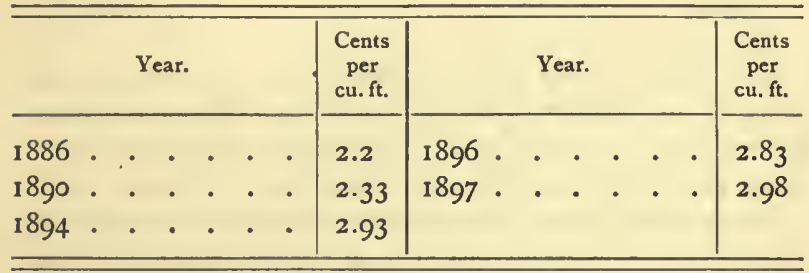

The prices for boards (I inch, I6-foot lengths) was per M ft., B.M.:-

\begin{tabular}{|c|c|c|c|c|c|c|}
\hline Widths & . . & . . & $6 \mathrm{in.}$ & 8 in. & to in. & 12 in. \\
\hline In 1886 & . . & .. & $\$ 12.50$ & $\$ 13.60$ & $\$ 15.75$ & $\$ 13.75$ \\
\hline In 1897 & . . & . . & 15.00 & 17.25 & I 8.00 & 20.00 \\
\hline
\end{tabular}

To gain an idea of the appreciation of the wood product, without reference to kind, size, and quality, the following series of figures will serve :-

Average Price per ioo Cubic Feet of Wood Realized by the Prussian Government for its Entire Crop (ABOUt 300,000,000 CUBiC FEet).

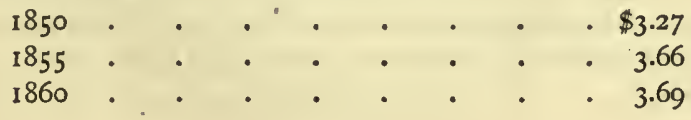


Average Price per 100 Cubic Feet of Wood Realized by the Prussian Government for its Entire Crop (ABOUT 300,000,000 CUBIC FEET) - Continued.

\begin{tabular}{|c|c|c|c|c|c|c|c|}
\hline 1865 & - & - & - & - & • & - & - \\
\hline 1870 & - & - & $\bullet$ & - & • & • & . \\
\hline 1875 & ${ }^{\circ}$ & - & • & - & • & • & - \\
\hline 1880 & $\cdot$ & - & • & - & • & • & - \\
\hline 1885 & $\cdot$ & . & • & - & • & - & . \\
\hline I 890 & - & . & • & • & • & • & . \\
\hline
\end{tabular}

The highest price for any district was obtained in 1888 , being $\$ 8.49$, while the lowest was $\$ 2.82$. The lower prices in later years are explained by the increased importations of wood, especially from Hungary, Russia, and Sweden.

The influence which development of means of transportation exercises on wood prices is interestingly exhibited in a comparison of the price prevailing in the district with lowest and the district with highest price, in Prussia. This relation changed during the last thirty years as follows, taking 100 for the lowest price: 1860, 100:600; 1870, 100:380; 1880, $100: 300 ; 1890,100: 220$. In other words, the range of price decreased in the thirty years of railroad building to one-fourth of the original one.

In 1892 the difference in prices was $100: 221$, when timber wood stood 100:267, firewood 100:177, while rye, the most general agricultural crop, showed the relation of 100 : II6 in the lowest and highest market (a range of only I 6 per cent); the bulkiness of the wood material circumscribing its transportableness probably accounts for this great difference.

To compare prices of wood in America no better means are at hand than the record of export prices on square timber from Canada, which brings the variable item of cost of production to a minimum, as given in a table in "Forest Wealth of Canada." 
Cents per Cubic Foot.

\begin{tabular}{|c|c|c|c|c|c|c|}
\hline \multicolumn{4}{|c|}{ Year. } & White pine. & Oak. & Elm. \\
\hline 1850 & . & •. & . . & $4-5 \frac{1}{2}$ & I $3^{-I} 4$ & $7-10$ \\
\hline 1860 & . &. & . . & $5 \frac{1}{2}-10$ & $14^{-1} 7$ & $7 \frac{1}{2}-14$ \\
\hline 1870 & . & . . & . . & $8 \frac{1}{2}-18$ & $19-23$ & $9-15 \frac{1}{2}$ \\
\hline I880 & . & . . & . . & $14-36$ & $43-52$ & $23-30$ \\
\hline 1890 & . & . & . . & $18-35$ & $42-49$ & $25-30$ \\
\hline 1894 & . & $\cdot \cdot$ & . $\cdot$ & $16-42$ & $45-5 \mathrm{I}$ & $25-32$ \\
\hline Rise & . & . . & . . & $12-36$ & $32-47$ & $18-22$ \\
\hline $\begin{array}{r}\text { Per } \\
\text { app }\end{array}$ & & $\begin{array}{l}\text { per ar } \\
\text { mate }\end{array}$ & $\begin{array}{l}\text { anum } \\
\text { ly . }\end{array}$ & $7-18$ & $5-7$ & $6-5$ \\
\hline
\end{tabular}

Showing not only a constant increase of not less than 5 per cent per annum, but also a variation in range, which indicates reduction in the supply of better quality.

The price of logs exported from Canada during the 25 years from 1878 to 1893 appreciated, according to the same authority for all descriptions, $3 \frac{1}{3}$ per cent, and for pine alone from $\$ 5.40$ to $\$ 8.33$ per $M$ feet, or 5.4 per cent. To explain the difference of these prices from the prices for square timber, it should be known that the square timber goes mostly from Quebec to Great Britain, the logs mostly from Ontario to the United States, a difference in market and location which depresses the log prices disproportionately. A study of the prices paid for timber limits in Canada, which are more accessible than such data with us, will also show the tendency and the rate of rising prices due to decrease of accessible supplies.

The reduction in supplies is also well indicated by the change in the size of merchantable logs, which, in the seven years from 1887 to 1893 , for which data are published in the above-cited document, changed in the Province of Ontario for pine from 122.5 feet B.M. per average log to 98.5 , and for other kinds from 79 to 57 feet B.M. 


\section{NOTES TO CHAPTER VI.}

P. 144. Acclimatization. - Acclimatization, i.e. use of exotic species for forest growing, has been sparingly practised except in planting where nature had not provided any native forest flora, the reason being that native woods usually satisfy the requirements, and that the long period of development before the real character of the wood and the behavior of the plant under new conditions can with certainty be determined deters the attempts. There would, however, appear to have been more hesitation than necessary on this last account. Trees which have lived in a climate for a decade during their infantile and youthful, tenderest stage, and behaved as in their native habitat, are not likely to change their character later. The Germans have for the last thirty years systematically tested and introduced foreign, especially American, species, with considerable satisfaction. Our white pine has been in existence in German forest plantations for over one hundred years and has been found most satisfactory. In Hungary over 170,000 acres of our black locust furnish to the winegrowers most satisfactory vineyard stakes.

While it may still be considered safest to rely upon the native flora, yet if exotics, climatically adapted, promise more rapid growth, larger production, silvicultural qualities or quality of wood superior to the native, as for instance the Norway spruce, it is proper policy to supplant the inferior native, provided that no more is expected of it than it does and can do in its native home.

P. 157. Weight Production per Acre. - It is to be understood that this equal weight production of various species from year to year presupposes the species to be, at least in general, adapted to the locality or site and climate; moreover, this statement refers only to the actual experience with German species in German climate and soils. This experience merely proves the self-evident fact that the same amount of water, sunlight, and temperature accessible in the same man- 
ner produces the same amount of wood material in weight, no matter what the species. The volumes would then vary inversely as the specific gravity or weight of the woods, or $v_{1}: v_{2}=\frac{I}{s_{1}}: \frac{I}{s_{2}}$, which is also borne out by the results of the German measurements.

P. 159. Yield Tables. - A picture of the progress of a woodcrop is gained from the study of the so-called yield tables, which give the contents of the dominant growth of fully stocked stands in Io-year periods. For each species and difference in soil and climate this must necessarily vary, hence normal yield tables are classified into five site classes. In reality there is rarely such a full stand to be found as the yield tables give; they represent the attainable maxima, serving as a standard of comparison.

The following tables refer to first-class sites, and show the difference in production between shade-enduring fir and spruce and the light-needing pine. An approximation to a statement of saw material in board measure can, for the older age classes, be obtained by multiplying cubic contents by 2 to 3 . Only the timber wood (over 3 -inch) is stated, and the amount of material to be derived in thinnings, which represents from 20 to 40 per cent of the final harvest, is omitted.

Yield Table of Fir, Site Class I.

\begin{tabular}{r|r|r|r|r|r|r}
\hline \hline Age. & $\begin{array}{r}\text { Number } \\
\text { of trces. }\end{array}$ & $\begin{array}{r}\text { Average } \\
\text { height, ft. }\end{array}$ & $\begin{array}{r}\text { Volume, } \\
\text { cu. ft. }\end{array}$ & \multicolumn{3}{|c}{ Volume increment. } \\
\cline { 1 - 3 } & Average. & Current. & Per cent. \\
\hline 20 & 5300 & 17 & 990 & 50 & 197 & 26.1 \\
30 & 2210 & 31 & 3,550 & 118 & 317 & 8.4 \\
40 & 1220 & 43 & 6,530 & 163 & 224 & 3.2 \\
50 & 750 & 50 & 8,615 & 172 & 172 & 1.9 \\
60 & 540 & 65 & 10,280 & 171 & 144 & 1.4 \\
70 & 410 & 73 & 11,675 & 167 & 125 & 1.0 \\
80 & 325 & 81 & 12,890 & 161 & 110 & .8 \\
90 & 270 & 88 & 13,950 & 155 & 96 & .7 \\
100 & 230 & 95 & 14,890 & 149 & 86 & .6 \\
\hline
\end{tabular}


Yield Table of Spruce, Site Class I.

\begin{tabular}{r|r|r|r|r|r|r}
\hline \hline Age. & $\begin{array}{c}\text { Number } \\
\text { of trees. }\end{array}$ & $\begin{array}{r}\text { Average } \\
\text { height, ft. }\end{array}$ & $\begin{array}{r}\text { Volume, } \\
\text { cu. ft. }\end{array}$ & \multicolumn{3}{|c}{ Volume increment. } \\
\cline { 5 - 6 } 20 & 2560 & 15 & $9 v e r a g e$. & Current. & Per cent. \\
30 & 1680 & 34 & 2,310 & 78 & 155 & 7.1 \\
40 & 1050 & 50 & 4,200 & 105 & 211 & 5.3 \\
50 & 720 & 60 & 7,640 & 119 & 155 & 2.7 \\
60 & 510 & 73 & 7,360 & 123 & 127 & 1.5 \\
70 & 380 & 82 & 8,560 & 123 & 113 & 1.2 \\
80 & 317 & 92 & 9,687 & 121 & 113 & .9 \\
90 & 265 & 99 & 10,744 & 120 & 99 & .8 \\
100 & 240 & 105 & 11,730 & 117 & 98 & .7 \\
\hline
\end{tabular}

Yield Table of Scotch Pine, Site Class I.

\begin{tabular}{r|r|r|r|r|r|r}
\hline \hline Age. & $\begin{array}{c}\text { Number } \\
\text { of trees. }\end{array}$ & $\begin{array}{c}\text { Average } \\
\text { height, ft. }\end{array}$ & $\begin{array}{c}\text { Volume, } \\
\text { cu. ft. }\end{array}$ & \multicolumn{3}{|c}{ Volume increment. } \\
\cline { 5 - 7 } 20 & Iverage. & Current. & Per cent. \\
\cline { 5 - 7 } 30 & 1700 & 23 & 775 & 39 & 98 & 13.0 \\
40 & 726 & 36 & 2,185 & 73 & 138 & 6.0 \\
50 & 510 & 63 & 3,820 & 95 & 113 & 3.0 \\
60 & 380 & 72 & 5,000 & 100 & 94 & 1.9 \\
70 & 300 & 80 & 6,935 & 99 & 80 & 1.3 \\
80 & 245 & 86 & 7,330 & 96 & 66 & 1.0 \\
90 & 200 & 92 & 7,840 & 87 & 58 & .8 \\
100 & 170 & 93 & 8,275 & 83 & 45 & .6 \\
\hline \hline
\end{tabular}

The average maximum total wood production per acre per year in a 100-year rotation under German conditions, for German species, German forest management, and for different site 


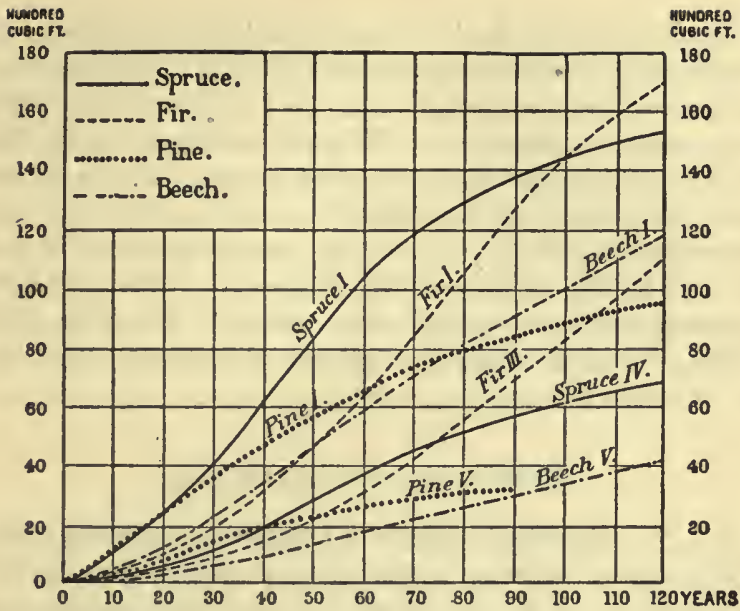

Diagram showing comparative progress of yields of spruce, fir, pine, and beech, on best and poorest site classes.

classes may be stated as follows, leaving out the yield in the thinnings, which may amount to as much as 40 per cent of the final harvest:-

\begin{tabular}{|c|c|c|c|c|c|c|c|}
\hline Site Class & - & . . & I. & II. & III. & IV. & V. \\
\hline & & & cu. ft. & cu. ft. & cu. ft. & cu. ft. & cu. ft. \\
\hline Scotch Pine. & - & - & 93 & 70 & 56 & 45 & 35 \\
\hline Norway Spruce. & • & . & I 54 & 127 & 99 & 78 & 56 \\
\hline Silver Fir & 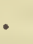 & . & 158 & 128 & 102 & 77 & \\
\hline Beech & - & - & 106 & 85 & 70 & 50 & 35 \\
\hline
\end{tabular}

By multiplying this average increment by 100, the years of rotation (or any number of years near that rotation), the total possible harvest per acre is obtained. It appears that 
fir and spruce are the best producers, beech next, and pine, the most light-needing species, but also the most frugal as to soils, produces the least. Our White Pine compares probably more nearly to the spruce. The usual actual production falls, to be sure, considerably below these figures. The entire production of wood per acre of all the German forests is estimated as 50 cubic feet per acre per annum, or a total harvest of 1750 million cubic feet, half of which is timber wood and probably 4 billion feet B.M. saw material. For France the entire product is estimated at 356,000 million feet, or less than 40 cubic feet per acre.

\section{NOTES TO CHAPTER VII.}

P. 177. Sprouting Capacity of Conifers. - The only conifer which sprouts vigorously and produces shoots growing into trees seems to be the Redwood (Sequoia sempervirens) of our Pacific coast. Indeed, the peculiar appearance in the location of some of the old giants in a circle suggests that these even may have originated as sprouts from stumps of still older trees.

\section{NOTES TO CHAPTER VIII.}

\section{P. 213. Soil-rent Theory. Practicability and Profitable-} ness of Silviculture. - The economic basis for forest management is not the same everywhere, hence the methods of calculating the productive capacity must vary. The soil-rent idea can apply only in highly developed, densely populated countries, where the closest use of soils is imperative.

Agriculture is not, as a rule, attempted on soils which do not promise a satisfactory return or soil rent, while the forest, finally, is relegated to the agriculturally useless soils which would bring no rent by other use. On account of the difficulty of transportation of forest products, location is of more moment than the natural fertility of the soil. While this limitation may be overcome by the building of roads and rail- 
roads, this is often not possible or financially practicable. Hence, areas distant from market may contain large supplies of timber of no value on account of their inaccessibility, and no fine finance calculation is practicable. Under such conditions, when not even crude exploitation pays, forest management upon financial basis is surely excluded. Such properties incapable of earning a rent must by necessity be looked upon differently from those near markets. While on the latter it may be possible to institute a sustained yield management, the former may only be carefully exploited without too much waste and some attention to aftergrowth.

\section{NOTES TO CHAPTER IX.}

P. 25I. Taxation based on Productivity. - In Germany no attempt is made to induce private owners to conservative forest management by reduction of taxes. Forest property is taxed like all other property upon its properly ascertained value, which, however, varies in different states. There is a soil tax (grundsteuer), an income tax, and a property tax.

The soil tax is determined upon the premise of a sustained yield management and the basis of productive capacity under such management - " not to be gauged according to accidental expenditures or improvements or neglects, but according to a natural management under usual and generally practised diligence." The yield is determined upon the basis of the usually applied rotation with the species and kind of management. But it is the yield which can be secured under these circumstances, not the yield which is actually secured, upon which the tax is based, so that the good manager who can secure a yield higher than the ordinary one is benefited, the poor manager who allows his forest to deteriorate is punished. Moreover, since, as we have seen, wood prices and net yields improve, the older tax valuations favor the owner.

Since the forest owner not only possesses the soil, but in a regulated forest management also the accumulated growing 
stock (see p. 20I) which represents usually 75 to 85 per cent of the total forest value, he is by so much richer than the farmer on similar soil, drawing interest not only on the soil value but also on this accumulated wood property. In Bavaria only the soil rent furnishes the basis for taxation, so that the largest source of income, the wood stock, is untaxed; other states recognize this principle, hence the forest pays more tax than the farm on soil of the same value and size. Formerly this was not done, and the forest owner was the favored taxpayer. In Prussia and Hesse the intention is to tax the soil rent only, but by peculiar method of calculation really a larger amount is taxed.

In Saxony and some other states a most just, elastic, progressive income tax for intermittent forest management is in vogue, which is collected only when the owner receives an income, and remains unpaid in years without an income from the forest. No regard is here paid as to what part of the forest property is responsible for the income, in other words, the separation of wood stock and soil is not considered. In Prussia, on the other hand, the income from a decimation of the wood stock is not considered as liable to tax, because it is merely a change in form of capital.

Of the whole forest value in Germany only $\frac{1}{4}$ to $\frac{1}{8}$ is chargeable to soil, soil values for forest purposes rarely exceeding $\$ 200$ and mostly not $\$ 100$ per acre (see p. 126).

In general terms the tax value of all the German forests figured at 3 per cent with a net income of $\$ 63,000,000$ assuming results equal to state forests, represents $\$ 2,100,000,000$ ( $\$ 700,000,000$ for state forests, $\$ 350,000,000$ for corporations, $\$ 1,050,000,000$ for private forests), or $\$ 60$ per acre - one-third the value figured on p. 50. (The Saxon state forests, which produce the highest net income, are figured as between $\$ 115$ and \$233.) Allowing $\frac{1}{6}$ for the soil, the wood capital represents $\$ 50$ per acre, or the total $\$ 1,750,000,000$. Allowing a similar division of earnings, namely, $\frac{1}{6}$ to be credited to soil and $\frac{5}{6}$ to stock of wood, the soil rent at 3 per cent figures 
30 cents per acre, varying (in 1895) between 17.2 cents in Prussia and 72.2 cents in. Saxony. The forest soil in Prussia in the tax lists is assessed upon the basis of a net yield varying from 18.3 cents to $\$ 1.25$, average 49.5 cents per acre, while the farm soils are taxed upon the basis of a net yield of 81 to 396 cents, or 182.5 in the average.

P. 263. Forest Fire Insurance. - The Gladbacher Fire Insurance Company in Germany insures forest properties according to age, species, and local danger. The fire insurance value of young stands is calculated by a discount with a 5 per cent interest rate on the final harvest value; for mature stands the actual present value is supposed to persist for 10 years. The premiums based for each 1000 mark insurance value are in the average,

for broad-leaved forests, . . . 0.85 mark;

for mixed conifer and broad-leaved forest, 1.20 mark;

for conifers pure, . . . . . 2 marks.

The minimum rate is 0.45 mark, the maximum 4 marks per Iooo mark value.

\section{NOTES TO CHAPTER $X$.}

There should have been mentioned in the text, as of particular interest to us, what position our neighbor Canada has taken with regard to her forestry interests.

Like the United States Canada possesses two forest regions, the eastern and the western, divided by a forestless prairie and plains country. The northern climate reduces both in the east and the west the species composing the forest; but on the whole, the type of forest found at the boundary of the United States continues for a considerable distance into Canada, until with the decimation of species and decrease in development, the more or less open woodlands of the northern forest type are reached, where spruce, aspen, and birch of inferior quality and no commercial, although of local value. 
similar to our interior Alaskan forest, in open stand and groves of greater or less extent, are scattered across the continent.

With only a small population, somewhat over 5 millions, on an immense area, 3,654,000 square miles, the availability of large parts of which are still unknown and only 75 millions of acres occupied, Canada has drawn on her immense forest resource mainly for export to Great Britain and the United States and a few other wood consumers, but the two firstmentioned countries dividing the bulk in nearly equal shares. The amount of exports is, however, not as large as we would be led to believe from the frequent references to Canada's position as an exporter of wood, for the values of forest and mill products seem not to exceed $\$ 30,000,000$, to which about 3 millions more of wood manufactures is to be added, the range of exports for the last ten years having been from $\$ 25,000,000$ to $\$ 35, \infty 00,000$, which is reduced by about $\$ 3,500,000$ of imports. This represents a per capita export of about 140 cubic feet. It would appear that the United States exports on the whole more forest product than Canada, against whom she maintains a suicidal wood tariff.

The great value of Canadian forests was early recognized, and even during the French régime reservations were made to protect the supply of oak suitable for shipbuilding, and in 1763, when the English took possession, a more organized system was established to accomplish the same object; a certain area being set aside in each township, where cutting was prohibited except by the contractors for the many yards. Again, in 1775 , the home government ordered the setting aside of large tracts of pine-bearing land. Under this system the navy yard contractors had practically a monopoly, and the colonial government received no revenue from its forests. In 1826 in Upper Canada a measure was passed permitting any one to cut timber on the ungranted lands by the payment of a fixed scale of rate to the Crown, and it is interesting to note that already there was an attempt made to perpetuate the 
forest by doubling the rate on all trees cut which would not square more than eight inches. By the Crown Timber Act in 1849 the granting licenses for one year only was permitted, with the provision that at the end of the year the government could make any desired change in the regulations. At first only a ground rent of 62 cents per square mile, or double that if unworked, was charged, but as competition for the limits began, the system of auctioning them was introduced, and till this time this system has persisted with a few modifications. In this way the government still owns the land and has a right at any time to refuse to renew licenses.

At present there is a division of authority in the forest administration between the Dominion and the Provincial governments. The Dominion administration is under the Department of Interior, and controls the land north of Quebec and Ontario, including Labrador on the east and extending west to British Columbia and Alaska. The Dominion also owns a strip of land in British Columbia along the Canadian Pacific Railway, 40 miles wide and 500 miles long, which is heavily forested.

This Dominion forestry branch has been established only four years, but already it has a fairly efficient system of fire rangers, and has commenced a great work of forest tree planting on the plains. This movement was really started by the Experimental Farms under Dr. William Saunders in 1889 , and since that time to $1901,1 \frac{1}{2}$ millions of young forest trees and cuttings and 8.5 tons of seed, chiefly box-elder and green ash, have been distributed among the settlers. This work is taken up by the Interior Department more extensively.

Most of the forest now being exploited comes under the jurisdiction of the Provincial governments, except in Manitoba and the territories, where the country is new and forest land scarce. In Prince Edward Island the forests are almost entirely under private owners, and not much has been done in the way of forestry. In the other provinces the forests are perhaps the most valuable form of public wealth. In all, 
a system of licensing timber limits with some minor variations in price and regulations is in vogue, and in that way the timber lands themselves are still largely owned by the government. The main problem before the administrations is the fire problem, and all have made some attempts at protection, but still large areas are burned over annually, except in Ontario, where the ranger system has been very effective, and in I 90 I the loss from fire was slight. During I90I this protection, one-half paid by the limit holders, cost only $\$ 30,000$, an insignificant sum when compared with the losses from fire in former years.

Already over 7,000,000 acres have been set aside by the Dominion or Provincial governments as forest reservations, and it is expected that in the near future this will be greatly increased. Under the Federal Government some ten reserves, containing 3,000,000 acres, have been established in Manitoba and the Northwest Territories on wooded mountain ranges and in the foothills of the Rockies. Ontario has four reserves, viz., Lake Temagami of $1,400,000$ acres, Algonquin Park of I, I09,000 acres, an 80,000-acre tract in Addington and Frontenac counties, and 45,000 acres in Sibly County, north of Lake Superior. In Quebec, the Laurentide Park contains $1,634,000$ acres, and in the last legislature in New Brunswick a bill was passed authorizing the setting apart of a large forest reserve on the Crown lands.

What is greatly to be commended in the forestry administration in Canada is, that the state retains the ownership of the land and can at any time set aside any portion desired, and that from the sale of the limits, ground rents, and royalties on timber cut, a revenue is procured, which in Ontario, at least, relieves the people from any direct tax for state purposes. If, under the present wasteful system of forest exploitation, such a revenue is procured, it may confidently be expected that a much larger amount will be realized when the reservations are increased, as is expected, and the forests are placed under scientific management. At present most of the 
reservations, except the Lake Temagami, consist of young trees, and it has not been decided what course will be taken to harvest the crop.

Forestry associations exist in the provinces of Quebec, British Columbia, and also a Dominion association, founded in 1898 , which is largely composed of lumbermen, making its future work more hopeful.

\section{NOTES TO CHAPTER XI.}

In addition to the statistics contained in Chapter II and the notes to that chapter the following additional data may be of interest. The writer must caution readers again that such statistics are not to be conceived as mathematically correct enumerations. Even census statistics may not be considered more than approximations, and contain elements of judgment and estimate. To make them practically useful the information they contain must be used with discretion; the information must be completed by estimate, i.e. by "logical inferences from data and relations reported." . While the enumerations should be reported by the enumerator exactly, the statistician is justified in rounding off figures, for he is interested merely in relationships which are more clearly brought out by such rounding off.

\section{Forest Area of the United States by States.}

The subjoined table gives an estimate of the areas which either bear commercially valuable forest or are capable of producing such without effort of man in our generation.

This table is based upon a similar table prepared by the writer in 1893 , corrected upon the basis of the farm area reported by the twelfth census.

The geographical arrangement and sub-additions have been made with a view of bringing out the relative commercial and economic value of the forest areas. 


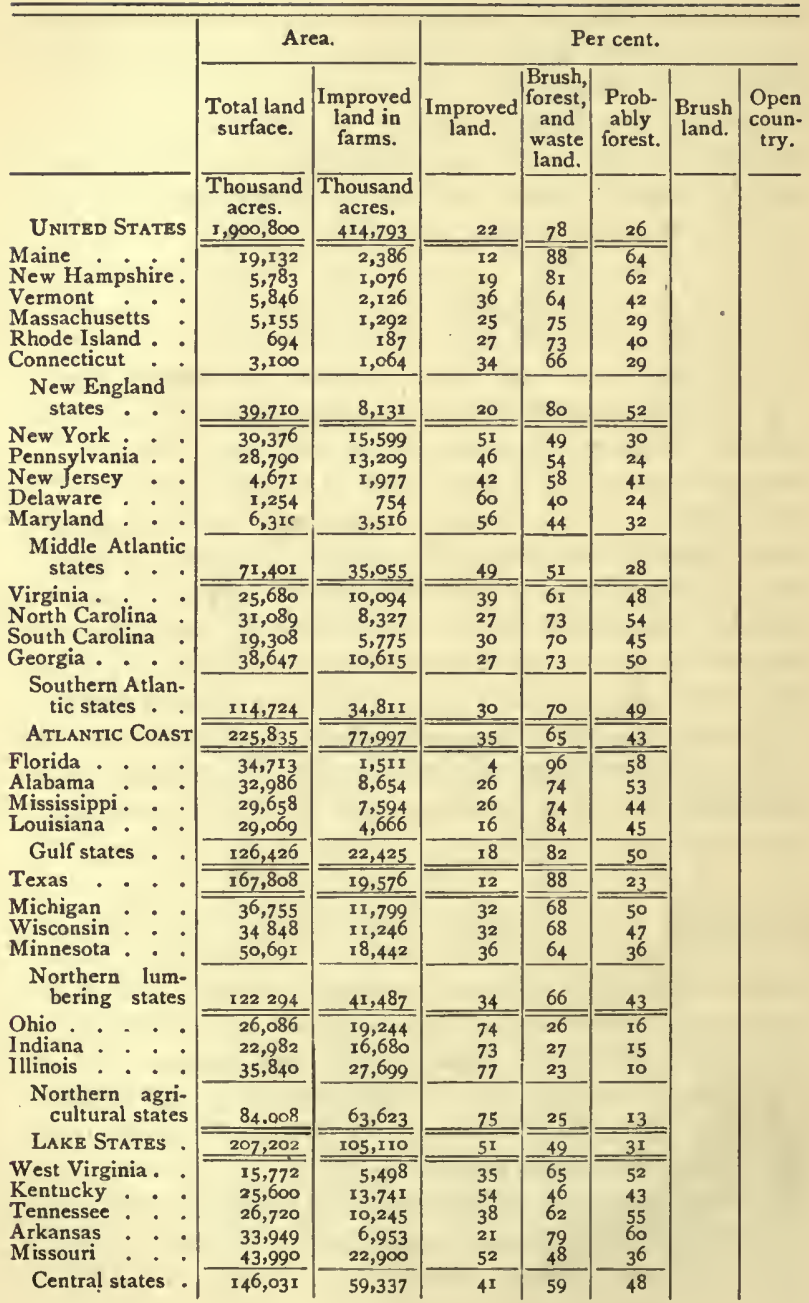




\begin{tabular}{|c|c|c|c|c|c|c|c|}
\hline & \multicolumn{2}{|c|}{ Area. } & \multicolumn{5}{|c|}{ Per cent. } \\
\hline & $\begin{array}{l}\text { Total land } \\
\text { surface. }\end{array}$ & $\begin{array}{l}\text { Improved } \\
\text { land in } \\
\text { farms. }\end{array}$ & $\begin{array}{c}\text { Improved } \\
\text { land. }\end{array}$ & $\begin{array}{c}\text { Brush, } \\
\text { forest, } \\
\text { and } \\
\text { waste } \\
\text { land. }\end{array}$ & $\begin{array}{l}\text { Prob- } \\
\text { ably } \\
\text { forest. }\end{array}$ & $\begin{array}{l}\text { Brush } \\
\text { land. }\end{array}$ & $\begin{array}{l}\text { Open } \\
\text { coun- } \\
\text { try. }\end{array}$ \\
\hline $\begin{array}{l}\text { Iowa } \\
\text { North Dakota. : } \\
\text { South Dakota : } \\
\text { Nebraska : : } \\
\text { Kansas : } \\
\text { Oklahoma : }\end{array}$ & $\begin{array}{c}\text { Thousand } \\
\text { acres. } \\
35,504 \\
45,308 \\
49,696 \\
42,998 \\
52,288 \\
24,960 \\
\end{array}$ & $\begin{array}{c}\text { Thousand } \\
\text { acres } \\
29,897 \\
9,644 \\
11,285 \\
18,432 \\
25,040 \\
5,511 \\
\end{array}$ & $\begin{array}{l}84 \\
21 \\
23 \\
43 \\
48 \\
22 \\
\end{array}$ & $\begin{array}{l}16 \\
79 \\
77 \\
57 \\
52 \\
78 \\
\end{array}$ & $\begin{array}{r}13 \\
1 \\
2 \\
3 \\
7\end{array}$ & & \\
\hline Prairie states & 250,754 & 99.809 & 40 & 60 & 4 & & \\
\hline INTERIOR States & $396,7^{85}$ & 159,146 & 40 & 60 & 20 & & \\
\hline 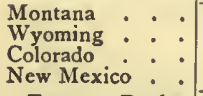 & $\begin{array}{r}92,998 \\
62,448 \\
66,332 \\
78,374 \\
\end{array}$ & $\begin{array}{r}1,736 \\
792 \\
2,273 \\
326 \\
\end{array}$ & $\begin{array}{c}2 \\
1 \\
63 \\
0.4\end{array}$ & $\begin{array}{r}98 \\
99 \\
97 \\
99.6 \\
\end{array}$ & $\begin{array}{r}18 \\
12 \\
16 \\
6 \\
\end{array}$ & $\begin{array}{l}20 \\
16 \\
21 \\
21\end{array}$ & $\begin{array}{l}60 \\
71 \\
60 \\
72 \\
\end{array}$ \\
\hline $\begin{array}{l}\text { Eastern Rocky } \\
\text { Mountain region }\end{array}$ & 300,154 & 5.127 & 2 & $9^{8}$ & 13 & 20 & 65 \\
\hline $\begin{array}{l}\text { Idaho.: : }: \\
\text { Nevada: } \\
\text { Utah : }: \text { : } \\
\text { Arizona : }: \text { : }\end{array}$ & $\begin{array}{l}53,545 \\
70,233 \\
52,601 \\
72,268 \\
\end{array}$ & $\begin{array}{r}\mathrm{I}, 4 \mathrm{I}_{3} \\
572 \\
\mathrm{I}, 032 \\
254 \\
\end{array}$ & $\begin{array}{r}3 \\
0.8 \\
2 \\
0.3 \\
\end{array}$ & $\begin{array}{c}97 \\
99.2 \\
98 \\
99.7\end{array}$ & $\begin{array}{l}20 \\
16 \\
14 \\
\end{array}$ & $\begin{array}{r}40 \\
9 \\
27 \\
12 \\
\end{array}$ & $\begin{array}{l}37 \\
90 \\
55 \\
74 \\
\end{array}$ \\
\hline $\begin{array}{l}\text { Western Rocky } \\
\text { Mountain region }\end{array}$ & 249,047 & $3,27 I$ & I. 3 & 98.7 & 8 & 22 & 69 \\
\hline $\begin{array}{l}\text { ROCKY MOUN- } \\
\text { TAIN REGION . }\end{array}$ & 549,201 & $8,39^{8}$ & 1.5 & 98.5 & 10 & 21 & 67.5 \\
\hline $\begin{array}{l}\text { California : : } \\
\text { Oregon : } \\
\text { Washington : }\end{array}$ & $\begin{array}{l}99,827 \\
60,518 \\
42,703 \\
\end{array}$ & $\begin{array}{r}1 \mathrm{r}, 958 \\
3,328 \\
3,465 \\
\end{array}$ & $\begin{array}{r}12 \\
5 \\
8 \\
\end{array}$ & $\begin{array}{l}88 \\
95 \\
92 \\
\end{array}$ & $\begin{array}{l}18 \\
35 \\
52 \\
\end{array}$ & $\begin{array}{l}27 \\
28 \\
20 \\
\end{array}$ & $\begin{array}{l}43 \\
32 \\
20 \\
\end{array}$ \\
\hline Pacific coast & 203,048 & 18,751 & 9 & 91 & 30 & 27 & 34 \\
\hline
\end{tabular}

Note. - The authority for the area of improved farm land is furnished by the census of rgoo. The areas of forest, brush, and waste lands were ascertained by subtracting the area of cultivated land from the total land areas of the several states, and are placed as per cent of the total areas in column 4. The part of these supposed to be forest is estimated on information obtained by various agencies. For the western section of the country the further subdivisicn into forest, brush, and open country is based partly on statistics gathered by Colonel Ensign and published in Bulletin 2 of the Division of Forestry, and partly on the map published in the report of the Forestry Division for 1892 .

These figures would indicate that, in round numbers, less than $4 \mathbf{I} 5$ million acres are turned into farm lands, about twothirds of which was hewn out of the forest; that the productive area of forest growth, by no means all virgin, falls 
somewhat below 500 million acres; that nearly 450 million acres are open country which is presumably incapable of producing any valuable forest growth on account of climatic deficiencies, leaving a balance of over 500 million acres as waste and brush land, of which at least three-fifths have been made so by the combined efforts of axe and fire.

The territorial distribution of the forest area may be broadly defined as follows:-

(I) The Atlantic forest, covering mountains and valleys in the east, reaching westward to the Mississippi River and beyond to the Indian Territory and south into Texas, an area of about 1,361,330 square miles, mostly of mixed growth, hardwoods and conifers, with here and there large areas of coniferous growth alone - a vast and continuous forest.

(2) The mountain forest of the west, or Pacific forest, covering the higher elevations below timber line of the Rocky Mountains, Sierra Nevada, and Coast Range, which may be estimated at 181,015 square miles, almost exclusively of coniferous growth, of enormous development on the northern Pacific coast, more or less scattered in the interior and to the south.

(3) The prairies, plains, lower elevations, and valleys of the west, with a scattered tree growth, on which, whether from climatic, geologic, or other causes, forest growth is confined mostly to the river bottoms or other favorable situations, an area of about $1,427,655$ square miles, of which 276,965 square miles may be considered under forest cover of deciduous species east of the Rockies and of coniferous and deciduous species in the west of this divide.

The maps to be found in the reports of the Forestry Division, United States Department of Agriculture, for 1893, and in the oft-cited H. R. Doc. I8I, give an idea of the relative location of these forest areas and their economic value. Volume XI. Part 3 of the Twelfth Census contains not only a very detailed and full elaboration of the statistics of the 
lumber industry, but also a map showing the distribution of that industry over the country by values produced per square mile. This shows the most intense concentration of this manufacture in the northern section of Michigan, Wisconsin, and Minnesota; in the middle west of New York and Pennsylvania, in Maine and New Hampshire, and, on the Pacific coast, in Washington and on a small territory in Oregon along the Columbia River, while the centres of intensive production in the Southern states are more widely scattered with reference to shipping ports along the coast and Mississippi River.

\section{Statistics of Wood Consumption.}

The eleventh volume of the Twelfth Census, containing reports on "Selected Industries," reaches the writer in time to give the following brief résumé of the lumber interests.

The census of 1900 for the first time seems to have secured tolerably full although still incomplete statistics of the iumber industry of the United States, which show that the estimate of the writer of 40 billion. feet B.M. (see pp. 40 and 349) annual consumption is as near the truth as it can possibly be stated, including all material requiring log and bolt size, for the sawmill product alone is placed by the census at 35 billion feet, precisely the amount which the writer deduced from the reported sawmill capacity in 1898.1 The allowance of 5 billion feet for staves and headings, railroad ties, round and hewn timber used locally, telegraph poles, etc., is, indeed, hardly sufficient. Since, however, in the census statistics there are undoubtedly duplications, we may perhaps still adhere, for all purposes of economic discussions, to our round figure of 40 billion as representing fairly our present annual consumption. The summary of the census (1900), mixing up sawmills, planir.g mills, and timber camps, stands as follows :-

1 H. R. Doc. I8I, 55th Cong., 3d sess., p. II9. 
Number of establishments (reporting or exist-

\begin{tabular}{|c|c|c|}
\hline $\begin{array}{c}\text { ing?) } \\
\text { Capital invested }\end{array}$ & & • \\
\hline Salaried officials, 12,530 & & - \\
\hline Wage earners, 283,260 & & - \\
\hline Miscellaneous expenses & & - \\
\hline Cost of materials used & & • \\
\hline Value of products, total & & - \\
\hline Saw mill & & $\$ 422,8 \mathrm{I} 2,06 \mathrm{I}$ \\
\hline Planing mill & & $107,622,519$ \\
\hline Timber camps & & $36,398,404$ \\
\hline
\end{tabular}

Quantity of sawed lumber, M ft., B.M. . 35,084, 166

The Chief Statistician of Manufactures, commenting on these statistics, which show an increase in lumber product of 30 per cent over that reported by the eleventh census, writes :-

"The consumption of wood in the industries is increasing at a much more rapid rate than the population, in spite of the fact that in many articles metals are substituted for wood. While the timber is being used more and more economically and the waste is being diminished year by year, still the rate of destruction of the forests is yearly increasing."

The figure of $\$ 318,000,000$ represents the cost of the logs and other raw materials at the various mills which produced the 35 million feet of lumber and whatever other products were produced in the mills. Discrepancies between the reported output of the logging camps ( 26 billion feet), and that of the sawmills, amounting to over 36 per cent (!), are explained by the compiler as due to failure of small concerns reporting on the former and to increase in the scale at the mill.

The sawmills alone seem to have produced from logs, bolts, and cords of wood valued at $\$ 135,000,000$ a product valued at $\$ 423,000,000$. In addition to the 35 million feet of umber valued at $\$ 390,000,000,{ }^{1}$ representing 92 per cent

1 In another table this is reported as $\$ 385,298,304$. Altogether the tabulations do not always agree. 
of the whole, the following materials were produced at the mills :-

Output of Factories using Wood Products.

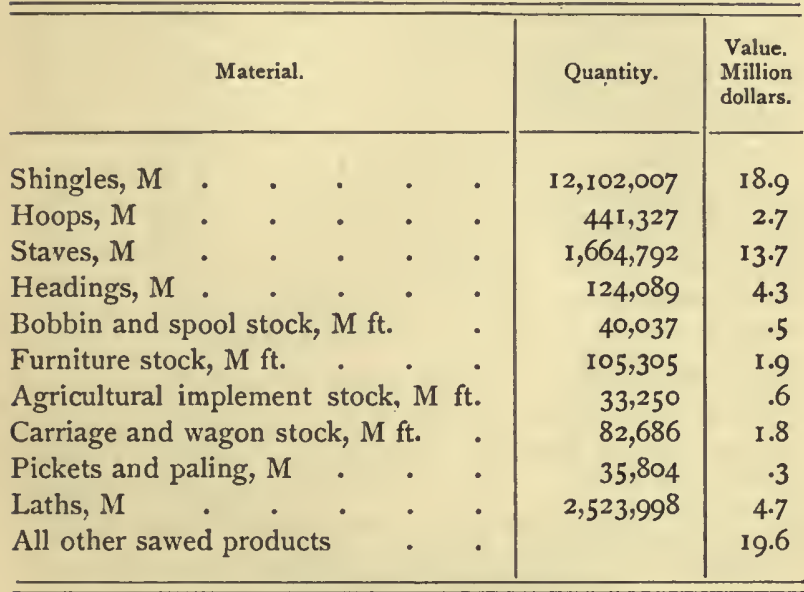

The mill product outside the lumber value was therefore round $\$ 70,000,000$.

These, as well as the following products of timber camps, exhibit the great variety of wood materials, all of smaller value, yet aggregating considerable quantities. While these represent reported amounts from regular mills and camps, an unknown quantity is furnished from irregular sources, farmers and jobbers.

Altogether it is certain that census figures must remain considerably below the actual truth, owing to the difficulty of reaching all the information.

The independent timber camps added to the 3383 million feet of logs cut for sale, valued at $\$ 20,600,000$, the following products, aggregating about $\$ 15,000,000$ :- 


\begin{tabular}{|c|c|c|c|c|c|}
\hline \multicolumn{4}{|l|}{ Material. } & \multirow{2}{*}{$\begin{array}{l}\text { Quantities. } \\
85,306\end{array}$} & \multirow{2}{*}{$\begin{array}{c}\begin{array}{c}\text { Value. } \\
\text { Thousand } \\
\text { dollars. }\end{array} \\
580\end{array}$} \\
\hline Logs for export, $\mathrm{M} \mathrm{ft}$. & - & - & - & & \\
\hline Hewed timber, $\mathrm{M}$ ft. & - & - & - & 39,759 & 348 \\
\hline Basket stock, M ft. & - & - & - & 7,443 & 28 \\
\hline Cooperage stock, cords & - & - & - & 82,546 & 347 \\
\hline Excelsior stock, cords & - & • & - & 12,670 & 49 \\
\hline Feuce posts, No. & - & - & - & 8,7 I $5,66 \mathrm{r}$ & 606 \\
\hline Hop poles, No. & - & - & - & $1,205,700$ & 12 \\
\hline Handle stock, cords & • & - & - & 6,423 & 42 \\
\hline Hemlock bark, cords & 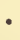 & - & - & 473,222 & I,945 \\
\hline Oak bark, cords & • & • & - & 39,844 & 229 \\
\hline Piles, No. & & - & - & 396,629 & 759 \\
\hline Paving stock, cords & & - & - & 554 & 2 \\
\hline Railway ties & & & & $22,591,894$ & 6,299 \\
\hline Shingles, rived, $M$. & & - & - & 41,433 & 78 \\
\hline Mast and spars, No. & - & & - & 2,580 & 29 \\
\hline Ship knees, No. & • & & • & 1,601 & 5 \\
\hline Telegraph poles, No. & - & • & - & 937,963 & 1,394 \\
\hline Wheel stock, cords . & - & - & 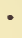 & 9,317 & 46 \\
\hline Charcoal, bush. & - & - & • & $6,796,334$ & 459 \\
\hline All other products & - & - & - & & 1,000 \\
\hline
\end{tabular}

The distribution of the sawed product as reported by regions shows as follows:-

\begin{tabular}{|c|c|c|c|c|}
\hline & & & Million feet B.M. & $\begin{array}{c}\text { Adding } 1 \text { for } \\
\text { non-enumerated } \\
\text { materials. }\end{array}$ \\
\hline \multicolumn{3}{|c|}{ New England, N. Atlantic states } & 5,530 & 6.3 \\
\hline Central states & - & • & 2,420 & 2.8 \\
\hline Lake states & - & - & 8,760 & Io. \\
\hline Southern states & - & - & 14,500 & 16.6 \\
\hline Pacific states & - & - & 2,900 & $3 \cdot 3$ \\
\hline Rocky Mountai & in states & - & 560 & .64 \\
\hline Miscellaneous & - & - & 400 & .46 \\
\hline
\end{tabular}


If we compare this distribution with that given on p. 350 for the census year 1890, allowing for the non-enumerated materials at the same proportion in all districts, it would appear that the cut in the first group of states has probably slightly increased, but that the cut in the Central and Lake states has very materially decreased, unquestionably owing to decrease in supplies; while the Southern states have increased their output to meet this deficiency, and the increase in the Western states is but slight. Although regionally the white pine district is now in its total production outstripped by the Southern states, yet the three states of Wisconsin, Michigan, and Minnesota are still by far the three largest lumber-producers, in the order named, with Pennsylvania a close fourth, these four states furnishing nearly one-quarter of the value and one-third of the product. The white pine product of the three Lake states has been reduced nearly 40 per cent since 1890 , the year of maximum production. At that time it was 8.6 billion feet (not including shingles); gradually decreasing, it has fallen now (I90I) to 5.4 billion.

The American Lumberman, which furnishes these data most acceptably, formerly ridiculing the idea of waning supplies, comments on this decline significantly:-

"We may say that if former methods of collecting statistics had been followed there would have been a heavier decline. That is to say, the report for I $90 \mathrm{I}$ is more nearly complete than that for any previous year. It means simply that the timber is disappearing, that the still increasing wants of the country must be and are supplied to an increasing extent from other sources. In that decline we see the chief stimulus to the growth of the lumber industry in the South and on the Pacific coast." And further accentuating the change of standards, which made earlier estimates of standing timber wrong: "But what a change in quality! If all the remaining white pine could be manufactured into lumber and put on the market at once, it is doubtful if there would be as much good lumber, to say nothing about uppers, as there was in 1882 alone." 
And referring to the low condition of stocks in the yards: "The reason of this decrease in stocks seems to be that the demand can no longer be satisfied by. drawing stocks down, but that the demand must in a measure remain unsatisfied or be supplied with other woods."

With due allowance for differences in manner of collating statistics, failures in securing information, and differences of values in money and price, the following figures of the various censuses may be used at least to show the tendencies of increase in the lumber output, giving the per cent of increase over each previous decade.

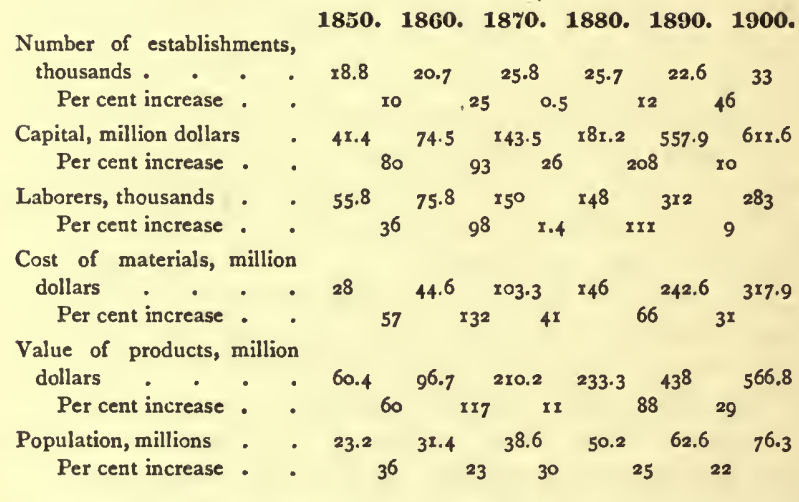

From this it would appear that while the population in the 50 years grew by 228 per cent, its lumber bill during the same period grew by 840 per cent, or from $\$ 2.60$ per capita to $\$ 7.43$, an increase similar to that of the European nations as noted on p. 453 et seq.

Exports of wood, its manufactures, and other forest products have also increased lately at a rapid rate, namely, as follows :-

Million dollars.

$\begin{array}{lllllllll}1894 & \cdot & \cdot & \cdot & \cdot & \cdot & \cdot & \cdot & 27.7 \\ 1895 & \cdot & \cdot & \cdot & \cdot & \cdot & \cdot & \cdot & 27.1 \\ 1896 & \cdot & \cdot & \cdot & \cdot & \cdot & \cdot & \cdot & 31.9\end{array}$


Million dollars.

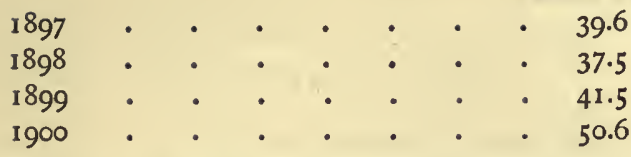

While imports have remained nearly stationary and usually below $\$ 20,000,000$ in value; of the exports less than 25 per cent are manufactured articles.

The census compiler furnishes the following table, attempting to show the change in proportions of the total lumber product furnished by geographical divisions from census year to census year :-

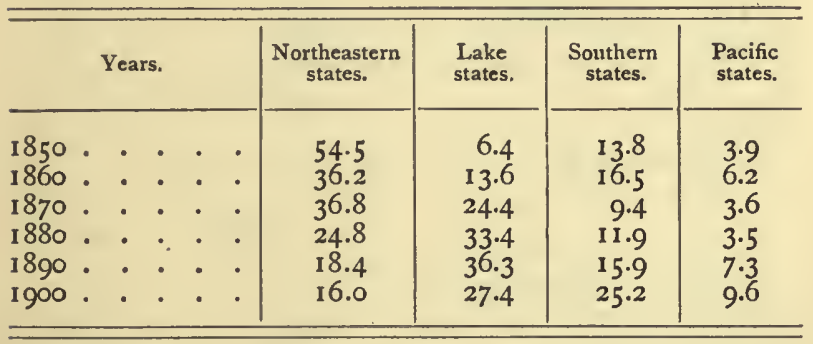

These figures represent only the reported mill cut with all the uncertainties accruing from differences in their collation, but bring out sufficiently clearly the change in supplies, namely, the steady decrease in the northeastern states, the beginning decline in the Lake states, the increase in the southern output, and the slower increase in the Pacific states, mainly for home consumption, hence in relation to increase of population.

The different species are reported to have participated in the total cut as follows, arranged according to the relative position in the supply, verifying the writer's estimate, that three-fourths of our consumption is of coniferous wood, the pines alone furnishing 50 per cent of all lumber cut :- 


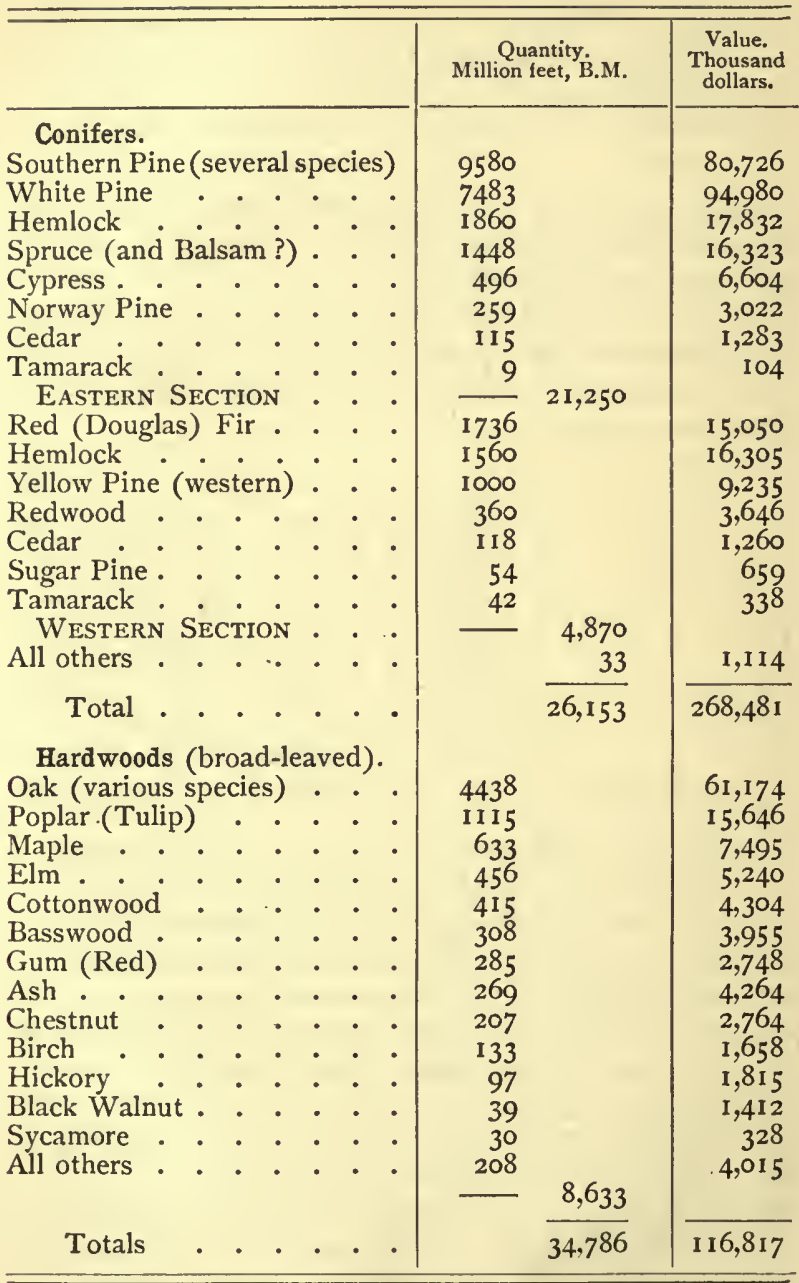


These figures do not, however, fully reveal the relative position of the different species in the wood supply; for the spruce, for instance, the consumption of sizeable material for wood pulp, with not less than 1000 million feet, will have to be added, and for other species from the same source some 300 million; the cut on farms, which is placed at nearly $\$ 120,000,000$ in value, in part log or bolt size material, and not brought to mills, will have to be considered probably mainly in the hardwood cut. On the whole, the distribution given on p. 350 remains relatively correct. It is especially interesting to note the large amount of hemlock reported as cut on the Pacific coast (see p. 361).

Statements are also made in the census report of the probable stand of uncut timber of the various species, without, however, giving the basis for such estimates, or rather guesses. These figures are as follows :-

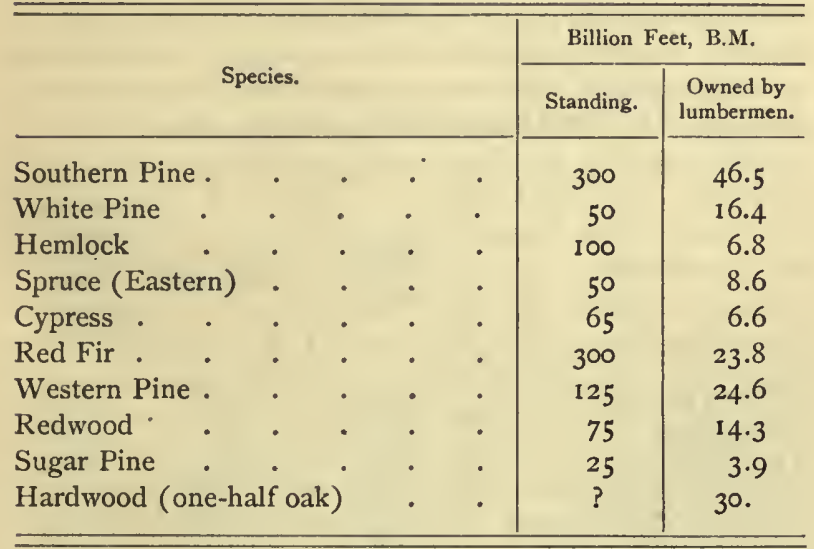

These guesses would indicate a stock on hand of merchantable coniferous wood of not less than 1100 billion feet, of which round one-half is credited to the Eastern states. The 
writer does not see any reason for accepting these guesses as better than his own, or to change his general deduction, that with a present cut of probably over 24 billion feet (including pulp wood), which is increasing 30 per cent in every decade, the Eastern supplies will be cut out sooner than they can be replaced by recuperative measures. That only 14 per cent of this valuable property is reported as owned by lumbermen is rather surprising. The total amount of all species thus held is stated as 215,550 million feet, "probably somewhat more than one-tenth the amount now standing in the country!"

In other words, the rough estimate of the writer recorded on p. 52 is accepted by the census compiler, Mr. Gannett, as within reasonable truth, and we would then have not fifty years' supply in sight. We had hoped the census would prove this sad foreboding unfounded!

The following tabulation, based probably on more substantial data than the estimate of standing timber, is of interest in showing the relative productiveness and value of timber lands in the various sections of the country. It reports the acreage, contents, and value (capital invested) of the forest holdings of the 8888 lumber firms reporting such.

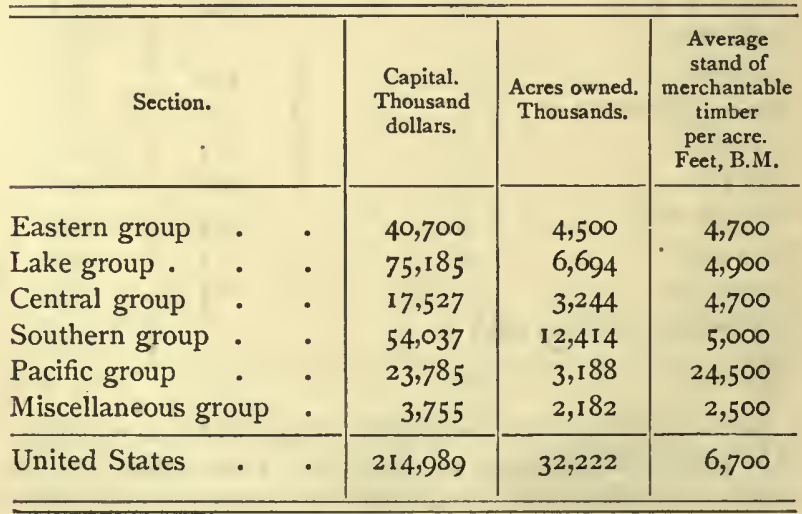


These figures accord closely enough with the writer's conception, which was used in making the computation of the standing timber recorded on p. 52 upon the basis of the area stated on pp. 472-473.

The compiler comments as follows: "The average stand of timber per acre, being that of selected tracts owned by lumbermen, is, of course, higher than the average of the country or state, and in the case of several of the states where the average stand has been obtained, it is known to be much higher. Thus in Minnesota the average stand is about onehalf that here given, or about 2000 feet per acre. The same is the case in Oregon and Washington, where the large stands here given $(24,500)$ must be divided by 2 to obtain the average stand of the state. The southern pine has an average stand, according to the best information, ${ }_{1}^{1}$ of not far from 3000 feet per acre, a little lower perhaps in the east and somewhat higher in the west."

With such reductions we can accept Mr. Gannett's forest area of 700 million acres and find the condition of supplies even worse than the writer has presented it in Chap. XI.

The average investment for stumpage would, from the above tabulation for the better lands, be $\$ \mathrm{I}$ per $\mathrm{M}$ feet or $\$ 6.70$ per acre; but it is well known that these figures are understatements as to the true stumpage value, and the tables recording the stumpage values for different states and different species show this to be the case. Here the stumpage value per $M$ feet is given as $\$ 2.18$, which, with an average stand of 6700 per acre, makes the stumpage value per acre \$14.60. That even these recorded stumpage values remain below the actual truth, at least in certain instances, may be judged from the statement that the stumpage for white pine ranges in the states in which it is of importance between $\$ 3.50$ and $\$ 4$ per $M$, when in actual sales double the higher figure has been

1 See Dr. Charles Mohr, "The Timber Pines of the Southern United States." 
paid, and this year millions of feet stumpage have been sold at more than $\$ 8$ per $M \mathrm{ft}$. Spruce stumpage is given as ranging between $\$ 2$ and $\$ 3$, when actual sales in New York were made at more than the latter price.

The range of average stumpage varies from 80 cents in Washington to $\$ 4.95$ in Iowa, while saw logs are valued from $\$ 4.02$ in Nevada to $\$ 12.16$ in lowa, or $\$ 6.28$ for the country, the cost of logging being therefore $\$ 3.90$ per $M$ in the average and may go up as high as $\$ 7$. At present, with increase in labor and provisions, this cost is increased considerably.

The average stumpage values per $M$ feet B.M. of different species based upon the statements of forest-owning lumbermen figure out as follows:-

Conifers

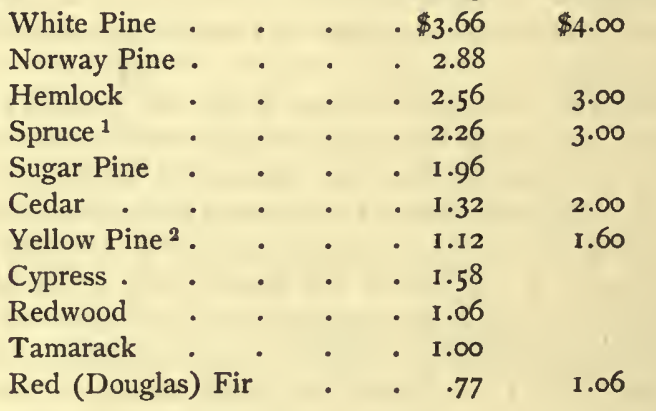

\section{Hardwood}

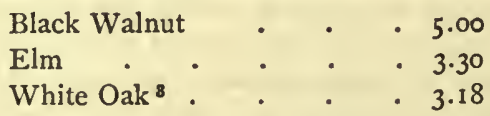

1 Spruce stumpage in New York is now not less than $\$ 4$.

2 Mixes southern and western yellow pine; the former alone appears to average $\$ 1.20$, its maximum $\$ 1.60$ in Virginia, an exceedingly low figure for good pine property, which is now often sold at more than double this figure.

8 Includes probably all commercial oaks. 
Hardwood - continued

Ash

Poplar (Tulip)

Chestnut

Maple .

Red Gum

Basswood

Cottonwood
Average. Maximum.

- 3.03

- $2.8 \mathrm{I}$

3.00

The lumber industry is stated to be the fourth among the great manufacturing industries of the country in value of products, being exceeded by the iron and steel, the textile, and the meat industry. But this does not state the relative value of forest products, including the large amount of fuel wood and other materials of home consumption not going through the mills, and the valuable by-products.

If all these unenumerated forest products are counted in, the forest resource as a producer of values is unquestionably second only to agriculture.

P. 342. Reservation of Mountain Forests in connection with Irrigation. - In the western country, as Mr. Newell states, ${ }^{1}$ "the forests of the arid region not only mark the greatest rainfall but also indicate the locality from which come the principal streams. The headwaters of nearly all of our rivers which give value to the lands are within the forested regions." Hence the close connection between the extensive irrigation plans and forest management.

\section{NOTES TO CHAPTER XII.}

P. 371. Fears of Wood Famine. - The fear of a wood famine troubled the minds not only of our ancestors in this country but still more so in the countries of Europe a hundred years ago, before railroad transportation and navigation had

1 "Irrigation in the United States," by F. H. Newell. ̇. Y. Crowell \& Co., 1902. 
been developed to their modern proportions, making us independent of local supplies.

This is most strikingly exhibited by the following list of titles taken from the catalogue of the library of the well-known German forest academy at Tharandt, which show that in Germany one hundred years ago forest conditions must have been somewhat similar to ours, or worse, and remedies, quack and otherwise, were being discussed as freely as with us.

Collection of economic information, how to promote woodgrowth, introduce better economy in the case of wood, and prevent scarcity of wood supplies by applying building timber more usefully, 1762 .

On the general deficiency of wood supplies and on the means how to meet it, 1765 .

Proposition, how to meet the general decrease of wood supplies most quickly and surely, if not entirely at least for the greater part, 1788 .

Prize essay on the question: How is the rapidly coming wood famine to be avoided and a proper reforestation of waste lands to be secured, 1794.

Answer to the question: How the scarcity of wood can be overcome, 1795 .

Open thoughts on scarcity of wood, especially of fire wood, in Schleswig-Holstein and how to help it, 1798.

On wood famine, 1799.

Something on deficiency of wood supplies, with propositions how to cure it, 1799 .

The Catalpa (!) ${ }^{1}$ a sure means of avoiding the wood famine, 1800 .

On some of the causes of wood scarcity which have not yet been recognized and appreciated, 1800 .

Forestry, or instructions how the deficiency in wood supply may be met, and their increase promoted, $180 \mathrm{I}$.

1 This has been pointed out with similar hopes in this country. See Bulletin No. 37, Bureau of Forestry, giving a full description of characteristics of plantations of the Hardy Catalpa. 
Contributions to the avoidance of a wood famine, 1801 .

Open thoughts on scarcity, prices, economy, in the use of wood, and on silviculture, 1802 .

Something on the general scarcity of wood in the Austrian states, 1805 .

Investigations on the value of wood and the importance of the economic use of wood, I 806.

Wood famine and the state forests, 1840.

On deforestation and increase of wood prices, with remarks on the propositions which are made for the conservation of forests, 1843 .

Short instructions for the increase and economic use of wood, 1845.

The cause of increased wood prices and the importance of the care and preservation of forests as the only means to reduce them, 1846 .

P. 409. Federal Forest Reservations. - There are at present writing (October, I902) 54 forest reservations, created under the act of March 3, 1891, embracing over 60 million acres, namely:-

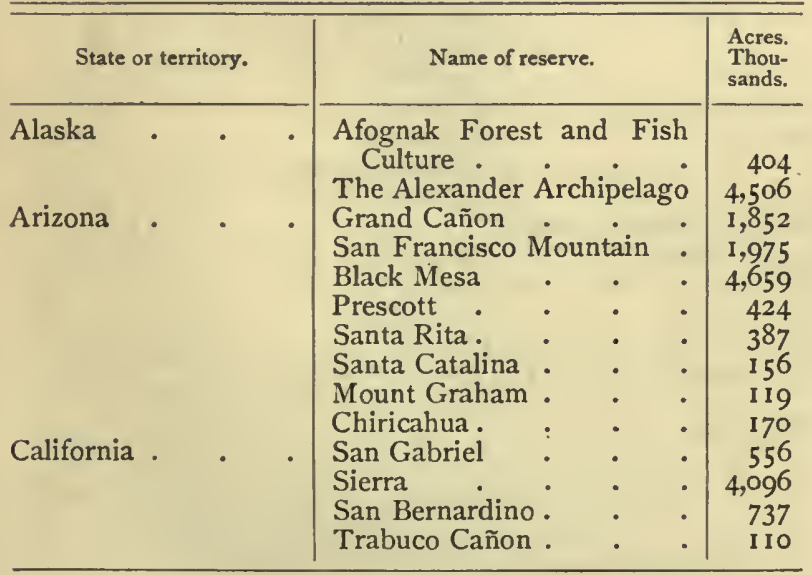




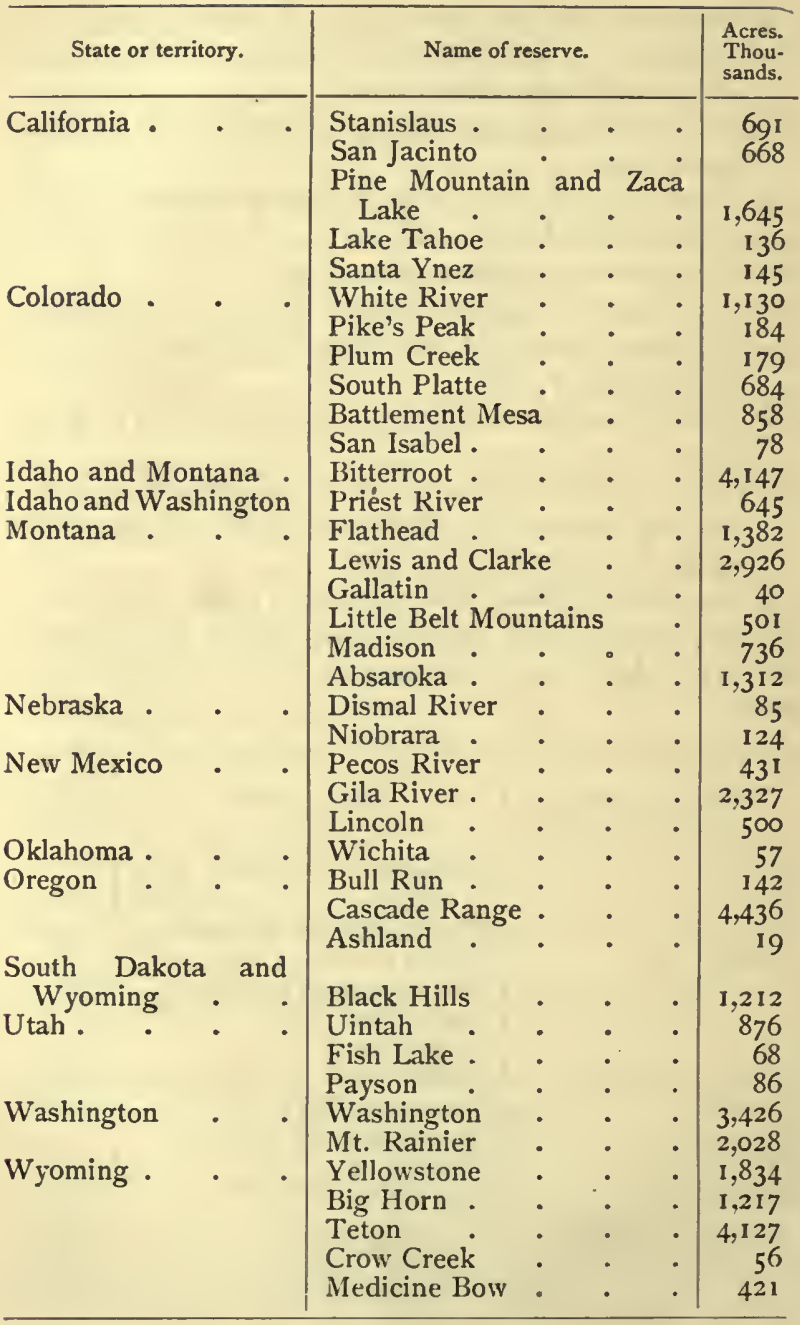




\section{BIBLIOGRAPHY}

A very full bibliography bearing upon the subject-matter of this volume, mainly of German literature, but with a few references to French, English, and other languages, is to be found in DR. ADAM SCHWAPPACH's Forstpolitik, Jagd- $u$. Fischereipolitik, which appeared in 1894 as the Ioth volume of the Hand-und Lehrbuch der Staatswissenschaften, edited by Kuno Frankenstein. The volume itself is probably the best and most complete work on the subject, written, to be sure, from German points of view and including the fish and game interests.

This bibliography divides the subject, outside of the last two phases, into I 6 sub-heads with over 600 titles (644 with repetitions), viz.:-

I. Encyclopædic hand-books, or histories of forestry, forest politics and forest law, and writings of general, theoretical, and methodological contents . . . . . . I Ig titles

1I. Collective works, reports, annuals, and magazines . . . . . . . . . . 96 "

III. Forest law and forest legislation of different States

IV. History and description of forest administrations in different states and parts of states . . . . . . . . . . . .

V. Conditions of production, economic significance, material and immaterial benefits of the forest . . . . . . . . . I28 "

VI. State forests and state forest administrations 40 "

VII. Education, experimentation, and association-The organs of forest politics. 
VIII. Means of transportation in forestry . . . 10 titles

IX. Tariff on wood . . . . . . . . . 10 "

$\mathrm{X}$. Forest servitudes (rights of user) . . . . 16 "

XI. Partition and collocation of forest property and associations for forest management . 5 "

XII. Forest laborers . . . . . . . . . 4 "

XIII. Protective forests . . . . . . . . 14 "

XIV. Supervision of private and communal forest management . . . . . . . . . I4 "

XV. Police protection of forests . . . . . I6 "

XVI. Forest statistics . . . . . . . . $3^{1}$ "

The scope of Dr. Schwappach's treatment of the part entitled Forest Politics, will appear from a statement of the headings :-

I. Conditions of production in forestry . . . 28 pages

II. The significance of forests in the national economy . . . . . . . . . . 18 "

III. Forest policies (Forstwirthschaftspflege) • 145 "

I. The state forest.

2. Forestry education.

3. Forestry experimentation.

4. Forest statistics.

5. Forestry associations.

6. Transportation of wood.

7. Tariffs on wood.

8. Servitudes.

9. Division and amalgamation of forest properties. I0. Insurance of forest laborers.

IV. Forest police . . . . . . . . 6I pages

I. Protective forests.

2. Supervision of private forestry.

3. Supervision of corporate forests.

4. Police protection. 
In the catalogue of the Library of the Royal Saxon Forest Academy at Tharandt, published in 1900 and containing a list of over 23,000 volumes, the subdivision entitled Forest Administration, Forest Politics, and Forest Statistics alone contains 731 titles.

In the "Handwörterbuch der Staatswissenschaften," edited by Conrad, Elster, Lexis, and Loening (Jena, 1900, Gustav Fisher), an excellent article on Forsten by $\mathbf{M}$. Endres treats the subject on 64 large 8 vo pages very comprehensively and somewhat in the manner of the present volume, in three chapters, namely, I, Significance, Extent, and History of Forests; II, Forest Management; III, Forest Politics. A selected bibliography accompanies each chapter; the last chapter more particularly referring to our subject contains only 63 titles and the entire bibliography about 160 titles. The writer is indebted for much statistical information to this article.

In the "Handbuch der Forstwissenschaft," edited by Dr. Tuisko Lorey (Tübingen, 1887, 3 vols. large 8vo), one of the best encyclopædic works for the professional forester, J. Lehr, the author of the very complete chapter on Forest Politics, contents himself with a bibliography of 24 titles.

These four lists lay naturally all or special stress on German publications.

The French literature contains only few comprehensive treatises on the subject, but a large amount of ephemeral or magazine writings, especially on the reboisement of the mountain forests, climatic influences, the duty of the state, etc. The best journal of reference is "Revue des eaux et forêts."

The best work on the extensive reboisement operations of the French government is that of Demontzey.

The English literature shows a considerable dearth of literature on all forestry subjects, except with reference to the forests of India, the Indian Forester being now the only English forestry journal since the Journal of Forestry was abandoned seventeen years ago. 
In the following list of books only a few standard works of general interest and works of reference are given, which cover the subject sufficiently for the general reader. The student is referred for fuller lists to the above-cited sources. The list of American reference books has been made as full as possible.

\section{GERMAN.}

Arndt, E. Die Privatforstwirthschaft in Preussen. Berlin, I889.

Arnold, v. Russlands Wald. Berlin, 1893.

Bedo, A. Die wirthschaftliche u. commerzielle Beschreibung der Wälder des Ungarischen Staates. Budapest, 1885.

Bernhardt, A. Die Waldwirthschaft und der Waldschutz mit besonderer Rücksicht auf die Waldschutzgesetzgebung in Preussen. Berlin, 1869.

Bernhardt, A. Geschichte des Waldeigenthums, der Waldwirthschaft u. Forstwissenschaft in Deutschland. 3 vols: Berlin, 1872-3. A standard work.

Dankelman, B. Die deutschen Nutzholzzölle. Eine Waldschutzschrift. Berlin, 1883.

Ebermayer. Die physikalischen Einwirkungen des Waldes auf Luft, etc. Aschaffenburg, 1873. The first attempt of a scientific discussion of forest influences on the basis of extensive experimental data.

v. Fischbach, C. Lehrbuch der Forstwissenschaft. Berlin, 1886. The best brief treatment of the technicalities.

Hagen-Donner. Die forstlichen Verhältnisse Preussens. 2 vols. 3d ed. Berlin, I894. An excellent, complete statistical and economic account of the Prussian forest administration.

Henko, K. H. Beiträge zur Statistik der Forsten des europäischen Russlands. Petersburg, 1888. Translated by Guse. Berlin, 1889.

Lehr, J. Beiträge zur Statistik der Preise, besonders des Geldes und Holzes. Frankfurt, I885. 
Lehr, J. Die deutschen Holzzölle und deren Erhöhung. Frankfurt, 1883. Economic arguments for retention and abolition of tariff on wood imports by two good authorities.

v. Löffelholz-Colberg, F. Chrestomatie: Die Bedeutung und Wichtigkeit des Waldes, etc. Leipzig, 1872. Interesting compilation of references and quotations from authors of all countries regarding the question of forest influences.

Lorentz Liburnau. Wald, Klima und Wasser. München, 1878. The best popular discussion of forest influences by the most prominent scientific investigator of the subject.

Lorey, T. Editor. Handbuch der Forstwissenschaft, 3 vols. Tübingen, 1887. The best encyclopædic professional handbook.

Mayr, H. Die Waldungen von Nordamerika. München, 1894. A good compilation, upon the basis of personal visits, on forest flora and forest conditions of the United States.

Rentzsch. Der Wald im Haushalte der Natur und der Volkswirthschaft. Leipzig, 1862.

Schindler. Die Forste Oesterreichs.

Schwappach, A. Handbuch der Forst- und Jagdgeschichte Deutschlands. Berlin, 1883 and 1892 .

Schwappach, A. Forstpolitik, Jagd- und Fischereipolitik. Leipzig, 1894 .

v. Seckendorff. Die forstlichen Verhältnisse Frankreichs. Leipzig, I 880.

v. Seckendorff. Über die wirthschaftliche Bedeutung der Wildbachverbauung und Aufforstung der Gebirge. Wien, 1883 .

Weber, R. Der Wald im Haushalte der Natur und des Menschen. Berlin, 1875 .

Woeickof. Die Klimen der Erde. Jena, 1887. Brings many data on the influence of forests on climate. 
Allgemeine Forst $\mathfrak{u}$. Jagdzeitung (since 1825). Frankfurt a. M. Zeitschrift für Forst- und Jagdwesen. Berlin. Since 1869. The two oldest and best German forestry journals.

Beiträge zur Forststatistik des deutschen Reichs. Berlin, 1884.

\section{FRENCH.}

Annuaire des eaux et forêts. Paris. (For statistical information.)

P. đe Boixo. Les forêts et le reboisement dans les Pyrénées orientales. Paris, 1894 .

J. Clavé. Études sur l'économie forestière. Paris, 1862.

M. Demontzey. Reboisement et Gazonnement des montagnes. $2 d$ ed. Paris, I 882.

C. Grandjean. Les landes et les dunes de Gascogne. Paris, 1896.

A. Maury. Les forêts de la Gaule. Paris, 1867 .

A. Noël. Études forestières. Note sur la statistique forestière. Paris, 1884.

Puton et Guyot. Code forestier. Paris, Igoo.

Revue des eaux et forêts. Paris. (The forestry journal of France.)

\section{ITALIAN.}

Bertagnoli. I Boschi e la nostra Politica forestale. Bologna, 1889.

Statistica forestale. Firenze, 1870.

\section{ENGLISH.}

John Croumbie Brown. I6 volumes on forests and forestry conditions in various countries. Edinburgh and London, 1875-1887.

B. H. Baden-Powell. Forest law. London, 1894 .

B. Ribbentrop. Forestry in British India. Calcutta, 1900. 
Wm. Schlich. Manual of Forestry. 5 vols. 2d ed. London, 1896.

Vol. I contains chapters on the direct and indirect utility of forests, the state in relation to forestry, and forestry in Britain and India.

Journal of Forestry and Estates Management. II vols. London, 1877-1885.

\section{American.}

No single book treats of the subject of economics of forestry professionally, but the journal literature, proceedings of associations, and official reports are discussing many phases of it. Among these should first of all be mentioned the various Government Reports :-

Reports of the U. S. Department of Agriculture, Government Printing Office, Washington, D.C.

The first comprehensive discussion, containing a large amount of information on the conditions then prevailing and the prospects, are two long articles, namely, one published in the report for $1860,-$

"The forests and trees of northern America as connected with climate and agriculture," by J. G. Cooper,

and the other, published in $1865,-$

"American forests, their destruction and preservation," by Rev. Frederic Starr.

The following is a complete reference list to forestry subjects in the reports of the Department of Agriculture from the years 1860 to 1886 :-

Forest acreage in farms by states, $1875,247$.

and farm areas by states, 1884,490 .

area of United States by states, $1885,186$.

cultivation, general remarks, 1851,53 .

on the Great Plains, article, $1872,316$.

$2 \mathrm{~K}$ 
Forest, culture, circular asking information, 1858,75 .

experiment, $1875,336$.

historical review, I 870, 226.

laws for encouragement, $1870,234$.

profits, $1870,232$.

destruction in the northwest, notes, 1872,443 .

fires, remarks, $1883,457$.

products, distribution of exports, 1872,59 .

extent and value, $1883,450$.

resources, Brewer's analysis, 1875, 352 .

schools, general remarks, $1883,459$.

trees, culture and management, I864, 43; 1872, I6I.

evergreen, in northern New England, report on causes of

destruction, I883, I38; 1884, 374; 1885, 3 19.

methods of planting, 1864, 45; 1870, 228.

of United States, Centennial collection, I875, I 5 I.

sowing seeds and raising young plants, 1878, 203.

transplanting, remarks, I 878, 204 .

report, 1850,455 .

warnings from history, $1865,225$.

Forests, American, destruction and preservation, 1865, 210.

evils of past destruction, $1865,210$.

and timber, statistical information, 1868, 447.

as connected with climate and agriculture, remarks, I860, 416.

climatic influence, 1883,$453 ; 1885,196 ; 1886,152$.

distribution in United States, 1885, I88.

increase or decrease, general remarks, $1885,190$.

influence on health, 1860, 443 .

soil, r860, 441 .

streams and droughts, I885, 192.

notes on rapid destruction, 1884,154 .

of United States by states, notes and statistics, 1875 , $249 \mathrm{ff}$.

Forestry, experiment stations, remarks, 1883, 158.

historical sketch of Arbor Day, 1886, 181 . 
Forestry, in schools, remarks, $1883,458$.

investigation, outline of system, 1887,614 .

progress, article, I88o, 653 .

list of publications, $1886,226$.

literature, remarks, 1886,183 .

of the Western states and territories, article, 1878,515 .

state encouragement, 1875,334 .

statistics, article, $1875,244$.

by stactes, 1884,137 .

In the reports after the year 1886 to 1893 the following articles, mostly prepared by the writer, bear on the subject of this volume :-

Report for 1886 -

Forestry problems of the United States.

General principles of forestry.

List of ninety most important timber trees of the United States.

Report for 1887 . (Special, not printed in report of Department of Agriculture) -

Trade notes and tariff on lumber - mill capacity of United States.

Systematic plan of forestry work.

Conditions of forestry interests in the states.

Report for I 888 -

Forest influences.

Cultural and trade notes.

Report for 1889 -

Seedling distribution.

Timber-culture acts.

Influence of forests on water supplies.

Report for $1890-$

Wood pulp industry.

Forestry education.

Artificial rainfall. 
Report for $1891-$

Forest planting experiments in Nebraska.

Southern lumber pines.

Forest reservations and their management.

Report for I892 -

Forest conditions of the United States and the forestry movement.

Forest fire legislation.

The naval store industry.

Report for 1893 -

Consumption and supply of forest products in the United States.

German forest management.

In the Year-book of the Department, published since 1894, the following articles appear:-

Year-book for I894-

Forestry for farmers.

Year-book for 1895 -

The relation of forest to farm.

Tree planting on western plains.

Year-book for 1896 -

Tree planting in waste places on farms.

The uses of wood.

Year-book for 1897 -

The work of the Division of Forestry in relation to the farmer.

Year-book for 1898 -

Notes on some forest problems.

Year-book for 1899 -

Progress of forestry in the United States.

Practice of forestry by private owners.

Year-book for $1900-$

Forest extension in middle west.

Practical forestry in southern Appalachians.

List of forestry associations. 
List of schools of forestry.

Progress in forestry.

Year-book for 1901 -

Timber resources of Nebraska.

Grazing in forest reserves.

Progress in forestry.

Besides these annual publications the following separate Reports on Forestry have been published by the Department, containing a large amount of information on various forestry subjects.

Vol. I. Report upon Forestry, prepared under the direction of the Commissioner of Agriculture, in pursuance of an act of Congress approved August 15, I876. By Franklin B. Hough. Pp. 650. Index. 1878 .

Vol. II. Report upon Forestry, prepared under the direction of the Commissioner of Agriculture, in pursuance of an act of Congress approved August 15, 1876. By Franklin B. Hough. Pp. 618. Index. 1880.

Vol. III. Report upon Forestry, prepared under the direction of the Commissioner of Agriculture, in pursuance of an act of Congress approved August 15, 1876. By Franklin B. Hough. Pp. 318. Index. 1882.

Vol. IV. Report upon Forestry, prepared by N. H. Eggleston. Pp. 42I. Index. I map. I884.

The following Bulletins of the Division of Forestry, Department of Agriculture, refer more or less directly to the subject of this volume.

No. 1. Report on the Relation of Railroads to Forest Supplies and Forestry, together with appendices on the structure of some timber ties, the behavior, and the cause of their decay in the roadbed, on wood preservation, on metal ties, and on the use of spark arresters. Pp. 149. Pls. 7, figs. 7. 1887.

No. 2. Report on the Forest Conditions of the Rocky Mountains, with a map showing the location of forest areas on the Rocky Mountain range, and other papers. Pp. 252. Map I, diagr. I. 1888. 
No. 5. What is Forestry ? By B. E. Fernow, Chief of Division of Forestry. Pp. 52. 1891.

No. 7. Forest Influences. Pp. 197. Figs. 63. 1893.

I. Introduction and summary of conclusions, by B. E. Fernow. 2. Review of forest meteorological observations, a study preliminary to the discussion of the relations of forest to climate, by M. W. Harrington. 3. Relation of forests to water supplies, by B. E. Fernow. 4. Notes on the sanitary significance of forests, by B. E. Fernow. Appendiccs: I. Determination of the true amount of preclpitation, and its bearing on theories of forest influences, by Cleveland Abbe. 2. Analysis of rainfall with relation to surface conditions, by George E. Curtis.

No. 9. Report on the Use of Metal Railroad Ties, and on Preservation Processes and Metal Tie-plates for Wooden Ties. By E. E. Russell Tratman, A. M., Am. Soc. C. E. (supplementary to Report on the Substitution of Metal for Wood in Railroad Ties, 1890). Prepared under the direction of B. E. Fernow, Chief of Division of Forestry. Pp. 363. Pls. 5. 1894.

No. 13. The Timber Pines of the Southern United States. By Chas. Mohr, Ph.D. Together with a Discussion of the Structure of their Wood, by Filibert Roth. Prepared under the direction of B. E. Fernow, Chief of Division of Forestry. Pp. 160. Pls. 27, figs. I8. 1896.

No. 16. Forestry Conditions and Interests of Wisconsin. By Filibert Roth. With a Discussion of Objects and Methods of ascertaining Forest Statistics, etc. By B. E. Fernow. Pp. 76. 1898.

No. 21. Systematic Plant Introduction. By David A. Fairchild. Pp. 24. 1898.

No. 22. The White Pine. By V. M. Spalding and B. E. Fernow. Pp. 185. 1899.

No. 25. Notes on Forest Conditions of Puerto Rico. By Robert T. Hill. Pp. 48.1899.

No. 26. Practical Forestry in the Adirondacks. By Henry S. Graves. Pp. 85. 1899.

No. 34. A History of the Lumber Industry in the State of New York. By William F. Fox. 1902. 
Miscellaneous Publications prepared by Agents of the Department of Agriculture. - Catalogue of the forest trees of the United States which usually attain a height of 16 feet or more, with notes and brief descriptions of the more important species. Pp. 38.1876.

Preliminary report on the forestry of the Mississippi Valley and tree planting on the Plains. By F. P. Baker and R. W. Furnas. Pp. 45. 1883 .

Arbor Day, its history and observance. By N. H. Egleston. Pp. 80. Figs. 12. I 896.

Miscellaneous Special Report No. 5. The proper value and management of government timber lands and the distribution of North American forest trees, being papers read at the United States Department of Agriculture, May 7 and 8, r884. Pp. 47. 1884.

Miscellaneous Report No. 10. A descriptive catalogue of manufactures from native woods, as shown in the exhibit of the United States Department of Agriculture at the World's Industrial and Cotton Exposition at New Orleans, La. By Charles Richards Dodge. Pp. 81. 1886.

Forestry in the United States. By B. E. Fernow. Report of United States commissioners to the Universal Exposition of 1889 at Paris. Vol. V, pp. 747-777. Pls. 6. I891.

Statements before Congressional Committees and in answer to Senate Resolutions. - Public timber lands, report of E. A. Bowers relative to desirable legislation. Ex. Doc., No. 242, Fiftieth Congress, first session. Pp. 24. 1888.

Statement on the relation of irrigation problems to forest conditions, by B. E. Fernow, before Special Senate Committee on Irrigation and Reclamation of Arid Lands. Fifty-first Congress, first session. Senate Report No. 928, Vol. 4, pp. I1 5-1 24. 1890 .

Statements in Report No. 1002, Fifty-second Congress, first session. (To accompany S. 3235) "to provide for the establishment, protection, and administration of public forest reservations, and for other purposes." Pp. 12. 1892. 
Senate Document No. 172, Fifty-third Congress, second session. Letter from the Secretary of Agriculture ... transmitting information in relation to investigations and experiments in the planting of native pine seed in the sand hills of the Northwest. Pp. 14. 8vo. 1894.

Statements in House Report No. 1442, Fifty-third Congress, second session. Investigations and Tests of American Timbers. Pp. 4. I894.

Statements in House Report No. 497. Public Forest Reservations. Pp. 23. I894.

Statement of B. E. Fernow, Chief of Forestry Division, to the Committee on Agriculture, House of Representatives [in support of H. R. 8389 and H. R. 8390 , providing for forestry schools], February i6, I 895 . Pp. 4.

Senate Document No. 40, Fifty-fifth Congress, first session, White Pine Timber Supplies. Statement prepared by the Chief of the Division. Letter of the Secretary of Agriculture. Pp. 21. 1897.

Senate Document No. 105, Fifty-fifth Congress, first session. Report of a committee of the National Academy of Sciences on forest policy for the forested lands of the United States, Pp. 49. 1897.

Report upon Forestry Investigation of the U. S. Department of Agriculture, 1877-1898, by B. E. Fernow. H. R. Doc. No. 18I, 55th Congress, 3d session, 1899. 401 pp. 4to.

Message from the President of the United States transmitting a report of the Secretary of Agriculture in relation to the forests, rivers, and mountains of the southern Appalachian region. Washington, D.C. Pp. 210. I902.

Reports of the U. S. Geological Survey, Washington, D.C. Sixteenth Report, I894-I895, Part II, The public lands and their water supply. By F. H. Newell. Pp. 463-532.

Nineteenth Report, 1898, part V, Forest Reserves.

Twentieth Report, 1900, Part V, Forest Reserves, gives detailed report on a number of reserves, also articles on forest conditions and standing timber of Washington and forests of the United States by H. Gannett. 
Reports of the Commissioner of the General Land Office, Department of the Interior, Washington, D.C., give statistical and administrative information regarding the management of public timber lands and forest reserves, also Forest Reserve Manual for the information and use of forest officers, 1902. Pp. 90.

Reports of Bureau of Statistics, Treasury Department, Washington, D.C., gives statistics of exports and imports, monthly, quarterly, and annually, prepares annually Statistical Abstract of the United States, and also issues in the Monthly Summary of Commerce and Finance valuable special reports, among which, The Lumber Trade of the United States, Igoo, pp. 108I-I I 69 .

Reports of Department of State, Washington, D.C. - Consular Reports contain references to forestry, and forest conditions in foreign lands.

Forestry in Europe, a special publication brings details of reports from the consuls of the United States, 1887, also Forest Culture in Sweden, by C. C. Andrews, 1872. Pp. 48.

Census of 1860, 1870, 1880, 1890, 1900, Washington, D.C., give statistics of lumber industry. As a result of the $9^{\text {th }}$ Census an article on The Woodland and Forest Systems of the United States, with a map showing forest distribution, by Prof. F. W. Brewer, was published in the Statistical Atlas of the United States, 1874 .

Vol. IX of the roth Census (1880), pp. 612, is the first comprehensive statement on forest conditions: Report on the forests of North America, by Chas. S. Sargent, 1884 .

Vol. IX, Part III, of the 12th Census (1900), "Selected Industries," contains an extensive compilation of the statistics of the lumber and other forest industries on 122 pages.

Smithsonian Institute Report, 1869: Forests and their climatic infuence, by A. C. Becquerel, translated from the French.

Reports of State Commissions. - California State Board of Forestry, 3 reports, 1885-1890. 
Colorado Forest Commissioner, 3 reports, 1885-189o.

Kansas State Horticultural Society reports on forestry since 1879 .

Maine Forest Commissioner, annual reports since 1891 .

Michigan Forestry Commission reports, 1887-1888, 1900190I.

Minnesota Chief Fire Warden, annual reports since 1895 .

New Jersey Geological Survey reports on forestry since 1880 .

New Hampshire Forestry Commission, annual reports since 1893.

New York Forest Commission (now Forest, Fish, and Game Commission), annual reports since 1886; Forest Preserve Board since $\mathbf{1} 897$.

New York State College of Forestry, annual reports of the director since $\mathbf{I} 899$.

North Carolina Geological Survey, Bulletin 5, 6, and 7.

Ohio State Forestry Bureau, five annual reports since 1886.

Pennsylvania Department of Agriculture, Division of Forestry, annual reports since 1895 .

Canada. - Report of the forest wealth of Canada by the statistician of the Department of Agriculture, pp. 339. Ottawa, I895.

Report of the Chief Inspector of Timber and Forestry, annual since 1899 .

Ontario Bureau of Forestry, annual reports since $189 \mathrm{I}$.

Association Reports. - Proceedings of the American Forestry Association, 1883-1897, Vols. I-XII.

American Economic Association, Vol. VI, No. 3, Ior pp., contains several papers on forestry subjects.

Canadian Forestry Association, reports since 1990.

Journals. - The American Journal of Forestry, edited by F. B. Hough, I vol. 1882-1883.

Garden and Forest, by C. S. Sargent, Vols. I-X. I 888-1 897.

The Forester (now Forestry and Irrigation), Vols. I-VIII, 1895. (Originally published by John Gifford, then by the 
American Forestry Association, now by H. M. Suter.) Washington, D.C.

Forest Leaves, published by Pennsylvania Forestry Association since 1892 .

Water and Forest, a quarterly, by California Water and Forest Association since 1900.

Forestry Quarterly (the first professional journal), published by students and faculty of New York State College of Forestry. 1902.

Books of Interest in Connection with the Subject. - George - P. Marsh, The Earth as Modified by Man, Chapters on The Woods and the Waters. 1877.

Popular Elementary Treatises (a few of the many).-E. Bruncken, North American Forests and Forestry. pp. 265. New York, 1900.

J. Gifford, Practical Forestry. pp. 284. New York, I902.

F. B. Hough, The Elements of Forestry. Cincinnati, 1882.

F. Roth, First Book of Forestry. pp. 291. Boston, 1902. 



\section{N DEX.}

ABBE, C., quoted, 432-433.

Absolute forest soils, 122, 243.

Acclimatization, 144, 460 .

Accretion, rate of, 108-109; laws of, 152-164; normal, 201-203, 206-208; maximum, 211-212.

Adirondack Preserve, 86, 387, 390.

Administration, forest. See Policy, forest.

Afforesting, defined, 83 .

Africa, forestry in, 290.

Age of timber trees, 4I, 43, IO), 355 ; in relation to growth, $\mathrm{I}_{53}-$ 154; classification by, 128-129, 201-204; felling, 208-2II, 226.

Agriculture, 17-18; use of wood in, 24: compared with forestry, 32, 106, I10-126, 240-24I, 243,334, 456,464 .

Air, temperature and humidity of, $69-70,435-439$; as food-provider, I20.

Alaska, forests in, 333; reservations in, 4 IO.

Alcohol, wood, 30, 190, 429.

Algeria, deforestation of, 12.

Allotment method of regulating fellings, 204.

Almirante, Admiral, 59.

Altitude, relation of, to species, I42.

American Association for the Advancement of Science, 377.

American Forestry Association, 382-383, 400-405.

Anerican Lumberman, quoted, 479480.

Ancus Martius, forest regulations of, 9 r.
Animals, as forest destroyers, 55 . 184-185.

Apennines, deforestation of, 58-59.

Arbor day, 92, 297, 379.

Area, forest, statistics of, $35-36,54$, 430-43I ; necessary size of, II5116, 132-133, 451 : in Germany, $3 \mathrm{r} 6$; in the U.S., $334-339,47 \mathrm{r}-$ 475 .

Aristotle, quoted, 58.

Asia, Western, deforestation of, 12.

Assessment of forest property, 250253.

Associations, forestry, $241-242,3^{16}$, $370,3^{81} \mathrm{I}-383,39 \mathrm{I}, 401,47 \mathrm{I}$; sporting, 346 .

Atlantic forests, $331-332,350-35 \mathrm{I}$, 474.

Australia, forestry in, 289-290.

Austria, wood production in, 47; experiments in, 64,443 ; exploitation in, 257; forest policy of, 27I, 294-295.

BACILLI, 78, 447 .

Bacteria, 120.

Baden, forest policy of, 322-323.

Bamboo, 192, 282.

Bark, use of, in tanning, 28, 86, 424 .

Bavaria, meteorological observations in, 63 ; forest fires in, 137 , $190 n_{0}-191 ;$ insect pests in, 137 , 185 $n$.; forest policy of, 320-321 ; wood prices in, 457 .

Becquerel, 61, 63.

Beluchistan, forests in, 286.

Berea College, Kentucky, forestry instruction at, 238,400 . 
Bibliography, 49I-507.

Biltmore, N.C., school at, 238, 399.

Bitterroot Reserve, 360.

Black Hills, 359.

Bole, growth of, $90, x 18-119,150$, 154-I56, 180-181.

Bookkeeping, in forestry, 226-227.

Bosnia-Herzegovina, forest policy of, 294.

Boston, park system of, 385 .

Botany, relation of, to forestry, IooIor.

Bounties, 244-245, 248-249, 268, 378. Boussingault, 6r.

Brandis, Sir Dietrich, 279.

Brazil, importation of wood by, 34 .

Brush wood, I55, 335 .

Budget, felling, 128, 201-222, 226.

Buffon, quoted, 60 .

Building construction, use of wood in, 26-27.

Bureau of Forestry, U.S. See United States Bureau of Forestry.

Burma, forests of, $28 \mathrm{I}$; teak in, 285.

Business, forestry as a. See Economy, forest.

By-products, forest, 28-3I, 424-425.

CALIFORNIA, forests of, $361-363$; forest legislation in, 397-398.

Campagna Romana, 77-78.

Canada, exportation of wood by, $37,253,258,468$; wood prices in, 458-459; forestry movement in, 467-471.

Capacity of forests, $42-46$.

Cape Colony, forest policy of, 290.

Capital invested in forestry, 125I39, 230 ; in the U.S., 32-33, 373, 485 ; in Germany, 50.

Carbohydrates, II9.

Carbonic acid, in forests, 77.

Carpenter, L. G., 447.

Cascade Range, forests of, $333,360-$ 362.
Cellulose, 25, 27, 42 .

Census reports, $376,422,471-480$.

Charcoal industry, $178, x 90$.

Charlemagne, forest regulations of, 300.

Chase, laws of the, $9,82-83,288$, 302-304.

Chemical changes in wood, ro8.

Chlorophyll, $x_{47}$.

Cicero, quoted, $5^{8}$.

Civilization, relation of, to forestry, I9, 2I-3I.

Clearing system, 45, I7 I-I73.

Cleveland, President, 403-404.

Climatic conditions, relation of, to forestry, II-14, I7-I8, 54-55, 59$7 \mathrm{I}, 90$, IOI-IO2, II7-II8, I4I-I46, $156,229,298-299,439-444$; in India, 280-28I ; in the U.S., 334, 368.

Coal, exhaustion of, $8-9$, II ; as fuel, 27, 421.

Coast Range, forests of, $333,36 \mathrm{I}-$ 362.

Code forestier, 217.

Colbert, forest ordinance of, 60 .

Colleges of forestry, in the U.S., 238, 390-391, 399-400.

Colorado, constitutional provisions of, 395; forest legislation in, 396397 ; irrigation in, 447.

Columbus, Christopher, 60 .

Commissions, forestry, $3^{84}$; in New York State, $3^{87}-3^{88}$.

Communal ownership, $269-273$; in Germany, 264, 30I-307, 3103 II.

Competition, destructive tendency of, $2,8,255^{-258}, 359$.

Conditions, forest, defined, $85,87-$ 90.

Conifers, value of, 34 ; in the U.S., $40-4 I, 348,350-362,48 I-484,486$; growth rate of, 108-109; transpiration of, I2I; sprouting of, I77, 464. 
Connecticut, forest legislation in, 394.

Consumption of wood, in the U.S., 25, 5I, 337-339, 475-480; statistics of, 36-4I, 4I6-429.

Cooper, J. G., 375.

Coöperation in forestry, 263, 266, $268,312,380$.

Cooper's Hill, England, forestry school at, 289.

Coppice, 129-13I, I77-I79, 356, $451,464$.

Cornell University, College of Forestry at, 238, 390-391, 399-400.

Corporation forests, in Germany, 317, 322-323.

Cover, forest, value of, $68-76,228$, $265,347,444$.

Crop, forest, when ripe, 102, 106IIO; comparison of, with agricultural crop, III-127; taxation of, 250-25I.

Crown, growth of, 147-150, 154I55; importance of, 158 ; temperature of, $43^{6}$.

Crown Timber Act, 468.

Culling, 44, 95, 127-128, 167-168, 173-I74, 189, 195-196, 337, 343345,357 .

Cuttings, improvement, I69-170.

Cypress, Bald, 356 .

DÉBRIS, I88-IgO.

Deforestation, effects of, 12-13, 58$63,93-95,265-267$; in Italy, 9I, 296; in Germany, 256, 313, 329 ; in France, 276-277; in the U.S., 367-368.

Dehra Dun, forestry school at, 289.

Dendrology, 100-10r.

Deserts, I2, 55 .

Deterioration of forests, $20,45-46$, I68, 178,229 ; in the U.S., 335 , 479-480, 481.

Diameter, growth in, 154 ; limit of, in cutting, 196, 209-2II, 217-22I, 352-353.

Disafforesting, defined, 83.

Distillation of wood, 30.

Distribution, of forests, $35,33 \mathrm{I}-337$, 43I, 474; of species, I4I-I 49 .

Districting, forest, 222-226.

Drainage, influence of forests on, 19-20, 72-75, 77-78, 444-447.

Dunes, sand, in France, 77,277 ; in Russia, 292; in the U.S., 368 .

Duties, protective, $245,253-258$.

Ebermayer, Dr. E., 63, 432.

Economic questions, relative importance of, 7-8.

Economy, of resources, 6-9, 4I5; forest, 96-97, 100, 102-103, I97227; in wood consumption, 339, 355 .

Education, forestry, 236-244; in France, 277; in India, 289; in Russia, 293; in Germany, 315316 ; in Japan, 330 ; in the U.S., 390-391, 399-401.

Egypt, forest policy of, 290.

Eminent domain, 16, 269-273, 415416.

England, royal forests in, 83 ; forest conditions in, 278.

Erichthonios, legend of, 58 .

Erosion, relation of forests to, 12, $19,75-76,367,445$.

Ethics, influence of forests on, 66 .

Eucalyptus, 77, 289-29o.

Europe, deforestation of, 12; paternalism in, 245 ; forest policy in, 274-278, 29I-329; forestry education in, 277, 293, 3I5-3I6.

Evaporation, 70, 437-438, 444 .

Exeter, N.H., forest legislation of, 369.

Exotics, 460.

Experiment-stations, 240-24x; in Europe, 64, 316; in the U.S.; $394-395,397$. 
Exploitation of forests, 2-3, II-12, I9, 44-46, 90, 95, 127-I28, I67I68, I95, I99, 228-230, 329, 343345 i effect of tariff on, 253-255, 258 ; in the U.S., $366-367,37^{1-}$ 376 ; in Canada, 468-469.

Exportation of wood, 37-40, 458$459,468,480-48 \mathrm{I}$.

Expropriation of forests for state purposes, 270-273.

FAMINE, wood, in the U.S., 36937 I, 374-376; in Germany, 487489.

Felling age, 208-2Ir, 226.

Felling budget, I28, 20I-222, 226.

Felling series, 223-226.

Fertility of soil, improved by forests, 120.

Finance, forest, 213-222, 452-459; in Germany, 324-328; in the U.S., $480-481$.

Fires, forest, 29, 133-134, 137, I68, 186-19I, 229, 344, 360, 365-367 ; protection against, I9I-I $96,259-$ $263,283-284,398-399,467,469-$ 470.

Fisheries, 9, II-I2.

Floods, relation of forests to, $6 r$, 73-75, 276-277, 318-319, 368, 445446.

Floor, forest, 72-73, 76, 444-446.

Florida, frost in, 70 .

Foliage in relation to wood production, I52, I55, I57, I79-180.

Forest, history of word, $81-84,448-$ 450 ; functions of, $85-87,228$; normal, 128-129, 20I-202.

Forest Leaves, $3^{8} 3$.

Forest Wealth in Canada, $45^{8}$.

Forester, defined, 97-98, 448-449.

Forester, The, $3^{8} 3$.

Forestry, history of, 9I-94 ; defined, $95-97,449$; classification of, I03I05.

Forestry Quarterly, 400.
Forests, classes of, $87,271-272$; state, in France, 275; in India, 280,288 ; in Russia, 292; in Roumania, 294 ; in Bosnia-Herzegovina, 294; in Austria, 295; in Italy, 296; in Germany, 306, $3^{10}$; in the U.S., (federal) $340-$ 342, 40I-4II, (separate states) $342,386-391,395,397-398$; revenue from, $45^{2-459}$.

Formula method of regulating fellings, 204-205.

Fox, W. T., quoted, 369 .

France, deforestation of, 12-13,6062,70 ; state control of mines in, 16 ; sand-dunes in, 77,277 ; forest policy of, 270, 275-277; importation of wood by, 4I7.

Franco-German war, effect of, on forestry, $329,453$.

French Revolution, effect of, on forestry, 60-6r, 93-94, 275, 306.

Frost, 142 ; in Florida, 70.

Fuel, wood as, 22-23, 27, 274, 282, 420-42I.

Future interests, safeguarded by state, 5-I0, 15-I6, 230-23I.

GAME, protection of, 9, 82-83.

Gannett, statistics compiled by, 339 , $363,483-485$.

Gauges, rain, $64,43^{2-434}, 43^{8}-439$.

Geographical distribution, of species, I4I-I 43; of forests, in the U.S., $33^{I-333}, 474-475$.

Geology, relation of, to forestry, Ior. Germany, consumption of wood in, 27, 37-40, 4I8-4I9; forest policy in, 47-50, 91-93, 300-329; forestry terminology in, 84; agriculture and forestry in, II2-I I4, I22, 450; forest revenues in, $132-135,452-$ 456; spruce growth in, 160 ; methods of regulating fellings in, $173^{-1} 74$; rides in, 193,222 ; districts in, 222 ; forestry schools in, 
$237-238,315,488$; tariff legislation in, 256-258; classification of forests in, 306-307, 309, 313-314; paper pulp industry in, $423-424$; acclimatization in, 460 ; wood production in, $462-464$; taxation in, 465-467; wood famine in, 487-489.

Gerwig, R., quoted, 72-73.

Gironde, sand-dunes in the, 277.

Gladbacher Fire Insurance Co., 467 .

Government. See State.

Grazing in forests, 73, 92, 284-285.

Great Britain, importation of wood by, 37, 416-4I7.

Greece, sterility of, 59 .

Group method of reproduction, 174.

Groves, consecrated, 57 .

Growth of trees, 106-109, $x_{4} 6-x_{5} 6$.

HARDWOODS, 34; rate of growth of, 108-109; coppice reproduction of, $177 ;$ in India, $282 ;$ in the U.S., 348-35I, 356, 482-487.

Harrison, President, 403.

Harvest, time of, I06-I10, 208-2II, 217-219; cost of, 125-126.

Harz Mountains, forestry school in the, 237.

Hemlock, use of, in tanning, 28, 424 ; in paper making, 423 .

Herodotus, quoted, 59 .

Herzegovina, See Bosnia-Herzegovina.

Hesse, taxation in, 466 .

Hodges, L. B., $3^{82}$.

Homer, quoted, 57-58.

Hough, F. B., 424, 432.

Huckleberry industry, 30-3I.

Humboldt, A. von, quoted, 62 .

Humidity, 7 I, I42, 437-444.

Hungary, forest policy of, 295; acclimatization in, 460 .

Hunting, 9, 82-83, 288, 302-304.

Hygroscopic water, I2I.
IDAHO, forests of, 359-360.

Importation of wood, 37-40; duty on, 253-258; by England, 278; by the U.S., $48 \mathrm{I}$.

Improvement, internal, 267.

Improvement cuttings, $169-170$.

Incendiarism, 262, 299.

Income tax, in Germany, 465-467.

India, forest administration in, II4II $5,217,278-289$; forest fires in, 192-193.

Indiana, forest legislation in, 246 , 394.

Industries, forest, 27-32, $421-429$, 487.

Insects, injury from, $I_{33}, x_{37}, x_{4} 6$, 282 ; protection against, $184-185$, 263.

Insurance, forest fire, 263,467 .

Intensive methods, $8,13,18,46-47$, II 3 -I I5, 452.

Interest ${ }^{\prime}$ on forestry capital, $x_{3} x$ I39, 213-215; in Germany, 50.

Internal improvement, 267 .

International Forestry Congress, 35.

Investment, forestry as an, 50, $x_{3} x-$ I39, 2I3-2I5, 345-346.

Irrigation, 75; in the West, U.S., $342,447,487$.

Italy, forest laws in, 58-59, 270, 296-297; deforestation of, 91 .

JAMAICA, 59 .

Japan, forest policy of, 329-330.

Jentsch, Dr. F., 456.

Journals, forestry, $316,383,400$.

Jungles, in India, 282-284.

KANSAS, experiment stations in, 394-395.

King, F. W., 440.

Knots, 90, 107, 180.

LABOR, required in forestry, 3,50, III-II7, 274, 450-45I. 
Lake region, U.S., pine supply in, 350, 478-479.

Land, as a resource, 10-11.

Land-owners, lumbering methods of, 342, 345-346.

Lapland, forest conditions in, 299.

Latitude, relation of, to species, I4I-I42.

Law, property, 4, 20; forest, in Italy, 58-59, 296-297; in Scotland, $83 n . ;$ in the U.S., (federal) 247-248, 378-379, 40I-4II, (separate states) 246-247, 369-371, 377-378, 384-399; in France, 276277; in India, 288; in Russia, 291-293; in Roumania, 294; in Austria-Hungary, 295; in Switzerland, 297; in Sweden, 299; in Germany, 300-305, 312-323; in Japan, 330 ; fire, 259-263, 398399.

Legislation, forest. See Law.

Liburnau, Dr. L., 443.

Light, importance of, 54, I47-158, 179-183.

Lightning, fires caused by, 189$190 n$.

Literature, forestry, $316,374-376$, 488-489.

Litter, 72-73, 120, 45 I-452; burning of, 188,444 .

Loans, state, 268-269.

Lockwood's Paper Trade Fournal, quoted, 42I-422.

Locomotives, fires caused by, 189Igo $n$.

Logging, expense of, 225.

Lumberman, methods of, 44-46, 53 , 167-169, I73, I95-196, 199.

Luneburg Heath, 268.

MCGEE, J W, quoted, 12.

McRae bill, 403-405.

Maine, forest legislation in, 377, 384 . Malaria, effect of forests on, 77-79, 447.
Malthus, 6.

Manufactures, use of wood in, 33 , 426-429.

Maple sugar, 29-30.

Mark system, 9I-92, 30I-306, 3IO.

Marseilles, agricultural society, quoted, 61.

Marsh, G. P., quoted, 7, 376.

Massachusetts, forest conditions in, 42,178 ; forest legislation in, 385-386.

Massachusetts Society for the Promotion of Agriculture, 370.

"Master schools," in Germany, 237 ; at Biltmore, 238, 399.

Mathematics in forestry, 65, 102IO3, I52-I53.

Mensuration, forest, 103, I52-I53.

Mercantile theory, 257.

Mesopotamia, deforestation of, 59 .

Metal, substitution of, for wood, $23 n$., 29; production of, in the U.S., 32.

Meteorology, relation of, to forestry, 63-71, IOI, 432-444.

Michigan, wood production in, 372; forest legislation in, 392.

Microbes in forests, 78,447 .

Middle Ages, forests in the, $8 \mathrm{I}-84$, 300-305.

Mill, J. S., 6.

Mills, saw, waste in, 4I, 4I9-420; influence of, on forestry, 345; in the U.S., 372-373, 475-477.

Mines, exhaustion of, 8 , II; state control of, 16; timber used in, 23; revenue from, in the U.S., 32. Minnesota, forestry association in, 242 ; forest legislation in, 242, 392-393, 398.

Mirabeau, Marquis of, 60.

Mississippi, effects of deforestation upon, 12.

Mohr, C., quoted, 355, 485 .

Moisture, relation of, to forests, 55 . $69-71,142,183,437-447$. 
Monsoons, 280.

Moss-cover, 72-73.

Mountain districts, best use of, 18 , 122; waste in, 28 ; waterflow in, $75-76,80$; forest districts in, 222, 487.

Mushroom industry, $3 x$.

Mythology of forests, $57-58$.

NANCY, forestry school at, 63 , 277.

Napoleonic Wars, effect of, on German forestry, 306 .

National Academy of Sciences, U.S., 404.

Nature element in forestry, II7I25.

Naval store industry, 29, 356, 425 .

Nebraska, Arbor day in, 379 .

New Alexandria, forest institute at, 293.

New England, coppice system in, I78.

New Hampshire, forest legislation of, $370,384-385$.

New South Wales, forest conditions in, 289.

New York State, reservations in, 342 ; forest legislation in, 369 , 386-39r, 398; wood production in, 372 .

New York State College of Forestry, 238, 390-391, 399-400.

Newell, F. H., quoted, 340, 342, 487.

Noble, J. W., 402.

Normal forest, 128-129, 20I-202.

Normal stock method of felling, 204-205.

North America, forest conditions in, 33I-334.

North Dakota, forest commissioner of, 394 .

Norway, forests of, 298.

Number of trees in a stand, I8I-I82; diminution in, $150-15 I, I_{5} 6,158-$ I59.
Nuremberg, forest-planting in, 9293.

Nurse trees, I75, 177.

OAK, use of, in tanning, 28,424 ; in the U.S., 348-349: reservations of, $370-371$.

Oettelt, method of ascertaining felling budget, 2 I7.

Officials, forest, in Prussia, I $13 n_{\text {. }}$; in India, $\mathrm{II}_{4}, 287$; payment of, 260 ; powers of, 262.

Ohio, forestry bureau of, 394 .

Olive, cultivation of, in France, I213,70 .

Orange groves, in Florida, 70.

Orchard, distinguished from forest, 86.

Oregon, woodland area of, $336 n$. : timber supply of, $3^{6} 3$.

Ownership of forests, communal, 269-273; state, 269-27I, 275-276, 280, 29I-293, 295; in Germany, 264, 30I-307, 3IO-3II, 3I7-3I9, $32 I-323$; in the U.S., $340-346$.

Oxygen, amount of, in forests, 77 .

PACIFIC forests, $33^{I-333,} 336,340$, $36 \mathrm{I}-364,474$.

Palestine, sterility of, 59,63 .

Paper-pulp industry, 25, 27, 345 , 42I-424.

Parks, public, 385 .

Paternalism, in the U.S., 232, 245249.

Penn, William, 369.

Pennsylvania, forest legislation in, $247,369,391$; state ownership in, 342.

Pennsylvania State Forestry Association, $3^{83}$.

Periodicals, forestry, $316,3^{8} 3,400$.

Pettenkoffer, 447.

Philippine Islands, forest policy in, 4 II.

Pine, naval stores from, 29; value 
of, 40-4I; exhaustion of, 234 i in the U.S. $347-362$.

Pioneering populations, 2, 53, 9495.

Plant material, distribution of, 245 , $248,315,469$.

Plantation, distinguished from forest, 86.

Plasmodia, 79.

Plato, quoted, 58.

Police, forest, I86, I88, I9I, 259-260.

Policy, forest, methods of, 228-273; in Italy, 91, 296-297; in France, 275-277; in India, 278-289; in Australia, 289-290; in Africa, 290 ; in Russia, 29I-294 ; in Bosnia-Herzegovina, 294; in Roumania, 294; in Austria-Hungary, 294-295; in Switzerland, 297-298; in Sweden, 298-300; in Germany, 300-329; in Japan, 329-330; in the U.S., (federal) $376-379,401-$ 4II, (separate states) 369-374, 384-400.

Pomerania, huckleberry industry in, 3 I.

Prairies in the U.S., 332, 474.

Precipitation, $69-70,43^{8}-439,44 I-$ 442.

Price of wood, statistics of, $134-135$. $13^{8}, 45^{6-459}$; stumpage, 220, 420, 485-486.

Priest Forest Reserve, 360.

Private enterprise, waste caused by, I-4, 20, 44-46, 228-230, 233-234, 272-273, 313; limitation of, I3I6; state control of, in Germany, 3I4-3I5; in the U.S., $342-346$, $3^{80}-3^{8} \mathrm{I}$.

Products, forest, 28-33; statistics of, I23-125; in the U.S., 349$350,426-429$.

Property, individual, $3-4,20,264-$ 266; mediæval ideas of, 262; expropriation of, 270-27I.

Protection (in politics). See Tariff.
Protection forests, 57, I7 I, I74, 234$235,267-268,27 \mathrm{I}-273,347$; in Germany, 3I8.

Prussia, forest production in, 30$3 I, 47-48$; stations in, 64 ; forest officials in, II $3 n$.; forest policy of, I22 $n .264,270,317-320$; cost of soil in, 126; fires in, 133, I37, $190 n,-192,262$; wood prices in, I38, $45^{6}-45^{8}$; state control of forests in, 308-309, 312 ; deforestation in, $3 \mathrm{I}_{3}$; forestry schools in, 315: taxation in, 465-467.

Public lands, U.S., 340-342, 403408.

Public schools, forestry instruction in, $239,388$.

Pulp, wood, 25, 27, 345, 42I-424.

RAILROADS, effect of, on exploitation, 2, 257, 278-279, 372, 374; state ownership of, 16 ; use of wood for, 23-24; danger of fire from, I89 $n,-190$, I94-I95, 262 : effect of, on wood prices, $45^{8}$.

Rain gauges, $64,432-434,43^{8}-439$. Rainfall, $64-65$; effect of forests on, $69-70,438-439$; in India, $28 \mathrm{I}$.

Ramann, experiments of, 446 .

Reforestation, I66-I67, I76, 248, 267-269; in Germany, 92, 309, $315,320,323$; in France, 277 ; in Russia, 293-294; in Roumania, 294; in Austria-Hungary, 295; in Italy, 296-297; in Switzerland, 297 ; in Sweden, 300.

Regeneration, natural, $167-173$; under nurse trees, $175^{-1} 77$; by coppice, $177^{-1} 79$.

Regulation, forest, 200.

Rent, soil, 213-217, 25I, 464-465.

Reproduction, I65, I69, I75-I79, 357.

Reservations, forest, in India, 280 , 288 ; in Russia, 292-293; in the U.S., $340-342,360,401-4$ II, 489- 
490; in New York State, 342, 386-390; in Pennsylvania, 342, 391 ; in Michigan, 392 ; in California, 397-398 ; in Canada, 468470.

Resources, exploitation of, I-4; economy of, 6-10, 4I5; classification of, ro.

Revenue from forests, 28-33, 212$217,220-222,452-459$; in Germany, 48-50, 132-136, 325-329; in India, II5, 285-287; in the U.S., 422-430.

Revolution (in forestry), I 10.

Ribbentrop, quoted, II4, 279.

Rides, fire, 193-194, 222.

Roads, improvement of, 9; use of, in forestry, $172,464-465$.

Rocky Mountain forests, 332-333, $35^{8}-360,363$.

Roman law, of property, 4, 20, 235 ; on forests, 58 .

Rome, ancient, forestry in, 9I.

Root, development of, I53-I54, I85-I86. .

Rotation, IO2, IIO, 208-213.

Rothrock, Dr., 39r.

Roumania, forest policy of, 294.

Russia, forest policy of, 29I-294; meteorology in, $44^{2}$; forest revenue in, 455 .

SAGINAW Valley, lumber production in, 374 .

St. Petersburg, forest institute at, 293.

Salary of foresters in India, 287.

Sands, shifting, in France, 77, 277; in Russia, 292; in the U.S., 368.

Sanitary influence of forests, 77-79.

Saunders, Dr. W., 469.

Sawing, waste in, 4r, 4I9-420.

Saxony, wood production in, 47-49, I34-135; felling budget in, 204; forest conditions in, 304, 314, 316,
$3^{18} 8$ forest revenue in, $3^{28}, 45^{2-}$ $45^{6}$; income tax in, 466 .

Scholarships, in forestry, 239-240.

Schools of forestry, at Nancy, 63 ,

$277 \boldsymbol{i}$ in Germany, $237-238,315$, 488 ; in the U.S., $238-239,390-$ 39I, 399-400; at Cooper's Hill, 289; at Dehra Dun, 289; in Russia, 293; in Austria, 295; at Vallombrosa, 297; at Zürich, 298 ; in Japan, 330.

Schubert, experiments of, 443.

Schwappach, quoted, $48 n$., 256, 49 I.

Scotland, forest laws of, $83 n$.

Seed, character influencing distribution of species, I43, I45-I46; reproduction by, $\mathrm{I} 68-\mathrm{I} 78$.

Selection system of clearing, I73I74, 217.

Seligenstadt, forests of, 92.

Sequoia, long life of, $x_{4} 6$; immunity of, from fire, 187; sprouting of, 464 .

Series, felling, 223-226.

Servitudes, 303-304.

Severance felling, 224 .

Seymour, H., 386.

Shelter wood, I75, 177 .

Ships, use of wood in, 24.

Sicily, deforestation of, 12,59 .

Silviculture, 10I, 165-196, 227.

Site, $156,158$.

Smith, Adam, 62, 93, 275, 307 .

Smith, Hoke, 404.

Snow, in forests, $74,439,444$.

Socialism, 232, 266-267.

Society for the Promotion of Agriculture, $370,380$.

Society for the Protection of New Hampshire Forests, 385 .

Soft woods, defined, 348 .

Soil, as a resource, $13,17-18$; varieties of, 56,156 ; relation of, to waterflow, 74-76; fertility of, I I9I20, 183; absolute and relative, I22-1 23, 243-244; cost of, I26; 
relation of, to species, 143 ; rent, 213-217, 25I, 464-465; tax, 465467.

Soudan, forestry in, 290.

South, U.S., forests in, 353-356.

South America, importation of wood by, 34 .

Species, distribution of, I4I-I49; in the U.S., 347-349, 481-483.

Sponge theory, 72-73.

Sport, influence of, 9,346 .

Spruce, growth of, 160 ; use of, for paper pulp, 160, 423-424, 483.

Stand, open and close, 89-90, 154156, 180-182; pure and mixed, 183; old and young, 201-203.

Standard-coppice system, 179, 451.

Starr, Rev. F., quoted, 375 .

State, relation of, to private enterprise, 4-10, 14-20, 230-235; administration of forests by, 124, I3I-I32, 138-139, I98, 206; educational function of, 236-244; promotive methods of, $244-258$; police function of, 258-267; ownership of forests by, 269-273, 275276, 280, 29I-293, 295, 306, 310, $340-342,386-391,395,397-398$, 40I-4II.

Statics, forestry, 214-222.

Stations, forestry. See Experiment stations.

Statistics, value of, $242-244,47 \mathrm{I}$; of forest finance, 30-33, 125-127, $132-138,220,287,325-328,45^{2-}$ 459 ; of forest area, 35, 54, 33434I, 430-43I ; of wood consumption, 36-4I, 5I, 337-339, 4I6-429, $475-480$; of wood production, $36-39,47-52,349-350,480-483$; of forest reservations, $489-490$.

Sterility, caused by deforestation, 59,63 .

Steuben, Baron von, 382 .

Stock, normal, I29-13I, 20I-205; taxation of, 25I-253, 465-467.
Stock companies, 133.

Strip method of reproduction, 174175, 190.

Stumpage, defined, $220 n$., 343 ; value in the U.S., 485-486.

Substitutes for wood, 26-29, 42 I.

Subterraneous drainage, $19-20,72$, 74-75, 444-447.

Sugar, maple, 29-30.

Sully, quoted, I7, 60.

Supply and demand, 233-234, 242243.

Survey, forest, 206-207.

Sustained yield, 199-222, 230, 259, 324,465 .

Swamps, danger from, 78-79.

Sweden, forest policy of, 298-300.

Switzerland, stations in, $63-64$; forest policy of, 270, 297-298.

Syrup, maple, 30.

Tanning, 28-29, 86, 424.

Tariff on wood, $245,253-258$.

Taungyas, 285 .

Taxation of woodlands, $245-253$, $378,465-467$.

Teak, 282, 285 .

Temperate zones, 40.

Temperature, effect of forests on, $62-63,66,69,434-437,441-444$; relation of, to growth, I4I-I42 147.

Terminology, forest, 8I-85, 448450.

Tharandt, forest academy at, 488 .

Thinnings, I79, 182, 193, 226.

Thirty-years War, effect of, on forests, 93, 305-306.

Ties, railroad, 23.

Timber, as a resource, II-12, I9: age of, 4I, 43, IO7, 355; size of, 217-221.

Timber culture acts, 246-247, 378379, 403.

Timber Trades fournal, quoted, 298-299. 
Time element, in forestry, ror-ro2, ro6-110, 127-r32, 198-r99, 205, 225. 230, 233-234, 24r, 255-256, 346.

Tokio University, forest department of, 330 .

Torrents. See Floods.

Transpiration, 77, r2r, 437-438.

Transportation, relation of, to exploitation, 2-3, 257, 278-279, 372, $374,464-465$; use of wood in, 24 ; expense of, $171-172$; relation of, to wood prices, $45^{8-459}$.

Tree Planters' Manual, 382.

Tree weeds, $43-44,98,160,168,210$, 347.

Trusts, 133,345 .

Tundras, 54-55, I42.

Turnus, 1 ro.

Twelve Tables, Laws of the, $5^{8}$.

UNITED STATES, waste in, 2-3, 45 , 52-53; merchant marine of, 24 $n$.; consumption of wood in, 25 , $5 \mathrm{r}, 337-339,420-423,475-480$; exportation of wood by, 34,37 , 480-48I ; timber supply of, 38,52 , $331-339,483-485$; forest terminology in, 84 ; rate of interest in, 136 ; paternalism in, 232, 245-249; exhaustion of forests in, 234, 353, 374-376, 479-480; education in, 230-239, 390-39r, 399-400; forest legislation in, $246-253,263,369-$ $370,377,384-411$; tariff legislation in, 253, 258; forest area in, $334-339,47 \mathrm{r}-475$; reservations in, $340-342,360$, 40r-4Ir, 489-490; wealth of, 429-430; forest labor in, 450 ; importation of wood by, $48 \mathrm{r}$; price of stumpage, $485-486$.

United States Bureau of Forestry, 2I7-2I9, 248-249, 377, 38r, 40r, 4 ro.

United States Chief Geographer, report of, 339,363 .
United States Department of Agriculture, 125, 374-375, 38r.

United States Geological Survey, $33^{6} n .-337,34^{\mathrm{r}}, 35^{8}, 360,405$, 409-4I r.

United States Patent Office, 374-375. Universities, courses in forestry at, 237-238, 3I5, 330, 390-39r, 399400.

VALLOMBROSA, forestry school at, 297.

Valuation, forest, $21_{3}-222$.

Value production, maximum, 212.

Vanderbilt estate, Biltmore, 238 , 399.

Vermeule, 446.

Vermont, forestry commission of, 386.

Vessels, wooden, 24 .

Virgin forests, waste in, $42-44,98-$

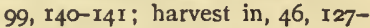
128 ; in the U.S., 339.

Volume development, I55-164; maximum, 2II-2I2.

WAGES of lumbermen, 50, II6-II7, $45^{\circ}$.

Ward, L. F., quoted, 266-267, 4r5.

Warder, J. A., 376, 382 .

Washington, forests of, $36 \mathrm{r}, 363$.

Waste of materials, $1-3,28-29,44-$ 46 ; in sawing, $4 \mathrm{~T}, 4 \mathrm{rg}-420$; in virgin forests, $42-44,98-99$, 140I4r.

Water, as a resource, II, I7-I9; drinking, 79; in wood, r2r.

Waterflow, influence of forests on, $6 I, 7 I-76,90,266,276-277,3 I 8-$ $319,342,368$.

Waterways, state care of, 14-I6.

Wealth, $3 r$; of the U.S., $429-430$.

Weeds, tree, 43-44, 98, 160, 168 , 2 ro, 347.

Weight of forest product, 157,460 .

West, U.S., settlement of, $2 r$; for- 
ests in, 332-333, 336, 339-342, 357$364,474-475$; irrigation in, 342, 447,487 ; forest legislation in, 377-378.

West Virginia, forest legislation in, 394.

Wind, $185^{-186}, 224,263,439-444$; effect of, on rain gauges, 432-433.

Wind-breaks, 13, 70-7I, 224, 440$44 I, 45 I$.

Wisconsin, deforestation of, I2; taxation of forests in, 252 ; woodland area of, $336 n .-337 n$.; wood production in, 372 ; forestry movement in, 377 ; forest legislation in, 393.

Wollny, experiments of, 446 .

Wood, importance of, 2I-26, 427 ; consumption of, $25,3^{6-4 I}, 5 \mathrm{I}$, 337-339, 4I6-429, 475-480; pulp,
$25,27,345,421-424$; substitutes for, 26-29, 421 ; growth of, Io6Io9; price of, I34-135, I38, 220, $420,456-459,485-487$; production rate of, $159-164$.

Wood-lots, I16, I3I, 198-199, 343, $3^{80}, 45$.

Woodland, defined, 84 .

Würtemberg, forest policy of, $3^{\text {I }}$ 3 I $8,321-322$.

YALE University, forestry school at, 238, 399.

Yield, sustained, 199-222, 230, 259, 324,465 .

Yield-tables, I59-164, 207-208, 2I8$220,46 I-463$.

ZÜRICH, forestry school at, 298; forest finance of, 324-326. 
"Deserves the heartiest of welcomes and ought to be read by everybody from the President down. Nothing on the subject has been published for years so effective, clear, and popular." - The Literary World.

\section{IRRIGATION}

\section{BY FREDERICK HAYNES NEWELL}

\section{Chief Hydrographer, United States Geological Survey}

This book has had an extended and notable sale, being largely purchased by Congressmen, Senators, and others interested in the public welfare of this country. The book deals clearly and interestingly with a problem now before our lawmakers' minds: How best to develop our vacant desert lands (two-fifths of our national territory) and make them fit for the home-seeker.

"A candid statement of unvarnished facts." - Forestry.

"Will be taken as authority." - Dallas (Texas) Times-Herald.

"The first comprehensive work of a popular character concerning an industry greater than the largest industrial combination of modern times." - Kansas City Star.

"Should have an important influence on the practice of irrigation, and also on legislation dealing with methods of land surveying and of water distribution." Israel C. Russell, Professor of Geology in the University of Michigan.

"A clear, simple, comprehensive, well-illustrated work by one who thorougbly understands all the conditions as they actually exist." - E. C. MuRPHY, Hydrographer, U. S. G. S.

"If there is a man in the entire United States who is fully competent to write a work upon Irrigation, it is Professor Newell." - W. M. WooldRIDGE, U. S. Commissioner, Industrial Agent G. N. Ry.

With 156 lliustrations \$2.00 net (By mail, \$2.20)

\section{THOMAS Y. CROWELL \& CO.}

\section{NEW YORK}






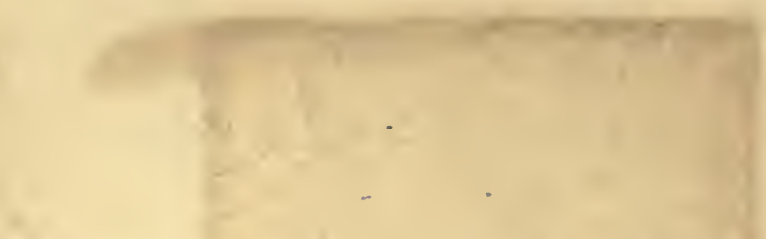

$\sqrt{2}$

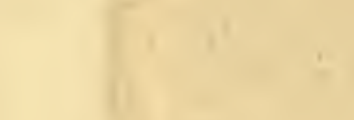

3

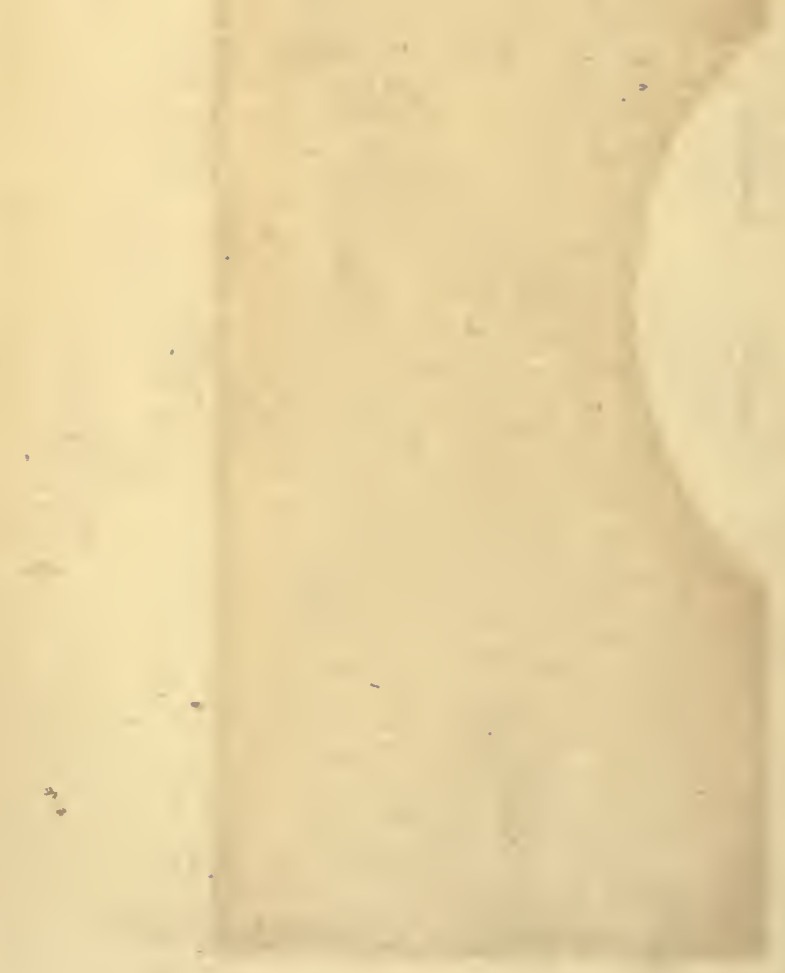

,

* 


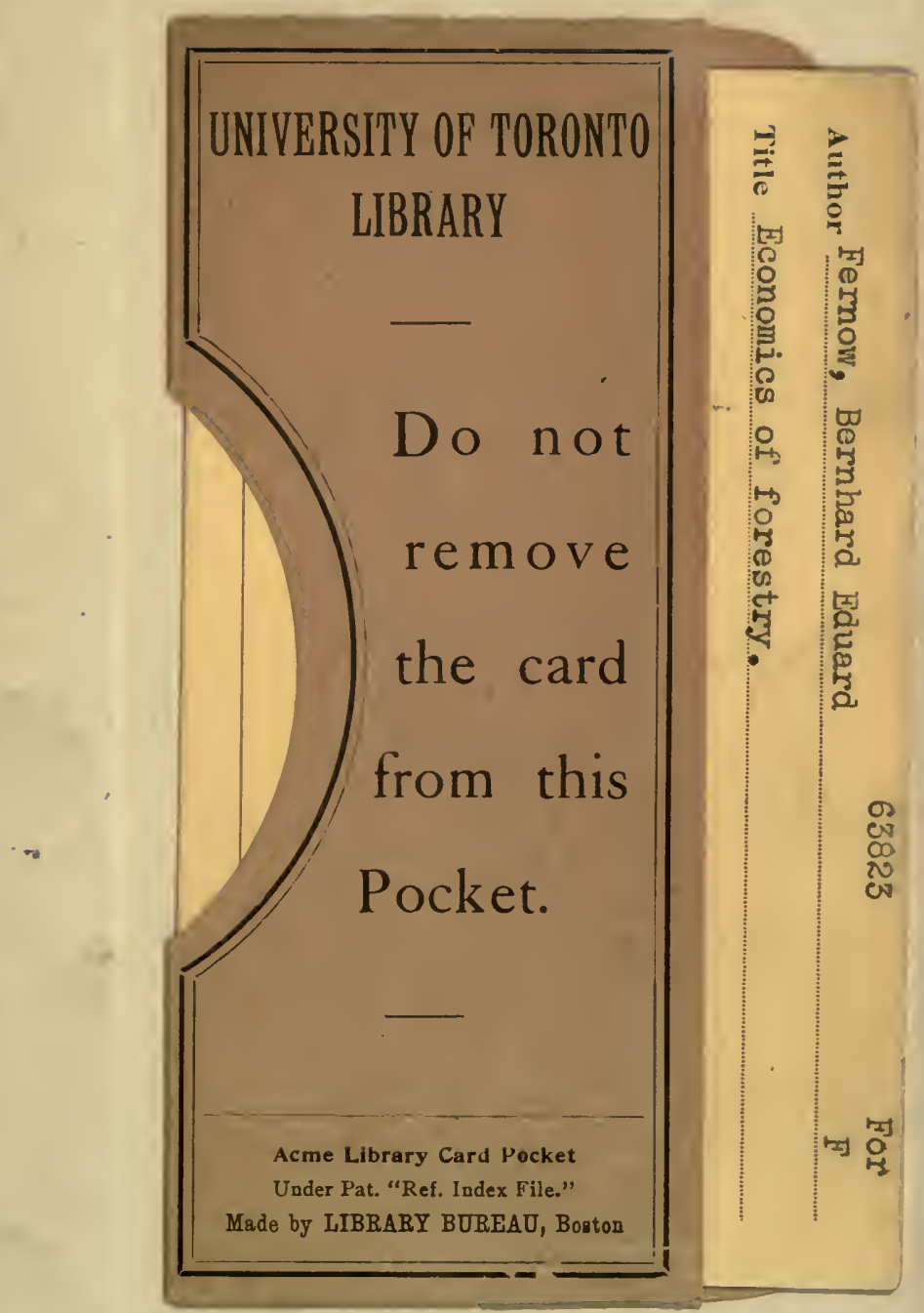




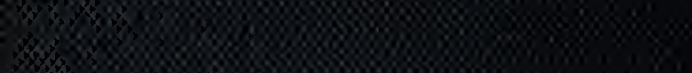

\%

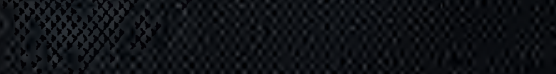

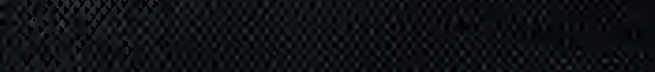

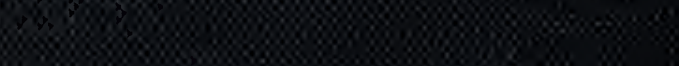
OW: Q67\% Qxy

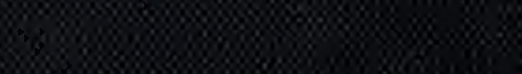

Q5\%

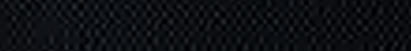

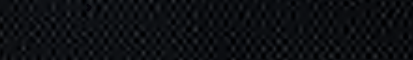

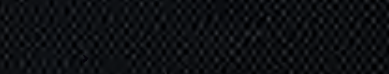

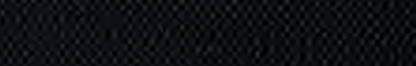

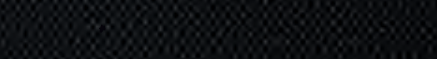

Wos

into

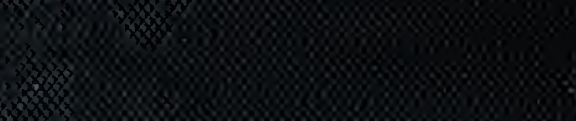

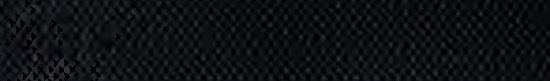

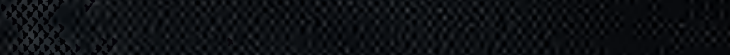

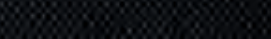

